\title{
AN EXPLORATORY CASE STUDY ON CHILD SEX TOURISM IN A PACIFIC COUNTRY: SAMOA
}

\author{
BY
}

\section{LURLENE VIRGINIA CHRISTIANSEN}

\begin{abstract}
A thesis
submitted to the Victoria University of Wellington in fulfilment of the requirements for the degree of Doctor of Philosophy in Pacific Studies
\end{abstract}

Victoria University of Wellington

(2015) 


\begin{abstract}
In 2006, The Committee of the United Nations Convention on the Rights of the Child, expressed concern about rising tourism in Samoa, and the possibility of associated sexual exploitation of local children. The Committee had recommended that the Government of Samoa devote further research to the sexual exploitation of children, including identifying its scope, and root causes. This thesis became a response to The Committee's recommendation to Samoa. I carried this study out in Apia, Samoa (2009). It presented three research objectives as follows, 1) To report the scope of child sex tourism in Samoa, 2) To identify, and report on the root causes that contributed to child sex tourism in Samoa, and 3) To present a set of recommendations as a baseline foundation for policy, advocacy, and research. Methodology was a qualitative, single embedded case study. Data sources were mixed-method and multi-perspective, aimed at triangulation to enhance trustworthy results. Data analysis was inductive. Anecdotal evidence revealed child sex tourism is a serious problem in Samoa. Victims were girls and boys (including straight and transgendered ones), perpetrators were all male; preferential and opportunistic. The data revealed 10 root causes facilitating CST in Samoa, as follows: 1) Poverty, 2) Hospitality, 3) Philanthropic exploitation, 4) Marginalisation of boys, 5) Family under pressure, and family dysfunction, 6) Unsafe schools, 7) Ifoga, or the culture of shame, 8) Sex tourism, 9) Tourism was excused of any action, and 10) Lack of awareness about child sex tourism. Additionally, four substantial root causes were identified, as follows: 1) Complacency, 2) Attitudes toward data collection, 3) Child sex tourism had to be 'proven' by statistics, and 4) Perpetrators beaten and deported leading to under reporting. This was a first study in Samoa. The baseline results this study presents, are important for policy development, advocacy, and for the academic research community, offer a platform to build on, both quantitative and qualitative.
\end{abstract}




\section{Acknowledgments}

To my husband, family and friends thank you all so much for your support, understanding, and patience to get to this end.

I would never have been able to complete this research without the support and friendship of my supervisor, Professor Peggy Fairbairn-Dunlop, who kept me motivated and inspired over the many years of research and writing. In addition, I gratefully acknowledge the assistance provided to me by Dr Alison Kirkman, my second research supervisor.

I wish to express my heartfelt gratitude to individuals and organisations that participated with me in this study in Samoa. Special thanks to JM, Warwick, David, and Robert. Pati in Apia, thank you so much!

I am extremely grateful to the University of Victoria Wellington, New Zealand for assistance in funding this study in Samoa. 


\section{Table of Contents}

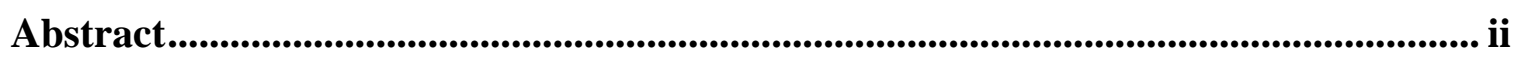

Acknowledgments ............................................................................................................... iii

Table of Contents ............................................................................................................................. iv

List of Tables and Figures ......................................................................................................... ix

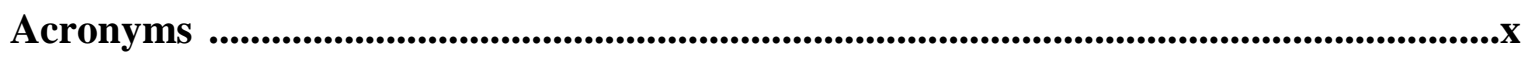

Samoan Terms........................................................................................................... xi

List of Definitions ........................................................................................................................... xii

Chapter 1: Introduction to the Study......................................................................................1

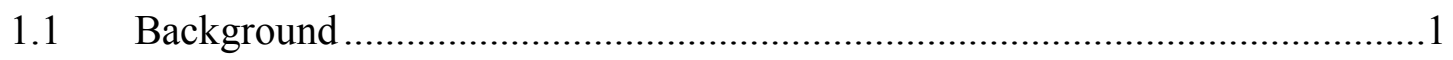

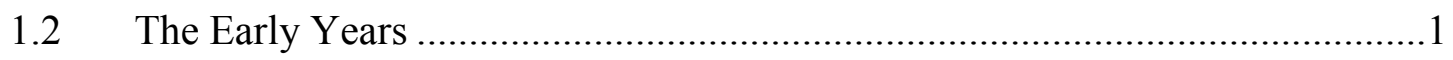

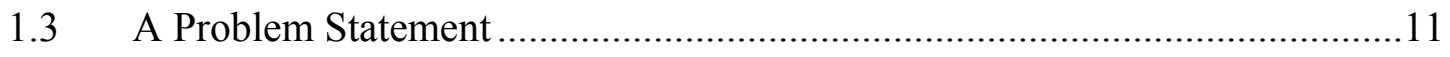

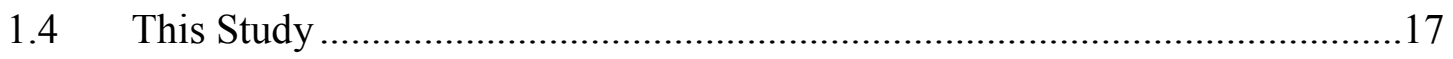

$1.5 \quad$ Research Objectives and Key Questions .....................................................22

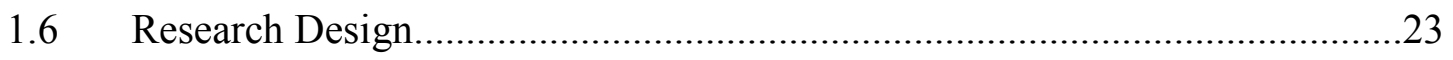

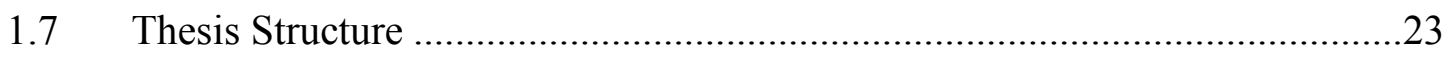

Chapter 2: Review of Literature ..............................................................................................25

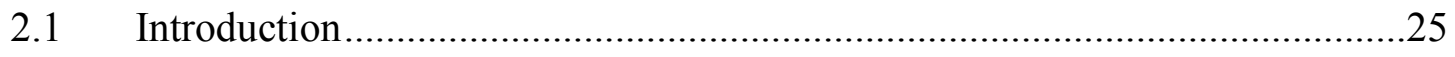

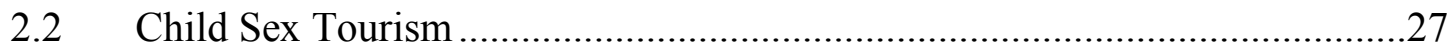

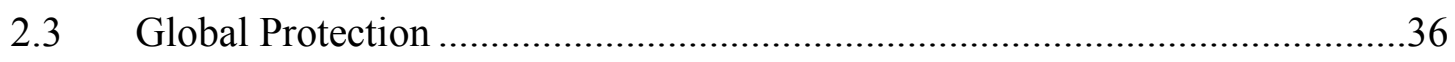

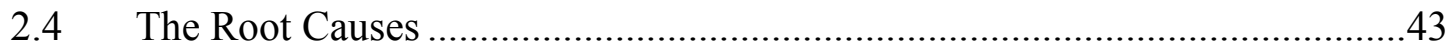

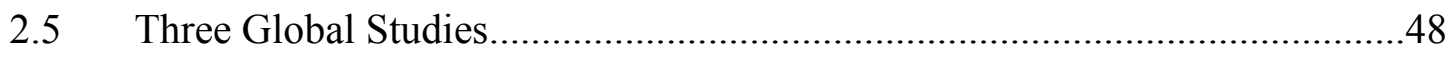


2.6 Four Root Causes Specific to a Tourism Setting ..........................................53

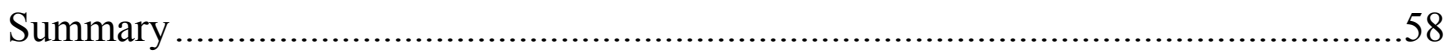

Chapter 3: The Environment of the Samoan Child............................................................59

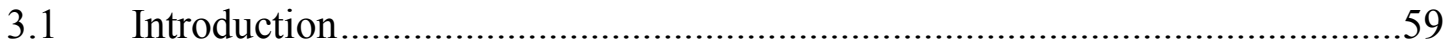

3.2 The Country, People and Socio-Economic Setting.....................................60

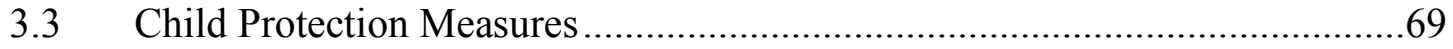

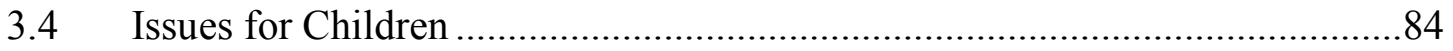

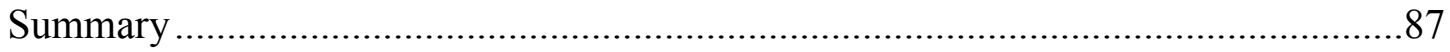

Chapter 4: Methodology and Research Design ........................................................90

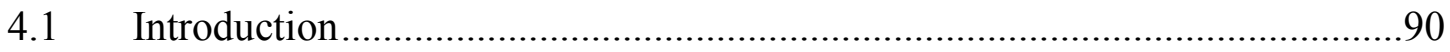

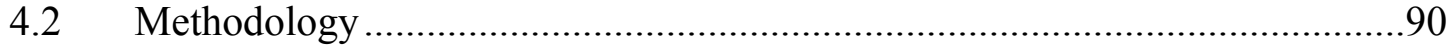

4.3 Conceptualising Samoan Space ( Va, Talanoa and Fa'afaletui).....................94

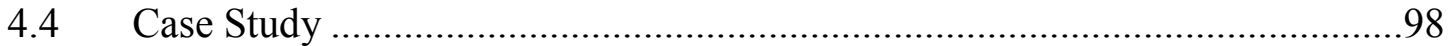

4.5 The Design and Conduct of this Case Study Research ................................100

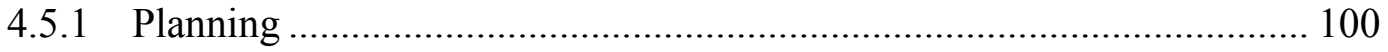

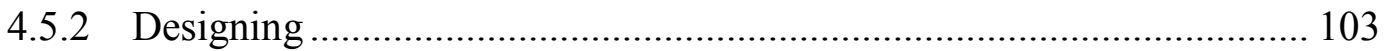

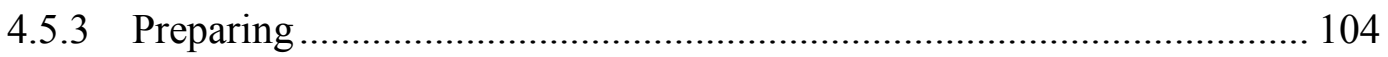

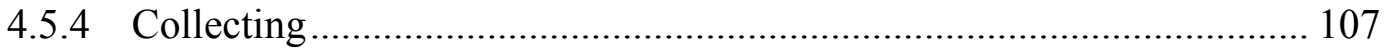

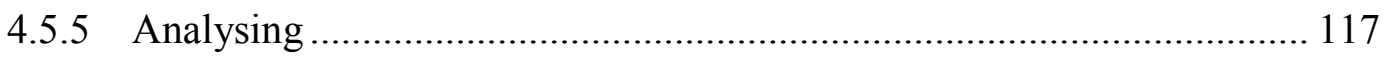

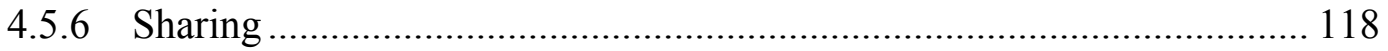

4.6 Strategies for Ensuring Trustworthiness ..................................................... 118

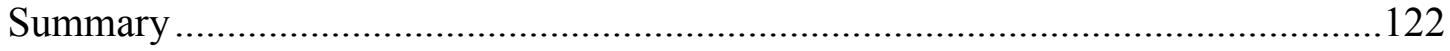


Chapter 5: Discussions, Section 1 .........................................................................................123

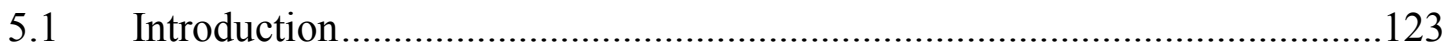

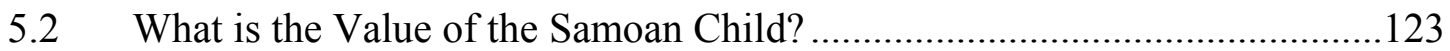

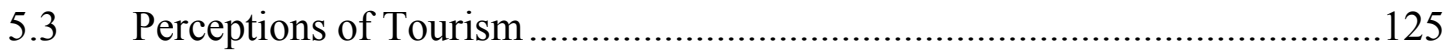

5.4 Perceptions of Child Sex Tourism in Samoa ………………………...............131

5.5 Eyewitness Testimony and Direct Observation ...........................................135

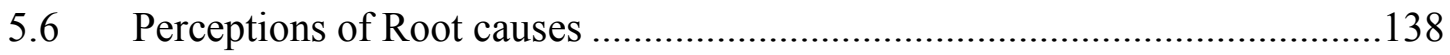

Chapter 6: Discussions, Section 2 .........................................................................................150

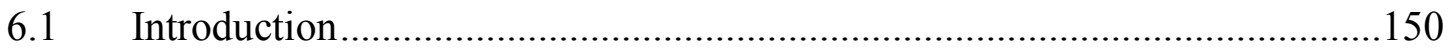

6.2 Views on Roles and Responsibilities...........................................................

6.3 Defining Child Sex Tourism...................................................................173

Chapter 7: Findings .....................................................................................................................176

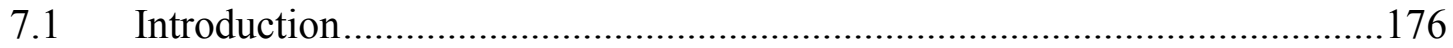

7.2 The Scope

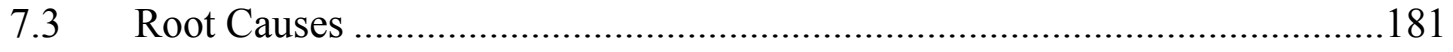

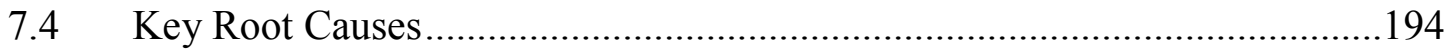

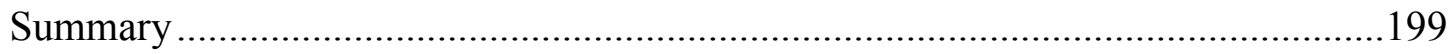

Chapter 8: Conclusions and Recommendations ..............................................................200

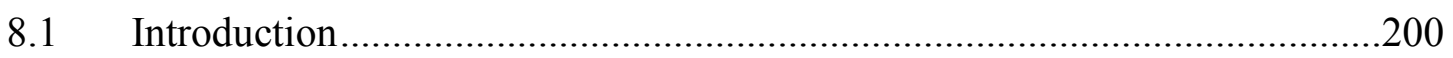

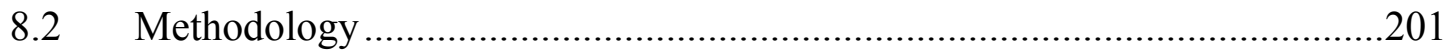

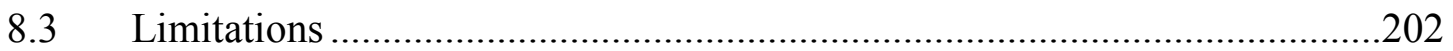

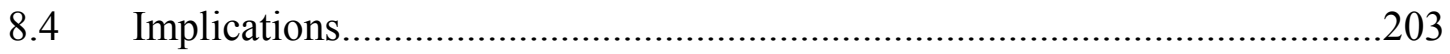




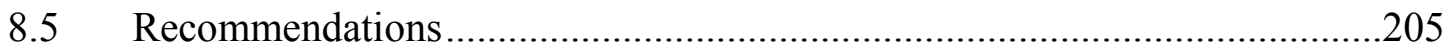

8.5.1 (According to Participants) ............................................................... 205

8.5.2 (From Data Analysis)....................................................................... 208

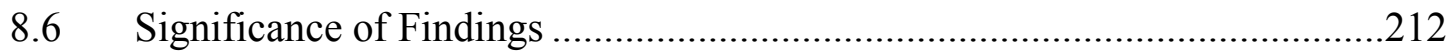

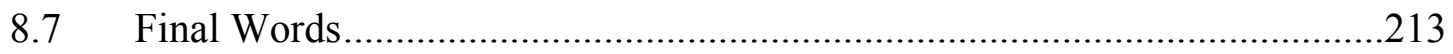

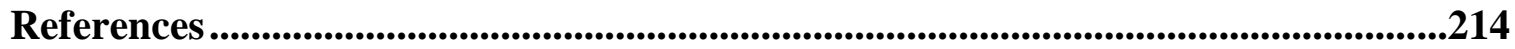

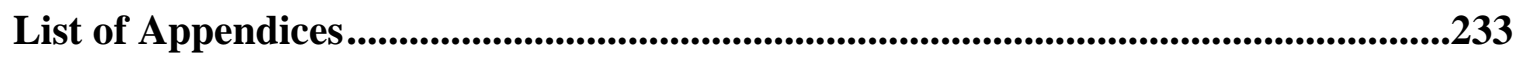

Appendix A: The CRC (1989) - A Fact Sheet Summary ...............................................233

Appendix B: Pacific Island Table of Treaty Ratification ..............................................244

Appendix C: The Revised Pacific Plan: Strategy (vi) ................................................245

Appendix D: Pacific Consultations and Workshops (2001-2007)..................................246

Appendix E: Pacific Signatories to Optional Protocols ..................................................247

Appendix F: Appendix F: East Asia Pacific Regional Commitment and Action

Plan against Commercial Sexual Exploitation of Children, 2001)......................248

Appendix G: A Pacific Statement of Commitment on Combatting Poverty and

Comercial Sexual Exploitation of Children and Youth, 2003 .............................252

Appendix H: East Asia Pacific Regional Commitment and Action Plan ........................253

Appendix I: Samoa: Proposed Plan of Action against CSEC ..........................................258

Appendix J: Consent to Participate in Research (Individual) .........................................260

Appendix K: Consent to Participate in Research (Focus Groups)....................................261

Appendix L: Questions to the Taxi Drivers (Survey) ……………………...................262

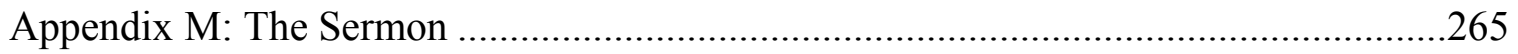




\section{List of Tables and Figures}

Table 1 Pacific Island Table of the Adherence to the United Nations

Convention on the Rights of the Child (1989)

Table 2 Root Causes (Yokohama, 2001) 43

Table $3 \quad$ Supply and Demand 44

Table 4 Push and Pull 46

Table 5 Push and Pull (Nepal, India, and Sri Lanka) 47

Table 6 Root Causes Specific to a Tourism Setting 53

Table 7 Samoa: Key Social and Economic Data (2006) 65

Table $8 \quad$ Tourism Arrivals and Earnings (2004 - 2011) 68

Table 9 The Samoa Tourism Authority Development Plan: (2009-2013): 69

SWOT Analysis

Table 10 Samoa: The CRC Partnership 76

Table 11 National Policy for Children of Samoa (2010-2015): 77

Table 12 Samoa National Plan of Action for Children (2008-2012): 79

Outcome 2: 2.1

$\begin{array}{lll}\text { Table } 13 & \text { Final Sample } & 105\end{array}$

Table 14 Attribution of Responsibility by Institutions and Groups 151

Table 15 Age of a Child in Samoa? Countries CST Happens in Most? 174

Table 16 What is Child sex tourism? Who is the Child Sex Tourist? 174

Table 17 Root Causes: According to Participants and Researcher 182

Figure 1 Map of Samoa 61

$\begin{array}{lll}\text { Figure } 2 & \text { The Fa'amatai Wheel } & 70\end{array}$ 


\section{Acronyms}

CEDAW Convention on the Elimination of all Forms of Discrimination

CRC United Nations' Convention on the Rights of the Child

CSA Child Sexual Abuse

CSEC Commercial Sexual Exploitation of Children

CST Child Sex Tourism

ECPAT End Child Prostitution, Child Pornography and the Trafficking of Children for Sexual Purposes

HIV/AIDS Human Immunodeficiency Virus / Acquired Immune Deficiency Syndrome

MOA Mapusaga O'Aiga

MWCSD Ministry of Women, Community, and Social Development

NCCCRC National Coordinating Committee on the Convention on the Rights of the Child

NGO Non-Governmental Organisation

SEC Sexual Exploitation of Children

STA Samoa Tourism Authority

TCU Transnational Crimes Unit

UNESCAP United Nations' Economic and Social Commission for Asia and the Pacific

UNICEF United Nations Children's Fund

UNWTO United Nations World Tourism Organisation 


\section{Samoan Terms}

Aiga Family, member of a family or extended family

Fa'asamoa To do things according to Samoan beliefs and practices

Fa'afafine In the manner of a woman

Fa'afaletui Multiple points of view

Fono Meeting or council

Ifoga An apology

Matai Entitled family members who are heads of extended families, and are responsible for the well-being of all family members

Pulenu'u Village mayor elected by chiefs of the village and the village representative in the National meeting of Pulenu'u

Talanoa To talk in an informal way, to tell stories or relate experiences

Va Physical spaces between people, between objects and between people and objects

Vatapuia Conventional relationships between people that is sacred 


\section{List of Definitions}

The following terms clarify specific language associated with any discussion of commercial sexual exploitation of children and child sex tourism.

\section{Child}

Every human being below the age of 18 years unless, under the law applicable to the child majority is attained earlier. (United Nations General Assembly, 1989, Article 1)

Children who have reached the age of 13 , but have not yet reached age 18 may be referred to on occasion as 'youth' or 'young people', while still being included in the broad definition of children". (UNICEF, UNESCAP and ECPAT, 2006, p. 15)

In Samoa, National law states childhood ends at 16.

\section{Child Sexual Abuse}

The World Health Organization Report on the Consultation on Child Abuse Prevention (1999) defines child sexual abuse as follows:

Child sexual abuse is the involvement of a child in sexual activity that he or she does not fully comprehend, is unable to give informed consent to, or for which the child is not developmentally prepared and cannot give consent, or that violates the laws or social taboos of society. Child sexual abuse is evidenced by this activity between a child and an adult or another child who by age or development is in a relationship of responsibility, trust, or power, the activity being intended to gratify or satisfy the needs of the other person. This may include but is not limited to the following

— The inducement or coercion of a child to engage in any unlawful sexual activity;

— The exploitative use of a child in prostitution or other unlawful sexual practices; 
- The exploitative use of children in pornographic performance and materials. (World Health Organization, 1999, p. 62)

\section{Civil Society}

...the wide array of nongovernmental and not-for-profit organizations that have a presence in public life and express the interests and values of their members or others, based on ethical, cultural, political, scientific, religious or philanthropic considerations. This definition of civil society, which has gained currency in recent years in academic and international development circles, refers to the sphere outside the family, the state, and the market. This excludes for-profit businesses, although professional associations or business federations may be included. (The World Bank, 2007, pp. 1-2)

\section{The Sexual Exploitation of Children}

In this study, the Sexual Exploitation of Children refers to Child Marriage / Early Marriage, Child Pornography, Child Prostitution, Child Sex Tourism, and Child Trafficking in Children for Sexual Purposes.

\section{Child Marriage, Early Marriage}

Child marriage or early marriage (the marriage of children below the age of 18) can be considered a form of commercial sexual exploitation of children when the married child is used as an object of sexual gratification in exchange for money or another form of payment. Accordingly, child marriage can also be a thinly veiled form of CST.

(ECPAT, 2008, p. 22)

For example, in parts of some Pacific countries, such as Papua New Guinea, the Solomon Islands, and Vanuatu, customary law remains strong, and allows girls to be married at puberty at around 12 or 13 years-old. (UNICEF Pacific and UNIFEM Pacific, 2007, p. 9) 


\section{Child Pornography}

Any representation, by whatever means, of a child engaged in real or simulated explicit sexual activities or representation of the sexual parts of a child, the dominant characteristic of which is the depiction for a sexual purpose. (United Nations General Assembly, 2000, Article 2c )

\section{Child Prostitution}

The use of a child in sexual activities for remuneration or any other form of consideration. (United Nations General Assembly, 2000, Article 2b)

\section{Child Sex Tourism}

Child sex tourism is the commercial sexual exploitation of children by men or women who travel from one place to another, usually from a richer country to one that is less developed, and there engage in sexual acts with children, defined as anyone under the age of 18. (NGO Group Convention on the Rights of the Child, 2005, p. 18)

\section{Child Trafficking in Children for Sexual Purposes}

The profitable business of transporting children for commercial sexual purposes. It can be across borders or within countries, across state lines, from city to city, or from rural to urban centre. (United Nations General Assembly, 2000, Article 3a)

\section{Commercial Sexual Exploitation of Children}

The "sexual abuse by the adult and remuneration in cash or kind to the child or a third person or persons," in the Declaration and Agenda for Action against Commercial Sexual Exploitation of Children. It is a process through which "the child is treated as a sexual object and as a commercial object" and "which constitutes a form of coercion and violence against children, and amounts to forced labour and a contemporary form of slavery. (ECPAT, 2008, p. 3) 


\section{Pacific}

The term Pacific refers to the 14 Pacific Forum States: The Cook Islands, Federated States of Micronesia (FSM), The Republic of the Fiji Islands (Fiji), Kingdom of Tonga (Tonga), Kiribati, Nauru, Niue, Palau, Papua New Guinea (PNG), and Republic of the Marshall Islands (RMI), Samoa, Solomon Islands, Tuvalu, and Vanuatu.

\section{Sex Tourism}

Trips organised from within the tourism sector, or from outside this sector but using its structures and networks with the primary purpose of effecting a commercial relationship by the tourist with residents at the destination. (UNWTO, 1995, p.1)

\section{Stockholm: Five 'Directives'}

\section{Child and Youth Participation}

Policies or programmes that have been created to involve children in planning.

(UNESCAP, 2006, p.15)

\section{Coordination and Cooperation}

Coordination and cooperation, constitutes those structures, mechanisms, sessions and/or agreements that facilitate dialogue and supportive action amongst various sectors, organizations and agencies against CSEC. (UNESCAP, 2006, p.15)

\section{Prevention}

Those policies and programmes that have been enacted in order to prevent the commercial sexual exploitation of children from occurring, by establishing mechanisms and raising awareness for communities and children, and to counter the demand for CSEC. Such actions include, for example, policies to integrate life skills into formal and non-formal education curricula, programmes to raise awareness on the sexual abuse and exploitation of children via the Internet and mechanisms to establish community 
surveillance in order to detect and prevent potential trafficking in children for sexual purposes. (UNESCAP, 2006, p. 23)

\section{Protection}

Laws, policies, procedures, and programmes that have been enacted to legally protect children from commercial sexual exploitation and to ensure that the rights of child victims are respected. Protective actions can be in the form of legal measures, such as laws prohibiting the possession of child pornography; child-friendly procedures, such as the provision of professional support and psycho-social counselling for children during an investigation; capacity-building for law enforcement, such as training for border police on trafficking in children; and special law enforcement units or task forces, such as the creation of a bureau on children's issues in the central policy department. (UNESCAP, 2006, p. 21)

\section{Recovery and Reintegration}

Policies, programmes, and procedures that have been created to recover children from situations of actual or potential abuse or exploitation, to rehabilitate child victims through the provision of medical treatment and psycho-social counselling and support, and to reintegrate children back into their communities and families when possible. Such initiatives include procedures for the safe removal of a child from an institution or establishment where he or she is being exploited, training on standards of care for shelters that are responsible for child victims of commercial sexual exploitation and the creation of life skills, and vocational training for child victims of trafficking."

(UNECSAP, 2006, p. 24)

\section{Tourism Sector or Tourism Industries}

The cluster of production units in different industries that provide consumption goods and devices demanded by tourists. Such industries are called tourism industries because visitor acquisition represents such a significant share of their supply that, in the absence 
of visitors, their production of these would cease to exist meaningful quantity.

(UNWTO, 2008, p. 5)

\section{Tourist (or overnight visitor)}

A visitor (domestic, inbound, or outbound) is classified as a tourist (or overnight visitor), if his/her trip includes an overnight stay." (UNWTO, 2008, p. 5)

\section{Travel / Tourism}

The activity of travellers. A traveller is someone who moves between different geographic locations, for any purpose and any duration. The visitor is a particular type of traveller and consequently tourism is a subset of travel. (UNWTO, 2008, p. 5)

\section{Urban and Rural (Samoa)}

In Samoa, the distinction between urban and rural women is not definitive mainly because of its geographical disposition, which makes communication and links easier to establish. Services received by those in the urban area also cover those in the rural areas. The only clear difference is that those in the rural areas are traditionally tied and governed by the laws of the village community, whereas those in urban areas do not have to live under such conditions of conformity." (Government of Samoa, 2003b, p. 84) 


\section{Chapter 1: Introduction to the Study}

\subsection{Background}

The introduction to this thesis explains my decision to carry out an exploratory qualitative single embedded case study on child sex tourism (CST) in Apia, Samoa. First, I discuss two photographic images that became the momentum for my two earlier academic studies. Owing to the character of the images topic, I had opted to describe the postcard and advertisement and not embed the two in this document. Second, I present a Protection Project (2005) statement about the CST situation in Samoa. In brief, the Protection Project reported that CST was not a serious problem. Then, I present a statement from the United Nations (UN) Committee of the Convention on the Rights of the Child (The Committee) having identified tourism rising in Samoa, had recommended that Samoa carry out a study on the sexual exploitation of children (SEC), that became the momentum for this CST study. From there, I present this study's five key research questions, and three research objectives. Next, I present methodology and research design. Finally, I outline the organisation of this study's remaining seven chapters.

\subsection{The Early Years}

My decision to carry out an exploratory qualitative single embedded case study on CST in Apia, Samoa, drew out of my two earlier courses of academic study (Bachelor of Fine Arts, 2000, and Masters of Arts (Art and Design, 2003). The first study's focus was on the sexualisation of South Pacific women and girls in colonial studio photographic imagery of the late nineteenth century. The second study focus was on the sexual exploitation of Pacific Island women in modern-day twentieth century travel advertising. This study on CST in Samoa is an extension of these two earlier studies.

Particularly, Critical Theory and the writings of a number of critical theorists, for example, Rosemary Betterton (1996) Rey Chow (1996), Gaytari Spivak (1988), Homi Bhaba (2004), and Frantz Fanon (1967) informed my ideas and artwork. Critical Theory 
looks at all forms of knowledge as power structures, and the framing of them (as in any communication) as power plays, so that communication of information always involves some kind of oppression or assertion of ascendency of one party over the other.

Language is Epistemology, Methodology, and Ontology. Because language conceptualises reality: and it does so according to the worldview of the culture wherein it evolved, so, it shapes thought, "knowledge", and then reality on the ground soon after that as people act on their understandings. The requirement that, in order to communicate, a certain language must be used, means accepting the rules of that language, which also means accepting the assumptions of that language. This is going to be the case in any post-colonial situation (which Critical Theory would call a still-colonial situation). The dictate by one party, and the acquiescence by the other, that a certain language will be the mode of communication and understanding, is immediately going to cast the power structure a certain way.

\section{Tahitian Women}

In 1999, a poster pinned to a wall in my art school studio caught my eye. The poster had, some years earlier, promoted a conference entitled Columbia University Symposium on the Arts of the Oceania; Pacific, in the Department of Art History and Archaeology, Columbia University, New York City in 1993. The poster displayed colonial postcard imagery of Maori, Tongan, and Samoan, Tahitian, and Hawaiian people. Among the images, one titled Tahitian Women was significant and stopped me in my tracks. Although undated, I assumed Tahitian Women was in all likelihood the work of the French photographer Lucian Gauthier (1875-1921). Gauthier worked in Tahiti between 1904 and 1921 (See Kakou, 2009). His body of work had been widely distributed in the form of postcards, establishing his fame (Quanchi, 2007).

Gazing at Tahitian Women, I felt that the title of the postcard, and the three female subjects portrayed in it, did not fit. Together, the physiology of the three females leaned towards pre-pubescent girls rather than what the title presented. The subject's 
breasts, although clear and central to the photo's narrative, depicted various stages of physical development. The artist had utilised repetition. For example, three bare-breasted girls, a lei on each head, a flower tucked behind each left ear (which in Tahitian tradition signifies taken, married or engaged), and the same patterned cloth wrapped securely around their waists. Coupled with repetition, was the way the three girls had been posed, to imply service, for example, two girls shown kneeling on each side of a third prepubescent girl staunch -like, standing at attention.

In my life, I had never seen Pacific children photographed like that. The artist seemed to imply Tahiti was a place full of women but with the bodies of pre-pubescent children, waiting to serve you - perhaps sexually? Had I interpreted Tahitian Women correctly? Where Tahitian Women, women or girls? To answer my query, I sought the opinions of my peers: three non-Pacific European males aged in their late 20s, 40s, and 50s. I asked, "In your opinion, are these people women or girls?" They replied, "Women.” I asked, “Are you sure?" They stepped closer, and replied, "Girls.” I asked, "Should these young girls be on public display, naked, like this?" One replied and the others agreed, "What's wrong with that? That's the way they went around; that was the island way". I asked, "Would you consent to your daughters displayed naked on a wall in a public space depicted that way?" One participant replied, "No, that's not our way."

After the men had left, their comments remained with me and bothered me. They bothered me because, despite their acknowledging, the 'women' were girls, not one of them expressed outraged of their being young girls, naked on public display, either as a crime of indecency or child pornography in our times, simply excusing those off as 'that was the island way'. Furthermore, their daughter's nakedness in that same position was not acceptable, for the reason that, it was not their 'way'. I took the poster down. 
Max Quanchi (2007), a senior lecturer of Pacific History, cited several chronological stages driving people's knowledge of the Pacific as a 'type of way'. As follows:

a) A literary fantasy in fictional lands and speculative mapping -1572-1779

b) Noble and ignoble savages - as seen in journals of exploration and philosophy and science texts

c) Loyal subjects and indentured laborers - the Colonial era, post-1842

d) Cannibals, primitive villagers and belles - the photographic image

e) Hollywood's South Seas - the filmic Pacific 1930-40s

f) Tourist stereotypes

g) Victims of doomsday scenarios - in an economic discourse in the 1990s

h) Oceanic people managing their own cultural renaissance. (pp. 9-10)

Exploring Quanchi's list (A-F), I discovered some unpalatable facts.

For example, through the medium of postcards, images such as Tahitian Women, constituted an outsiders view of the generic South Pacific as a feminised Eden, exotic and erotic, mature yet youthful, sexually attractive yet excitingly innocent, that considered the pornography of its time, posted on mass to European countries such as Germany and the United Kingdom, two colonising empires expanding their interests throughout the South Pacific at the time.

In The National Geographic magazine, from its first inclusion of a bare-breasted woman in 1896, through to the early twentieth century, the magazine became the cornerstone of classic photography of nearly nude, typically third-world women as ethnographic evidence of another people's culture. The Geographic drew on and acculturated the audience's knowledge as regards race, gender, and sexuality, with the marked subcategory in each case being black, female, and unrepressed, fuelling racial and gender subordination (Collins and Lutz, 1993). The nakedness of the Geographic's subjects appeared in a continuum, with the nude as a perennial theme in Western Fine 
Arts. For example, Post-Impressionist/Primitivist French artist Paul Gauguin (18481903), presented Tahitian nudes sitting, standing or lounging, often presented at the salient Center of National Geographic photography of the non-Western world. For example, the October1986 edition (pages 490-491), depicted women in a Gauguin-like setting, reminiscent of Micronesian women sitting and lying down in a manner of Gauguin's Polynesian paintings. Gauguin became the subject of scrutiny by author David Sweetman, mainly for the artist's lifestyle and conduct in Tahiti and Hiva Oa. Sweetman's 1995 biography of Gauguin described him as a syphilitic pedophile who used local Tahitian cultural traditions to excuse away two sexual relationships, he had with 13 and 14 year-old girls, the latter that bore him a child (Sweetman, 1995).

Likewise, art historian Barbara Buenger, referred to Gauguin's friend, the hugely popular and renowned German artist Ernst Kirchner (1880-1938), who, never having travelled to the islands of the Pacific, still created a woodprint entitled: Naked Couple in the Sun (1910) that blatantly depicted a pedophiles after sex encounter, with a Pacific child. Buenger (1989) described the print as follows:

Kirchner's dark teenager sits with her enlarged genitals fully exposed as she selfconsciously plays with her feet. His stereotypical image of the catlike South Seas adolescent bride who has uninhibitedly enjoyed sexual pleasure with a white - now shy, self-conscious, and hesitant - Western male is a romance similar to those told by Gauguin in Noa, $\mathrm{Noa}^{l}$, Robert Louis Stevenson, and numerous other writers of South Seas fiction. (p. 94)

In the academic research genre, the American anthropologist Margaret Mead published Coming of Age in Samoa (1928), that detailed her three-month research and study interviewing youth on the island of Tau in the Samoan islands in 1925-1926, that became an immediate success with the public and academia, and was recognised as a scientific classic and bestseller. Mead portrayed Samoa as a society where love was

${ }^{1}$ [1919], referring to Gauguin's autobiographical account of his time in Tahiti. (See Gauguin, 1947) 
available for the asking. She wrote on the subject of Samoan girls experimenting freely with sex and taking countless lovers before marrying. She described Samoan teenagers free of sexual hang-ups, living in a laid-back culture, with premarital sex casual and loose. Supposedly, punishment for crimes was by exchanging a few mats. Weighing up her interpretation of Samoa, and Samoan youth, I suggest Coming of Age in Samoa could likely to have had sent countless tourists flocking to Samoa for a piece of the action.

In contrast, the New Zealand anthropologist, Derek Freeman (1983), asserted that Mead's two young Samoan female participants had duped her, leading to incorrect conclusions. According to Freeman, the reality of Samoan culture had been exceedingly different from Mead's portrayal of Samoan society. Samoans, he said, held puritanical attitudes regarding sex. For example, Freeman noted Samoans had placed enormous emphasis on a woman remaining a virgin before marriage (See also Freeman, 1998. Regarding Mead's place in this discourse, see Holmes, 1987, Durutalo, 1992).

\section{A Travel Planner}

The second of the two images was a travel planner advertisement I had discovered in a New Zealand monthly magazine. Looking the advertisement over, I noticed similarities to Tahitian Women. In this advertisement, a solitary woman walked leisurely in a tropical beachscape. She was back on; therefore, her facial features were anonymous. Her hourglass figure complimented her sarong and bikini top; her long blonde hair cascaded effortlessly down her back. She could be viewed sexually.

Photo-shopped in close proximity to her was the full face of a young Pacific Island girl smiling with what appeared to be coral pink lipstick on her lips, and the rest of her body was not visible. Her face aligned to the height of the woman's head, therefore, was the frontal face of a child and the back on body of a woman. To link them both, each had a floral wreath on her head. To their left, a computer screen depicted a solitary yacht that was anchored out to sea off the coast of a tropical location. Interpreting the Video Planner advertisement could hold an interpreter of subliminal messaging occupied over 
time. For instance, the computer offered anonymity, and the lone yacht offered the casual predator a floating lair. However, the child's lipstick was an undeniable sexualising element that coupled with the child's face and the woman's body, had constructed what could only be termed a type of Pacific 'Lolita'.

In all, I considered the advertisement's artistic designer did not demonstrate neither moral nor ethical responsibility, nor the integrity and effectiveness of responsible advertising, towards ensuring Pacific children were not sexualised alongside sexualised adults. I contacted the travel agency responsible for this advertisement to voice my concerns. The representative did not, (or could not), reply to my enquiry; therefore, I was put in touch with the photojournalist who had taken the girl's picture.

The photojournalist explained that he and his colleague had filmed a sporting event on the island of Maui, in Hawaii, that was for a video promoting Hawaii. He had photographed the girl after her performance with a large cultural group at the game. He said the child's traditional costume had caught his eye, which was why he wanted to include her in his video. He and his colleague had introduced themselves to the girl's family and asked their permission to photograph her. He explained that the girl's parents were genuinely delighted that visitors from New Zealand had been interested enough in their daughter's performance to take part in his video.

The photojournalist was adamant he had not applied lipstick or makeup to the girl. He had assumed her family or dance group performers had put the lipstick on her. He rejected the idea that the girl had been sexualised (Personal communication, 17/4/2004). At the end of it all, I considered that the photojournalist had missed the point. Nevertheless, the photojournalist's explanation prompted the question, other than the face of the girl, and the leaf garland in her hair, where was the traditional costume that had caught the photojournalist's eye? Perhaps my questions pricked a conscience. In the magazine's subsequent issue, the advertisement reappeared, although the girl had been removed and the text reworded. 


\section{Thailand}

It was while thus engaged in this study of promotional imagery for tourism in the Pacific that I soon realised that the stereotypical images I was looking at, obviously had a receptive audience that acted upon the sexualised depictions of Pacific women.

My early literature search on this issue often returned to one point:, since the 1990s crackdowns on pedophiles in the Southeast Asia sex sectors, such as Thailand and the Philippines, new pedophile routes had emerged in countries such as Latin America, Africa, and Eastern Europe. Commonly referred to as the 'push-down, pop-up syndrome' or 'transnational creep', These countries lacked a stable economy, were burdened with high rates of unemployment, presented great disparities between the rich and the poor, and a large under-age population (NGO Group Convention on the Rights of the Child, 2005, Jullien, 2003).

Staying with Thailand, by the mid-1990s, Thailand had emerged from multiple wars, trauma, the brutalisation of its people, and an economy ruined. Unemployment was rife, and along with the subjection of its economies driven by dictatorships and foreign interests, provided the necessary infrastructure for the development of the sex industry (Zafft and Tidball, 2010, Lau, 2008; Tepelus, 2008; Zitze, 2007, Jhappan, 2005, Prasso, 2005, Leung, 2003, Hoose, Clift, and Carter, 2000, Rao, 1999).

Tepanon (2006) presented a description of that era. She referred to the Thailand Deputy Prime Minister's call to the Thai nation to consider a sex tourism industry to avert economic ruin and advance employment. Montgomery, (2008) cited the minister's call as follows:

I ask all governors to consider the natural scenery in your provinces, together with some forms of entertainment that some of you might consider disgusting and shameful because they are forms of sexual entertainment that attract tourists... we must do this because we have to consider the jobs that will be created for people (p. 906). 
Following the Ministers call to the nation, within a decade, Thailand's reputation had plummeted, both in the region, and global (Arnold and Bertone, 2002; Lau, 2008). Thailand became a source country of adult and child prostitution, a transit and destination country for women and children, trafficked for the purposes of the Thai sex industry and then CST (O’Briain, Grillo, and Barbosa, 2009; Tepelus, 2008; Zitze, 2007; Poulin, 2004; Lim, 2003, Ryan and Hall, 2001; Hoose, Clift, and Carter, 2000). Predictably, cultural, traditional, family, and community values, rapidly declined, and children quickly learnt that tourists could provide luxury items or cash that as O'Connell Davidson (2004) remarked, became one-way locals tapped into "privileges reserved for tourists and elite locals" (p. 39). Other times, by family or friends, children were trafficked within or outside borders, often, if not always, into sexual servitude, and always against their will.

Baker (1995) estimated 800,000 children under the age of 16 had entered into prostitution in Thailand. Warburton and Camacho de la Cruz (1996) estimated approximately 200,000-prostituted children in Thailand. A Joint United Nations Programme on HIV and AIDS or UNAIDS (2004) reported in 2004 that Thailand had around 570,000 infected adults and children, representing approximately eight percent of the region's population (UNAIDS, 2004).

Freelance writer and sociologist, Alice Leuchtag (2003) reported, paradoxically, the Thailand government could not acknowledge the HIV/AIDS epidemic without contradicting the continued promotion of sex tourism. Estes' (2001) annotated bibliography on commercial sexual exploitation of children (CSEC) cited many researchers having researched and reported on the impact of sexual abuse and sexual exploitation of Thailand's children. He noted few children were able to escape their molestation unharmed; virtually all had suffered long-term physical and emotional injuries, posing complex service challenges for the justice and human service systems.

Acknowledging the sheer size of the Southeast Asia sex tourism operation, resulted in a number of strong regional policy and global actions. For example, the 1997 
ESCAP Resolution 53/4 to combat sexual abuse and sexual exploitation, including trafficking. The 2001 Bangkok Regional Commitment and Action Plan against Commercial Exploitation of Children (pre-Yokohama, 2001). On a global scale was the First World Congress on Commercial Sexual Exploitation of Children, in Stockholm, Sweden, that adopted the Stockholm Declaration and Agenda for Action (1996). In addition, the Second World Congress on Commercial Sexual Exploitation of Children, in Yokohama, Japan, that adopted the Yokohama Declaration and Agenda for Action (2001), elaborated on in chapter 2.

Ed Susman (2003), connected Pacific HIV/AIDs to the sexual stereotypes associated with colonial depictions of South Seas women and girls, including present-day Southeast Asia sex tourism, and transnational creep into the Pacific. Susman explained:

For centuries, men have journeyed to the South Pacific, drawn by warm temperatures, blue lagoons, and tempting women. Today, tourism remains crucial to the economies of many of the small island nations of the region, but their charms also have made them destinations of choice for sex tourists - who seem to have caused the latest regional eruption of HIV infections.... That is absolutely the situation in many parts of the South Pacific... For many years, Asian countries such as Thailand, Korea and Taiwan were well-known destinations of sex tourists and harbours to widespread commercial sex industries. More recently, however, their red-light districts became hot spots in the global HIV epidemic. Despite efforts by governments and non-governmental organizations to promote safe practices during paid sexual exchanges, fear of infections seems to have contributed to the migration of sex in the tourist trade to the South Pacific. (p.1)

Additionally, in his report, Susman had remarked, that at a regional meeting in Vanuatu, officials had warned that a crackdown on pedophiles in the Solomon Islands might result in child molestation cases in a number of the other tourism-hungry islands. In addition, the same report cited Joyce Yu, resident representative of the United Nations Development Programme in Apia, Samoa remarked, and "We are fairly certain that AIDS was brought to the South Pacific by a tourist (Susman 2003, p.1) 


\subsection{A Problem Statement}

A 2005, trafficking report from The Protection Project about Samoa, piqued my interest. The Protection project is a legal Human Rights Research Institute, based at the School of Advanced International Studies at Johns Hopkins University in Washington, DC. Citing a senior government official, the Protection Project had presented the CST situation in Samoa as follows:

In 2003, a 49-year-old Australian male yachtsman received a 2 year and 9 months jail sentence for indecently assaulting a 15-year-old Samoan child. The attorney general said, although child sex tourism was not a serious problem in Samoa, this conviction showed that Pacific governments were taking child sexual exploitation seriously. (The Protection Project, 2005)

The Protection Project statement presented some concerns. First, it had the potential to downplay the seriousness of CST in Samoa, simply based on a single prosecution. Second, the Protection Project statement could have fueled complacency, a false sense of security, and less vigilance on CST within the Samoan community. Third, on a global scale, the exact numbers of child sex tourists operating in any single country are elusive. Typically, estimates had prevailed. Vermeulen and De Hauw's (2004) reported a study on the efforts of European Union countries to collect data on either offenders or child sex tourists that revealed modest returns. Independent special policy expert Sandy Ruxton, (2001) asserted victim numbers held on record were a significant underestimation of the phenomenon, taking into consideration its illegal, and hidden character, and complicity of governments, and law enforcement officials who ignored the situation. The earlier Baker (1995), and Warburton and Camacho de la Cruz (1996) estimates, had revealed differences in deducing exact numbers.

\section{Fiji: A Case for Complacency?}

The Protection Project report emphasised, Pacific governments were taking a serious stance to combat CST. How seriously were Pacific governments taking the CST 
problem? To find out, I selected Fiji as a case study because the island nation is commonly referred to as the tourist hub of the Pacific. Providing early background, a news media report from Nette (1999), discussed the case of Mark Mutch, and his part in a the sexual abuse of Fijian children, and the subsequent pedophile ring that had operated because of his abuses. The sexual abuse of Fijian girls had been discovered by accident rather than by the vigilance on the part of Fijian authorities. Mutch, an Australian residing in Fiji, had sent his computer to Australia for repair. Technicians subsequently discovered thousands of child pornography images of Fiji children on the hard-drive that were reported to the Australian police.

Commencing 1990 to 1997, when he was arrested, Mutch had lured local primary school girls to his home for sex (Nette, 1999). He had approached his victim's families, offered to support them financially, and to pay their children's school fees, thus gaining their trust and confidence (UNESCAP, 2009). Having photographed the children naked, and sexually, the images were uploaded to an online pedophile network, following which; a number of pedophiles had travelled to Fiji to join in on the sexual abuse of the children. The police discovered four young girls, between four and 14 years of age, had featured in Mutch's pornographic collection (Nette, 1999, see also State v Mutch, 1999). In addition, following the breaking of the case, reportedly, a number of executives and officials left Fiji immediately.

The incident generated extensive press coverage, and Pacific-wide discussion involving non-government organisations (NGOs), members of the police force, senior government officials, and the community. The report quoted government officials who conceded that Pacific-wide complacency, had contributed to the abuses of the children (Nette, 1999). Consequently, Fiji amended its legislation, thus making the production and trade of child pornography illegal through the Juveniles Amendment Act of 1997. In 1998, Fiji's cabinet passed a motion implementing tougher sentences for perpetrators of child sexual abuse. In addition, as a result of increased pressure on the tourism industry, the Australia-Fiji Memorandum of Understanding for Joint Action to Combat Child 
Sexual Abuse and Other Serious Crimes, was established (ECPAT 1998). National and international commitment strengthened, and co-operation increased among Pacific nation governments and international NGOs, private sector parties and other civil society groups such as women's groups and church organisations, all calling for harsher legislation to protect children from foreign pedophiles.

Incidentally, at the same time in 1999, Robert Marlow an Australian under the Child Sex Tourism provisions of the Commonwealth Crimes Act of 1914 had been committed to stand for trial in Australia for allegedly sexually abusing four Fijian boys.

\section{A Special Rapporteur Report (1999)}

Despite all of the aforementioned actions, Fiji complacency remained. Evidence of this was arrived at in a 1999 report from Ofelia Calcetas-Santos, the United Nations' Special Rapporteur on the Sale of Children, Child Prostitution, and Child Pornography. The Rapporteur had travelled to Fiji, to acquire information amid reports that Fiji had become a popular destination for sex tourists and the tourism industry's response to CST was unknown. The Rapporteur discovered child prostitution operated on an extensive scale. Parents were offering their own children for sexual services in return for payment. The root causes driving children's sexual abuse and exploitation were poverty, money, boredom, lack of education, lack of enforcement, and tourist demand and sex tourists coaxing island taxi drivers to facilitate child prostitution.

Calcetas-Santos reported Fiji fell short of its commitment to the CRC. She reported the Minister of Tourism had sent a representative to speak to her. The representative said the Minister was aware the tourist industry was a contributory cause in the growth of pedophilia in Fiji, nevertheless, the Minister did not consider the problem was yet of sufficient gravity to merit the government's active involvement in preventive measures. The representative reported budgetary constraints had prevented a focused CST agenda. He reported the topic of CST had featured at all major tourism 
conferences, and that "the Fijian Ministry of Tourism does not consider that it has a role to play in this regard" (United Nations Commission on Human Rights, 1999, p. 11).

\section{The Pacific Interagency Report (2006)}

For many small island developing countries, tourism is regarded highly as a driver of economic growth, generating substantial incomes for the majority of countries within the region and features strongly in national and regional development plans.

Understandably, many Pacific countries embrace tourism as their number one economic growth sector. During the period 1990-2003, economic growth in East Asia and the Pacific was the fastest in the world. By 2004, Tourism had generated substantial incomes for the majority of Pacific countries within the region (ESCAP, 2006). For Fiji, tourism has brought significant financial and developmental benefits, drawing in investment and creating employment.

Approximately seven years after the aforementioned Rapporteur report from Fiji, a groundbreaking Pacific Interagency report noted, the majority of CST in the Pacific operated in Fiji. The report was entitled "Commercial Sexual Exploitation of Children (CSEC) and Child Sexual Abuse (CSA) in the Pacific: a Regional Report" (UNICEF, UNESCAP, and ECPAT, 2006). Five Pacific countries had participated in the report. Participating countries were, Papua New Guinea (HELP Resources, Inc, 2005), Fiji (Save the Children Fiji, 2004), Kiribati (Pacific Regional Rights Resource Team, 2004), The Solomon Islands (Christian Care Centre of the Church of Melanesia, 2004), and Vanuatu (Wan Smol Bag, 2004). To attain a wider understanding of the CSEC and CSA problems in the Pacific, the Cook Islands and Samoa had agreed to conduct their own individual situational study on CSA and CSEC, following publication of the Pacific Interagency 2006, report.

Generally, the study's findings confirmed the "existence of some opportunistic child sex tourism in the Pacific, but the studies did not provide evidence of the highly organised child sex tourism networks that exist in other parts of the world" (p.37). 
The report noted "anecdotal evidence of foreign visitors seeking sex with children" (p.37). Furthermore, as the tourism industry developed and more tourists arrived the risk of CST would rise accordingly:

...the Pacific region is becoming more attractive to child sex tourists because of the crackdown on child trafficking and prostitution in Asia, because in the Pacific there are "loopholes in laws and limited public awareness" of the issue. In light of these risks, more research needs to be done to identify types of child sex tourism in the Pacific and the opportunities for exploitation facilitated within the tourism industry. (p.38)

The Pacific Interagency report findings were significant although predictable. The report verified Pacific-wide complacency. In all five Pacific countries, one or more types of the CSEC operated alongside Pacific government's obligation to the CRC and other human rights agreements, binding and non-binding. The report highlighted complex and inter-related root causes listed as follows:

...gender discrimination and particularly the low status of women and children, poverty and the lack of educational and employment opportunities and a lack of protective legislation, services and regulation, contribute to making Pacific children highly vulnerable to sexual violence. A culture of silence among authorities and adults perpetuates the suffering that children experience. The studies also indicate that some children are at particular risk of being sexually abused or sexually exploited, or both, such as children who experience parental neglect and abuse, children living without their natural parents (including those who are informally adopted) and children suffering economic hardship or poverty of opportunity. (UNICEF, et al, 2006, p. ix)

Perpetrators of the abuses comprised "family members, teachers, shop owners and workers, wholesalers, businessmen, public servants, politicians, pastors and church workers, NGO workers, military personnel, farmers, seafarers, loggers, drivers, youth and tourists" (p. 47). Adults had sexually abused and exploited children, frequently involving a third person or persons. Facilitators were, "taxi drivers, nightclub owners and workers, security guards, and hotel owners and employees" (p. 48). The Papua New Guinea study 
discovered, “... In some areas, children and youth acted as go-betweens, establishing contact with local girls and their families for adult male perpetrators" (p. 48).

For the reason that there was limited regulation of the tourist industry and immigration, the report noted, perpetrators had easy access to children, therefore, could readily engage children in sexual abuse and sexual exploitation. The report noted, the hospitality industry provided easy access to children and bar staff and security guards facilitated CSEC in most of the countries, in particular Papua New Guinea.

With this background, the report presented two related recommendations. The first recommendation was as follows: "More research needs to be done to identify types of child sex tourism in the Pacific and the opportunities for exploitation facilitated within the tourism industry" (ibid: 38). A longer recommendation was as follows:

The tourist industry develop a code of conduct aimed at combating the commercial sec and child sex tourism as well as training and awareness-raising for service providers (such as hotel and bar staff, night club owners and staff, tour operators, resort staff, taxi drivers, boat operators) in the recognition of strategies to prevent child sexual abuse and exploitation, and reporting obligations. (ibid: 125)

Regarding the Pacific tourism response to this issue, early indication from The South Pacific Tourism Organization, (renamed south-pacific.travel) was lack-luster. The South Pacific Tourism Organisation is Pacific wide with a membership, represented by both the public and private sectors. It promoted itself as committed to achieve sustainable growth in the sector for the benefit of the people of the South Pacific. According to its website, "south-pacific.travel," the organisation was the mandated intergovernmental organisation for the tourism sector in the South Pacific. The executive structure of the organisation consisted of the Council of Tourism Ministers. In addition, the Organisation operated in partnership with member states (of which many, if not all, were Pacific countries involved in the Pacific Interagency Report (2006), the private 
sector, and the donor community. Notably, on its website is no Code of Conduct or clear statement that CST was not wanted in its Pacific member countries.

\section{The World Sex Guide: Fiji}

Since the Mutch case, the aforementioned Special Rapporteur report, and the Pacific Interagency report (2006), noting Fiji had the worst CST problem in the Pacific, a website named "The 'World Sex Guide', that is a forum for sex tourists to compare and contrast their sexual experiences in numerous countries, presented a discussion on sex in Fiji, that included, where to find girls of all ages for sex. As posted from a member named 'Jas':

Fellow punanilovers ...Lautoka: After 9pm circle the city, centre and you will find many streetwalkers. Now, with these street walkers, take note that some are full-time professionals and others are school students and sort of total amateurs for quick money.... Nadi: well, there are a couple of local brothels, one is the Nadi motel, you come here at night usually after 9 pm, and you can find assorted girls of various ages, although you can speak with the receptionist to find a girl of your choice, they usually have phone numbers. Another good place is the youth hotel - (sic hostel).This place is in the "road OPPOSITE Nadi Bay hotel" it is a beat-up joint, but you can find some good punaniz here. Overall, taxi drivers are a good help. (Jas, 2008)

\subsection{This Study}

Samoa ratified the CRC in 1994. Therefore, as requested by Article 44 of the

CRC, Samoa as a ratifying state, must submit a progress report two years from the date of ratification to The Committee of the CRC (The Committee), that comprises 10 independent experts, elected by state parties. Following final observations and recommendations, state parties such as Samoa, reported to The Committee once every five years. 
Samoa had submitted its initial report in 2005, approximately 10 years after ratification (See Government of Samoa, 2005) and not two years. Having considered Samoa's initial report, The Committee came back with a detailed list of concluding observations and recommendations. One recommendation from The Committee to Samoa related to "Special Protection Measures" (referring to CRC Articles.22, 30, 38, 39, 40, and 37 (b)-(d) and 32-36 of the Convention). Under the heading, "Sexual Exploitation" The Committee raised a concern. As follows:

[55]. The Committee is concerned that the growing tourism industry in the State Party may expose children to sexual exploitation. (UNCRC, 2006a, p. 12)

The Committee then provided a final recommendation. As follows:

[56]. The Committee recommends that the State party

a) Conduct a study to determine the root causes and the scope of sexual exploitation

b) Use the outcome of this study to develop and implement an effective and comprehensive policy addressing the sexual exploitation of children, in accordance with the Declaration and Agenda for Action and the Global Commitment adopted at the 1996 and 2001 World Congress against Commercial Sexual Exploitation of Children (p. 12) `

The Committee's recommendation [\#56], to Samoa, became the momentum for this study. For a number of reasons, I considered The Committee's recommendation had headed in the right direction. For example, the recommendation appeared consistent with global recognition of the patterns of CST, now spreading into small island developing states where tourism was a mainstay for economic growth, and complacency to human rights, particularly, child rights remained.

Three examples substantiate my point. First, in 1994, an Australian cleric had been convicted of four counts of indecent assault of two boys under his care in Australia. After his release, the church sent him to Samoa. When there, he had roamed at will for 
some years. In 2004, Samoa deported him back to Australia to face outstanding sexual abuse charges (Auseugaefa, 2004).

Second, prior to the prosecution of the Australian tourist for the sexual abuse of the Samoan child, a Samoan newspaper report, had already some four years earlier, warned Samoa to pay attention to CST there. The, report discussed rising tourism, poverty worsening, an operational prostitution industry, and pedophiles grooming families to gain access to their children. The report noted Samoa had an increase in the application of four forms of CSEC, namely child pornography, prostitution, trafficking and pedophilia. Specifically, the article reported prostitution were visible in Apia and for adults involved in the practice, prostitution had become the only viable way to earn a living, despite risking mortality by means of HIV infection. The report noted Samoa had relied heavily on the tourism industry to boost its economy, and Samoa's low-incomeper-capita rate. Reportedly, business people had groomed families to gain access to their children for sex, since these families were comparatively poor, and accepted help. Moreover, the law was not strong enough to remedy child prostitution, and pornography (Lesa, 2000).

The third reason concerned a New Zealand man and his former partner adopting Samoan children for suspected sexual abuse: As presented about the case:

...with the purpose of providing Samoan children with a new life in New Zealand. They had adopted eight children from four Samoan families, and then carried out 36 indecencies on three of the adopted children. The man had befriended the children's families, provided food, clothing, and money in exchange for an adoption. The man had fitted his house out with Play station, pool table, basketball court, and video games. Charges included extraterritorial offences (those committed in Samoa) (UNESCAP, ECPAT, UNICEF, and UNEAPRO, 2003, p.17)

In addition to the three aforementioned examples, following Samoa's initial report to The Committee of the CRC (in 2005), The Committee had recognised a lack of data on 
forms of SEC in Samoa, and requested more information on prostitution, pornography, and trafficking. Specific areas for answers were as follows:

1. What special protection measures were in place;

2. Statistical data by sex, age and by islands for the years, 2003, 2004 and 2005, on the numbers of children sexually exploited, including prostitution, pornography and/or trafficking; street children and the number of children who received assistance;

3. Child victims who received recovery, counselling and other forms of assistance; and

4. Children under the age of 15 who were employed, children abusing alcohol, using narcotics and drugs, and the number of children who received assistance. (UNCRC, 2006, pp. 24-25)

The delegation did not respond to The Committee's request. Notable however was the Committee did not include a request for more information on CST or child bride/informal marriage.

In addition, in 2005, The Committee on the Convention on the Elimination of All Forms of Discrimination Against Women (The CEDAW Committee), having considered Samoa's combined initial, second and, third periodic report, recommended Samoa to "commission a specific study on the extent of prostitution in the country, women trafficking, and the involvement of children in such, in the country" (United Nations, CEDAW, 2003, p. 50). Furthermore, a United Nations Population Fund report (2006), on the adolescent sexual and reproductive health situation in Samoa (1995-2005), observed Samoa's precedent efforts investigating CSEC was lacking. Specifically, the report noted, "In Samoa, no studies on sexual exploitation were found, so there is only very little anecdotal information about these forms of commercial sexual exploitation" (p. 57).

\section{Is a Study Needed?}

From all of the above, I considered a CST study was needed in Samoa. Nonetheless, prior to my commitment to a study, I needed to determine Samoan viewpoints regarding The Committee's recommendation to Samoa. Did they think a 
study was needed? I adopted the practice of case study expert Winston Tellis (1997). Tellis advised, in exploratory case studies, data collection could commence prior to the definition of the research questions and hypotheses. Therefore, to gauge Samoan opinions, I presented this study's research proposal, at two conference events, the first in New Zealand, and the second in Samoa, in front of Pacific audiences.

My first presentation was to delegates at the conference entitled, Building Pacific Research Capacity and Scholarship in Aotearoa New Zealand (2008), held at the Fale Pasifika, University of Auckland. Over 122 Pacific academics, scholars, development and policy participants, emerging researchers and community leaders attended this conference. My paper entitled, What Value, the Pacific Child (Christiansen, 2008a), spoke about Pacific tourism and CST, and The Committee's recommendation to Samoa. Participants, young and older, generally agreed with The Committee's recommendation that a study was needed. Following my presentation, an older Samoan woman whispered to me she was glad the study was happening. She asked, "Did you see some of them squirm?"

The second conference was at the National University of Samoa. I presented my paper entitled, What Value, the Pacific Child (Christiansen, 2008b) to the Fourth Measina Conference, entitled: E le o le fusing pogo le fishgig ago le nausea o le fa'asamoa: In search for the core elements of the fa'asamoa (December 15 -17, 2008). Participants at this conference, were academics and researchers, although predominantly Samoan community leaders, and the public. I realised that while for a number of Samoans, the possibility of CST operating in Samoa did not enter their conscious, others suggested awareness this was an issue. ${ }^{2}$

\footnotetext{
2 See: Measina a Samoa Conference (2008). edited by Fonoti I Upati L. Fuata'I and Telesia Lafotanoa 2008. Measina a Samoa 2008: papers presented to the Measina a Samoa conference, 15-17 December 2008 National University of Samoa, Le Papaigagala campus. Vol 4. National University of samoa. Le Papaigagala.
} 
A third party I needed to consult with was with my 72-year-old Samoan-born mother. I asked her opinion about this issue in Samoa, and should I do this study. She could not recall CST happened there, although, I noticed, she struggled with the concept, and did not really understood what CST was, and what I was asking her to recall. However, she did say, "O.K/, you go do the study," and then added, "If those people go to Samoa to do that kind of thing to our children, then they should be taken out to sea for the sharks to eat!" I agree. CST is a deplorable crime against children, families, communities, and nation; CST was against my principles, values, and beliefs. I was not raised by my mother to practice or condone violence against children, sexual, physical, or emotional.

\subsection{Research Objectives and Key Questions}

Having satisfied myself about the necessity for a Samoa CST study, I set to establish research objectives, and key research questions. Drawing out of the Protection Project statement (2005), and The Committee's recommendation to Samoa (2006), I formulated three research objectives as follows:

1. To report the scope of child sex tourism in Samoa,

2. To identify and report the root causes that contributed to the risk of child sex tourism in Samoa, and

Of Note: In addition to the above, I presented this topic at two other conferences:

2010: Globalisation and Public Policy: An International Cross Cultural Research Exchange Conference. Institute of Public Policy Auckland University of Technology, Auckland, New Zealand. In partnership with National Conference of Minority Public Administrators (COMPA) and Texas A\&M University USA. 10 12 August (2010). Paper title: Another view of tourism: Child sex tourism in Pacific countries.

2008: Dev-Net. Peripheral Vision - Thinking about and practicing development (Aotearoa and the South Pacific region). Victoria University of Wellington, New Zealand. December 3-5, 2008. Paper title: Towards tourism development: What value the Pacific child? 
3. To present a set of recommendations as a baseline foundation for policy, advocacy and research.

To achieve this study's three objectives, I formulated five research questions as follows:

1. How do Samoans view tourism in Samoa: Positively or negatively?

2. Is CST a problem in Samoa?

3. What are the root causes for CST in Samoa?

4. Whose responsibility is it to prevent CST in Samoa?

5. What actions need to be taken to prevent CST in Samoa?

\subsection{Research Design}

Fieldwork was a one-month study, from April 4 to May 4 2009, in Apia, Samoa. Methodology was a qualitative, single, embedded case study. Given the seminal nature of this study, I utilised a qualitative research approach. Qualitative research is flexible, allowing changes in research design as seen fit. Apia became the case study because Apia is the tourist hub of Samoa. Because this was the first known study of its kind in Samoa, there was a need for the clarification of definitions.

\subsection{Thesis Structure}

Seven chapters follow this introductory chapter. Chapter 2 is a review of literature. I present a context to The Committee's recommendation to Samoa. I explore the CST phenomenon, and I introduce the various international declarations referred to in the recommendation to Samoa. Chapter 3 presents the environment of the Samoan child. I look at tourism in the national development picture. Featured are traditional and state protection measures for children protection against issues such as CSEC. I raise a number of long-standing issues for children, considered symptomatic of root causes enabling a CST environment. Chapter 4 is a discussion of methodology and research design. I describe the single embedded qualitative case study design, data analysis, and 
the trustworthiness of the results. I present a brief discussion on the Samoan va, talanoa, and fa'afaletui, a conceptual model included into this study's design. Chapter 5 (Discussions, Section 1) answers the study's first three research questions. Chapter 6 (Discussions, Section 2) answers the remaining two research questions. Chapter 7 is a discussion of the results of chapters 5 and 6 . Chapter 8 presents conclusions, limitations, and recommendations. 


\section{Chapter 2: Review of Literature}

[56]. The Committee recommends that the State party

a) Conduct a study to determine the root causes and the scope of sexual exploitation

b) Use the outcome of this study to develop and implement an effective and comprehensive policy addressing the sexual exploitation of children, in accordance with the Declaration and Agenda for Action and the Global Commitment adopted at the 1996 and 2001 World Congress against Commercial Sexual Exploitation of Children (p. 12) `

\subsection{Introduction}

Up to the present time, chapter 1 had described this study's background, the problem statement was established, and rationale for this study needed, given. The secondary data presented CST as an under-researched phenomenon in the Pacific and in Samoa specifically. Despite the enormity of the CST problem worldwide, at the same time, generally, the CST literature remained scant, and no study solely devoted to CST had been conducted in the Pacific. The Pacific Interagency Report, 2006, (chapter 1), had been invaluable research for identifying the scope of the CSEC in the Pacific region - including compelling evidence that CST operated to some degree in a number of Pacific countries. Nonetheless, only a small proportion of the report was assigned to CST. Briefly, in its recommendations, The Pacific Interagency Report had recommended a closer inspection of the tourism industry. Although as soon will be discussed, rising tourism and the tourism industry, were the only root causes driving CST.

To meet The Committees recommendation, I had set five research questions, and three research objectives. Now, with this in mind, I wanted to know what, The Committee's recommendation to Samoa entailed. Clearly, I needed to understand CST, 
and the contextual root causes behind it, to meet this study's three objectives. Therefore, this chapter aimed to answer the questions, "What is CST, What are the root causes, and the effective and comprehensive policy addressing the SEC, in accordance with the Two World Congresses (Stockholm (1996) and Yokohama (2001), that The Committee had referred to?

For the most part, because the literature on CST in the Pacific was scant, my literature review had to draw on situational studies, otherwise termed country reports. Three in particular were most beneficial. The study's focus was specific to CST in a tourist setting, so I read each study closely. A glance at the publication dates of the three studies, confirmed the tremendous boost to research given by The First World Congress in Stockholm in 1996, and the Second World Congress in Yokohama 2001. The two congresses had prompted governments and NGOs to commission research focusing on the CSEC from many different disciplines, instigating a wave of publications in the years immediately following, of which only a small proportion are referred to here. By crossreferencing from among these publications, I aimed to demonstrate a level of comprehensive understanding of the root causes that produced vulnerability and susceptibility to CST.

Generally, the three situational studies were at the initiative of UNICEF, or NGOs such as ECPAT (End Child Prostitution, Child Pornography and the Trafficking of Children for Sexual Purposes), in cooperation with UNICEF (United Nations Children's Fund), for improving data for awareness, policy development, and change. As products of action research, these three studies were important advocacy documents conceived to generate further research, as well as educate, and advocate. Each of the reports had consistencies in definition, aims, and required outcomes similar to my own study. Furthermore, largely, in these three studies, I looked closely at methodology and data collection methods as could be fashioned in my own research approach in Samoa. I had seen in the three, that their objectives and questions had similarities to one another and my own study's objectives and questions. 
In addition, this literature review drew early impetus on the work of principle researchers, having in the last 25 years explored and reported on sex tourism, CSEC and CST. Authors such as, Judith Ennew, (1986) Jeremy Seabrook, (1996 and 2000), Julia O’Connell-Davidson) 1996 and 2004), Laura Barnitz (1998), Montgomery, (1998 and 2001), and Eva Klain (1999. In addition, are Donna Hughes, (1999, 2001 and 2008); Karene Jullien (2003); Richard Estes, (2001); Ryan and Hall (2001); Hall and Hall (2007), and numerous others.

Taken as a whole, the remainder of this chapter contextualises The Committee's (2006), recommendation to Samoa. To begin with, I deliver this study's working definition of CST. Second, I provide a profile of the perpetrator and victim. Directly, I introduce the Two World Congresses that The Committee had referred to and their relevance to combating CST. Third, I present what is termed root causes for CSEC and CST. Fourth and last, I present and discuss the three situational studies. Finally, I present four root causes I suggest provided a suitable starting point for discussion and the identification of CST in the Samoan environment. A summary follows.

\subsection{Child Sex Tourism}

Tourism is one of those few economic sectors through which least-developed countries can increase their participation in the global economy. Tourism lecturer John Swarbrooke (1999), rated tourism highly for its economic and social activities, and positive impacts on local economies. Zitze (2007), asserted that socio-economic development, boosted by tourism promotion and growth, was crucial for many countries worldwide, particularly developing ones. For small island developing countries, with limited employment opportunities, tourism can contributed significantly either in the service and commercial sectors such as hotels, restaurants, nightclubs, taxi services and souvenir sales, or indirectly from the supply of goods and services drawn out of additional economic sectors such as agriculture, horticulture, and animal husbandry. 
Shaw and Williams (2004) supposed that if tourism were developed and managed in a socially responsible manner, host communities benefitted, in either increased living standards or significant improvement to community facilities and services. The impotence of tourism for the global economy is seen in a Centre for Responsible Travel fact sheet, (CREST, n.d), having had projected by 2010, that travel and tourism worldwide would account for 9.2 percent, US \$5,751 billion of world gross domestic product and approximately 235 million jobs. Clearly, tourism is big business.

In contrast, there is another view of tourism. Pacific scholar Helu-Thaman, (1993), remarked tourism and tourism development were uneven, creating an erosion of traditional values; increased cost of living, rapid increases in land prices, pollution, and environmental degradation. The NGO CLARANET described tourism as the - new imperialism, the single most destructive global force unleashed by man\| (CLARANET, n.d.). The NGO, ECPAT (2008), presented tourism as an unregulated and unmonitored industry with negative impacts for community, family, and children, and that no sector had earned greater blame in the spread of HIV/AIDS, prostitution, and drug addiction. Dorothy Rozga (2013), an ECPAT executive, reported the figure of child victims of CSEC, at over two million cases annually. In the wake of such condemnation, the concept of sustainable tourism development", an idea premised on the needs of tourists and host regions were met while protecting and enhancing opportunities for the future of local populations, seemed floating on wishful thinking.

\section{A Definition}

Before engaging with this topic, what I knew about CST came from television and newspaper reports that were usually sensationalised. For example, about a celebrity operating in the murky underbelly of pedophilia (such as the world-renowned musician Gary Glitter) or a child abducted - missing without trace - for the purpose of sex. Always the perpetrator was male, and termed a pedophile of two types. The first type was notably the shadowy sexual predator, a stalker of children, aimed to solicit psychological 
unease through sexual undertones. The second type was the 1980s pedophile, overweight, balding, a male in his late 60s, largely from a European country, at the bottom end of the middle class. To access children, this pedophile travelled to Asia or Africa. Thereupon, to lure children, he had bought beads and trinkets for trade purposes.

Inquiring further, I soon found out, that what I thought I knew was, in fact, misguided. In defense of my mistaken belief, to demonstrate this point, I turn to Davidson (2004), who explained that in the 1990s, ECPAT International had resorted to stereotypical images of the child sex tourist, mainly for impact and public support. Although the ECPAT campaign was particularly effective in gaining international sympathy, and support, and public awareness of the phenomenon, the stereotypes remain to this day.

Generally, there was no single universal definition of CST. Instead, there was the $\mathrm{UN}$ and international agencies, constantly in consultation with specialist agencies, and NGOs, to ensure an appropriate definition. I had noticed academic researchers often shied away from conventional internationally recognised definitions of CST, preferring instead to devise their own definitions that in reality, I suggest, did not capture the phenomenon in all its many forms.

To illustrate my point, I refer to the website 'Research Gate' that had presented two abstracts for two articles from the same authors about CST. The first abstract described the contents of its corresponding article titled: Child sex tourism: Facilitating conditions, legal remedies, and other interventions (Panko and George, 2011). The articles abstract read as follows:

Commercial sexual exploitation of children puts a black cloud upon the myriad promises offered by the tourism industry. This article provides an overview of some of the major topical areas that appear in the current debates on child sex tourism (CST) and attempts to synthesize a conceptual model that encompasses the scope of CST. As an academic 
field of inquiry, the circumstances that provide a fertile ground for the worldwide growth of the CST phenomenon are addressed. Selected international regulatory responses against CST are presented. Finally, a range of other potential interventions is proposed. (Research Gate, 2015)

Notably, the abstract had detailed the author's attempts to synthesize a conceptual model the encompassed the scope of CST, the authors had fashioned on their definition of CST as follows: "CST refers to touristic pursuits for the express or otherwise purpose of having sexual encounters with children and the consequent ramifications for various stakeholder groups" (Research Gate, 2015). That the model had been fashioned on a definition of CST, I suggest was ambiguous, questioned its relevance to the CST debate and the scope of CST as a whole.

Similarly, the second of the two abstracts corresponded to the authors' article entitled Child sex tourism: Exploring the issues (Panko and George, 2012). The abstract presented the article's upcoming contents as follows:

In this paper, the trauma experienced by child victims of commercial sexual abuse in the touristic setting is discussed. An overview of treatment modalities for the victims such as trauma-focused cognitive behavioural therapy and eye movement desensitization and reprocessing are presented. The efforts of outstanding movements around the world in eradicating CST are highlighted. The paper also considers the complex web of relationships that constitutes the CST distribution system. (Research Gate, 2015)

To carry this discussion through, Panko and George had defined CST as follows:

Child sex tourism (CST) refers to a particular kind of tourism organized to satisfy the need among certain customer segments for establishing commercial sexual relationships with children. It is an expression of contemporary slavery and a major human rights challenge facing our generation. (Research Gate) 
I suggest that in each of the two abstracts, were two points that needed to be raised. First, despite each article focused on CST, and published within a short time of each other, the authors had not remained consistent to a single definition of CST. Second, the CST definitions were not consistent with any international definitions.

Does a consistent definition matter? According to The NGO Group for the CRC (The NGO group), a definition of CST should be clear and consistent. Another thing was increasingly, governments, UN agencies and NGOs were recognising that "unless there are clear and agreed definitions in relation to SEC/and CSEC, the data collected, the strategic responses designed, the legislation implemented and the protection interventions developed, will be most likely impaired” (p.7). Moreover, The NGO Group also said inconsistency created "serious issues around protection, incidence and prevalence understanding and programmatic interventions" (p.8). Henceforth, The NGO Group asserts under these circumstances, the consequences of inconsistency in definition resulted in what the group termed, "ineffective and flawed responses, while the gathering of data based on varying definitions can skew programme designs." (NGO group, 2005, p. 9)

Essentially, the NGO group had highlighted increased understanding and clarity when describing sexual abuse against children such as child sex tourism. What could not be understated was that the definition of CST and others associated with CSEC needed to be consistent, and where possible, universal. Overall, The NGO Group summed up the reasons for remaining consistent: "To correct difficulties caused by national laws that consistently ignore internationally agreed standards, such as the definition of a child, and which create serious issues around protection, incidence and prevalence understanding and programmatic interventions." (p. 8).

In particular, the NGO group explained that any definition of CST should not restrict understanding of CST as 'tourism organised' specifically around 'commercial exploitation'. Nor should the definition simply stress the 'prior intention' of the traveller 
(as Panko and George do in abstract two). Indeed, CST needed to cover opportunistic / situational exploiters as well as preferential and pedophile perpetrators. In addition, The NGO Group recognised sex tourists were not exclusively holidaymakers but also business people, transport workers, and military personnel. Moreover, sex tourists are not necessarily foreigners but also those persons who can be away from home in their own country (NGO Group, 2005). With this in mind, I had decided to define CST as corresponded to the definition provided from The NGO Group as follows:

Child sex tourism is the commercial sexual exploitation of children by men or women who travel from one place to another, usually from a richer country to one that is less developed, and there engage in sexual acts with children, defined as anyone under the age of 18. (NGO Group, Convention on the Rights of the Child, 2005, p. 18)

\section{Perpetrator}

Characteristically, people's perceptions about the child sex tourist are as an old male perpetrator. Montgomery (2001), remarked, that "the usual stereotype of a child sex tourist was of an old man who had to buy sex in Thailand, as no-one in his home country would willingly agree to have sex with him for free" (p. 192). Zafft and Tidball (2010, citing O'Grady, 1992) presented the public's perception of the pedophile, typically as a repugnant or psychotic criminal. In comparison, Sanchez-Taylor (2010) added, "People's perceptions of the child sex tourist were mostly built from visions of pedophiles and child molesters travelling to another country to commit a crime" (pp. 60-61).

However, ECPAT (2008) states: "Child sex tourists may be married or single, male or female (though the majority are male), foreign or local, wealthy or budget tourists and from a high socio-economic or a disadvantaged background" (, p. 12). Jacqui Saradjian, a clinical psychologist, had studied women who had sexually abused children, and established that somewhere between 20 percent of all incidents of child sexual abuse by women, had consequences for children, just as severe as the effects of sexual abuse by male perpetrators (Saradjian, 1996). 


\section{Situational / Opportunistic, Preferential and Pedophile}

Patterns of social behaviour typically define the child sex tourist as either one of three distinct categories: Situational/Opportunistic, Preferential, or Pedophile.

\section{Situational / Opportunistic}

Situational users are offenders who do not regard themselves as prostitute users in general. They do not intentionally travel for engaging in sexual acts with minors, but see it as something worth experiencing. Driven causes for them are the supply for child sex, the possibility to act anonymously and the impunity afforded by being a tourist. These types of offenders do not prefer children in general. Situational users are the most common types of users. (ECPAT, 2008, p. 12)

\section{Preferential}

Preferential users can be seen as the opposite of situational users. These types of offenders intentionally seek children for a sexual purpose. They prefer children in general, and are often confused with pedophiles. Preferential users can be male or female, however the majority being male, from all kinds of backgrounds. They represent the minority of child sex tourism offenders. (ECPAT, 2008, p. 12)

\section{Pedophile}

Pedophiles are probably the most well known types of child sex offenders, although they represent a minority of child sex tourism offenders. Pedophilia, in general, is a clinical term used to refer to adults with a sexual preference for pre-pubertal children. It is also defined as being a personality disorder. They do not show preferences for a certain gender and furthermore they do not see sexual acts with children as being harmful.

(ECPAT, 2008, p. 12)

As understood by Nishta Desai (2001), who is a director of children's rights in Goa, a realistic description of the life of a pedophile, was one of intense secrecy, expressly networking in clusters with other pedophiles, operating in highly organised 
pedophile networks. In the early 1990s, Ron O'Grady (1992) founder of ECPAT described the pedophile as a middle-aged professional likely to be married, involved in the community and or a religious group. This individual fashioned a respectable role in society, with the purpose of disguising his or her clandestine activities. Henceforth, it became commonplace for pedophiles to be educators and intellectuals - considered upstanding members of civil society. According to Baker (1995), countries such as Sri Lanka, had at least 10,000, boy prostitutes, many of whom regularly received as little as US\$1.00 per day for fulfilling the requests of pedophiles, several of whom were Westerners spurred on by newsletters such as the Spartacus International Gay Guide, published in Germany in several languages.

Simultaneously, Tepelus (2008), remarked, law enforcement agents tended to blur the distinction between the sexual abuse of children by pedophiles and non-pedophiles, treating all offenders convicted of sexual crimes against children as 'pedophiles '. Notably, The Revised Pacific Platform for Action on Advancement of Women and Gender Equality (2005-2015) A Regional Charter (See Appendix C: The Revised Pacific Plan: Strategy (vi), have ignored the situational/opportunistic and preferential child sex tourist operating in the Pacific, preferring to focus on combating 'pedophilia' in the Pacific instead. Moreover, the Samoa Tourism Authority SWOT analysis (elaborated on in chapter 3), followed suit, aiming only to combat 'pedophilia' in its Samoa Tourism Authority Plan.

\section{Victim}

Although girls remained for the most part the greater numbers of victims to CST, older men are increasingly sexually exploiting boys. Seabrook (2000) remarked that despite a number of countries having enacted laws to protect all children from child prostitution, including an absence of a clear definition of child prostitution for the protection of boys, a review of a number of countries' laws was deemed necessary. 
Susman (2003) notes of the Pacific, “... when most people talk about exploitation of under-age children for sex in the South Pacific, the focus is on young girls. But there is also exploitation of boys, although that is less acknowledged and less frequently addressed." (p. 3)

ECPAT International, partner organisations and social researchers in Bangladesh, India (Mumbai and Hyderabad), and Pakistan, approved situational analysis studies designed to assess the extent and nature of sexual exploitation of boy children in these countries. The report's findings noted some serious effects for transgendered boy's operating as prostitutes:

Each day, boys involved in prostitution run the risk of rape, violence, drug abuse, sexually transmitted infections including HIV/AIDS, and even death. They frequently face harassment and are stigmatised by their communities, particularly if having sex with men. Homosexuality is socially, culturally, and legally unacceptable in most parts of South Asia and many boys who have sex with men, whether they are homosexual or not, are commonly branded as such. (p. 10)

The report noted that the prostitution of adolescent boys in Lahore and Peshawar was rife, and that, "boys with alternative sexual identities - zenanas and chawas ${ }^{3}$ (boys with transvestite and feminine characteristics) made up the majority of boy victims of prostitution in Lahore" (p.xi).

\footnotetext{
${ }^{3}$ Zenanasare biologically male, sometimes castrated, but prefer,to all intents and purposes, to present themselves in a feminine way; they dress like women and refer to themselves in the feminine form. Chawascontinue to dress and act as men but prefer sex with other men. Those who have penetrative sex with zenanasor chawasare known as giryas. Social stigma surrounds the construct of penetrative sex because it feminises at least one of the men involved (p.48).
} 


\subsection{Global Protection}

\section{The Convention on the Rights of the Child (1989)}

In 1989, the UN General Assembly, taking effect on 2 September 1990, unanimously adopted The Convention on the Rights of the Child (CRC). The CRC is a treaty ratified by more countries than any other treaty in human history. The preamble to the CRC identifies children as a separate group requiring "safeguards and care, including appropriate legal protection" in order for them to "fully assume [their] responsibilities within the community." Article 1 of The Convention referred to a child as "every human being below the age of 18 years, unless under law applicable to the child, majority is attained earlier." There are four core principles of the CRC: 1) Non-discrimination; 2) The best interests of the child; 3) The right to life and survival; and 4) Development and respect for the views of the child.

Samoa is a state party to the CRC. Therefore, has a responsibility to administer special protection for children against sexual exploitation. Articles 19, 32, 34, 35 and 36 of The Convention, protect children from sexual exploitation and abuse, including their entry into prostitution and pornography. Article 19, pertaining to sexual abuse, required state parties to apply appropriate action to protect children from all forms of physical or mental violence, injury, or abuse, including sexual abuse by parent(s), guardian(s), or caretaker(s). Article 32 protects children from inducement or coercion to engage in any unlawful sexual activity, namely prostitution or other unlawful sexual practices, including the exploitative use of children in pornographic performances and materials. Article 34 is particularly relevant to CST. This article recognises the cross-border aspects of the sexual exploitation of children by requiring governments to take action through national, bilateral, and multilateral measures. Article 35 calls for similar action with regard to the abduction, sale and trafficking of children, which is linked to the global child sex industry. Finally, Article 36 requires state parties to protect children against all other 
forms of exploitation prejudicial to any aspects of the child's welfare for example, CSEC. (See Appendix A: The CRC (1989) - A Fact Sheet Summary).

By 24 January 2014, all Pacific countries had ratified one or more of nine UN Human Rights Conventions (See Appendix B: Pacific Island Table of Treaty Ratification (1978-2008). As Table 1 (Pacific Island Table of the Adherence to the United Nations Convention on the Rights of the Child), and a large number of Pacific countries had ratified the $\mathrm{CRC}$, significantly, increasing institutional responses and frameworks aimed at combating the sexual exploitation of children.

Table 1: Pacific Island Table of the Adherence to the United Nations Convention on the Rights of the Child

\begin{tabular}{lcl}
\hline Country & Year & Date \\
Federated States of Micronesia & 1993 & 5 May \\
Vanuatu & 1993 & 7 July \\
Fiji & 1993 & 13 August \\
Marshall Islands & 1993 & 4 October \\
Nauru & 1994 & 27 July \\
Samoa & 1994 & 29 November \\
Papua New Guinea & 1995 & 2 March \\
Solomon islands & 1995 & 10 April \\
Palau & 1995 & 4 August \\
Tuvalu & 1995 & 2 September \\
Tonga & 1995 & 6 November \\
Kiribati & 1995 & 11 December \\
Niue & 1995 & 20 December \\
Cook Islands & 1997 & 6 June \\
Note: From Pacific Island Table of the Adherence to the United Nations Convention on the \\
Rights of the Child: https://treaties.un.org/Pages/CNs.aspx. \\
\hline
\end{tabular}

The Optional Protocol (Child Prostitution/Pornography, 2000)

A number of optional protocols operated concurrently with the CRC of which a number of Pacific countries were signatories (See Appendix E: Pacific Signatories to Optional Protocols). Of relevance to CST is The Optional Protocol to the Convention on the Rights of the Child on the Sale of Children, Child Prostitution and Child 
Pornography, 2000 (United Nations General Assembly, 2000). This Protocol, adopted by the UN General Assembly on 25 May 2000, took effect on 8 January 2002. It covered the same ground as Articles 1, 11, 21, 32 to 36 of the CRC; it strengthened the measures already in place in the CRC, and added extra protection for children from forms of abuse and exploitation and from sale for non-sexual purposes, such as forced labour, illegal adoption, and organ donation (Neal, 2007).

The Optional Protocol presents Article 10 (1-4), which requires state parties to protect children against CST as follows:

1. State parties shall take all necessary steps to strengthen international cooperation by multilateral, regional and bilateral arrangements for the prevention, detection, investigation, prosecution and punishment of those responsible for acts involving the sale of children, child prostitution, child pornography and child sex tourism. State parties shall also promote international cooperation and coordination between their authorities, national and international non-governmental organizations and international organizations;

2. State parties shall promote international cooperation to assist child victims in their physical and psychological recovery, social reintegration and repatriation

3. State parties shall promote the strengthening of international cooperation in order to address the root causes, such as poverty and underdevelopment, contributing to the vulnerability of children, the sale of children, child prostitution, child pornography and child sex tourism; and

4. State parties in a position to do so shall provide financial, technical or other assistance through existing multilateral, regional, bilateral or other programmes. (p.6)

Tepelus (2008) remarked that under international legislation, any tourist who intended to have sexual relations with a child was in violation of the $\mathrm{CRC}$ and the 
Optional Protocol. Chetty (2007), observed that the Optional Protocol placed clear obligations on state parties to take certain actions relating to the sale of children as a criminal offence, as opposed to the $\mathrm{CRC}$, under whose terms state parties have merely agreed to take 'appropriate measures'.

Notably, Samoa was not a signatory to The Optional Protocol to the Convention on the Rights of the Child on the Sale of Children, Child Prostitution, and Child Pornography (2000). According to a Treaty Body Monitor report, (2006), in 2005, having presented its initial report to The Committee, The Committee replied, enquiring if Samoa planned to accept the two Optional Protocols of the Convention. The first protocol presented the category 'On the Sale of Children, Child Prostitution, and Pornography (2000)'. The second presented the category 'On the Involvement of Children in Armed Conflict.' Simultaneously, The Committee enquired if Samoa planned to cause The Hague and International Labor Organisation (ILO) Conventions into law. The delegation replied, "Samoa did not have armed forces and it already had laws banning pornography, which also covered children" (p. 2), accordingly, the report noted Samoa delegates saw "no use in adopting the Optional Protocol to the Convention of the Rights of the Child on the Sale of Children, Child Prostitution and Pornography (2000). The delegation, did not comment on The Hague and ILO Conventions" (p. 2). It did not reply to the question relating to child prostitution.

\section{The Two World Congresses}

The earlier presented recommendation of The CRC Committee to Samoa (2006) referred to the 'Two World Congresses'. In August 1996, The First World Congress against Commercial Sexual Exploitation of Children (CSEC) had been organised by ECPAT, UNICEF, and The NGO Group for the CRC. The first of the two congresses was held at Stockholm, Sweden (ECPAT, 2008). The Stockholm Agenda for Action is considered a framework for the prevention of CSEC. 
Stockholm (1996), presented The Agenda for Action, an action plan aimed to highlight existing international commitments, to identify priorities for action and to assist in the implementation of relevant international instruments. It called on states, and all sectors of society, including national, regional, and international organisations, for action against the CSEC in five areas: 1) Protection, 2) Prevention, 3) Cooperation and Coordination, 4) Youth Participation, and 5) Recovery and Reintegration (Stockholm, 1996).

Stockholm defined 'Prevention' as follows:

Encompassing those policies and programs that had been enacted in order to prevent CSEC from occurring, by establishing mechanisms to do so and raising awareness for communities and children, and to counter the demand for CSEC. Such actions included, for example, policies to integrate life skills into formal and non-formal education curricula, programs to raise awareness on the sexual abuse and exploitation of children via the Internet and mechanisms to establish community surveillance in order to detect and prevent potential trafficking in children for sexual purposes. (Stockholm Declaration and Agenda for Action, 2008)

\section{'Protection' was defined as follows:}

...laws, policies, procedures, and programs that had been enacted to legally protect children from commercial sexual exploitation and to ensure that the rights of child victims were respected. Protective actions can take the form of legal measures, such as laws prohibiting the possession of child pornography, child-friendly procedures, such as the provision of professional support and psycho-social counseling for children during an investigation; capacity-building for law enforcement, such as training for border police on trafficking in children; and special law enforcement units or task forces, such as the creation of a bureau on children's issues in the central policy department. (Stockholm

Declaration and Agenda for Action, 2008) 
The Committee recommendation to Samoa; to "develop and implement an effective and comprehensive policy addressing the sexual exploitation of children", appeared to have aligned to the Second World Congress that took place in Yokohoma, Japan, in 2001. The number of participants attending Yokohama totaled 3,045. Delegates were child rights activists from 134 governments and 25 intergovernmental agencies, including a Samoa delegation. Yokohama delegates, pledged to develop National Plans of Action to implement the Stockholm Declaration and Agenda for Action in five key areas: 1) Coordination and Cooperation, 2) Prevention, 3) Protection, 4) Recovery and Reintegration, and 5) Child Participation (UNICEF, 2001). Since Yokohama, a growing number of Pacific countries, including Samoa, had attended, consultations and workshops convened to improve data collection, including regional and national strategies to combat root causes fueling CSEC (See Appendix D, Pacific Consultations, Workshops, and Reviews: between 2001 and 2004).

The United Nations World Tourism Organisation (UNWTO) is a UN agency responsible for tourism. The organisation contributes to economic development, paying particular attention to responsible and sustainable tourism, and assisting developing countries interested in nurturing tourism (UNWTO, 2011). As a follow up to Stockholm (1996), the UNWTO had recognised its networks and establishments were used for CST, that was in conflict with tourism aims, and that the tourism industry should actively combat it. In response, the WTO had hosted a voluntary task force on child prostitution and tourism, later renamed The Task Force to Protect Children from Sexual Exploitation in Tourism (1997). This move established a corresponding Child Prostitution and Tourism Watch on the Internet (Now renamed the World Tourism Network on Child Protection). The UNWTO, issued a: Statement on the Prevention of Organised Sex Tourism (UNWTO, 1995). The UNWTO:

... rejects all such activity as exploitative and subversive to the fundamental objectives of tourism in promoting peace, human rights, mutual understanding, respect for all peoples and cultures, and sustainable development [and] denounces and condemns in particular 
child sex tourism, considering it a violation of Article 34 of the Convention on the Rights of the Child and requiring strict legal action by tourist sending and receiving countries.

Specific to CST, is Article 2 of the UNWTO Global Code of Ethics for Tourism's, 10 principles:

Article 2 (2) Tourism activities should respect the equality of men and women; they should promote human rights and, more particularly, the individual rights of the most vulnerable groups, notably children. Article 2 (3) The exploitation of human beings in any form, particularly sexual, especially when applied to children, conflicts with the fundamental aims of tourism and is the negation of tourism; as such, in accordance with international law, it should be energetically combated... and penalised without concession by the national legislation of both the countries visited and countries of the perpetrators of these acts, even when they are carried out abroad. (UNWTO, 1999)

\section{The ASEAN Response}

Stockholm's focus on coordination and collaboration between and across countries and states was seen in 2005, where the Association of South East Asia Nations (ASEAN) ${ }^{4}$ Regional Taskforce, passed a resolution called for regional-wide public education campaign, drawing together all ten ASEAN countries in a united stand against CST. The ten ASEAN member countries campaign declared these explicit objectives:

1) To mobilise responsible travelers and local citizens to report suspected CST on dedicated hotline numbers,

\footnotetext{
${ }^{4}$ The Association of Southeast Asian Nations (ASEAN) was formed in 1967 by Indonesia, Malaysia, the Philippines, Singapore, and Thailand to promote political and economic cooperation and regional stability. Brunei joined in 1984, shortly after its independence from the United Kingdom, and Vietnam joined ASEAN as its seventh member in 1995. Laos and Burma were admitted into full membership in July 1997 as ASEAN celebrated its $30^{\text {th }}$ anniversary. Cambodia became ASEAN's tenth member in 1999. As of 2010 the Association of Southeast Asian Nations (ASEAN) has 10 member states, one candidate member state, and one observer state. (Dept of State, nd, http://www.state.gov/p/eap/regional/asean/)
} 
2) To deter potential child-sex offenders, and

3) To create a culture of intolerance toward the sexual exploitation of children." (Child Wise, 2007, p. 31).

A key element in the campaign was to involve the commercial sector closely and to win its commitment. Local and international businesses united to participate in the ASEAN-wide advertising campaign. Moreover, National Tourism Organizations were included into the campaign. Generally, The ASEAN example provided a benchmark against CST, which other countries actions can be measured, and assessed. Hailed as world best practice by the UNWTO, the regional campaign raised awareness, promoted reporting amongst the local community and travellers; promoted vigilance, in addition, ensured a sector-wide approach to the issue, promoted by the tourism industry and actively engaging the commercial sector.

\section{$2.4 \quad$ The Root Causes}

Table 2 (Root Causes, Yokohama, 2001), related to what delegates attending Yokohama, (2001), considered were the root causes driving CSEC.

\section{Table 2: Root Causes (Yokohama, 2001)}

\begin{tabular}{ll}
\hline 1 & Improve educational access to children, especially girls \\
2 & Provide for physical and psychological recovery and social reintegration of child \\
& victims \\
3 & Criminalize the commercial sexual exploitation of children (and not the child victims) \\
5 & Allocate adequate resources to counter commercial sexual exploitation of children \\
6 & Provide adequate measures to protect children from child pornography on the internet \\
\hline & Note: From UNICEF, 2001, Para. 6. \\
\hline
\end{tabular}


Mehr Khan, UNICEF Regional Director for the East Asia and Pacific Region, presented children's entry into sexual abuse and exploitation the result of five systemic failures (International - National - Community - Family - Child). As follows:

1. International: Restrictions on legal migration, Negative effects of globalization, Poor border control, Financial crisis, Economic disparities, Poor enforcement of international law.

2. National: No channels for legal migration, Economic disparities, Bad social service scheme, Flawed citizenship laws, Denial of problem, Poor justice system, \& law enforcement, Skewed budget allocations, Poverty, Corruption gender discrimination, War, No minority rights.

3. Community: Gender roles, Exclusion of vulnerable groups from decision-making, Low child protection capacity discrimination Economic marginalization of some groups. Unemployment.

4. Family: Unemployment, No jobs, No social benefits, Lack of knowledge of trafficking. Attitudes against girls HIV /AIDS, Drugs, Poverty, Abusive environment, Consumerism.

5. Child: No school, Poverty, Sexual abuse/rape, Gender expectations, Drug abuse, No job, Statelessness, Consumerism. (Mehr Khan, 2005, p. 41)

\section{Supply and Demand}

As Table 3 (Supply and Demand), there is also, what are termed, supply and demand.

\section{Table 3: Supply and Demand}

\section{Supply}

Poverty

Globalisation

Gender bias

Family breakdown

Lack of laws and law enforcement

Increasing materialism

Rural-urban migration

Subsistence to a cash economy

\section{Demand}

Tradition and culture

Sex tourism

Criminal networks

HIV/AIDS

Profit

The growth of child pornography industries Promotion

Note: From Child Wise, 2004, p. 3. 
These sets of causes looked widely at the context of demand, including the complete global economy and tourism industry, attempting to identify the modus operandi of the sex tourist. The supply causes related to economic policies, globalisation, traditional practices, state, and family protection mechanisms not working. The demand causes appeared to be the after effects of the night before, the established causes. Jhappan (2005) considered the supply side of CST was harder to reign in than the demand side; in addition, working on the root causes on the supply side was harder. That was because supply is rooted fundamentally in poverty and, as such, is determined on a micro level as a structural requirement of neo-liberal capitalist globalisation. According to Brungs, (2002), NGOs in the Asia-Pacific region specifically tended to address supply and demand causes by running wide-ranging community grass roots projects to combat CST. Programmes addressed specific root causes for child prostitution, such as poverty, family disintegration, and discrimination such as seen more on the supply side.

Vivit Muntarbhorn an international human rights expert, and law professor, presented in Stockholm (1996), what he described as the five Cs that create a demand for CSEC: 1) Cash, 2) Cars, 3) Cell phones, 4) Computers, 5) Consumerism.” He specifically considered the Stockholm (1996) implementation process to be unclear and that challenging its implementation was what he termed five extra Cs obstructing the effective guarantee of the child's rights explicitly: 1) Crime, 2) Corruption, 3) Collusion, 4) Clientelism, and 5) Complacency. Muntarbhorn argued that these five Cs, had manifested in contemporary society, and that their link to demand often resulted in a decline in values, and the treatment of children as objects of exploitation, rather than as subjects of rights. He noted that demand causes went hand-in-hand with supply, and that the components of these causes were diverse. He declared intervention against supply and demand, called for integrated measures linked to the multi-pronged approach adopted at Stockholm. As follows: 1) Coordination/Cooperation, 2) Prevention, 3) Protection, 4) Recovery and Reintegration, and 5) Child participation” ( Muntarbhorn, 2001). 


\section{Push and Pull}

In addition to 'root causes' and, 'supply and demand', are what are termed the 'push and pull' causes (See Table 4. Push and Pull). Push and pull, looked to group a combination of causes, mostly societal failings that pushed children into vulnerable situations.

\section{Table 4: Push and Pull}

\section{Push}

Violence or other dysfunction;

Lack of job opportunities;

Low education levels or the wrong skills for the jobs that are available;

Family pressures or a sense of responsibility to provide for the family; Ignorance about the physical and psychological impact of sexual abuse.

\section{Pull}

Perception that being with the tourist increases personal status and opportunity;

Unregulated and aggressive tourism development across the region, whether or not tourism arrivals have dropped or increased;

Welfare policies and programmes not implemented; Aspirations for a better life.

Note: From Child Wise, 2004.

Unlike 'supply and demand', the 'push and pull' specifically referred to the tourism industry as a contributory cause. Two other causes that had not arose in 'supply and demand', but recognised in 'push and pull', was 'ignorance about the physical and psychological impacts for children" and "no social welfare polices'. The 'push and pull' identified 'aspirations for a better life', a perception often supported by mass marketing, and consumerism, that had crept into even remote rural areas through increasing globalisation of communication technology, and advertising.

By way of an example, as Table 5 (Push and Pull: Nepal, India, and Sri Lanka ) below, an ECPAT International study conducted in Nepal, India and Sri Lanka (2003), 
was convened to determine what 'push and pull' causes created children's entry into CST. Findings aimed to help policy makers develop policy, and programmes to close gaps. Essentially, as Table 4 presented, all aspects of the 'push and pull' list operated in the three countries. In sum, although 'root causes',' supply and demand' and, 'push and pull' are similar, and sometimes coined as if synonymous, there were some differences nevertheless.

\section{Table 5: Push and Pull: Nepal, India, and Sri Lanka}

\section{Push}

Lack of education opportunities, especially for female children; Ignorance about the physical and psychological impact of sexual abuse; Abuse within the family, close community; Welfare policies and programmes not implemented; Aspiration for a better life; Desire for consumer goods;

Perception that being with the tourist increases personal status and opportunity; Unregulated and aggressive tourism development across the region whether or not tourism arrivals have dropped (Nepal) or increased (Sri Lanka).

\section{Pull}

The powerless position of children in society; Constructs of gender and violence;

Organised crime, including trafficking of children;

Sexualised promotion of tourism; Inaction by police and other authorities, corruption; Involvement of third-person agents - taxis, tour guides, family members; Migration to tourist areas; Demand for children as sexual objects; Existence of prostitution and sex tourism.

Note: From ECPAT International, 2003, p. 7 


\subsection{Three Global Studies}

\section{Gambia...The Smiling Coast! A Study of Child Sex Tourism in the Gambia and the Involvement of Dutch Tourists (The Child Protection Alliance and Terre des Hommes Netherlands (2003).}

This study was the result of research collaboration between two NGOs with a common concern for the rights and protection of children from exploitation and abuse. One was the Child Protection Alliance, comprising 48 organisations and institutions established specifically to act as a watchdog for children's rights and child protection. The other was Terres des Hommes Netherlands, composed of volunteers in the Netherlands who are dedicated to the welfare and protection of children. Conducted independently of Government and UNICEF this study had a focus on CST.

Of the three situational analyses, this one was the most similar to my own. I studied it in detail, to draw lessons in designing my methodology. The study devoted a small section to recording its premises and the rationale behind the structuring of its methodology, so mainly inferred.

The Gambian research, conducted in October and November 2002, sought to answer three questions:

1. Does child sex tourism happen in The Gambia?

2. Are Dutch tourists involved?

3. If so, what international standards and local actions can be called upon to prevent and protect children from being targeted by abusers? (Child Protection Alliance and Terre des Hommes, 2003, p. 7). 
This study presented three research objectives aimed to do the following:

1. Gather qualitative information through one-to-one interviews with individuals, organisations and institutions involved with tourism or services to children who had been abused or exploited, in order to determine if child sex tourism was happening in The Gambia, and if Dutch tourists were involved;

2. Present a comprehensive report in which the problem was illustrated, and pathways identified to protect children from sexual exploitation; and

3. Complement the UNICEF/Gambia Government's Study on the Sexual Exploitation of Children in the Senegambia Region. (p. 7)

Key participants included people from diverse backgrounds and from institutions involved in tourism and children's services. Interviews took place over a four-week period. Qualitative methods directed the study. They included in-depth, one-to-one interviews with key people from the community, such as those representing community organisations and institutions who were involved with tourism or tourism services, and children who were abused or exploited. Other qualitative methods were mapping and focus groups involving a cross-section of community members.

Findings revealed that the vast majority of key participants interviewed believed that tourists and others were sexually abusing children, and that action was required urgently to identify abusers. It became clear that many complex cultural and religious norms combined to create an environment where the exploitation of children was possible. The findings provided context to CST and its occurrence in The Gambia, citing underlying reasons such as poverty, the overall position of children within the culture, and a culture of silence towards abuse, keeping the sexual abuse hidden, and discouraging children from coming forward to report abuse to their families or to the authorities. 
Having provided context and evidence for CSA by tourists, including Dutch nationals, the report examined Gambian and Dutch laws and international conventions and protocols (such as the CRC and the Stockholm declarations, to learn how children might be protected from tourists and how offending tourists could be prosecuted in the Gambia or Holland, using extraterritorial legislation. Using suggestions from the people interviewed, and linking these to experiences gained through the implementation of the aforementioned declarations, the study provided strategies for future action, in line with the Stockholm Declaration and Agenda for Action directed towards the Government, the tourism industry, NGOs, the media, parents, justice authorities, and law enforcement. The Gambian Government, NGOs, and donors tasked to develop a research agenda.

\section{A Situational Analysis of Child Sex Tourism in India (Kerala and Goa) (EQUATIONS and ECPAT International, 2003)}

This study in India (Kerala and Goa), was the collaboration between two NGOs: Equitable Tourism Options (EQUATIONS) and ECPAT International (2003). The study aimed to do the following:

1. Gather information on the nature, scope and manifestations of child sex tourism (CST) in the selected sites of Southern India (Goa and Kerala);

2. Identify key-actors connected with CST in selected tourism settings;

3. Study the interplay within and outside the tourism industry that facilitates CST; and

4. Identify actions that can be taken at different levels to combat CST based on findings. (p.7)

Upon completion of the research, the plan was to develop integrated interventionist strategies with clear roles and responsibilities for each stakeholder to combat CST in the areas under research. Sources of data included interviews with the 
children, with NGOs, law enforcement personnel, legal professionals, state and national government bodies, tourism facility owners, and tour operators, including focus group discussions, surveys, and observations of tourist sites where CSEC was prevalent. The study found CSEC on a very large scale.

The report's findings in Goa and Kerala identified causal causes as 1) Absolute and relative poverty, 2) Consumerism and materialism, 3) Illiteracy, 4) Migration and Unemployment, 5) Family breakdown/dysfunction, 6) Children of school age in the labour market, 7) Procurement within families, and 8) Development policies without regard to child and family security.

Of the three situational studies I investigated, this study gave most attention to designing and proposing a plan to enable state government measures to give the tourism industry a role that would sustain the local population. Final recommendations were the development of coordinated, overlapping measures at local, regional and national levels, designed to establish economic conditions, which could encourage a change in the profile of tourism within the economy. EQUATIONS argued it must be understood that tourism is complementary to other economic industries such as agriculture, horticulture, and manufacturing. That diversification could sustain the cultural wellbeing of the populace.

\section{Extent and Effect of Sex Tourism and Sexual Exploitation of Children on the Kenyan Coast (UNICEF and the Government of Kenya, 2006)}

This report was comprehensive, clear in information and tone, and direct in its recommendations. A disclaimer that the views contained in it did not necessarily reflect the views of either the Government of Kenya or UNICEF accompanied the study. The methodology was incisive to penetrate the heart of the issue. Even so, the researcher was unable to involve cohorts of boys and girls from primary schools, which were either involved in sex tourism or aware of its existence. 
Official approval was not forthcoming, so the researcher used four other methodologies: key participant interviews, focus groups, enumeration of hot spots and hot spot mapping, along with sex worker diaries. Key participants were people most closely associated with tourism, tourists, and sex work. These included government staff, members of national and international NGOs, parents, students, community elders, health professionals, and representatives of community-based and faith-based organisations.

Methods of data collection were interviews, focus group discussions with child sex workers and civil society groups, enumeration of hot spots and hot spot mapping. Youth groups identified key sites. Other methods included female sex workers carry a sex worker diary to elicit sensitive sexual patterning information. The study found up to 30 percent of all 12-to18-year-olds living in these identified areas were involved in casual sex work. A further two to three thousand girls and boys were involved in fulltime, year-round commercial activity (ibid.). Many full-time child sex workers had migrated to the coast from other parts of the country, inducted into sex work before they arrived. The SEC was not limited to coastal areas or to tourists, but in communities across Kenya. About one in every 10 children had participated in sex work before reaching puberty.

The causal causes pushing sex tourism and sexual exploitation in Kenya were as follows: 1) Weak local economies, 2) Insufficient leakage of tourist receipts into those economies, 3) High levels of household poverty and unemployment, and 4) The high turnover of tourists who believed a beach holiday in an exotic locale were incomplete without sexual encounters with the local population. The study then reviewed existing law enforcement, legislation, and government policy, and then presented a set of preconditions in place for sex tourism and sexual exploitation to thrive. These comprised weak local economies, which received little of the total profit generated by the tourist industry. Offshore tourist agencies produced high levels of household poverty and unemployment. 


\subsection{Four Root Causes Specific to a Tourism Setting}

Table 6 (Four Root causes Specific to a Tourism Setting), below, lists complied the three situational analysis results, revealing a problem not just tourism-related but comprising other economic, cultural, social, structural and political causes as well.

\section{Table 6: CST: Root causes Specific to Tourism Setting}

\section{Gambia}

Poverty

The position of children within the culture

A culture of silence towards abuse

Kenya

Weak local economies

Insufficient leakage of tourist receipts in to those economies

High levels of household poverty and unemployment

The high turnover of tourists who see a beach holiday in an exotic locale as Incomplete without sex with the local people

\section{India (Kerala and Goa)}

Poverty, absolute and relative / Consumerism/ materialism

Illiteracy / Migration and Unemployment

Family breakdown/ dysfunction

Children of school age in the labour market / Procurement within families

Development policies without regard to child and family security / Tourism

Inner mechanisms: motivation and core beliefs and profit

Drawn from the findings of the three situational studies, as Table 6, (CST: Root

Causes Specific to a Tourism Setting), above, I had identified four causes, that I

considered were a suitable starting point for discussion of root causes and identifying

CST in the Samoa tourism setting. The four root causes were: 1) Culture and Tradition,

2) Poverty, 3) Family Breakdown, and 4) Complicity.

\section{Poverty}

Jullien (2003), identified poverty as a key cause in fostering child prostitution, and its conspicuous location in under-developed countries with unstable economies having high unemployment, enormous disparities between rich and poor, and large 
under-age populations. In addition, Sealy-Burke's (2006) study in the Caribbean revealed that Caribbean children were economically deprived, and poorly educated, that for the most part, made them susceptible to CSEC. The cost of education had become a luxury few families could afford, which meant little in the way of opportunities or prospects for the advancement for children.

Jeremy Seabrook traced the symbiosis of tourism, and child prostitution, subsequently asserting poverty, in conjunction with unemployment, had forced countless women, including young girls, into prostitution (Seabrook, 2000). Zafft and Tidball (2010), reported poverty in the Philippines had defined the social conditions of countless children. In 2007, 40 percent of Filipinos were living below the poverty line.

Associated with poverty was philanthropic exploitation. Trinidad's (2005) study in the Philippines presented philanthropic exploitation associated with poverty, he explained as follows:

Foreigners 'adopting' children by giving them money to buy things they need such as clothes and school supplies and providing tuition for their education. Because poor parents do not have the resources to send their children to school, let alone buy these supplies for their children, they accept such offers of "magnanimity. Other times, these foreigners lend or give the families large sums of money to start a small business or to have their houses repaired. (p. 68)

As documented (chapter 1), in Samoa, philanthropic exploitation operated as a Samoan problem by way of the New Zealand couple who had adopted eight Samoan children under the pretext of giving them an improved life. Invariably, the case of Mark Mutch in Fiji (1999, chapter 1), presented a situation of philanthropic exploitation, for the reason that Mutch had helped pay for the upkeep of his victims' families' homes, as well as the children's schooling. 


\section{Culture and Tradition}

In the Gambia report (above), the cultural practice of hospitality, facilitated children's sexual exploitation. The report noted that locals were friendly, and hospitable, often welcoming tourists into their homes to share food. From an early age, children learnt that white tourists conferred gifts, and were financially powerful. On a larger scale, tourists had offered hosts a year's school sponsorship for their newfound friends. However, a number of tourists harbored sinister agendas, which featured manipulation of this system for their own needs (Child Protection Alliance and Terre des Hommes, 2003). In addition, Trinidad's (2005) research in the Philippines supported the Gambia study's finding, having reported the welcoming nature of Asia and Pacific people to their countries (a cultural norm), and often supported CST.

A second cultural cause identified, was the devaluation of girls in society. Sanchez-Taylor (2010) remarked that the social status of girls in the least-developed countries restricted their education, which compelled them into unskilled and low-skilled jobs. UNICEF Pacific and UNIFEM Pacific (2007) included Pacific children who were often the lowest status in society. Furthermore, a girls' place in society created a vulnerable situation, because of their less significant place in society than that of boys.

\section{Family Breakdown}

The nuclearisation and fragmentation of families were a fundamental cause for foreign tourists sexually abusing children (Jeffrey 1999, Griffen 2006, and Levesque 1999). Hughes (2001) explained that single-mother-headed households were becoming common in urban areas worldwide and that this state of affairs, along with nuclearisation and fragmentation of families, left children without extended family protection vulnerable to CSEC. Furthermore, Estes (2001) added that forms of migration, such as fleeing war, drifting to urban centers out of economic need, including street dwellers, and children with disabilities or parental support, were amongst those causes making children 
at particularly high risk of sexual abuse, since access was easy and straightforward. Associated with family breakdown was sexual abuse and neglect (Jeffrey, 1999).

Jones and Trotman Jemmott's (2009) study on CSA in the Eastern Caribbean referred to numerous victims of CSEC were victims of CSA in the home before entry into CSEC. Cannon (2001) noted that family dysfunction created a number of root causes that affected the likelihood of somebody abused or becoming an abuser. Seghorn, Prentky, and Boucher (1987) noted that persons, who sexually abused children, were themselves usually sexually abused as children and, were more likely to have had sexual deviance within the family and a high incidence of childhood neglect.

Generally, CSA was a widespread but under-researched problem in the Pacific (Secretariat of the Pacific Community, 2005). The Interagency Group had recognised CSA was an under-researched issue, therefore, had included it into the (2006) Pacific Interagency Report to determine scope and cause. A later UNICEF Pacific and UNIFEM Pacific (2007) report on CSA in the Pacific, noted the sexual abuse of girls was sporadic for several reasons. Reasons included secrecy, reproductive health education rarely provided in schools because of taboos regarding sexual matters, and beliefs that sexual education would encourage sexual experimentation among schoolchildren. In addition, "in small communities with little privacy, accusations of sexual abuse - no matter how valid - can lead to ostracism of the victim and her family" (p. 11). Griffin's (2006) CSA research in the Pacific had identified children largely at risk. These children were inclined to be those who were not cared for by their biological parent, or else were supporting their family or themselves, through sex work to pay for school fees, or simply, to cover transportation costs. 


\section{Complicity}

O'Connell Davidson (2001) remarked that despite Stockholm (1996), and undertakings to improve data collection methods, a number of participating countries had become complicit. According to her:

In the five years since Stockholm (1996), a number of countries reformed existing laws or introduced new laws to strengthen the legal framework pertaining to the sexual abuse and exploitation of children. However, it is rarely possible to assess the impact of such reforms, since incredibly few countries have heeded calls to improve data collection methods. Accurate and consistent data on investigations and prosecutions of cases of sexual abuse, violence, or exploitation against persons under the age of 18 are not available, and this is a situation that urgently needs to be remedied. (p. 31)

In addition, in their report on Protecting Children and Adolescents against Commercial Sexual Exploitation in Central America, Panama and the Dominican Republic (Sorensen and Claramunt, 2003), these researchers discovered that in each of the three countries, three out of every four adults did nothing to prevent or stop CSEC, or consistently ignored the problem altogether. Similar findings were confirmed in the aforementioned Kenya study (Government of Kenya and UNICEF, 2003). The researchers had revealed a high level of acceptance of child sex work in coastal communities which enabled children to easily drift into casual transactional sex, in exchange for no more than extra pocket money. The report noted complicity on this scale reflected a fundamental breakdown, and corruption of families and communities, and a failure by authorities to provide protection for children by prosecuting those responsible for promoting, and profiting from child sex work (Government of Kenya and UNICEF, 2003). 


\section{Summary}

Chapter 1 concluded that The Committee recommendation to Samoa was exactly right. In examining the global literature, CST is a global problem, numbers are immeasurable, children are all genders, and perpetrators are anyone. Despite this lot, the academic research on CST remained scant; therefore, I turned to other sources of data to understand the CST context. The global data demonstrated that the root causes do not always correspond with increased tourism as a major facilitator, because there is no one cause but a raft of causes, embedded in economic, social, cultural, and political vectors driving the problem. As the Thailand example presented, CST can advance at an alarming rate, for any country willing to ignore a sex tourism industry. Chapter 3 presents the environment of the Samoan child. 


\section{Chapter 3: The Environment of the Samoan Child}

I interpret the rights of children as meaning the responsibility of mother, father, family, village and nation to do what ought to be done to promote and protect the interest of children. Lapse/s in performance of this responsibility breaches custom and/or village/government policy and/or law. (Tamasese Masiofo Filifilia, 2006)

Finally, on behalf of the Government of Samoa I say to the Samoan people and to citizens of other countries that the Government will do all in its power to (a) prevent sex offenders coming to Samoa; and (b) protect Samoan citizens, especially our children. (Auseugaefa M.T. Vaasatia Poloma Komiti, the Chief Executive Officer of the Prime Minister and Cabinet, 2004, p. 2)

\subsection{Introduction}

Child sex tourism (CST) is a global problem in the Pacific. At regional level The Revised Pacific Platform for Action on Advancement of and Gender Equality (20052015), had recognised pedophile related tourism was an issue in the Pacific, as had agencies such as the Pacific Regional Chiefs of Police after Mutch some years earlier. The Pacific Interagency Report (2006) undertaken on CSEC and CSA in five Pacific countries, reported all forms of CSEC operated in the five Pacific countries and that CST operated in most countries to varying degrees. Although Samoa was not a participatory country in The Pacific Interagency report (2006), by way of the prosecution of an Australian for the sexual abuse of the Samoan child, Samoa had a child sex problem, although the scope and root causes of CST in Samoa were unknown.

Samoa had been slow in acknowledging the serious potential for CST in Samoa. That tourism was the new engine of national economic growth for Pacific nations such as Samoa, added complexity to this issue. That the Ministry of Tourism promoted Samoan 'hospitality' as 'a unique tourism experience' also had the potential to blur the lines between what was a cultural norm and hospitality 'abused' by locals and tourists. 
The opening quotations to this chapter, shows the seriousness CST presents to small Pacific countries such as Samoa. When Pacific signatories adopted The Convention on the Rights of the Child, (CRC), and the CRC was interpreted as consistent with, and fulfilled by traditional custom in its regard for the protection of children. In a speech to the New Zealand Samoan National Women's Synod in Auckland in 2006, Tamasese Masiofo Filifilia, described Samoa's interpretation of The Convention as being completely consistent with the values of fa'asamoa, as 'what we do and have always done', and as aligned to the preamble to the CRC, that reads "the growth and well-being of all its members, particularly children should be afforded the necessary protection and assistance so that it can fully assume its responsibilities within the community". (CRC, 1989, p.1).

The second statement from the Office of the Prime Minister and Cabinet, related to the Australian cleric sent to Samoa by his church, following sexual abuse charges against him in Australia, and his deportation back to Australia by the Samoan government to face outstanding sexual abuse charges against him (chapter 1). Essentially, the Prime Minister and Cabinet statement set the scene; a zero tolerance to CST operating in Samoa.

Four issues necessitated this chapter. First, to build the 'case'. Second, to understand the environment the Samoan child resided in. Third, to identify a sample of relevant organisations and agencies mandated to protect children against CST. Fourth, to identify root causes enabling a CST environment. With this brief background, the remainder of this chapter presents first: The Country, People, and Socio-Economic Setting. Second: Child Protection Measures and Third: Issues for Children.

\subsection{The Country, People and Socio-Economic Setting}

Figure 2, is a map of Samoa. The two islands that form Samoa lay between latitude 13 and 15 degrees south and 168 and 173 degrees west, near the international dateline. The two main islands of Samoa are Upolu and Savaii. Eight smaller islands are 
located 2,600 miles southeast of Hawaii, 1,800 miles northeast of New Zealand, and 2,700 miles east of Sydney, Australia.

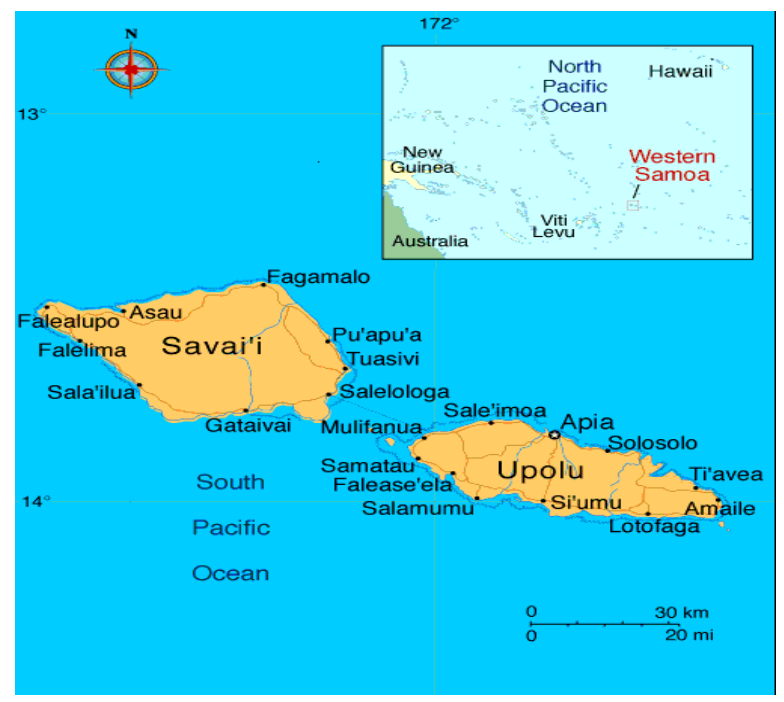

Figure 1. Map of Samoa: From Magellan Geographix www.maps.com).

Samoa remained largely rural with the majority of its population scattered throughout the two main islands of Savaii, and Upolu. The Apia Urban Area represented the urban area, while the other three regions made up the rural population. Samoa consists of four major statistical regions: 1) Apia Urban Area, 2) North West Upolu, 3) The remainder of Upolu including Manono and Apolima Islands, and 4) Savaii. In 1962, Samoa became the first Pacific Island state to gain independence. New Zealand and the British Commonwealth, exerted a strong influence over the framers of the new state's constitution (Samoa Constitution, 1960), but throughout the colonial period, the traditional chiefly forms of government had remained dominant.

Following an UN-monitored national referendum, Samoa's Constitution combined the two systems: the Westminster Parliamentary system, and the matai (chiefly and extended family) system, to comprise Samoa's unique form of government. The Samoan Constitution attempted to maintain the Western Democratic tradition's regard for 
individual human rights by guaranteeing certain individual rights, regardless of his or her status in traditional society. This dual system continues to this day (Meleisea, 1987). Samoa is a nation founded on God. Attending church, praying and other religious activities are a normal part of everyday Samoan life. Churches provide spiritual leadership and much of the material help and services for families, which in other countries would be the responsibility of the State (Va'a, 2006).

The fa' asamoa that is the heart of Samoan society, means 'in the manner of Samoans'; an alliteration that carries the notion of collective well-being rather than individual focus. Samoan oral history recounts that the Samoan people have always been in Samoa; that Samoan earth and Samoan humans came into existence together (Meleisea, 1987). Fa'asamoa values are from symbolic narratives found in Samoa's creation stories; ancestry, and land are indivisible concepts; to locate oneself by culture is to do the same by genealogy and by earth. Similarly, to damage one culturally is to damage one's genealogy, and to damage the Samoan earth. These accounts are the genealogical and evolutionary explanations of how the islands of Samoa and the Samoan people came into existence (Samoan Working Group, 2012).

Underpinning fa'asamoa are customs and traditions central to maintaining Samoan life based on the following:

...fas 'aaloalo (respect, reciprocity or sharing and receiving), alofa (love and compassion), tautua (service, aganu'u talimalo, hospitality) and fealofani (positive relationships), values (tulaga e fa'atauaina), cultural practices ( $f a^{\prime}$ a Samoa), and beliefs (talitonuga) are exhibited in the loving and caring nature of the people. Samoan identity (faia ma le fa'asinomaga) is based on the extended family (aiga potopoto), with strong links to the land. Relationships ( $v a$ fealoai) are significant in the family, village, district structure and in communicating with others, e.g. between brother-sister (feagaiga), parent-child (matua-fanau), elder-youth, (matua-la'ititi), eldest and youngest sibling (ulumatua ma le ui'i), experienced versus knowledge, (mua mai-muli mai), husband-wife (tane-ava), matai and family (fa'amatai,) matai in the village council and district level. 
(Government of Samoa and Ministry of Education, Sports and Culture, 2004, p. 13)

Family is the closest English word to the concept, aiga. The Samoan Working Group (2012) defined aiga in multiple contexts as follows:

1. A social unit in a village where matai direct their religious, economic and political activities;

2. A self-sustaining economic group where members including the head, cooperatively contribute the products of their labour for the common good of the whole family;

3. In an extensive sense, aiga incorporates communal ties with the Gods, ancestors, and the divine heritages, the sea, land and sky;

4. In its inclusive essence, aiga is a descent group or kinship in all its dimensions. (p.16)

The aiga extends between villages by kinship, its concepts span across all of Samoan society. The aiga, is the main organisational unit in the fa'asamoa, where life's passageways are cultivated and nurtured (Tofaeono, 2000), offering a key protective and support mechanism for family members and children. Aiga has a wider meaning of kinship that extends among all things that have communal ties, be they familial ties between blood relatives; economic ties among a social unit; ancestral ties; or ties with the divine, the sea, the land, and the sky: Protocols, customs, and traditions are founded upon aiga (Samoan Working Group, 2012). Within the context of fa' asamoa, the idea that a Samoan has no aiga is not readily comprehensible to Samoans, mainly because inherent in the notion of being Samoan is the profound connection to aiga and fanua (land), which are important underpinnings of Samoan identity and belonging as follows:

[To have no aiga $]. .$. is comprehended not only to mean homelessness, landlessness and rootlessness, - it also means annihilation of living relations, poverty in material security, deprivation in rational thinking, and, more importantly, a collapse of the ethical orientation. It involves the erosion of religious-cultural consciousness, the forgottenness of the divine, and a sign of the divine's very absence in bodily-relations. Hence, 
disembodiment of the aiga means the breakdown of a complete cyclical life-supporting system. (The Samoan Working Group, 2012, p. 17)

Within the Samoa social system are termed fa'afafine, (born males, loosely described as 'in the way of women).' Within their historical role, fa'afafine was carers for, and guardians of aiga. Today, many fa' afafine offer their service to aiga with matai or chiefly titles bestowed on them, in recognition of their services to the family. Fa'afafine remains integral members of Samoan society, heirs to family and chiefly titles, and lands through extended family consensus. Although sexual orientation remained as a sensitive issue in Samoa, given the religious and cultural beliefs of mainstream society, a fa'afafine association operated freely in Samoa. Today, fa'afafine was employed in tourism and hotel industries, and as industry entertainers (Farran and Su'a, n.d.).

\section{Social and Economic Setting}

As Table 7 (Samoa: Key Social and Economic Data, 2006), in 2006, Samoa's population was just under 180,000, at which time 22 percent of the population lived in Apia, the administrative and commercial capital, and 53 percent in small villages along

the coast. The people of Samoa are mainly Samoan including some mixed decent such as European, Chinese, and other Pacific islanders. The language is mainly Samoan, although English is widely spoken, particularly in the Government and private sectors. The World Bank classified Samoa as a middle-income country (World Bank, 2010). Samoa has international telecommunications with phone, fax, telex and internet services, mobile networks and an international airport 35 kilometers distant.

\section{Health}

The Samoa health system is a public and modern private health sector and a traditional health sector. NGOs academic institutions, communities and development partners played various roles within these health sectors. The Ministry of Health was responsible for regulatory oversight of the health sector. The Community Health 
Services supplied outreach services. Each village had a health committee, often affiliated with national women's organisations, or national church organisations. A Samoa AIDS (Acquired Immune Deficiency Syndrome) Foundation operated in Samoa. Shuaib (2007) reported Samoa rated strongly on most key human development indicators, with a life expectancy of 72 years for females and 65 years for males. An estimated 41 percent of the population was under 15 years of age, reflecting a high fertility rate, although offset by significant levels of out-migration

Table 7. Samoa: Key Social and Economic Data (2006) Population

Total Population

Annual population growth rate

Urban population

Net out-migration

Health

Economy
Estimated life expectancy at birth: Females Estimated life expectancy at birth: Males Infant mortality rate per 1000 of live births Total fertility rate Gross domestic product per capita Main industries
Approx. 179,186 (2006)

$22 \%$ in Apia and $53 \%$ in coastal villages

$1.4 \%$ (2006)

$22 \%$

$1.6-2.2 \%$ per annum

72

65

12

4.8

$\$ 2,722$ (2006)

Tourism, light manufacturing, fishing, construction, subsistence agriculture and remittances

*Education Literacy rate percent Male 99 Female 98

Note. From Shuaib, 2007, p.5.

*Note. From Secretariat of the Pacific Community, (2010). Date range 1990-2008.

\section{Education}

Samoa's education system comprised an eight-year primary and five-year secondary programme. Education was not compulsory for children over 14. Literacy rates were high. Figures show, a 65 percent participation rate for 15 to 19 year olds at secondary school. Pre-school education was informal, largely organised at the village level. In 2007, there was a primary school enrolment rate of 100 percent and a secondary school enrolment rate of 85.7 percent. Education at secondary level is very expensive, placing an extra burden on families to school their children for better opportunities. In 
2008, Samoa passed the Education Act making education compulsory between the ages of five and 14 (Treaty Body Monitor, 2006). New Zealand provides substantial assistance to support basic education in Samoa and scholarships for tertiary study in New Zealand and the region

\section{The Economy}

Constraints to economic growth included the small population, isolation from main markets, a restricted range of sellable products, and an economy susceptible to natural disasters and environmental damage, as seen in the 1990s with two devastating cyclones (1990 and 1991), and taro leaf blight in 1991. For a number of years, Samoans have migrated to other countries for better opportunities such as salaries, and living conditions. Samoa fit the Migration, Remittances, Aid and Bureaucracy model) (the MIRAB model), principally attributable to a heavy reliance on aid and remittance inflows (Bertram, 1999). Remittances were the largest source of income for some Pacific countries, meeting economic needs at the same time as family systems maintained an extension of cultural collectivism and duty to the family. More recently, the migratory flow had moved in the opposite direction, with skilled migrants from other countries coming into the region (OHCHR and PIFS, 2009).

\section{Poverty / Hardship}

According to an AusAID (2012) report, poverty existed in forms of social exclusion, and poverty of opportunity to participate (the capability approach). In addition, financial poverty (often termed hardship), manifested in ways such as a lack of access to basic services such as healthcare, education and, clean water. Moreover, an AusAid report (2012) noted, elements of hardship existed in three major areas:

1. Economic: Unemployment; Limited markets for agricultural production; Limited land cultivation due to lack of able-bodied men to work the land; and continued land disputes; 
2. Public services: Increased school fees and school dropout rate, and Limited access to basic services and infrastructure (such as transport); and

3. Social: Increased alcohol use, drugs, and robberies; Increased domestic violence, child abuse, teenage pregnancies and suicides; and Erosion of respect for village authorities and parents. Further stressors included opportunities to participate fully in the socioeconomic life of the community; and access to productive resources and income-generation support systems (rural credit, capital, markets, skill) to meet the basic needs of the household, and/or customary obligations to the extended family and village community. (p. 12)

\section{The Strategy for the Development of Samoa (2008/2012)}

The Strategy for the Development of Samoa (2008/2012), presented a five-year plan aimed toward "an improved quality of life for all." The Strategy listed seven national development goals for the $2008 / 2012$ period. Particularly, in relation to prevention of causal causes for CST, Goal 3, 4, and 5of the Strategy was relevant to this study:

1. Sustained macroeconomic stability;

2. Private sector-led economic growth and job creation;

3. Improved education outcomes;

4. Improved health outcomes;

5. Community development (improved village governance and improved economic and social well-being);

6. Improved governance in the public sector; and

7. Environmental sustainability and disaster risk reduction. (Government of Samoa and the Ministry of Finance, 2008.

\section{Tourism}

The Government of Samoa invested heavily in international air transport, such as the national airline, Polynesian Airlines, and the Polynesian Blue services between Australia, New Zealand, and Samoa. International cruise ships had called on Apia since 
2007. While stays at the port were usually short, while thee, tourist spending contributed significantly to the local economy such as local craft markets, taxi services, including providing long-term jobs for workers in the ports that regularly hosted them.

Table 8. Tourism Arrivals and Earnings (2004 - 2011)
\begin{tabular}{|l|l|l|}
\hline Period & Total Arrivals (Air and Sea) & $\begin{array}{l}\text { Tourist Earning (Gross) (Samoa Tala- ST: } \\
\text { National currency of Samoa). }\end{array}$ \\
\hline 2004 & 98,155 & \\
\hline 2005 & 101,807 & ST\$ 203.5 million \\
\hline 2006 & $\begin{array}{l}115,882 \text { (Increase of } \\
18.8 \%)\end{array}$ & ST\$236.3 million \\
\hline 2007 & 122,356 (Increase of 5.5\%) & ST\$2 262.5 million \\
\hline 2008 & 122,163 (December 0.2\%) & ST 288.4 million \\
\hline 2009 & 129,305 & \\
\hline 2010 & 129,500 & \\
\hline 2011 & 45,022 & \\
\hline
\end{tabular}

Note. From Government of Samoa and Samoa Bureau of Statistics, 2014, p.5:

Samoa Government, 2009, p. 4.

Table 8. (Tourism Arrivals and Earnings, 2004 - 2011), shows tourist arrivals and earnings in the period 2004-2011. Within this period, tourism earnings had climbed steadily from Samoa Tala \$236.3 million in 2006, to Samoa Tala \$288.4 million in 2008 . Total visitor numbers had increased by 1,042, in 2008/09. Similarly tourism receipts increased by $\$ 44.73$ million in 2008/09.

\section{The Samoa Tourism Authority Development Plan (2009-2013)}

The Samoa Tourism Authority Development Plan (2009-2013): A Guide to Sustainable Tourism, (Government of Samoa and Samoa Tourism Authority, 2009), presented tourism a significant contributor to the Samoan economy, as seen in government support of the tourism sector with a number of policies aimed at encouraging investment. 
In The Plan, The Ministry of Tourism promoted Samoa tourism in the following way:

The "Samoan Experience" is underpinned by strong themes of pristine nature, soft adventure, cultural appreciation, personal rejuvenation, indulgence and self-discovery, safety and security whilst also enjoying truly warm and genuine community welcome and exceptional and world-renowned Samoan hospitality (Government of Samoa and Samoa. Tourism Authority, 2009, p.5)

The Samoa Tourism Authority (STA) markets Samoa as a holiday destination in selected international markets. The STA does not support a Code of Conduct or Code of Ethics against CST. Table 9. (The Samoa Tourism Authority Development Plan (20092013): SWOT Analysis) below, recognised prostitution and pedophilia were negative threats of tourism. Seemingly, the Samoa Tourism Authority SWOT located the problem facilitated by hotel workers.

\begin{tabular}{|c|c|c|}
\hline SWOT & Strategic Implication & Response Required \\
\hline $\begin{array}{l}\text { Threats } \\
\text { The negative aspects that } \\
\text { can come with increased } \\
\text { tourism visitation (e.g. } \\
\text { prostitution, drugs } \\
\text { pedophilia, drunkenness). }\end{array}$ & $\begin{array}{l}\text { Deterioration of social well- } \\
\text { being. } \\
\text { Local resentment and } \\
\text { disaffection with tourist and } \\
\text { tourism sector. }\end{array}$ & $\begin{array}{l}\text { Risks need to be recognised and } \\
\text { understood. Strategies to be } \\
\text { developed to minimise and } \\
\text { mitigate occurrences. } \\
\text { Ensure that a hotel background } \\
\text { check of employees is } \\
\text { incorporated within the } \\
\text { accreditation standards. }\end{array}$ \\
\hline
\end{tabular}

Note. From Government of Samoa and Samoa Tourism Authority, 2009, p. 109

\subsection{Child Protection Measures}

\section{Traditional Structures}

In the absence of nationwide police coverage, the traditional fa' asamoa systems remain the major source of social protection for many families today. The Fa'amatai Wheel (Figure 3 below) below detailed a clear demonstration of village life and structure. 
The fa 'amatai highlights the central role of the family chief known as the matai, and clarifies where other groups position themselves in relation to the matai and to one another. Elaborate protocols and behaviors support the fa'amatai, based on values of alofa (love), service, respect for seniority, and those of higher rank, reciprocity, prioritising family over individual good, and the presence of the sacred in all activities (Fairbairn-Dunlop, 1991).

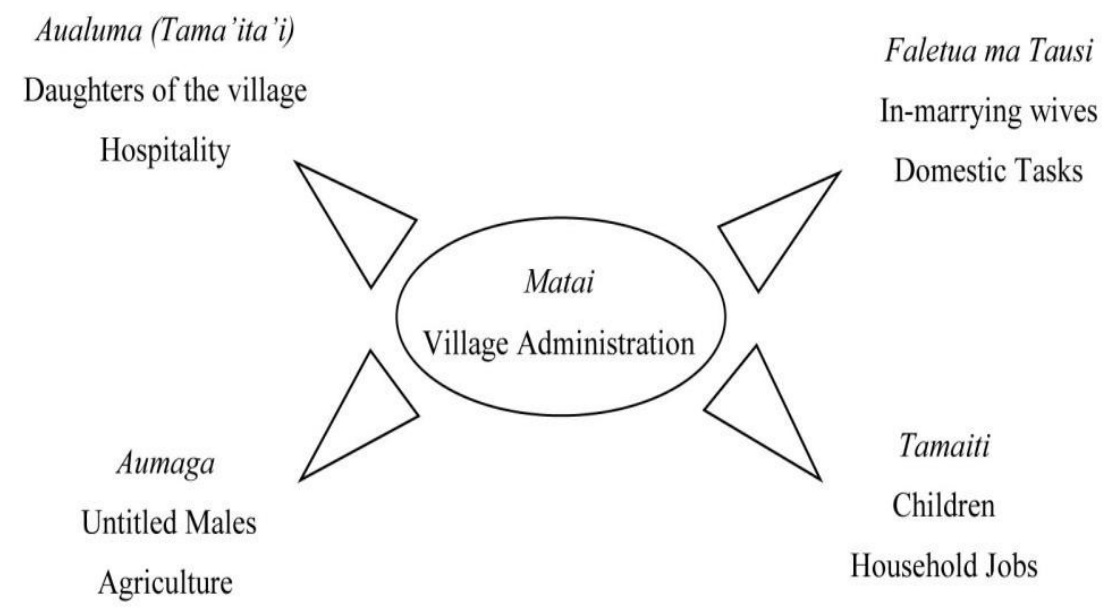

Figure 2. The Fa'amatai Wheel: (Fairbairn-Dunlop, 1996)

Aualuma (tama'ita'i) were unmarried virgin daughters of the matai who held privileged positions within the $f a$ 'amatai as teachers, healers priestess, makers of wealth. Their role of hospitality had high importance in bringing sacredness to every occasion, and in building family strength through marriage, thereby, extending the family power bases. Aumaga (sons of the matai and untitled men). The aumaga comprised youth and untitled males, and were the village workforce responsible for agricultural production, fishing, and protection. The faletua ma tausi (wives of the matai), were considered to be of lower status because they had lost their virginity through marriage. Wives usually had 
no rights in their husbands' village. The tamaiti (children) continued to operate as the basic system for the definition of roles, relationships, and division of labour in villages.

All family and community members were responsible for the education, safety, protection, and 'good behaviour' of children. In addition, the family for the reason given in the Samoan saying, 'Oamio o tamaiti, eta'uai le lelei o le aiga' carefully guided the movements and conduct of children or the conduct of one's children reflected the status of one's family (McPherson, Spoonley, and Anae, 2001).

\section{State Protection Mechanisms}

\section{Legislation}

Samoa's penal code is contained in the Crimes Ordinance (1961). The Ordinance, is modeled after New Zealand's Crimes Act at that time, provided the following penalties for crimes of sexual violence against children, and some protection against CST:

[s50] Sexual intercourse or attempted intercourse by man with young related girl (under the age of 21) living in his family - up to 7 years imprisonment [s51] Sexual intercourse with girl under 12 - up to 10 years imprisonment [s52] Indecency with girl under 12 - up to 7 years imprisonment [s53] Sexual intercourse or indecency by man with girl between 12 and 16 - up to 7 years imprisonment (it is a defence to a charge if the person charged proves that the girl consented, he was under the age of 21 years at the time of the commission of the act, and that he had reasonable cause to believe, and did believe, that the girl was of or over the age of 16 years)

[s54] Indecent assault on woman or girl - up to 5 years imprisonment [s58B] Indecent act between women over 21 and girl under 16 - up to 5 years imprisonment [s58C] Indecency between man over 21 and boy under 16 - up to 7 years imprisonment 
[s58D] Indecency between males 12 - up to 5 years imprisonment (boy under 16 can be charged if other male involved under 21 years of age) (Government of Samoa, 1961, pp. 18-21)

Under The Ordinance, the legal age for consensual sexual activity for a girl with a male or female non-relative, was 16 . There was no minimum legal age for consensual sex for a boy with a female non-relative, but a boy under the age of 16 could not consent to sex with a male over 21 . No minimum age exists for consensual sex between males where one of the males is under 21 . Homosexual sexual activity between any age group is an offence (Government of Samoa, 1961).

\section{Prostitution}

Under Section 16, enticing or soliciting for prostitution is illegal. The Ordinance provided offences for keeping or operating places of resort and brothels for homosexual activity and prostitution (Section 58J and 58K). It was unlawful for any person to exploit prostitution, including living on the earnings of prostitution (Section 58L) and procuring for gain or reward sex between a woman or girl and any man who is not her husband (Section 58M). Other sexual offences in relation to children under The Ordinance provide for non-prosecution of the child victim.

\section{Child Trafficking}

Article 83 covered the trafficking of children. In the case of the abduction of a woman or girl, "Every one is liable to imprisonment for a term not exceeding 7 years who takes away or detains any woman or girl, whether she is married or not, without her consent, or with her consent obtained by fraud or duress. 


\section{Pornography}

Pornography is under Crimes against Morality and Decency:

Article 43. Distribution or exhibition of indecent matter - (1) Everyone is liable to imprisonment for a term not exceeding 2 years who, without lawful justification or excuse:

(a) Sells, expose for sale, or otherwise distributes to the public any indecent model or object; or

(b) Exhibits or presents in or within view of any place to which the public have or are permitted to have access any indecent model or object or indecent show or performance; or

(c) Exhibits or presents in the presence of any person in consideration or expectation of any payment, or otherwise for gain, any indecent show or performance.

\section{Extra-Territorial Jurisdiction}

There were also external legislative actions supporting Samoa's domestic legislative structure, which could be used to safeguard the rights of children against international abusers such as The Samoa Crimes (Extra-Territorial Jurisdiction) No. 16 Amendment (2003) This was an amendment to the Crimes Ordinance of 1961 and applied to acts, omissions, and events, which occur outside Samoa. Section 3 notes that the Court of Appeal and the Supreme Court and the District Court have jurisdiction to hear and determine any matter for which this Ordinance or any other law provides with Court, jurisdiction irrespective of whether an act or omission or event occurs in Samoa or any other place (Government of Samoa, 2003).

\section{The Pacific Transnational Crime Unit (TCU)}

A division with particular responsibility in relation to CST is Samoa's division of The Pacific Transnational Crime Unit (TCU). The TCU worked within the Police. The 
Unit coordinated with 13 other Pacific Island Countries, Australian and New Zealand Police, and US Federal law enforcement to combat the spread of organised crime into the Pacific such as illicit activities including drug trafficking, child sex tourism, fraud, illegal fishing, money laundering, cybercrime, illegal logging, human trafficking, and people smuggling. The Department of Immigration maintained the border control function and engaged in security intelligence and networking in suspected areas of crime.

\section{Law Enforcement}

The Samoan Police enforced National laws, although the police are only a skeleton force - in the absence of nation-wide police coverage; the traditional systems remain the major source of social protection for families today. The record of Samoa's Police in enforcing its child protection laws is slight in comparison with the estimation of the child abuse problem. The Domestic Violence Unit of the Police handled the issues of violence against women and children as reported.

\section{Village Law}

There are more than 300 villages in Samoa. Governance at the village level is the remit of the Village Council of Chiefs (fono o matai), on which every family is represented by their own family chief. The fono o matai is responsible for the village economy, and village development, and the amount and condition of village assets. The village Council of Chiefs is also responsible for village law and order, and village protection. Each village has its own legal customs and processes, and systems of compensation, and reconciliation in the event of transgressions and crimes. The village liaises with national government through the Pulenu'u (equivalent of village mayor). The Pulenu' $u$ is elected by the village and is usually one of the village's Council of Chiefs. One traditional system of justice is the ifoga, a system whereby the offender's family make an apology to the victim's family for bringing shame to the village in any way. Village Councils have the authority to apply social sanctions for misdemeanors, such as fines, through to banishment. 


\section{National Committees, Partnerships, Policies, and Action Plans}

In Samoa, the overarching framework for the realisation of child rights is the CRC administered through the Ministry of Women, Community, and Social Development (MWCSD), which serves as the national focal point for The Convention. Established in 2004, the MWCSD collaborated with Government ministries and NGOs in the implementation of the CRC and CEDAW. The Ministry of Women Affairs Act (1990) regulated the MWCSD, as the office responsible for developing gender-related policies in Samoa. In addition, because the MWCSD was the national focal point and coordinating agency to the CRC, therefore, had a role to implement and promote the CRC nationally.

\section{The National Coordinating Committee on the Convention on the Rights of the Child}

A number of pivotal committees and partnerships operated in Samoa, typically undertaken for child advocacy, monitoring, and developing national programs of action, and evaluating implementation of the $\mathrm{CRC}$ and national programs of action. The first was the National Coordinating Committee on the Convention on the Rights of the Child; (NCCCRC), chaired by the assistant chief executive officer of the MWCSD. The Committee representatives, comprised 12 government agencies, 13 Samoa Government and three youth representatives, each of whom were tasked with ensuring national policies were in place to address children's issues across all government sectors (Committee on the Rights of the Child, 2006).

The NCCCRC, implemented activities for the protection of children from abuse and neglect, and examining policy, and legislation relating to the implementation of the CRC in Samoa to ensure the fulfillment of the provisions of the CRC. The primary functions of the NCCCRC were to develop a National Plan of Action for the implementation and monitoring of the $\mathrm{CRC}$, and to review and advise government on legislation and policies to ensure the fulfillment of CRC provisions. 


\section{The CRC Partnership}

As Table 10, (The CRC Partnership), in the various fields of the MWCSD work as covered in the CRC, The Ministry had facilitated the establishment of The Partnership of the Convention on the Rights of the Child, (The CRC Partnership), in October 1999 As Table 10. (Samoa: The CRC Partnership), The CRC Partnership comprised Government and NGOs, all of which had direct responsibilities in the implementation of the different CRC articles. The main criteria for membership of the partnership stipulated that a member organisation must have crosscutting and relevant core functions that address the Government's obligations in realising the children's right for life, health, education, and protection from all areas stipulated by the Convention. Membership was on organisational levels rather than individual to ensure continuity and sustainability.

\section{Table 10. Samoa: The CRC Partnership}

Governmental Organisations

MWCSD Division for Women, Division for Youth, Division for Research, Policy, Planning \&

Information Processing

Ministry of Health Division for Maternal Child Health Strategic Development \& Planning Division Ministry of Education, Sports \& Culture Curriculum Material \& Assessment Division Ministry of Justice and Courts Administration Courts Division

Ministry of Police, Prisons \& Fire Services Human Resource Division
Non-Governmental Organisations

ECPAT Samoa

Loto Taumafai Education Centre for Children with Disabilities Aoga Fiamalamalama for Children with Intellectual Disabilities Youth for Christ

National Council for Early Childhood Education Samoa Centre Catholic Family Ministry / Fiaoloa Crisis

Note. From the MWCSD (n.d)

\section{The CEDAW Partnership}

Samoa ratified CEDAW (The Convention on the Elimination of all Forms of Discrimination) in 1992. The MWCSD chaired the CEDAW Partnership. Certain provisions in CEDAW made specific reference to young girls, thereby, indicating that the term 'women' encompassed them. As related to girl's protection from CST in Samoa, 
“Article 6: Trafficking and Prostitution, directs all States Parties to "take all appropriate measures, including legislation, to suppress all forms of traffic in women and exploitation of prostitution of women" (United Nations General Assembly, 1979). Membership consisted of government, non-government, civil society, and private sector organisations with a focus related to different areas for the advancement of women. (Government of Samoa, 2009).

\section{National Policy for Children of Samoa (2010-2015)}

Table 11 (National Policy for Children of Samoa (2010-2015): Reduction of Abuse, Violence, and Exploitation), below, presents the National Policy for Children of Samoa (2010-2015).

\begin{tabular}{|c|c|c|c|}
\hline Outputs & Indicators & $\begin{array}{l}\text { Responsible } \\
\text { Agencies }\end{array}$ & $\begin{array}{l}\text { Time } \\
\text { Frame }\end{array}$ \\
\hline $\begin{array}{l}\text { Government officials, NGOs, all } \\
\text { sector partners in collaboration } \\
\text { with village authorities and village } \\
\text { social groups actively promote } \\
\text { child protection and the best } \\
\text { interests of the child }\end{array}$ & $\begin{array}{l}\text { Level of understanding on } \\
\text { child abuse risk and } \\
\text { protective causes. }\end{array}$ & $\begin{array}{l}\text { MWCSD } \\
\text { and sector } \\
\text { partners }\end{array}$ & 2015 \\
\hline $\begin{array}{l}\text { All victims of child abuse, neglect } \\
\text { and exploitation are better served } \\
\text { through the effective and } \\
\text { coordinated implementation of an } \\
\text { inter-agency response system } \\
\text { guided by protocols } \\
\text { and referral procedures }\end{array}$ & $\begin{array}{l}\text { An Interagency } \\
\text { Protocol/Response System is } \\
\text { developed and a roadmap is } \\
\text { planned and developed } \\
\text { for future actions }\end{array}$ & $\begin{array}{l}\text { MWCSD } \\
\text { MOJCA } \\
\text { MPPS } \\
\text { AG Office } \\
\text { MOH } \\
\text { NHS } \\
\text { MOA } \\
\text { SVS }\end{array}$ & $\begin{array}{l}2010- \\
2015\end{array}$ \\
\hline $\begin{array}{l}\text { Village authorities actively } \\
\text { promote child protection } \\
\text { mechanisms in the development of } \\
\text { their village plans. }\end{array}$ & $\begin{array}{l}\text { Child protection focus } \\
\text { reflected in village plans } \\
\text { Number of children all } \\
\text { attending school }\end{array}$ & $\begin{array}{l}\text { MWCSD } \\
\text { MOA, } \\
\text { MOPP, } \\
\text { MESC }\end{array}$ & $\begin{array}{l}2010- \\
2015\end{array}$ \\
\hline
\end{tabular}


The policy document operated as the overarching framework for children, providing the necessary direction for the care, protection, and development of children from birth to 18 years, directing all government stakeholders, and partners for child development and protection. This Policy aimed to provide the basis for monitoring programs, and services targeted at child development and child protection in order to respond to their needs. As Table 11, above, three of the six outputs in the National Policy for Children (2010-2015), related directly to the 'exploitation' of children. Specifically, at least 13 agencies had been tasked to action this policy.

By way of focus, the Policy appeared to locate child protection, to protection against child abuse, neglect, and exploitation; three issues directing UNICEF's work in the Pacific, and three issues aligned to Article 19 of the CRC framework. The document did not stipulate the forms of child abuse it aimed to cover, such as sexual, physical, or emotional abuse (inside problem), or outsider abuse such as from foreign workers or, tourists. Neither did it define the types of 'exploitation' it aimed to tackle, such as child vendor exploitation (an inside problem), or sexual exploitation of children by outsiders (an outside problem). Nonetheless, Article 19 appeared to be the focus of the Policy to the detriment of Articles 34, 35, and 36 for example

\section{The National Plan of Action for Children (2008-2012)}

Table 12 (Samoa National Plan of Action for Children, (2008-2012), Outcome 2: 2.1 below), appeared to have mirrored the directives of the National Policy for Children (2010-2015), as above. Eight organisations had been tasked to push the National Plan of Action for Children. 


\begin{tabular}{|c|c|c|c|c|}
\hline Outcomes & Outputs & Indicators & $\begin{array}{l}\text { Responsible } \\
\text { Organisations }\end{array}$ & $\begin{array}{l}\text { Time } \\
\text { frame }\end{array}$ \\
\hline $\begin{array}{l}\text { 2. Children are } \\
\text { better served } \\
\text { by well } \\
\text { informed and } \\
\text { coordinated } \\
\text { child } \\
\text { protection, } \\
\text { social services } \\
\text { which ensure } \\
\text { greater } \\
\text { protection } \\
\text { against and } \\
\text { respond to } \\
\text { violence, abuse } \\
\text { and } \\
\text { exploitation }\end{array}$ & $\begin{array}{l}\text { 2.1 All victims of } \\
\text { child abuse, neglect } \\
\text { and exploitation are } \\
\text { better served } \\
\text { through effective } \\
\text { and coordinated } \\
\text { implementation of } \\
\text { the inter-agency } \\
\text { response system } \\
\text { guided by protocols } \\
\text { and referral } \\
\text { procedures }\end{array}$ & $\begin{array}{l}\text { An Interagency } \\
\text { Protocol/Response } \\
\text { System is } \\
\text { developed/A } \\
\text { roadmap developed } \\
\text { for future actions } \\
\text { Regular and active } \\
\text { meetings conducted } \\
\text { with CRC } \\
\text { partnership and the } \\
\text { NCCRC to monitor } \\
\text { the implementation } \\
\text { of the Inter-Agency } \\
\text { Response System }\end{array}$ & $\begin{array}{l}\text { Ministries of: } \\
\text { Women, Justice \& } \\
\text { Courts, Police, } \\
\text { Office of the } \\
\text { Attorney General, } \\
\text { NHS } \\
\text { NGOs - MOA, } \\
\text { Samoa Victim } \\
\text { Support, ECPAT } \\
\text { Samoa }\end{array}$ & $\begin{array}{l}2008- \\
2012\end{array}$ \\
\hline
\end{tabular}

Note. Government of Samoa: Samoa National Plan of Action for Children (2008-2012)

\section{The Stockholm Agenda: Regional Workshops and Consultations}

Fiji, Samoa, and Vanuatu, had adopted the Stockholm Declaration and Agenda in December 2001, the Cook Islands in September 2003 and Papua New Guinea in May 2004. Between 2001, and 2007, a number of high-powered delegations had attended four pivotal regional consultations aimed at discussing strategies for combating CSEC in the Pacific. The relevance of these workshops and consultations for Samoan children, are discussed next.

\section{The East Asia and Pacific Regional Consultation for the Second World Congress against CSEC (2001) (ECPAT International, ESCAP, UNICEF, Save the Children (2001)}

This consultation held in Bangkok, placed an emphasis on the development of a research and data agenda. It called for significant improvement in quality research and data collection, aimed to improve data gathering to inform policy and programmes to 
address CSEC, develop and support a research agenda on CSEC and support sharing inter-county sharing of findings. In addition to develop and support a research agenda on CSEC, aimed to ensure the participation of children and young people in research on CSEC, and for the inclusion of universities and other educational institutions as key partners in the recovery, and reintegration processes, including training and research. Participants requested ECPAT International, ESCAP, and UNICEF to assist countries with the development of national plans of action that could be used to monitor the implementation of the Stockholm Agenda for Action. Pacific Island countries were especially encouraged to adopt the Agenda for Action. (See Appendix F: East Asia Pacific Regional Commitment and Action Plan against Commercial Sexual Exploitation of Children, 2001).

\section{The Pacific Regional Workshop on Combating Poverty and Commercial Sexual Exploitation of Children (2003) (UNESCAP, ECPAT and UNICEF, 2003)}

This second consultation was a workshop held in Fiji, attended by the Cook Islands, Samoa, and Fiji. Co-organised by The Interagency Group (ESCAP, UNICEFEAPRO and ECPAT International), in cooperation with the Government of Fiji and UNICEF (Pacific), its focus was on assisting countries to incorporate The Convention on the Rights of the Child obligations and Stockholm Commitments into national action plans. The workshop discussion was on poverty, and CSEC in the Pacific, with member countries incorporating their obligations under the CRC and the Stockholm (1996) commitments into national plans of action.

Adopted at this conference was a Pacific Statement of Commitment, which highlighted Pacific countries' awareness of CSEC, as an emerging issue (See Appendix G: A Pacific Statement of Commitment on Combating Poverty and Commercial Sexual Exploitation of Children and Youth, 2003). Furthermore, was a regional action plan aimed to combating CSEC that included 10 selected commitments for monitoring (See Appendix H: East Asia Pacific Regional Commitment and Action Plan, 2003). 
In addition, participating countries were tasked with devising their own National Plan of Action to combat CSEC in accordance with Stockholm (1996), detailing programs and activities aimed at: 1) Prevention, 2) Protection, 3) Recovery and Reintegration, 4) Coordination and Cooperation, and 5) Child /Youth participation (UNESCAP et al., 2003, pp. 48-51) (See Appendix I: Samoa: Proposed Plan of Action Against CSEC). A key recommendation of the workshop was to conduct situational analyses in Pacific island countries and to share the finding regionally, as many Pacific islands countries did not know the national or regional situation of CSEC and requested assistance in this regard.

\section{The Post Yokohama Mid-Term Review of the East Asia and Pacific Regional Commitment and Action Plan against CSEC (2004) (ESCAP, ECPAT and UNICEF, 2004).}

In 2004, in Bangkok, ESCAP, ECPAT, and UNICEF, organised the PostYokohama Mid-term Review of the East Asia and the Pacific Regional Commitment and Action Plan against Commercial Sexual Exploitation of Children. This Mid-Term Review was in response, to the aforementioned 2003, ESCAP, ECPAT and UNICEF Pacific Regional Workshop on Combating Poverty and Commercial Sexual Exploitation of Children (2003) (UNESCAP, ECPAT and UNICEF, 2003).

The review provided a training workshop on CSEC and the closely linked issue of child sexual abuse (CSA). The review aimed to enable seven countries to undertake situational analysis research on CSEC and CSA. Countries selected to participate were, Fiji, Solomon Islands, Vanuatu, Kiribati, and Papua New Guinea. The Cook Islands and Samoa had each agreed to conduct their own situational study soon after. Between 2004 and 2008, ECPAT, ESCAP, and UNICEF supported the development of situational analysis research in the seven Pacific island countries. The situational analysis had three objectives: 1) documentation of the existing situation of CSA and CSEC in each participating country, 2) identification and analysis of the causes and root causes 
surrounding the issue, including profiles of children, exploiters and key actors, 3)

documentation and analysis of government, civil society and country-based international organisation responsibilities, related interventions, and the level of coordination on work to combat child sexual abuse CSA and the CSEC.

Generally, the importance of the Mid-Term Review for Pacific children, was it enabled delegates to learn more about current trends of CSEC, and CSA, and to discuss the region wide situational analysis, because of the lack of data on CSEC in the Pacific region, and to share the findings regionally. That was because many Pacific countries did not know the national or regional situation of CSE, and had requested assistance from UNIECF in this regard (resulting in the Pacific Interagency Report, 2006 chapter 1).

\section{The Regional Stakeholders' Consultation and Planning Workshop on the Commercial Sexual Exploitation of Children and Child Sexual Abuse in the Pacific (2007) (UNESCAP, 2007)}

A Samoa delegation comprising the MWCSD, the NGO Mapusaga O'Aiga, and the National Council of Churches, had convened in Suva, Fiji, aimed to share key findings of The Pacific Interagency Report, (2006). Discussions centered on root causes, gender issues, and social and economic causes contributing to CSEC. Strategies to strengthen the capacity of Government and civil society were debated and national plans of action developed.

\section{Civil Society}

In conjunction with the State and the extended family system, the Church is the third institution to make up the foundations of Samoa's society. The extended family and the church are Samoa's main institutions for most of its modern history, with those of the state maintaining until very recently a less significant profile in the day-to-day lives of most Samoan citizens. 
Non-Governmental Organisations (NGOs) play a large role in Samoa's society, often included in consultations and initiatives with government bodies. The concept of social services and social welfare remained new concepts in Samoan society. In cases where the extended family did not adequately work in such a way as to protect the rights of children, NGOs filled in the gap. Generally, NGOs operated without governmental checks or regulations (Treaty Body Monitor, 2006).

The Samoa Umbrella Non-Governmental Organisation (SUNGO, 1997), served dual purpose. First, to provide alternative development options and assistance to vulnerable groups in Samoa, and second to provide input into Government policy from NGOs, Community Based Organisations, and Civil Society Organisations on issues about which they were concerned.

The largest NGO, in Samoa is Mapusaga O'Aiga; (MOA) considered the lead NGO for the CRC, and the main NGO working against domestic violence and the physical and sexual abuse of children and incest. The organisation raised awareness about sexual abuse and domestic violence and educated people about these issues. The NGO, ECPAT Samoa (End Child Prostitution/Pornography and Trafficking, of note, not associated with ECPAT International), worked to develop public awareness and carry out community outreach programs on CSEC and child abuse issues in general.

Victim Support (established in 2005), was another NGO that worked with victims and survivors of crime and sexual crime. The organisation offered safe houses, and shelter, including assistance with legal and police procedures, welfare and education. The independent media were generally active and expressed a variety of views without restriction. The local television station collaborated with the MWCSD providing coverage on activities carried out at the community level, including local efforts addressing violence against children. 


\subsection{Issues for Children}

\section{Sexual Abuse}

As presented in The National Policy for Children (2010-2015), from January to June 2010, there were 296 cases of domestic violence involving children. In the last 12 months abuse was listed as indecent assault, rape, and carnal knowledge (Samoa Government and the MWCSD, 2010).

\section{Longer-Standing Issues}

Samoa, had submitted its initial CRC report to The Committee of the Convention on the Rights of the Child in November 2005, nearly a decade after ratifying the CRC in 1994. The Samoa report noted a long list of outstanding issues and themes for children. As follows:

1. Poverty: As a developing country, poverty was inhibiting the full implementation of the Convention;

2. Birth registration and adoption: Lack of measures to ensure births were registered. Most forms of adoptions were informal;

3. Education: Concerns about Samoa's reservation to Article 28 (1) (a) of the Convention. This article calls on the State to "make primary education compulsory and available free to all";

4. Health: Statistics showing malnutrition and disease;

5. Child abuse: Physical abuse and children with mental health issues lacked medical staff;

6. Juvenile Justice: No formal juvenile justice system existed;

7. Child privacy was not respected;

8. No measures were in place to prevent the exploitation of children;

9. The Committee stated that a lack of statistics made it very difficult to identify domains and areas where children's rights might be violated; and

10. The Committee recommended that the State improve its system of data collection and that it use findings in its amendments of laws. (Treaty Body Monitor, 2006, pp. 2-5) 
Urbanisation and rural - urban - drift had resulted in "increased youth crime, due to unemployment, peer pressure, and children looking after children and lack of parental supervision" (Government of Samoa and UNICEF, 2006, p. 52).

\section{NGOs Harbor an Increased Workload}

The proliferation of responsibilities usually handled by families increasingly had become the domain of NGOs. Evidence for this was Samoa's social care system was fraying. The Treaty Body Monitor to the CRC had this to say on the situation:

There was an understanding that a shift from the extended family system to a more centralized form of social service delivery would require a gradual change of perception. However, the concept of social services and social welfare remain new concepts in Samoan society. In some of the cases where the extended family did not adequately work in such a way as to protect the rights of children, NGOs had to fill the gap. NGOs operated without governmental checks or regulations. (The Treaty Body Monitor (2006, p.3)

\section{Child Vendors}

A qualitative pilot study undertaken by the MWCSD (2005), on child vendors in Samoa, noted the increasing visibility of child vendors, especially at tourist sites such as nightclubs, and the significant contribution that these sales made to family incomes. The study reported that some parents and families had contributed to their children's commercial exploitation, in allowing their children to take on an adult role to provide for their families. I should note, the child vendor's pilot study had not investigated or linked these children on the streets, out at night selling wares, as a precursor to their sexual abuse from child sex tourists (MWCSD, 2005). 


\title{
Complicity - Stakeholders Don’t Want to Know
}

\author{
A United Nations report entitled Samoa Government Questionnaire on the \\ Implementation of the Beijing Declaration and Action (1995), and the Outcome of the \\ Twenty-Third Special Session of the General Assembly 2000 (United Nations, 2009); \\ reported youth were the most vulnerable group in Samoan society. The questionnaire \\ reported resource constraints prevailed, inhibiting at the national level the work on \\ women and children.
}

Furthermore, having attended The Regional Stakeholders' Consultation and Planning Workshop on the Commercial Sexual Exploitation of Children and Child Sexual Abuse in the Pacific (ESCAP, 2007), that was convened to discuss the Pacific Interagency Report's (2006) findings, of the seven Pacific countries attending, Samoa was the only country of the seven, that had not completed its situational study on CSEC and CSA.

The Samoa delegation explained that its study "was in the final stages of writing." It itemised the importance of carrying out the study and detailed the findings use:

1. To complete the situational analysis on CSA and CSEC, disseminate the findings, and incorporate them into the draft National Policy on Children and the Country Programme Action Plan for Child Protection/National Plan of Action for Children (2008-2012):

2. To obtain Government endorsement of the National Policy on Children and the National Plan of Action. Other plans were to facilitate the amendments and changes to the policy and legal framework in line with the Convention on the Rights of the Child legislative compliance review for Samoa;

3. To lobby for child protection, to be reflected in the Government's list of priorities and thus in the National Development Strategy, and to continue to link the work on child protection, CSEC and CSA; and

4. To combat CSEC and CSA, to foresee the obstacles foreseen, and to implement strategies for overcoming them. (p. 11 ) 
The Samoan delegation presented to the workshop, a number of challenges it had to fulfilling the situational study, such as limited understanding of CSEC in Samoa, and getting CSEC onto the Government's list of priorities. "There was limited information about CSEC for evidence-based advocacy, as well as "the territorialism of organisations, which limits the sharing of information with other partners" (p11).

\section{Marginalisation of Boys}

A United Nations report entitled Samoa Government Questionnaire on the Implementation of the Beijing Declaration and Action (1995), and the Outcome of the Twenty-Third Special Session of the General Assembly, 2000 (United Nations, 2009); reported youth were the most vulnerable group in Samoan society. The questionnaire reported, although work for the advancement of girls was on going, males fared less well, and that the social and economic costs to society of not recognising the marginalisation of boys, and their lack of opportunity, could be inestimable within ten years.

\section{Summary}

Samoa is a states party to the CRC, and a committed partner to non-binding agreements such as Stockholm (1996), having reiterated that commitment at Yokohama (2001). Indicators were that the Samoan government had been slow to acknowledge the presence of the SEC, having presented its initial report to the $\mathrm{CRC}$ approximately 10 years from ratification. Samoa still had not completed its situational analysis report on CSEC and CSA. What had happened to it? I would put this question to the MWCSD in fieldwork.

The Samoa Tourism Authority Plan, the Authority had recognised pedophilia was a negative aspect of tourism, and set to action towards monitoring hotel workers suspected to facilitating the practice. That the STA promoted Samoa 'hospitality', fit Pacific cultural norms of hospitality, but also had the potential for CST. The discussion 
on 'Issues for Children', exposed an over abundance of root causes creating an environment to the sexual exploitation of Samoan children. Next, is Chapter 4, on Methodology and Research Design. 


\section{Chapter 4: Methodology and Research Design}

\subsection{Introduction}

Chapter 1 had presented the background to this study. A Protection Project statement, and a recommendation to Samoa from The Committee of the CRC, resulted in my decision to carry out an exploratory study on CST, including its scope, and root causes in Samoa. I set three research objectives:

1. To report the scope of child sex tourism in Samoa,

2. To identify and report the root causes that contributed to the risk of child sex tourism in Samoa, and

3. To present a set of recommendations as a baseline foundation for policy, advocacy and research.

This study's methodology, involved ethnographic fieldwork. The clandestine nature of the crime was always going to make my fieldwork difficult. I considered methodology required a single embedded qualitative case study. Fieldwork was a onemonth stay in Apia, Samoa, and April to May 2009. Data sources were interviews, focus groups, and last-minute survey with taxi drivers, in addition to direct observation, and stories. The Samoan va, talanoa, and fa'afaletui added a conceptual / spatial element for understanding Samoan space, respectful relationships, and problem solving for consensus. Therefore, the remainder of this chapter explains 1) Methodology, 2) Conceptualising Samoan Space (Va, Talanoa and Fa'afaletui), 3) Case Study Design, 4) Data Analysis, and 5) Trustworthiness.

\subsection{Methodology}

It appeared that the researcher should explain his or her worldview so that readers can better assess the objectivity and validity of their methods and findings. These 
worldviews or paradigms include one's ontology or basic philosophical questions of how one regards 'being' or 'reality'. Also considered is epistemological orientation (how one defines 'knowledge', in the understanding of knowledge as a relationship, autonomous of reality, between the known and the knower). Third is methodology which includes the relationship between these first two autonomous parties, namely how we know 'reality' (Denzin and Lincoln, 2005).

Qualitative research has a long-standing history in exploratory studies. Agrawal and Gibson (1999) explained that while methodologies employed in social science studies vary, they are typically, qualitative, and they cite the importance of engaging with local stakeholders. Underpinning qualitative research is an ontological view that reality is, at best, a social construction explored through a science of meanings, phenomenological insights, and subjective processes.

Elliot Eisner (1991) described qualitative research as "descriptive, incorporating expressive language and the presence of voice in the text" (p. 36). Because qualitative research is flexible, it permits researchers some freedom to formulate general questions, and to gather data using multiple methods and data sources. In fact, Denzin and Lincoln (1994) regard qualitative researchers as 'bricoleur', a term coined by French anthropologist Claude Levi Strauss), the essence of 'bricoleur', which was flexibility. Harper, (1987) described a bricoleur as a handyman or handywoman, making good use of tools available to complete a task, putting together whatever works to do the job, in a doit-yourself, adaptive-to-the-circumstances kind of way, choosing from the many methods of qualitative research enabled a multi-dimensional perspective, "more akin to observing a crystal from many angles, one that was constantly in process of developing” (p. 208).

Flick (2002) remarked qualitative research adhered to an inductive strategy. This means rather than starting from existing theories and testing them, that this study was not, it required sensitising concepts for approaching the social contexts under investigation. According to Hoepfl (1997), the qualitative research approach to data collection, offered 
a high level of face validity, while preserving the richness of data, its chronological flow, thus decreasing retrospective distortion.

\section{Empathic Neutrality}

From the outset, I knew I could not remain completely neutral on this topic. Child sex tourism is a sensitive topic; it can cause emotional and mental harm. Almost all parties in the environment would feel some type of emotion, either ranging from disgust and anger to sadness to shame. Any discussion on the topic could take place amid a consciousness of legality and illegality, guilt, and fear; people are very likely to lie about their involvement in it. Regarding fieldwork in Apia, and knowing the way of the fa'aSamoa, I knew that if I were to remain neutral, would close doors.

That Samoan's participated with me, meant people had to trust me, which meant I had to be transparent. I had to show humanity and heart on this issue. Therefore, I followed Patton (1990), who asserted that a researcher should strive towards 'empathic neutrality', and become non-judgmental instead, to strive to report results in a balanced way. Patton noted the terms objectivity and subjectivity had become "ideological ammunition in the paradigms debate" (p. 55), and he chose instead 'empathic neutrality'. Empathy he said is "a stance toward the people one encounters, while neutrality is a stance toward the findings" (p. 58).

Pacific scholar and researcher TimoteVaioleti (2006) remarked institutional research requirements and objectivity as foreign concepts to Pacific knowledge:

\footnotetext{
Historically, research has been driven by hypotheses and often by an institution's approved questionnaires. These do not require a personal relationship between the researcher and the participant in order to obtain the information. The interactions are guided by approved ethics, but these are based on different thinking from that of pacific peoples. The disparity between the objectivity base of much traditional research and the
} 
subjectivity of the participants is often not recognised in Pacific research contexts. (p. 22)

Denzin and Lincoln's introduction to the third edition of The Sage Handbook of Qualitative Research (Denzin and Lincoln, 2005), described a turning away from the positivist paradigm of the latter nineteenth, and first half of the twentieth century. The Positivist paradigm assumed data could be gathered objectively at the source, and analysed objectively by the researcher. Positivism fostered the idea that the lone ethnographer could venture into an unknown cultural environment, and bring the logic and clarity of Western scholarly and scientific discipline to societies too 'childlike', too 'confused', or too 'primitive' to understand their own structures.

Evidence for this was Margaret Mead's Samoan research of the 1920s and 1930s. Credited as valid data in its positivist time, its ontology was exposed, by a more critical time and paradigm, as a web of deceit spun by her informants; and its epistemology, to be her own fantasies of sexual freedom, with a far more direct link to her American uppermiddle-class liberal background, than to Samoan culture.

Vaioleti (2006) imagined Meads' situation as arising from her ignorance of the protocols of talanoa, defined as 'talking in an informal way, telling stories or relating experiences':

Talanoa firmly places the power to define what the Pacific issues are within the encounter between the researcher and the participant. Participants will disclose information only when they feel the time is right and the context appropriate. If protocols are ignored, the participants may end the talanoa. Worse, they may reciprocate ( $u t u$, totongi) the wrong to teach researchers a lesson, to remind them of their obligations in this symbiotic relationship. This kind of reaction is apparent in Meads' (1928) research, based on three months' fieldwork on the American Samoa island of Ta'u. Her young female participants 
misinformed her as totongi for her culturally insensitive questions and approaches about their social lives. (p. 16)

Alternatively, the post-positivism paradigm, acknowledged that realities are socially and culturally constructed (the ontology of a particular culture), by those for whom they have a particular interest (the epistemology of a particular researcher), and by those processes of knowledge transfer, they set up between them (the methodology of a particular research design). These latter concepts of ontology, epistemology and methodology have been generally called interpretive, or the constructivist paradigm. That this study employed the constructivist paradigm was because it embraced an ontology that was local, specific, and co-constructed; an epistemology that understood findings as subjective, co-created; a methodology that was hermeneutic and naturalistic.

\subsection{Conceptualising Samoan Space (Va, Talanoa and Fa'afaletui)} $\mathrm{Va}$

In December 2008, I had presented this study to delegates at the Fourth Measina Conference in Apia (chapter 1). Concurrently, I had used that time as a pilot study, to get to know the case site, and test and modify my research design - particularly research questions, and interviewing techniques (Yin, 1994).

I had planned to carry out nighttime observations of the Apia site to observe child vendors and the night time scene in general. To drive me around, I had hired a taxi driver. He was a husband, and father of three, a taxi owner and operator, an ex-Ministry employee, village chief and trainee pastor; a man with many hats and responsibilities. Over three nights, we would sit outside bars or hotels or on a sea wall where small children and teenagers gathered. I would explain my research, a topic he knew little about. Over nights, he came to understand my study. When it came time for me to leave Samoa, he expressed interest in my study and before I left he said, "Aiai a se isi mea e mana'oaifeso 'otamaipevala' au mai”' in Samoan, meaning, if you need help, call me. 
While I did not know how to name it at the time, this period of one week, and the three nights on the sea wall in Apia, were the time and place of my coming to understand $v a$. By telling and hearing each other's roles and responsibilities in the world, we came to know the relational space; that a serious matter could be discussed, without the danger of transgression and imbalance.

$V a$ refers to physical spaces between people, between objects, and between people and objects. $V a$ is the space that relates and which is conceptualised and lived out holistically, and is the context by which meanings are set to things (The Samoan Working Group, 2012). $V a$ is fundamental to fa'asamoa and to Samoan understanding. Where the Samoan report of the Human Rights Council spoke about the "values of respect for one another and the principles of reciprocity," it refers to $v a$. Samoan people co-exist in $v a$ relationships. The Samoan conceptual worldview and its tangible expressions are interdependent and relational. "A whole belief system revolves around the concept of $v a$. In the context of human interaction and relationships, $v a$ is the space that relates and which is conceptualised and lived out holistically, and is the context by which meanings are given to things" (The Samoan Working Group, 2012).

I came to understand that $v a$ was something we take out of, according to the obligations and requirements that each of us is under; circumstances structured into roles by our particular position in time and place. Understood too was that this taking out required a putting back, a reciprocal exchange, and that this putting back would be in a different form, because time, and circumstances change. Also understood was the concept of reciprocity; that each of us has a different role, different structured circumstances, different duties, which each must fulfill if the world balance of taking out and putting back is to be maintained; and so each of us must be allowed space and respect to carry that out. Because the human role is to interact, complications arise, but are not impossible to mediate, if the principle of reciprocity is held to, and within the contemplation of every smaller aspect of space and time, we contemplate its 
consequences in the balance of all things in wider space and time. Recognition of $v a$ occurs when social norms are utilised and obeyed.

Tusi Tamasese's short film Vatapuia (Tamasese, 2009) is about this space: literally, space made sacred. A widow and widower each inhabit a separate space, space that is sacred to the relationship of each with their deceased spouses. They get to know each other only by way of very precise, careful, and respectful unspoken rituals, conducted through the offering and accepting of food. Less than a dozen lines are spoken by the two in the whole film, never talking about them. Communication is done through observation of the actions of the other; actions to do with maintaining and fulfilling duties of contemplation and respect towards the vatapuia of the spousal relationship of each. The boundaries of this sacred space remain in place even though the spouse of each had evidently been buried for a long time.

The film showed the boundaries of this sacred space contemplated and respected in physical and actual ways. The widow and widower arrange physical space around them by the way they orient themselves, in sitting, in respect of the other elements of the world large and small; be they the perimeter of the house, the spouse's grave, the sea, or the sky. Similarly, in temporal space, a certain length of time has to pass between each action: whether large, as between the burial of one's spouse and allowing oneself to watch TV; or small, as between a question and an answer in a conversation. This vatapuia extends among and holds in balance all things of time and space: the sky, the sea, the earth, the burial place, plant life, the house, food, and social space. The composition of the film itself, the length of time within framed views and the rectangles of those views, contemplates vatapuia between the sitting mat, the porch, the grave, and the space between sea, mountain, field, and sky. 


\section{Talanoa}

In the context of human interaction and relationships, $v a$ is at the heart of talanoa. In this study, talanoa was not used as a methodology or method, other than to conceptualise the 'space' in which I would be working, in the process of dialogic exchange, and interaction for understanding the problems through respectful and mutual sharing of views, experiences and beliefs through the process of talanoa. Talanoa is a derivative of the words 'tala', meaning tell or communicate, and 'noa' meaning anything or in general.

A number of Pacific academics have emerged, reconciling traditional approaches of academic research. For example, Sitiveni Halapua (2003), TimoteVaioleti (2006) and Semisi Prescott (2009), having all spoken and written about a system of communication of knowledge called talanoa. They say talanoa best allows people to use customary Pacific ways to communicate their knowledge and concerns, and have them weighed and understood. The essence of talanoa is that it is face-to-face, an open-ended discussion without restrictions. "Within the use of the philosophy of talanoa, ideas are floated, combined, and discussed. No time constraints are placed upon a talanoa session. Discussions are often lengthy, so to achieve consensus" (Prescott 2009, p. 66, citing Robinson and Robinson, 2005).

Kolone-Collins (2010) remarked that talanoa involves stories that are filled with emotion, and content, a holistic and embodied amalgamation of emotions, knowledge, interests, and experiences (Farrelly and Nabobo-Baba, 2012), utilised for problem solving and policy-making. Informal interviews or general discussion, for example, does not mean without protocols, because openness requires the recognition of the different positions people occupy in life. People cannot leave these positions. Understood and acknowledged are parties taking responsibility for the discussion remaining open. As part of this acknowledgement, an important protocol is making an apology and request for forgiveness for any offence caused, past or future. One should be respectful in the 
presence of these responsibilities, and humble in acknowledging the position one has placed people in (Prescott 2009).

\section{Fa'afaletui}

In Samoan culture, there are three perspectives. The perspective of the person at the top of the mountain, the perspective of the person at the top of the tree, and the perspective of the person in the canoe who is close to the school of fish. In any big problem, the three perspectives are equally necessary. The person fishing in the canoe may not have the long view of the person at the top of the tree, but they are closer to the school of fish

(Tamasese, Peteru and Waldegrave, 1997, p. 301)

The concept of $F a$ 'afaletui, conceptualises the merging of many viewpoints or bodies of knowledge, and places strong emphasis on collectivity, which facilitates the gathering and validation of important knowledge, and multiple views on an issue. This understanding of what knowledge is, and how knowledge is constructed, shared, and evaluated aligns with the concept, important in qualitative research, of triangulation.

\subsection{Case Study}

In various investigations, particularly in sociological studies, case studies had been utilised by a number of researchers to investigate CSEC on-site, for example, research reports from O'Connell Davidson and Sanchez-Taylor (1996), including Shaft and Tidball (2010) were the case studies.

Yin (2003) provided the following definition of case study:

A case study is an empirical inquiry that investigates a contemporary phenomenon within its real-life context, especially when the boundaries between phenomenon and context are not evident. The case study inquiry copes with the technically distinctive situation in 
which there will be many more variables of interest than data points, and, as one result relies on multiple sources of evidence, with data needing to converge in a triangulating fashion, and as another result benefits from the prior development of theoretical propositions to guide data collection and analysis. (Yin, 2003, pp 13-14)

I considered case study was an ideal methodology for carrying out an in-depth investigation in Samoa (Tellis 1997). Apia was selected as the case, the study of the case was the scope of CST and related causes. Like many qualitative case studies, this research had exploratory, descriptive, and explanatory characteristics. It was exploratory because CST is under-researched in the Pacific, and specifically in Samoa. It was descriptive, detailing events as they unfolded. The explanatory aspect was an explanation of the root causes for CST in Samoa.

Case study brings to research design an ability to look more closely at a specific phenomenon, usually from the viewpoint of participants. It comprehended, and provided for a close collaboration between the researcher, and the participant, enabling participants to tell their stories (Crabtree and Miller, 1992). Through these stories, participants had the opportunity to describe their views of their realities; which in turn enables the researcher to understand participants' actions (Baxter and Jack, 2008).

Stake (1995) remarks:

For a research community, case study optimises understanding by pursuing scholarly research questions. It gains credibility by thoroughly triangulating the descriptions and interpretations, not just in a single step but continuously throughout the period of study...For almost any audience, optimising understanding of the case requires meticulous attention to its activities. (p. 444)

The case study was single embedded. The single embedded case study provided a means of integrating quantitative and qualitative methods into the case (Yin, 2003). The 
embedded aspect was built into the case, because case involved not one unit of analysis, but six groups as the units of analysis (Tellis, 1997; Yin, 2003). The embedded aspect supports triangulation, considered a critical cause for triangulation in qualitative research. That triangulation is achieved relied on multiple sources of evidence, with data converging. Snow and Anderson (1991) proposed that triangulation should be factored into as many of the layers of research as possible, such as data, investigators, theories and even methodologies.

\subsection{The Design and Conduct of this Case Study Research}

In utilising a case study approach, I followed Robert Yin's respected handbook, Case Study Research: Design and Methods (Yin, 1989). The handbook I found useful to retrace the conduct of the study chronologically, with reference to the stages he advised, to explain decisions, especially mid-process shifts, and adaptations in methodology. The following design sections, therefore, equate with the six stages that make up the six chapters of his book, and describe my research approach to 1) Planning, 2) Designing, 3) Preparing, 4) Collecting, 5) Analysing, and 6) Sharing.

\subsubsection{Planning}

\section{Changes to Design}

The flexibility of case study design resulted in four planning changes: 1) A change in location, 2) A cultural adviser, 3) A focus group facilitator, and 4) A survey with taxi drivers.

\section{A Change in Location}

Initially, I had considered a larger comparative study of two Pacific countries that were Fiji, and Samoa. Fiji is the hub of Pacific tourism and CST was a serious problem. 
Samoa, on the other hand, was an emerging tourist destination, with a CST problem. I followed Yin (2003), who had suggested, in case study research, it was better to pursue a case that was more convenient, close and allowed easy access, so that the researcher could spend more time, and develop closer relationships with participants in order to gather the information needed.

\section{A Cultural Adviser}

My pilot study in Samoa (while attending the Fourth Measina in 2008) allowed me to pilot my interview skills and questions, and to gain early access to organisations and groups, I had identified in chapter 3 to approach for participation, (such as from The CRC Partnership, for example). In addition, the pilot study had enabled me to find an NGO I could base myself with for advice and guidance for the upcoming fieldwork. Although one NGO had tentatively agreed to host me, when I returned to begin fieldwork, there had been a delay in official approval, for the reason that the approval letters could take some time, and the sensitivity of this topic.

I considered the tight timeframe and, my objectives, so I returned to the taxi driver I had met in my earlier one-week pilot study who had offered to help me with fieldwork, should I need it. I termed him a cultural adviser. He was a native-born Samoan who was a fluent Samoan / English speaker with traditional Samoan family values; he wore many hats. He was a former government ministry employee, village chief, trainee pastor, and a taxi driver-owner operator of several years' experience with a handy knowledge of the Apia street scene. Because he was so well respected, he became a primary access point to participants I thought I would have trouble talking to. He accompanied me to interviews and focus group discussions, and always explained to me the correct protocols to observe when requesting an interview, especially with people of high rank. He undertook translations when needed. The day's events ended after a debriefing session, long discussions, and clarification. I discussed interview questions 
with him for cultural relevance and sensitivity. He adhered to the ethical components of the study, in particular, the importance of maintaining confidentiality.

\section{A Focus Group Facilitator}

I had planned to carry out an urban focus group discussion in Apia. Because I had not based myself with an NGO, as I had planned to do, the focus group discussions were in doubt. In fieldwork, I had interviewed a civil society participant who was working around child protection matters. He had conducted many focus group discussions in his role as person in charge of this NGO group. I asked him if he would help me organise an urban focus group discussion, and he said he would. He also offered to organise a rural focus group discussion, and run that too.

In addition to his NGO work, the focus group facilitator was Samoan born, a male, and village chief. Acknowledging my limitations in running a formal focus group discussion with Samoan people, I welcomed his offer. I was not a strong Samoan speaker, nor was I conversant with Samoan cultural protocols at the formal level of focus group discussion. Particularly in the rural village, I was mindful about the time it would take me to bring a focus group together, with participation not assured. In addition, the focus group facilitator was an experienced organiser. I could learn from watching him organise and run the discussion. His offer benefitted him too, because he wanted more information on this issue, a reciprocal exchange benefitting us both.

\section{A Survey with Taxi Drivers}

The cultural adviser had offered to put together a taxi driver group to attain their viewpoints. As fa' afaletui, I had already engaged a group of high-end government officials, and a middle group of civil society, but I had no group on the ground such as taxi drivers. I accepted his offer. As in numerous reports, (such as the Pacific Interagency Report, 2006), taxi drivers had facilitated CST, placing them in a bad light. I 
considered the taxi drivers were the unheard voices on the ground, the ones close to the action, although, rarely consulted in-depth.

\subsubsection{Designing}

\section{Research Questions}

I designed my research questions to fit my three objectives. First, I wanted to know the scope of CST, the root causes, and areas for future work. I discussed the questions with the cultural adviser for cultural sensitivity. Questions to all participants (individuals and groups) were:

1. How do you regard tourism in Samoa: Positive or negative?

2. Is CST a problem in Samoa?

3. What are the root causes that could enable CST in Samoa?

4. Whose responsibility would it be to prevent CST in Samoa?

5. What actions are needed to prevent CST in Samoa?

Where possible in interviews, focus groups, and surveys, I used a starter question, "What value, the Samoan child" This question was designed to put participants at ease, and remind them, why we were there. Usually the discussion focused on parents raising their children today. I mentioned my own family, my children, and grandchildren, and aspirations I had for their future. These were just things that parents and grandparents, uncles, and aunts talked about when discussing raising family. Once they accepted and trusted me as an ordinary person, out came their stories.

Participants' answers to Question 2, asked of all groups - triangulated - would determine the scope of CST, (Objective 1). Questions 1, 3, 4 and 5, determined root causes (Objective 2). Question 5, were participants viewpoints to provide recommendations to close gaps, based on their own knowledge and context (Objective 3). 
Flexibility was assured using the five semi-informal, open-ended questions, that could be probed, and for follow-up to unanticipated answers. Depending upon whom I was interviewing, I had supplementary questions. My piloted study had trailed the five questions with a senior representative of a UN donor agency, a Samoan NGO and a senior New Zealand High Commission official. Participants appeared to appreciate the topic; the questions flowed smoothly, leading to long discussions.

\subsubsection{Preparing}

\section{Sampling / Sample}

The sampling process was purposeful. Maxwell (2009) defined purposeful sampling as "a strategy in which particular settings, persons, or events were deliberately selected for the important information they can provide that cannot be gotten as well from other choices" (p. 235). Chapter 3 enabled me to identify individuals and organisations, which I knew, were information-rich, such as organisations on the CRC Partnership (chapter 3) and organisations that had attended the three regional workshops as presented in Appendix D (Pacific Consultations, Workshops and Reviews: 2001-2004).

Pacific researcher Kolone-Collins (2010) noted that within the scope of the research, participants should hold in-depth knowledge on the issues. Charmaz (2000) adds that sampling is for refining ideas, not increasing the size of the original sample. Ritchie, Lewis and Elam (2003), supported Charmaz's view for three reasons:

First, if the data is properly analysed, there will come a point where no new evidence emerges in each additional fieldwork unit. This is because a phenomenon needs only to appear once to be part of the analytical map. There is therefore a point of diminishing return where increasing the sample size no longer contributes new evidence. Second, statements about incidence or prevalence are not the concern of qualitative research. There is therefore, no requirement to ensure that the sample is of sufficient scale to 
provide estimates, or to determine statistically significant discriminatory variables.

Third, the type of information that qualitative studies yield is rich in detail. There will therefore be many hundred of 'bites' of information from each unit of data collection... sample sizes need to be kept to a reasonably small scale. (pp. 83-84)

Sirakaya-Turk, Uysa, Hammitt, and Vaske (2011) defined a sample to be "a small part of the population that represents the whole population - it is not the size that matters, but what matters is how well the population is represented by the sample group" (pp.9596). Jennings (2001) mentioned the term 'thick descriptions' to indicate the collection of in-depth information of, usually, a small number of participants.

\section{Final Sample}

Criteria for participation were to be Samoan, living in Samoa; be over the age of 18 , and participate freely with me in this study. As Table 13 (Final Sample), the 38 participants in my study were all Samoan, living and/or working in the Apia urban / periurban area. Comprising six groups of no more than 10, they included higher-level government officials and policy makers, police, church officials, educationalists, community workers, workers in the tourism sector, and chiefs and highborn women of village council.

\section{Table 13: Final Sample}

\begin{tabular}{lllll} 
Group & Sample & Numbers & Gender & Method \\
\hline 1 & Government & 3 & 1 Male / 2 Female & Semi-structured interview \\
2 & Intergovernmental & 2 & 1 Male / 1 Female & Semi-structured interview \\
3 & Civil society & 6 & 3 Male / 3 Female & Semi-structured interview \\
4 & Focus group (urban) & 10 & 2 Male / 8 Female & Focus group discussion \\
5 & Focus group (rural) & 10 & 8 Male / 2 Female & Focus group discussion \\
6 & Taxi drivers & 7 & 7 Male & Survey questionnaire \\
\hline
\end{tabular}


Recruitment was face-to-face; to assist me to build rapport and a higher level of motivation for participants to participate in this study, as opposed to e-mail and phone calls, which I considered inappropriate for this type of study. All participants in Groups 1 to 4 spoke fluent Samoan, and good English. Groups 5 and 6 were fluent Samoan speakers, with good to moderate English. Although most people I approached responded positively and nobody declined participation, a request to interview one person was too short notice. His office directed me to another contact. Another participant I had talked with informally, agreed to a follow-up interview, but did not attend.

\section{Ethical Arrangements}

This study was granted ethics approval from the University of Victoria Ethics Committee of the Faculty of Humanities and Social Sciences New Zealand. Most interviewees and focus groups participants consented to audiotaping, that could stop on request.

I considered confidentiality and anonymity to be significant ethical issues in my research process, and a study like this. All participants received information explaining the background and purpose of the study, and research procedures. I explained that the data was for $\mathrm{PhD}$ research in the Faculty of Va'anamou Pacifika, Humanities, and Social Sciences at Victoria University of Wellington, New Zealand. All participants (individuals, focus groups, and survey) signed a consent form. (See Appendix J: Consent to Participate in Research (Individual), (See Appendix K: Consent to Participate in Research (Focus Groups). I assured participants I would not disclose their names or personal information in my research, and that only relevant details that helped in answering the research questions would be included. I assured participants that the audio tapes would be securely stored. 


\subsubsection{Collecting}

Tellis (1997) cites Yin's (1994) six sources of evidence for data collection in the case study protocol:

1. Documentation

2. Archival Records

3. Interviews

4. Direct Observation

5. Participant Observation

6. Physical Artifacts (p. 8)

In consideration of Yin, I utilised the following data sources into this study:

1. Interviews

2. Focus group discussions (urban and rural)

3. Surveys in the form of a questionnaire

4. Direct and participant observation

5. Stories

\section{Interviews}

Interviews are an important source of information in qualitative research and, highly recommended for case studies. They allow for both the flexibility and room to focus on certain themes, which emerge during the interview. More importantly, rapport and trust between researcher and participant assist to generate deep and accurate information.

Preparation of the interview guide was an on-going refining process, given the paucity of reported data that drew on literature. Additional scoping strategies, in discussions with agencies and conference participation, were necessary because of the 
newness of this issue. Individual interviews were semi-structured, considered one of the most common forms of qualitative research methods.

Before interviews, the cultural adviser explained the most appropriate way to conduct an interview. The advice he gave was that all parties within had to be very aware of the status of each contributing person, his or her age group and blood ties, their ancestry, as well as their professional and social status (Vaioleti, 2006). He considered the introduction was important, because people did not know me. He explained that the proper protocol was to first introduce myself, my background, and then explain the main purpose for requesting their help. He said that I should always keep conversations open, because that was how trust was established. He continued:

As we go around and introduce ourselves, the proper Samoan way is when you come in $[\ldots]$ that you honour that person due to respect. You should already know what title that person holds. We communicate when we meet; always have to honour that person and thank that person for seeing you before the conversation start - that is the vatapuia. Like another main orator or chief; he knows how to respect the other chief; that is a part of the relationship before starting any conversation, then vatapuia starts to build up. He knows why you are here and for what purpose. If you do not follow protocols, he will not open up. If you ask me questions and I do not know who you are, you will not get this information. (Cultural Adviser)

Usually, interviews were carried out in people's offices, typically within a twokilometer perimeter of central Apia. For interviewing, I used an open-ended, semistructured interview guide, which allowed for probing. While I had five research questions to ask, as the interview progressed, the discussion usually took the lead from the participant's interests and roles. Usually the discussion adjusted itself to new knowledge supplied by the participants, or discovered within the conversation, leading to new insights and discussions. 
I listened attentively. For clarification, I asked, "what do you mean?" or, "why would you say that"? I paid careful attention to facial expressions and other body language. I took into account non-verbal communication. I assured participants they could take as long as they wished. Interviews were on average 45 to 60 minutes and sometimes longer. At the end of the interview, I acknowledged the participants time and participation in the study. In the Samoan context, it was respectful to provide a small gift if someone had done a kind service. I typically provided a small gift such as, food or soap.

\section{Problems}

Groenwald (2004) points out that "researchers must at all times ensure that recording equipment functions well and spare batteries, tapes, and so on, are available. The interview setting must, further, be as free as possible from background noise and interruptions" (p.2). One interview started out favorably with the recording device working correctly and weather conditions favorable. However, halfway through the interview there was a heavy downpour. Because I did not want to interrupt the discussion, I left the tape running. However, transcription was a long and laborious task. The sound of rain compromised (to some degree) the quality of the audio recording.

\section{Focus Group Discussions}

Focus group discussions offered different perspectives on a phenomenon under investigation. Morgan, 1997 and Rabiee, 2004, considered focus groups to be a wellknown way of capturing the interaction between participants, and, rather than for seeking quantitative information on actual events or instances, they are well suited for exploring norms, beliefs and practices, and are a powerful tool for collecting information relatively quickly, yielding a broad range of views on a specific topic over a relatively short time. Pacific scholars and respected researchers, (Tamasese, Peteru, Waldegrave and Bush, 
(2005), regard focus group discussions highly, since they allowed for the development of a consensus of views around issues of importance.

Conversely, Morgan (1997) wrote that researchers had less control over the data produced as well as generally keeping participants focused on the topic. Difficulties in recruiting and assembling data arose, as people were busy, less articulate, or less confident. A shared group can compromise confidentiality and anonymity. Holloway and Wheeler (2002) observed that recording data could present problems when many people are talking at the same time, and that tape recorders record only those who are nearer. Focus group discussions are not replicable. In addition, the validity and reliability of the findings are difficult to ascertain on their own; and some participants can dominate the discussion and influence the outcome or perhaps even introduce bias.

\section{Preparing for Focus Group Discussions}

One criterion for participation was willingness to participate, over the age of 18 , and a mix of males and females considering relative status in the community. Preparing for the focus group discussions involved a vigorous process of translating documents from English to Samoan and Samoan to English, involving the cultural adviser, the focus group facilitator, and myself. I did this to diminish the chance of losing the meaning of Samoan principles and concepts. In focus group discussions, particularly the rural group, I anticipated the Samoan language would be the main communication medium. I expected full Samoan protocols. Sessions recorded were with the full approval of the participants. The cultural adviser took notes when the discussion was in Samoan, and I took notes when the discussion was in English. Following the group discussions, the cultural adviser and I discussed what had happened. I asked that he clarify the notes I had made at certain points in the discussion. 


\section{General Proceedings for Focus Groups}

The focus group facilitator translated all relevant documents from English to Samoa and the cultural adviser checked these documents for accuracy. Documents were the information sheet and questions to each group of participants. Preliminary arrangements included:

1. Ensure the facilitator was clear about his role

2. Ensure I understood how to operate the digital recording equipment

3. Take notes on paper as a backup if the digital recording equipment failed

4. Familiarise myself with the focus group before the discussion began

5. Ensure I had enough copies of the consent to participate forms

6. Test the recording equipment

7. Ensure venue, time, and refreshments were organised

8. Compensate participants for their time and out-of-pocket expenses (such as transport home by car, bus, or taxi).

\section{Focus Groups Questions (Urban and Rural)}

1. What value, the Samoan child?

2. What are your thoughts about tourism for Samoan people today: Positive and negative aspects?

3. Do you think child sex tourism may become/is already a problem, in your country? In your opinion when is CST a big enough problem bout which to take action?

4. What reasons do you think make children easy targets for paedophiles and opportunistic tourists in Samoa?

5. Whose responsibility is it to combat this problem in Samoa? Why do you think that? 
6. If you had first-hand knowledge that a tourist was trying to lure a child for sex, would you report it? Whom would you contact? Why would you contact that person or organisation?

7. If you had the power to combat this issue in Samoa, how would you go about it? What might be the barriers?

\section{The Urban Focus Group Discussion}

The urban focus group discussion ran at the focus group facilitator's office. Preparing for the focus group interviews involved meticulous planning to ensure we were all on the same page. The interview was in a mix of Samoan and English, but mainly Samoan. Consent to record was agreed to. There were ten participants. The participants were split into two groups of five, named Group 1 and Group 2. Group 1 was composed entirely of women, mainly from NGO and grass roots organisations. Group 2 were mainly men from government agencies and the church. The group was set up like this because of the roles and genders of the participants, for example offering interesting comparisons. Group 1 and 2 answered Question 1. Group 1-answered Questions, 1, 2, and 3. Group 2 answered Questions 3, 4 and 5.

\section{Questions and Replies}

Following the groups reading of the information sheet- each group took the opportunity to ask me questions as follows:

\section{Group 1:}

1. Was this study a first study on CST in Samoa? I replied, with regard to CST, it was.

2. What age did I define child, because someone's child, aged 60, was still someone's child. I replied 18 as the CRC, although I was aware national law declared 16 to be the age of consent. 
I was asked to contextualise the lead question: "What value, the Pacific child?" A participant suggested that the 'Pacific child' should be the 'Samoan child' to keep the study in context. I agreed. Another comment was about outside researchers studying Samoan issues and distorting findings, using Margaret Mead's study as a primary example. I replied that it was not my intention to distort findings.

\section{Group 2:}

The women in this group wanted more information about CST: Their questions related to if a problem was found:

1. What assistance was available to community organisations to carry out preventive work?

2. Is there any assistance available for families needing help in this area, or if identified or if sexual tourism? What type of help is available?

3. Would there be assistance available to a particular group of women who work within this area?

4. What impact does sex tourism have, in Samoa, in relation to the tourism industry? Does it have any impact? How would people outside Samoa perceive the people of Samoa?

5. If there is a crisis, which area should families turn to for help?

6. Are there any territorial laws to control tourism legislation or tourism behaviours?

7. How important is this forum to setting recommendations for legislation?

8. Will there be back-up from people from international tourism countries?

\section{The Rural Focus Group Discussion}

The rural focus group discussion had been held in a rural village approximately 40 minutes from central Apia. To the adviser's knowledge, there had been no formal discussion on CST in this village. The group's participants included high chiefs, matai, orators, and women from the village committee. The group numbered approximately 10 , 
although at times numbered swelled. These were mainly onlookers who listened to the discussion and at times voiced their opinions. This meeting was very formal as is the case for village meetings, and was mainly in Samoan with some English.

\section{Proceedings}

1. Seating according to status

2. Prayer

3. Introductions

4. Permission to use audio tape

5. Focus group facilitator read out the information sheet

6. A break for refreshments

7. Participants read information sheet (translated from English to Samoan)

8. A discussion on what was read

9. Wrap-up

10. Lunch

11. Questions sheets left with village chief.

This meeting was lengthy (nearly two hours), and conducted mainly in Samoan. I received two sets of data from this group. The first was from the reading of the information sheet and the discussion from it (notes taken, and audio taped). The second was from the questionnaire sheets left with the group and returned a few days later. The cultural adviser rechecked the transcripts against the original document, searching for loss of meaning from the Samoan version to English. The earlier warnings from Morgan (1997), that researchers have less control over the data produced as well as generally keeping participants focused on the topic, were unfounded. Both focus groups were well organised and the facilitator, and participants were respectful at all times. No participants left the discussion before end. 


\section{Problems Encountered}

The two focus group discussions were audio recorded to ensure the accuracy of the notes taken and to prevent missing information. The urban and rural focus group discussions were in large rooms. I had to second-guess where to put the audio recorder. Before the discussions began, participants had spoken loudly. Once greetings were over and the formalities began, participants' voices became soft. Initially, I relied on the pitch of people's voices based on greetings when they had arrived. I did not place the recorder too close, because I did not want it to be intrusive. When the time came to transcribe the discussions, I had to listen carefully; transcription was a long and laborious task.

\section{Survey}

Yin (2003) remarked that quantitative methods such as a survey could be included into case study methodology. An unexpected inclusion intro this study was the taxi driver group. The cultural adviser was a taxi driver owner and operator, and had offered to arrange a taxi driver sample to understand how they perceived this issue, based on their knowledge and experiences in the tourism environment. The taxi driver survey was a questionnaire the drivers could complete by themselves, into his study. Criteria for inclusion included the driver being over the age of 18 and working in Apia (central / periurban) from a range of locations. The final sample was all male aged 29 to 65 . The least amount of time a driver had worked driving taxis in Apia was nine months; the longest was over 30 years. Areas serviced by drivers included the Apia flea market, nightclubs, hotels, airport, wharf, and port.

Participants took up to an hour or more to complete the survey questionnaire (see Appendix L: Questions to the Taxi Drivers). I felt that the length of time they took to answer the questionnaire, was not because of the number of questions or any difficulty, other than the fact that it was a very serious issue and they wanted their opinions known (as one taxi driver said, after he had completed the questionnaire). Upon collection of the 
questionnaires, I thanked the drivers for their time and presented a small donation to compensate for loss of earnings.

\section{Problems Encountered}

The taxi driver survey was written in English. The survey had been piloted on the first driver and required one adjustment. For example, the driver had completed the survey and handed it back to me. He was talking to the cultural adviser about a German tourist who had disembarked from a cruise ship berthed in Apia. This tourist then approached this driver, requesting from him access to prostitutes, girls, and young boys for sex. I looked at the participant's answers and noticed this information was not in his survey, so I asked him why. He replied that he did not know how to spell 'German' so he had decided to leave this vital information out. For the remaining drivers, I let each participant know that if he had any difficulty understanding or completing the questionnaire; the cultural advisor and I were nearby should he need help. No other driver sought assistance.

\section{Direct Observations}

Yin (2003) considered site observation was an important data source to supplement other forms of data sources in case study research. With the purpose of attaining first-hand knowledge of what was happening in the Apia nightlife environment, I conducted a number of direct site-specific observations (Tellis, 1997), mainly at night, outside nightclubs, bars and hotels. The cultural adviser accompanied me on most nighttime observations, sometimes with a colleague. I took notes and audio recordings for longer observations.

\section{Stories}

Often times I was told stories about prostitution, operating in Samoa, with one particular story involving young adolescents. I utilised direct observation to verify these stories. According to Yin (2003), observation supplements other forms of data collection 
and triangulation. Stories became a valuable source of important and comprehensive information. One participant referred to stories as gossip, although it was gossip that saved people's lives. During fieldwork, people told me about adult prostitution and child prostitution operating in Samoa. I verified these stories through direct observations.

\subsubsection{Analysing}

For the data analysis, I drew information from all the interviews, focus groups, survey, personal notes from observations, stories, and my reflexive journal in order to present a view of the data that was relevant to the objectives, rather than separating the data. After a field visit, interview or focus group discussion, my field notes were typed up and transcribed verbatim as suggested in the literature (Miles and Huberman, 1994, (McLellan, MacQueen, and Neidig, 2003). I followed McLellan, et al, 2003, re-checking transcripts, especially for punctuation, so as not to change the intent or emphasis of participants' responses.

Data sources for analysis-included interviews, two focus group discussions, surveys, direct observation, stories, and journal notes. These data sources were analysed by means of a qualitative approach, focused to determine the scope of CST in Samoa and to search for root causes. Once the data was gathered, the qualitative data was summarised, themes identified and the findings recorded for conclusions and recommendations. To achieve the latter, I first had several tasks to complete. By means of an open coding technique, the interviews, focus groups, surveys and my notes from direct observations were converted into text. After that, I analysed these documents, based on their content, in order to eliminate the data that was not relevant in relation to the research questions and objectives. The open coding involved various concepts related to CST and contextual causes.

During the content analysis, less relevant passages and paragraphs of the text were removed and similar fragments combined and summarised. This data reduction 
facilitated data clustering and, finally, the formulation of the conclusions. I selected appropriate quotations that conveyed the core theme or essence of the category to use in the findings. The analysis ceased when I felt I had exhausted the data, answered the questions and objectives, the overarching questions of this study, and provided recommendations that were relevant to findings.

\subsubsection{Sharing}

I anticipated the results of this study were reported at a forum in Apia convened especially to do so.

\subsection{Strategies for Ensuring Trustworthiness}

Shenton (2004, following Guba, 1981), proposed four criteria he believed researchers needed to consider in ensuring a trustworthy result: 1) Credibility (in preference to internal validity), 2) Transferability (in preference to external validity/generalisability), 3) Dependability (in preference to reliability), and 4) Confirmability (in preference to objectivity) (p. 64)

\section{Credibility}

Credibility was concerned with, "How congruent are the findings with reality?" (Shenton, 2004, p. 65). To achieve credibility, in this study, I utilised the following:

- Qualitative case study methods (interviews, focus groups, and observation).

- I developed an early familiarity with the site, culture, and prospective organisations, for example, my pilot studies (2008).

- I included a chapter devoted to the context of the case site, to familiarise myself with the setting before fieldwork. 
- Background data drew on external documents. These included Samoa's implementation report to The Committee to the CRC (Government of Samoa, in addition, Samoa's first, second and third reports to the CEDAW Committee and, documents from the Pacific and East Asia Pacific regional workshops and consultations Samoa had attended, and the roles and responsibilities Samoa had taken on in them each.

- Urban and rural focus group participants and taxi driver participants were randomly selected outside my control. Selection of these groups was by the focus groups facilitator and cultural adviser; I was not involved in the selection.

- The focus groups and taxi driver survey offset the usual participants such as government ministries and civil society, enabling multiple voices and perspectives exhibiting characteristics of similarity, dissimilarity, redundancy, and variety, to gain greater knowledge of the case study site.

- Regarding triangulation, I employed multiple data sources and methods $F a$ 'afaletui as a conceptual framework triangulation. In addition, I applied site triangulation (participation of informants within several organisations).

Tactics to help ensure honesty included:

- Revealing myself as an independent researcher

- Participants had an opportunity to refuse to participate, a strategy aimed to establish a rapport

- Participants advised there were no right or wrong answers, and that they had the right to withdraw from the study at any point, without explanation.

- Frequent debriefing sessions occurred between my supervisor and cultural adviser.

- Peer scrutiny occurred when I presented this study to four conferences where I was aiming at feedback. 
- I applied 'reflective commentary'. I used an audio journal, to record my feelings, impressions, concerns, favorable moments, and root causes generated.

- My background, qualifications, and experience were presented in chapter 1. Funding for this study was included in the acknowledgements. Ethics approval was recorded.

- I had kept audio tapes, field notes, and transcripts, to establish a chain of evidence and accuracy of the data from the data collection discussions.

- The mall samples enabled a thick description of the issues.

- This study results were congruent with those of past studies as I included in chapter 2 (the three situational analyses); producing this study's results of root causes and root causes related to the existing body of knowledge.

\section{Transferability}

Shenton (2004, citing Merriam, 1998) notes that external validity "is concerned with the extent to which the findings of one study can be applied to other situations" ( $p$. 69). Following Shenton (2004), I provided a detailed description of methodology to allow comparisons. These included:

- The number of organisations taking part in the study and base of location.

- Any restrictions on the types of people who contributed data

- The number of participants involved in fieldwork

- The data collection methods employed

- The number and length of the data collection sessions

- Keeping the sample in all groups small, and

- The time over which the data were collected. 


\section{Dependability}

Shenton (2004) remarks that dependability is evaluated by whether or not the process of research is logical, traceable, and clearly documented, particularly in the methods chosen, and the decisions made by researchers. Regarding triangulation:

- Used multiple data sources.

- All interviews were tape-recorded for verification and future use.

- I undertook peer review and debriefing.

- I employed overlapping methods and an in-depth methodological description to allow this study to be replicated as far as it could.

\section{Confirmability}

Shenton (2004) advocates a confirmability strategy that evaluates the extent to which findings are qualitatively confirmable through the analysis being grounded in the data, and through examination of the audit trail such as steps of the research process, reflexivity, the researcher's background, education, perspective and school of thought.

I applied confirmability through:

- Multiple sources of data utilised.

- Triangulation to reduce the effect of investigator bias.

- An admission of my beliefs and assumptions appears in chapters 1 and 2.

- Limitations to the study presented, including recognition of the shortcomings in the study's methods, and their potential effects.

- Maintained two results sections chapters 5 and 6) that were cleared of outside influence (summary) to allow the two sets of data to be scrutinised without prejudice. 


\section{Summary}

This chapter dealt with the research methodology of this thesis, which included the research design, the selection of the research site and case studies, the data collection methods, the data analysis methods, in addition to an assessment of the trustworthiness of the results. In order for me to understand the scope of CST and root causes, I employed an embedded single case study method. Criteria for participation were Samoan, residing in Samoa, over 18 years of age, and being willing to participate in the study. I used the literature to develop a case study protocol. The development of the conceptual framework benefited from my pilot study. The pilot interviews helped to identify the relevant issues and contextual causes. In addition, the pilot study enabled me to increase my insight into the case site. I used multiple sources of data collection: interviews, focus groups and a survey including documents stories and observations. Sampling was purposeful.

The data analysis process involved coding data, searching for relationships by crosschecking major themes and integrating the data into a common coherent explanatory model to answer the research questions. Data was analysed manually so as not to miss any nuances that computer programmes would not pick up. To ensure a high-quality case study, several strategies reduced threats to credibility and transferability throughout the process. Next, chapters 5 and 6, present the five case study questions and answers. 


\section{Chapter 5: Discussions, Section 1}

\subsection{Introduction}

This chapter is the first of two discussion chapters. Specifically, it presents discussions around the first three of this study's five questions. As follows: 1) Perceptions of tourism : Positive or negative, 2) Is CST a problem in Samoa, and 3) What are the root causes for CST in Samoa. Chapter 6 presents Question 4, on roles and responsibility. Neither of the two chapters contains a summary. To do so would be to interrupt the integrity of the discussions. Chapter 7 is an extended summary of results of the four questions discussed in this chapter 5 and 6. The answers to Question 5, relating to actions needed to be done to prevent CST in Samoa, are discussed, and presented in Chapter 8.

\subsection{What is the Value of the Samoan Child?}

Perceptions about the value of the Samoan child became a necessary starting point for discussions. The question 'broke the ice' and softened the tone of conversation, so that people became comfortable and receptive to the difficult questions to come. I anticipated that even asking if CST was a problem in Samoa, might be viewed as sacrilegious or offensive, perhaps inferring that Samoan parents, and the wider aiga system were not looking after their children as well as they should. However, the question needed asking.

Participants' responses to the question about the value of Samoan children, confirmed the valuing of the family in the fa'asamoa, and children's place within the aiga, as outlined in Chapter 3. Urban and rural focus group participants spoke powerfully and lovingly about the value of children for them. The mothers in the urban focus group shared the following description of the value of Samoan children in Samoan society: 
Children are our country and families' future, a God-given gift (responsibilities), heirs of our families' land/pride. Children understand cultural protocols, for example, reverence, respect, love - above all, love [alofa]. Children are the essence of country - religion, aiga [family], especially parents. They are the future generation, the ultimate importance. Children advise strongly to parents in relation to improvements and developments within the family.

In the rural focus group discussion, emotions ran high at the very thought of foreign tourists travelling to Samoa to sexually abuse Samoan children. One of the female participants, a mother, sent a stern warning to any child sex tourist attempting to sexually abuse her child:

Tourism is good for the economy of the country - the tourism industry is good for the economy of the country's development. However, if this is happening to the extent of breaking the law and customs, then stop this honor of tourism. They [the tourists] can come and look at the country but do not do such evil ways here. The bad side of tourism is harmonizing the bad attitudes of tourists with the future generation of this country, our children. Sex tourism is unacceptable. If the people are aware of this, I believe there will be a bad reaction from the people of Samoa because they care about the safety of their children. I disagree with tourist's behaviour like that. Money is not the only issue. They underestimate the reactions of the people of Samoa if they just come here to harass the children. If I personally come across any of those acts, I will kill anybody that does it here in my country!

An older participant in the civil society group talked about the difficulties facing parents to raise their children in today's modern and troubled times. He explained:

Samoa is a Christian country, we value Christianity as a one of the very solid foundations of belief; and that is why the culture of Samoa is unique. In addition, we can see introducing this Western style, shaking the foundation, the mind of people, leading to uncertainty. That's why I think the people of Samoa should look back and build up that foundation, a solid Constitution to stop any kind of Western style taking over our values. Western influences make the founding document [the Constitution of Samoa] unstable, 
uncertain of working in today's global climate. Increased tourism, TV, internet, expats returning home bringing in new Western influences; the foundations of the Constitution of Samoa are shaky like lue; it is like lue, you shake it, but shaky ma-lue-lue that is the uncertainty. The foundations of the Constitution are shaking so it's not stable. How do you make the foundations stable? How do you stabilize family in today's rise of western influence? Who wrote the Constitution? Smooth $f a^{\prime}$ ' -lue is a different meaning in the Samoan translation. That is a nice smooth environment like a swinging pendulum of a clock. Samoa is not swinging like a pendulum clock.

\subsection{Perceptions of Tourism}

This was a question used early in discussions to determine if people were identifying increased tourism with CST as The Committee had risen in its recommendation to Samoa. Given the view that tourism was the engine of economic growth for Samoa, this question was hotly debated, generating positive and negative answers depending on the participants' situation.

The positive views of tourism lent much more towards economic growth for the betterment of the country, improved lifestyles for Samoans, as well as tourists, and hosts interacting together contributing to long term - friendships and children's education. All civil society participants considered that the tourism industry had grown exponentially over the last few years, and had contributed much needed economic growth for Samoa, and an improved lifestyle for those villages with beach fale accommodation. Urban and rural focus group participants spoke highly of tourism for Samoa's economy, as did taxi drivers. A civil society participant explained further:

There are tourism positives for people nowadays, especially for those villages with beaches. The positive impact is they are becoming more business-minded and improving the landscape. In the last twenty years when you travelled to Samoa, there was nothing; beaches were bush. So, tourism is positive for the environment. Not only that, but villagers are utilising the available natural resources that are available. 
In the taxi driver survey, all seven drivers had focused more on the 'cash' side of tourism development and the money they received from tourism. This was not surprising given this was the job that they did to support their families. Tourist dollars provided much needed income. For some, it was the main source of income, although most dives supplemented their income from other sources such as shop keeping, security work, fishing and farming. Taxi drivers were positive about the personal economic benefits of tourism. Three of the seven drivers had moved from a rural setting to work in the urban centre, with one commenting, "the oldest can now manage the farm and the wife look after the shops."

The question to drivers about if tourism had made them better off economically, net from four taxi drivers the following answers:

Yes. Tourism industry has improved a lot from the last few years. It has provided us with more business than in the past, although I'm studying at university, so it's quite hard to drive a taxi and take care of my family who relies on me as well.

No. Not many tourists touring around the two island like before.

Yes. Better money, but sometimes-long hours. The money is not enough. Some days there are no jobs at all.

No. Long hours and the money is not enough unless overtime. That's why I drive taxi after work to help raise my kids, pay school fees, get their lunch, and pay other bills.

The taxi driver, who had noted a downturn in tourists sightseeing trends, was open-minded to new tourism ideas and ventures to bring in more money. He said, "Need more tourists to bring more money to the country; we need to bring in new ideas to secure a good living in families. Tell villages to improve beaches to the standard they need." 
Education opportunities were another positive cause for increased tourism. For example, tourists were funding educational secondary school scholarships that enabled Samoan families in hardship an opportunity to provide their children with a secondary school education. The participant explained: "From Level 9 upwards, this is a difficult area. After Year 9, the parents won't send [children] to school because of the money. So a student at college level who is failing because of the cost, those are the ones we target."

Tourism was viewed as enabling overseas 'guests' [tourists], the opportunity to appreciate Samoa's natural beauty and splendor. Urban focus group participants viewed international travel as contributing to world peace. Nearly all of the taxi drivers wrote that learning about a tourist's culture, in addition to forming friendships, improved their own reputations expanded their knowledge base and enhanced their positions in society, therefore they were known as 'good' tourist drivers because they knew how to meet tourist's needs. Comments included "Every tourist I [have] been driving around is a learning experience for me...different personalities. I really enjoy working in this job to improve my reputation...I answer questions tourists ask and explain things they come across."

While many participants appreciated the money tourists contributed into the economy, there were many negative comments about tourism. These were largely framed in tourism impacting on the fa'asamoa way of life, what it would mean for the future, and especially what they termed 'tourist bad conduct' negatively influencing Samoan children. An older male in the civil society group mentioned that along with rising tourism, Samoans needed to maintain their customs, values, and traditions for their children's sake. The impact of tourism and tourists on the Constitution of Samoa was another contentious issue, likened to the very fabric of the fa'asamoa, ripped apart by tourism.

Discussions in the civil society group lingered mainly on the lack of community consultation around tourism development. Consequently, people were very suspicious of 
tourism development because people did not know where the government and tourism policies were taking them. A civil society participant remarked:

The topic of your study is a big question we ask now. We can see there is something shaking the Constitution of the Samoa, and the culture, as tourism increases in Samoa bringing in the influence and CST. There is a big impact going around, shaking, the foundation is shaking. The people don't seem to know where they are heading, with customs, values, and principles. We should look in areas that Samoa is still holding, building up that solid foundation so that Samoa is not shaking again, because we can see what is going around.

Rising tourism was considered a contributing cause to 'more sex tourism', alluding to an already active sex tourism industry operating in Samoa. In particular, participant's opinions were that increased tourism would contribute to an increase of STDs and HIV/AIDs in Samoa.

On this point, a participant relayed a story about a past sporting event held in Samoa. Reportedly, a number of countries had attended the event and condoms handed out in athletes packages. However, an official on moral grounds removed the condoms. According to a participant, pressure was put on the official to reinstate all condoms. Although condoms for males were reinstated, female were not. The participant then referred to an earlier study that found Samoa had one of the highest STD rates in the Pacific. The participant also considered that a program or programs should be put in place to prevent the spread of STDs for locals and tourists, and that if the government was attracting tourists to Samoa, there should be a policy for sexual health protection for both.

In the civil society group, one participant, an hotelier, discussed the unregulated tourism industry, particularly, several taxi organisations operating in Samoa but no taxi industry body, considered a weakness of the tourism industry. The participant pointed out how attempts had been made to resolve this issue with the Samoa Tourism Authority, but 
to no avail. The participant suggested that the taxi driver glut might well push taxi drivers into facilitating CST because drivers would be competing for fares.

Other civil society participants considered 'tourist bad conduct' was a major downside of tourism development. Tourist bad conduct was described as female tourists wearing inappropriate clothing in and around villages, especially women in bikinis [nudity], and couples kissing on beaches where children watched. As one participant in this group stated: "This type of bad conduct is not good for our children to view because children may be tempted to replicate that behaviour, so [it can create] bad attitudes for the future generation of Samoa. The children think, OK, let's go with it".

Another civil society participant said villagers were the ones who usually bore the brunt of 'tourist bad conduct'. One older participant reminisced back to vatapuia 'relational space' between people once operated in Samoa and should operate again, even in today's modern times. She used the Samoan concept of vatapuia as an example:

There is this thing they call the vatapuia that is, the sacred space between individuals - as if you had a space. If you look at the Samoan way of life, you all lived in the fale, which had no walls; what was yours truly was. It was your space. People always respected you wherever you went. People will say you give respect to everybody because they have sacredness around them and that everyone is supporting of that. However, you know you watch on TV the palagi idea of space; they're always up into someone's face.

Participants of the urban focus group also felt that bad tourist conduct affected the children who observed them. In the rural focus group, they were irate about the absence of a tourist code of conduct to manage tourist behaviour in and around villages or other places where tourists converged.

Following a lengthy discussion, the view was something had to be done:

Should have pamphlets for awareness - things like that - so the tourists coming over are aware that the tourist is not allowed to walk in the village because it is prohibited. 
Owners of beach fales should let tourists know they are only allowed bikini and top where they swim. They can only walk on the beach with bikini but not inside the village.

This group then suggested that tourists should know their boundaries and be told, "This is your perimeter." In the taxi driver survey, four of the seven taxi drivers described 'tourist bad conduct', as "the tourist telling drivers that they disagreed with the way religion was practiced in Samoa", to "disputing fares", and "looking down on taxi drivers, to "always thinking they knew better." Not all participants held the view that bad tourist conduct was influencing Samoan values and traditions. One of the younger NGO participants in the civil society group asked: "Well, who is making the changes?" and added, "Let the tourists be." He explained:

People make changes by observing. That's what I've learnt applying to situations here. When they want to change the Samoan house to a palagi house, you get rid of that Samoan house that you have to maintain every three months because that palagi house thirty years on, the roof is still strong. Just because overseas tourists influence change, like how the tourists dress and act, you can't just go to them and say, you can't wear your bikini there, because, that's not how we do business, so let them be.

But when they do other things that they do on the beach, and people are looking and adopt some of the palagi ways, then things change little by little. If they don't maintain the natural scenery then this changes will make kids go the other way. So I think it's a bad impact if we don't put up programs or alternatives to keep the naturalness of the culture.

When you talk about the weaving, the tourist from overseas wants the coulored things. Now there's modern ways of weaving, things change, people want to get modern materials. See my bag? That is not Samoan because the product is not 100 percent. It's a global bag. The taxi driver in the past he knows there's a big change on the way. I don't think the Samoan can sing as he used to sing. Kids adopt these things not only actions but also verbal things. 


\subsection{Perceptions of Child Sex Tourism in Samoa}

The previous section of valuing of child and the mixed views of the benefits of tourism had set the basis for the discussion of the following two research questions, 1) perceptions of CST in Samoa, and 2) perceptions of the root causes.

In general, participants appeared open to discussing their views on this question about CST in Samoa based on inside knowledge and experiences. In discussions, there did not seem to be any noticeable silence on this issue. Some participants stated that the research was long overdue. As the discussions evolved, a consensus emerged across all groups. Responses in each group varied with some participant's opinions that CST was an issue, others saying it were not, while others did not know. Government and intergovernment, civil society, the urban and rural focus groups and taxi drivers, to give a sense of perspective of the issue of CST provided by each group. In this part, I include two-eyewitness testimony of CST happening in Samoa, including my own observation during fieldwork of child prostitution operating in Apia.

\section{Government and Intergovernmental}

The senior member of government was unsure if CST was a problem in Samoa, but conceded: "If you have 100, 000 tourists, you can expect one or two or maybe more will be coming in for different reasons." Likewise, the intergovernmental participant did not know if CST was a problem. At the same time, the participant observed that sex tourism in general, has "always been there." A senior government official differed, stating, "We know for a fact [that CST exists] - there's a lot of evidence out there. It's a matter of convincing the people responsible for policy development and law reform to do something about it. It's also to do with different sectors having their own priorities."

The Samoa Tourism Authority employee did not know if CST was a problem in Samoa "because there had been no reports to say otherwise." In contrast, a participant from the Samoa Hotel Association said, "Most of us who are in the upper level of our 
tourism industry, we are all geared to that - we know there are things happening. I know this is a problem."

A senior police officer of the Transnational Crimes Unit, held a more staunch approach, probably because of his job. He considered that CST was a major concern and that tourists could easily exploit young Samoan children. He continued, "...like any other Pacific Island countries, we are not immune from this disease - it's a major issue. I think any organisation over here involved in trying to combat this issue is very concerned at the rise." He said that currently, three investigations were underway in Samoa. The persons under investigation were all male, two tourists from Australia, and one from the United States. Two other members of the police force concurred with the senior officer's view. One commented: "Yes, we do consider CST a problem and the sooner the better to resolve this problem. Because it is now a problem in Samoa, I would be very glad to see that people of Samoa must be aware of this problem."

\section{Civil Society}

Civil society participants appeared to have more knowledge about CST operating in Samoa and spoke freely on the topic. One NGO worker was of the opinion that "Samoa is becoming a country with a problem of CST and a possible destination country for tourists to seek sex with our young children." A senior researcher said young boys were involved because of the adult $f a$ 'afafine behaviors. In the participants view: "There is homosexuality in Samoa; it is being practiced openly. People are turning a blind eye and they're not connecting it to a sin and that is wrong."

One participant reported CST was happening in the rural villages, and that "no report had come out about it yet" Another NGO worker provided scope telling CST was happening in urban areas, within the boundaries of Apia, and rural areas outside of Apia. This participant said "It all depended on how the relationship had been formed, the length of stay" and thought it was easier to locate pedophile tourists in the urban areas than in the outside villages." He said: 
There was a van going round stopping at children along the road. He was giving them cakes and lollies so when a child came in, that one child will be the main target, and that child will go and ask another child, will they come back another day. He will pick them up - unseen, but it's happening.

\section{Another civil society participant said:}

I think this is an issue that should be taken up seriously. Because tourism is increasing and this is part of tourism, if we continue to turn a blind eye to it [CST], we will end up being a haven for this kind of thing. But hey, it has to be taken up seriously by the authorities. But we certainly have a problem. We need to do something now. Look at the numbers coming in. Imagine 100 tourists coming in. Imagine at least five slip through the net. To put all your eggs in one basket is a bit scary.

I think there are some classic cases already. I don't think the government and the church should turn a blind eye anymore. I think it needs somebody to say, "Yeah, this is the problem." I think, especially at the moment with so much happening with the financial crisis, people will turn a blind eye. Yet it's an emerging issue. Might as well intervene now than to wait until it's serious and will cost us more to handle.

\section{In the words of another participant:}

I've heard that the people that are working for the [donor agency] were staying in Samoa and I heard that they were with young girls in nightclubs, and that they gave the girls some money. People are looking for that [sex], especially the palagi, I think it's the mentality. I think it's the same as the Samoan boys. So probably, we can't just keep away from that bad thing. They don't go to those girls to have a good relationship but to exploit them. It's hard to determine.

\section{Urban and Rural Focus Groups}

The urban focus group assigned to answer this question believed CST was a problem, although only a recent one, although this group was undecided about what to do next: "It has existed, but recently, we need action now, period, but how?" The rural focus group 
participants also believed that CST was a problem in Samoa. They said, "CST compromised the welfare and safety of Samoan children and that it should be stopped." Closing statements included "It is a very big and dangerous act and should not be happening here in Samoa. It should stop now before it destroys the system of Samoa and her identity." At the conclusion of this discussion, my cultural advisor told me, now that the high chief was aware about what CST was and entailed, he remembered an incident involving a young Samoan girl and an old tourist living together and that the tourist was helping the family out with the upkeep of the family home.

\section{Taxi Drivers}

I had assumed that the taxi drivers could be less inclined to talk about this issue for fear of placing the tourism industry in a bad light. Nonetheless, just as the policy and practitioner participants were open on this issue, so too were the taxi drivers. Four of the seven drivers believed that CST was a problem in Samoa, having heard either about it or from direct experience.

Their comments included the following remarks:

Yes, it is already happening here in Apia, also in back villages but has not exposed yet.

Yes. Heard about it but no report seen so far.

Yes. What I've heard, but I haven't seen it happen.

Yes. Need money.

One of the four taxi drivers talked about how a cruise ship tourist had approached him, wanting to know where to find sex with local prostitutes, girls, and boys.

Well, the negative side is the single male tourists that come to this country, some want to look for prostitutes to have sex with; also, some gay men want to have sex with young boys. I told them that Samoans are not like that. I said our girls have value; they are not 
street girls. I was sad when they asked me for that. I felt like hitting them in the face. But I went home.

One other driver was not sure. He said, "I don't really know. World is moving forward and whatever happens overseas it will eventually get here." The remaining two drivers thought that CST was not a problem in Samoa because "Churches were teaching children to be good by learning from the Bible." The second driver elaborated further: "Because I'm sure they [the child sex tourist's], know about Samoa and its culture. I think it already happens in Samoa few years back but the Samoan culture plays a big role in the children's lives. So I'm positive that parents handle their children quite well by the looks of it."

\subsection{Eyewitness Testimony and Direct Observation}

Two eyewitness accounts of CST operating in Samoa were included in this thesis, although, heavily edited.

\section{Account 1}

[Participant]

This happened in 2007-2008. There was a young boy. I think he was 15 . One tourist took him out. He [the tourist], came here, made the relationship with that village. The 15 yearold boy, a fa'afafine, is from this family in the village. The family had been in touch with the tourist through the internet. The man went out of the country and come back again. Then he take this [photos] of this sexual act with him [the boy]. Then the tourist he introduced another one [boy] and another one [boy] and girls. So, when this young boy saw that this was going to be a big thing, the boys having sex, and him [the tourist] taking photos, the boy reported it. The boy came here [to my office] and he was crying. He goes to [.... College] The boy said, 'I'm ashamed to explain.' Then we talked about it. I stood up and comfort him, and he let it all out. I said 'you go and ask these people [remaining victims] to come here and we have a talk all 13 of them starting from one person.' 
[Researcher] From which country?

[Participant] Peru.

Then I hold the man who was responsible. I was concerned for the children because their names will be in all the reports. All the children came in here. They talked about it and apologised. The only good thing was there weren't any sexual acts [with the girls]. So, when they came in they just apologised to the system. The main thing was he [the tourist] was giving them money.

[Researcher] What were the sexual acts?

[Participant] With him and the boys, the acts were with the fa'afafine, just to them and then he started to take photos.

The participant explained that the once the tourist had sponsored the boy's education, then the grooming process had begun. Sponsorship enabled the tourist to return to Samoa often under the guise of checking the boy's progress at school. Taxi drivers helped:

When they come, they go to the taxi-drivers. That's what happens. Sometimes they go from the hotel with the taxi driver and they make friends if the tourist stays here for a week. That's another way. Then the taxi driver helps. They will not go to that family but the driver will know go to the school and have this meeting with girls, those are the target ones, because he has a very good relationship with family. The young ladies or young children at high school or secondary school, they are the target of that person because he has the good care of that family. He will think of them as his target too. 


\section{Account 2}

[Participant] There was a white man doing that [sex with children] in his pickup. He would pick up girls. My friend was looking for this tourist. He had come here as a tourist, went back to his country and then came back to Samoa. He [the tourist] did not know how long he was staying. I asked my friend what his name was. He gave me his name and a description of his appearance and I thought that I had seen him. We hopped in the car to where I had seen him, and by chance, we passed him on the road talking to young girls. I asked, "Hey, what are you doing?" The tourist was very old and thin, maybe 64. Then these young girls say, "He always does this to us." Not only was he doing this with this girl but with some others.

[Researcher] How many others?

[Participant] He had had sex with six girls under the age of 16.

[Researcher] What nationality was he?

[Participant] German.

In many informal conversations, participants would tell me where CST was happening in and around Apia, day and night. One story was current, about three young girls participating in prostitution in the Apia centre, facilitated by adult fa'afafine. After the local nightclub had closed, one fa 'afafine would front for punters and walk up and down the sidewalk while another would lounge on a concrete wall. When a driver had stopped and the two talked, the fa' afafine would motion to one of three young girls (hiding behind a bush on a seat) to go with the driver of the car. I decided to follow this story up.

That night I went to the Apia central area after the nightclubs had closed. In company with my cultural advisor and another male observer from the church, we 
observed an incident happen almost exactly as had been described by the participant earlier that day. Because this incident involved children (minors), and prostitution is a crime in Samoa, the incident was reported to police. Some months later, the feedback that came back to me about the incident, was that the punter an employee of a New Zealand company, was deported back to New Zealand under a Memorandum of Understanding between Samoa and the perpetrators company.

\subsection{Perceptions of Root causes}

In the previous section, there was strong consensus that CST was clearly a problem in Samoa; a number of examples supported the claim. This section presents participant groups' answers to the question, "What are the root causes for CST in Samoa?" Following data analysis, ten themes emerged:

1. Financial pressures

2. Hospitality and 'the tourist as trader'

3. Sex tourism

4. Family breakdown

5. Legal process and law enforcement

6. Data collection

7. Gender bias 'Marginalisation of boys'

8. The child as individual and the right to privacy

9. Donors - Tunnel vision

10. Ifoga / Shame

\section{Financial Pressures}

According to a civil society participant, poverty had always existed in Samoa, and, paradoxically, it was because of the high standard of living of the rich. There were divisions between the rich and the poor societies in Samoa. He explained: 
There are two kinds of societies in Samoa the rich and the poor society. The rich here enjoy, they can afford, and they are high-ranking people, the business people. When you talk about the rural communities, those people suffer because they can't even afford a mutton flap. It's not just a high standard of living; they just don't have enough income.

One senior officer of the police said she could accept that some people were in need of financial support, but stated, "It is poverty that draws the interest of Samoans to tourists," reiterated in the interviews, focus groups, and taxi driver survey.

\section{Hospitality and 'The Tourist as Trader'}

While poverty was seen as the underlying cause for CST in Samoa, the phenomenon most often talked about in conjunction with poverty was hospitality, or 'over hospitality' and the 'tourist as trader'. For example, "Samoan families provided hospitality and offered trust, which the tourist took as an opportunity to 'pay his way in' and abuse Samoan hospitality." (NGO)

'Over hospitality' was habitually offered, and "the palagi turns around and pays in another thing, "sexually abusing our children." He said that things could go either way, alluding to families facilitating this practice. He said, "Samoa is a very enclosed culture people can't just walk in - unless there is a built - up relationship then things start to go both ways." He talked about the community needing protection from the 'global savvy' tourist.

The culture of hospitality was a Samoan habit. Two NGO participants talked about how, over the years, Samoans had been pushed to be friendly and hospitable and how this type of tourism promotion had been driven into the Samoan psyche to apply when dealing with tourists. Comments included, "That's the perception we have...a customer is the most important. But it doesn't mean they can come here and do whatever they like." A longer comment was: 
There is a saying in Samoa, 'palagi have sweet lollies'. Sometimes a tourist comes in and goes to a family, the family helps the palagi out, but he has other things on his mind.

Here he is a foreigner, so we have 'to love him.

Another of the NGO representatives said that despite hospitality being a traditional and popular custom in Samoa, these days hospitality was offered with caution. He explained: "When I was young, the tourists come to families with a clean heart. The Samoan will share the Samoan experiences, but nowadays-big difference. When you look at the tourist, you can tell there's something he's thinking of." He explained how tourists groom families so that the abuse can start:

They say to the family, "When I come back I will build this for you." So, when a tourist comes in and offers money, they accept it. But, that is the way the tourist gets in to find a way to have sex with the young people. Once a tourist creates a relationship with a family, they then leave the country but then come back, go home. Because Samoa is a very enclosed culture, people cannot just walk in unless there is a close relationship, and then things go both ways.

The participant said that the high cost of education and the lack of financial prosperity created vulnerable families to these 'tourist types'. He explained:

We have a sort of habit, hospitality of us towards any people - so when a palagi comes in our families show hospitality. Another thing in our communities, there are some poor families with a big population of people in the family - so when a tourist comes in and offers money they accept it. But that is the way of other tourists to find a way to have sex with the young people. That is sometimes the poverty of the people and showing hospitality. They lie to people, to the grassroots families who have limited funds. Our people we needed finance for schooling and for family problems - so when they see and hear of a traveller or foreigner coming in and offers this sort of thing they accept it and show their appreciation - but they don't know, he's paying his way in - especially those sort of payment to stay here for three to six months. 


\section{Sex Tourism}

Prostitution operated in Samoa. Prostitution was raised so often, it appeared as a commonly accepted part of Samoan life people accepted, but did not know how to combat. For example, in the government group, it was stated: "Two people have said this: a mother pimps her daughter at the market. What should we do about it? What can we do? Nothing! You can go there now and see it happening." According to this participant, prostitution was rife and that people who had left Samoa some years earlier had recently returned and could not believe how much the country had deteriorated because of more tourism and more prostitutes.

Homosexual / gay sex tourism was less talked about but alluded to often. For example, only one civil society participant talked about homosexuality and homosexual tourism involving fa 'afafine adults and boys' involvement. The participant explained that some years back there were one or two boys who were effeminate, but that was nothing to do with 'homosexuality'. However, "these days you could tell boys were sexually abused

when they were growing up and child sexual abuse is currently one of the bigger issues in Samoa." In the participants view, the underlying issues for the sexual abuse of boys by tourists were that "homosexuality was practiced openly in Samoa and people were turning a blind eye to it and that the Church condemned homosexuality, but they did little to stop it." The participant explained:

I think about the ban of the movie, Milk, the fact they didn't show it. People who make the decisions think there is no homosexuality; they won't accept that there is. It's almost like they are being naïve; pretending it doesn't happen. They don't want to rock the boat; they don't think about it; they don't make it an issue. Because the guys doing it don't want to face up to the fact that they are sinning, they are doing harm in some way, no responsibility.

In an informal discussion with a senior health professional, our discussion turned to the fa' afafine, and sex tourism issue. The participant had not really noticed this 
correlation. Although the discussion turned to the increased trend of secondary - school aged boys displaying fa' afafine tendencies toward the end of the school year, maybe not a development issue other than it corresponded with the height of the tourism season and sex tourists demand for sex with transgendered boys. She felt that this phenomenon needed more investigation.

\section{Family Breakdown}

As noted, aiga [family] is the main organisational unit in Samoa. Despite this, across all groups were strong views about the breakdown of the traditional village and family systems. According to one civil society participant, children had a place in the system when they were born, but now many children did not realise their place because it was not passed down as before. She said that children were taught which village they were from, so that was where they belonged, regardless of whether a girl or a boy. Nevertheless, problems arose when the child left the system or did not live by that system.

Poor supervision of children was another issue raised. A civil society member expressed her concern about some parents who were not watching their children, as they should. She said that whenever she went to Savaii, she often thought about the children walking around unattended and there was no sense of security. She felt that parents cared about their children, but were often naive about how unsafe it was for them to be walking around unattended. She continued:

The importance of worrying about children walking to the shops; we have cases of children taken or lost but it doesn't give them a scare. People used to be watching, but people don't anymore. Their minds are focused on different things. They don't really watch out for each other like they used to do. 
An NGO participant explained that there were many problems facing children and youth today. He talked about children living in families in which there was physical, emotional, and verbal abuse. He said that this mainly occurred when a child went from a rural to an urban family. He explained the situation:

Lot of problems, faced by the young people especially children. Like the CRC is children under 18, but the government of Samoa legislature defines children as 16 and under. I still work under the CRC guidelines. Also, there are many problems, as a person goes from a rural to urban family; I have observed this for so many years. For example in the family sections there is that culture, I don't think it's a culture it's a way people believe in themselves, but it's not a culture that a child should only behave because you hit them for a mistake, throw a stone. That's a way we discipline children. Most of the children had been abused, especially physical. Most of the children have lost their knowledge because of that. I didn't collect any data or evidence from the police department but I believe that there are many abused children living in families suffering physical abuse and emotional and verbal abuse.

\section{The participant explained that certain forms of abuse aligned with the child's} gender:

I'm not sure because when you talk about hitting then I think many boys are verbally abused, I think boys is the most victims. When you talk about the rape, incest and all those things then I think the girls are more victims of these abuses, I think sexual abuse is their worst. I think fa 'afafine suffer towards the girl's side of sexual abuse. Put in line with girls abuse. It's hard for us to put the fa'afafine on a separate agenda. Here in Samoa people always deny the fa 'afafine perspectives. I am not sure why. I don't know. I'm trying to work it out for certain reasons. Once they talk about fa'afafine, they talk about male gender. In my knowledge, a male gender has a different feelings or perspective from with people with a fa'afafine gender. They have their own feelings and perspectives that are different from men. That's the mentality of any Samoan. You speak on behalf of the fa'afafine they get so upset. 
All taxi drivers listed some type of family dysfunction driving CST in Samoa. Comments were a lack of parental or adult supervision and parental neglect as the most important circumstances that placed children at greater risk to sexual exploitation. They raised circumstances where there was no mother or father at all; that parents were separated, deceased, or old; or where children had their own free will or were orphans; or where children's upbringing was by different families because they had come from broken families. Another issue was the increased trend of child vendor's not in school because they were out on the street selling items to support family. A participant in the civil society group considered that the children who were not in education were much more vulnerable because they were more exposed to the risks of abuse. "We are quietly concerned about the increase of child vendors, that's one way of shifting roles...kids earning."

\section{Legal Process and Law Enforcement}

Another underlying cause often raised was the lack of a legal process and law enforcement. One senior government official said that one of the bigger issues inhibiting child protection efforts in Samoa was that despite many programs having been implemented on the ground, this work was not reflected in policy or of efforts that organisations and agencies were making toward legislation and law reform. Her view was that the people responsible for policy development and law reform should do something about it; that often people would say legislation is lacking, when the problem was that a large proportion of current legislation was still not enforced.

One NGO participant said “The police, they don't know who to deal with, and do nothing." Unclear reporting mechanisms, confusion, or ambiguity about who people should report suspicions or firm cases to, were also seen as root causes of CST. As one Police participant said: "People don't know where to go to report to. They don't have a solid built-up system to deal with this issue." 


\section{Data Collection}

Three participants raised the need for new research. One was a government participant, another was a senior researcher, and the third was an NGO worker. The government participant commented that the lack of research was "a weak area in the work that we do and we know it. It's also one of the things which is limiting the attempts to facilitate [the $\mathrm{CRC}$ ] commitment to making data available and statistics to support the kind of arguments we are making."

A criticism made by a civil society participant was that the government employed young graduates to do research and because of their inexperience, they were regurgitating the same data instead of finding something new. This participant suggested, that CST was unlikely to be looked into because researchers who wanted to dig deeper, were stifled by what the government wanted researched and appeared in the research. She said:

You have to put it into context, sometimes, when you're just trying. I keep thinking about how great it is, this education, but many of our young graduates have gone overseas and come back and because of their lack of experience, they just reach for these things. Look around, a lot of the ministries, a lot are just graduates who haven't had that much experience in life in that sense that they're just regurgitating stuff they've read, and without thinking - is this really what we need in Samoa? - Should we really be doing it this way - but then maybe government has policy to do it because that's where the money comes from - because the United Nations does it this way or the UN might stop the funding - but still we need to have values for ourselves, don't we?

According to a NGO participant, "To just see the whole number is the problem how do we know it's not big? That's because they aren't doing the research.

\section{Gender Bias: 'Marginalisation of Boys'}

Another issue was the work of CEDAW. Women and girls' lives had increasingly improved; however, one civil society participant was concerned about a lack of programs 
for men and boys. The participant considered boys were the 'lost people of Samoa' and all the problems affecting children were because they did not know where they were heading and had lost themselves because of what was happening in society. She said:

I don't think CEDAW helped us with its Decade of Women. It didn't help the boys; it helped the women. I feel so strongly, I always ask, "Look around you - where are the boys?" Those men who were expected to become good farmers are sitting idle because there's no training for them to become good farmers ...just all the things coming through the women's committees and not for the men.

The participant asserted that boys would one day have families, although she had been looking at this one family in particular who were struggling because they had no money. On the one hand, while the girls in this family went to school, the boy had left school to work in the plantation. As continued:

So when he grows up, what sort of a life is he going to have? He has had no training to do with these things, so it's going to be a vicious cycle. What about the education of boys? Look at all the issues that are happening now, the drugs, where are men and boys going to be taught. They're getting their cues from the TV, videos, violence, because that's all they do is sit around and talk about it - idle hands, up to no good - there is a huge gap.

The participant was of the opinion that the UN were pushing for women's rights, but that they were working with Third World countries where women were really in need, "but then they try to push it everywhere. They have never come to Samoa to see what's happening here; it's a different context." Generally, she believed that men needed leadership training, because a lot of work was for the women but not for the men.

\section{The Child as Individual and Right to Privacy}

Female participants, (mainly those in the civil society group), considered that the CRC's position on child as an 'individual' and 'right to privacy', placed children in vulnerable positions to sexual abuse, that was against the communal right of Samoans 
who were taught to watch out for each other and to see things were "working out for everyone". As one of the older female civil society participants elaborated:

It's like individual 'rights' coming. I'm an individual. I'm no longer part of this whole network of family and stuff, which I think is dangerous. If you go talk to people about the

biggest things that people are against from the $\mathrm{CRC}$, it is always against the rights; "What do you mean by this right of this child?" It's because of the individualistic idea that that a person exists by themselves without a family. It's because really, in Samoa, we never see you as a separate person. It is who is your father and who is your mother your sister and brother. You always see the child as a member of this family or community. You are never seen as on your own.

Conversely, one civil society participant believed that the CRC had benefitted hugely the work for children. In his words:

I think the best benefit for children is the CRC to provide the major law to protect them. For the benefit of children there hadn't been an increase of reports to the police of incest, rape and abuse since we have been conducting workshops and awareness raising to rural areas where we encourage children to speak up on their views on what's happens to them.

Most of the children were taught by their parents to be respectful to elders, instead of opposing them; children just listen, just like the saying, "children are not seen or heard," that is what has happened here. Therefore, once the children were identifying different kinds of abuses, as well as parents knowing more about the CRC, children started to report to the police. So, there's an increase of reports because the police always refer children for counselling and all that stuff. I've seen changes.

\section{Donors - Tunnel Vision}

Yet another civil society participant considered that international donor agencies applied tunnel vision to child protection work. One criticism was donors were not moving out of the 'norm' to investigate new issues such as CST. 
In the participant's words:

Yes, I am guided by these mandates. I always think to myself perhaps if I can make a move, to move forward I cannot just stand here, I cannot just sit here. So I think to myself it is better for me to conduct a research, a survey, because it's not only for children that have been abused - and for children that have been exploited - sexually exploited or for those children who have been commercial sexually abused and not only in the families but outside those areas. You see, there's a lot of exploitation - sexual exploitation is happening in not only nightclubs and tourism, but in other fields, which usually are unknown and need more work.

\section{Ifoga / Shame}

In discussions, an often-discussed key cause for non-reporting was the culture of 'shame'. As noted from one participant:

The fact is that people in Samoa hide things because they do not want embarrassment or disgrace to the family and village. Because of the village system in Samoa, we have to protect our identity and our good reputation of village and family so sometimes we have to hide those things. Not easy to get around. 


\section{Chapter 6: Discussions, Section 2}

\subsection{Introduction}

The chapter drew on material from in-depth interviews with those whom I regarded as having a formal role and mandate in combating the sexual exploitation of children, such as the key representatives of the Samoan government, donor agencies, and NGOs. The focus was on how each agent saw the role of his or her agency, what they were doing, and their views on who should be responsible for preventing CST, and whether they were aware that CST required a holistic response.

\subsection{Views on Roles and Responsibilities}

In all of the interviews, focus groups, and surveys, I asked my research participants who they attributed responsibility for preventing CST in Samoa to (See Table 14. Attribution of Responsibility by Institutions and Groups), below. In discussions, it was common to hear expressions of no organisation working on CST, or no organisation wanting to be in charge of children. Although CST required a holistic approach to prevention, and participants had in fact said 'everyone' was responsible, 'everyone' was only a few.

Generally, the Government of Samoa was pinned down as primary 'responsible', through its auctioning various human rights treaties for children, although, participants felt that the Government of Samoa was not yet fulfilling even its statutory obligations to the CRC, ignoring CST. Moreover, two other comments in the Civil Society group were the Government of Samoa was turning a blind eye to CST. n Regarding government ministries, the Ministry of Tourism with its state-owned enterprise the Samoa Tourism Authority, was identified by the taxi driver survey group in particular, as an organisation with a primary responsibility to address this issue; very many participants felt that Ministry of Tourism should take a lead on this issue and provide CST awareness-raising 
material in the Samoa Tourism Authority fale and tourism-related venues and outlets at the very least.

\begin{tabular}{|c|c|}
\hline $\begin{array}{l}\text { Government Ministry and } \\
\text { Intergovernmental } \\
\text { - Everybody } \\
\text { - Ministry of Police } \\
\text { - } \text { ECPAT Samoa } \\
\text { - Victim Support } \\
\text { - Village chiefs } \\
\text { - Parents }\end{array}$ & $\begin{array}{l}\text { Civil Society } \\
\text { - Government as duty bearer to the CRC } \\
\text { - MWCSD as children's focal point for the } \\
\text { CRC }\end{array}$ \\
\hline $\begin{array}{ll}\text { Urban Focus Group } \\
\text { - } & \text { Everyone } \\
\text { - } & \text { Government } \\
\text { - } & \text { Policies and Legislation } \\
\text { - } & \text { Village council - Village laws and } \\
& \text { protocols } \\
\text { - } & \text { Church - Christian principles } \\
\text { - } & \text { Families - cultural values - parents }\end{array}$ & $\begin{array}{l}\text { Rural Focus Group } \\
\text { - The duty of everybody if they do have the } \\
\text { knowledge } \\
\text { - } \text { The power - the government. All } \\
\text { government sectors that deal with such } \\
\text { issues -MWCSD, Police } \\
\text { - Law } \\
\text { - NGOs ECPAT - Victim Support - MOA } \\
\text { - Villages - Chiefs, Councils and Parents }\end{array}$ \\
\hline \multicolumn{2}{|c|}{$\begin{array}{l}\text { Taxi Driver Survey } \\
\text { - Everyone } \\
\text { - Government } \\
\text { - The Tourism Authority and Police to enforce } \\
\text { - Shurch } \\
\text { - Should be discussed at Village Council }\end{array}$} \\
\hline
\end{tabular}

Other opinions were the lack of responsibility to curb CST from the Law and Justice sector to keep up to date with emerging issues needing new laws to combat such as CST. There needed to be 'specific-to-the-crime' legislation. Comments from civil society and taxi drivers included "State a law for this issue"; "We should have a law to solve this problem if a problem is known." One civil society participant said, "Here in Samoa we don't look at that we don't have legislation against that', while another member of the same group said, "the law should be very specific for CST for awareness for the people." Ironically, police participants implied that there were no systems of reporting. The participant of the TCU told of constraints preventing the Unit's advancement on the issue, mainly to do with needing collaboration from NGOs. Law enforcement was acting in isolation. A National Policy on Children had been prepared 
and a Children's Bill had been drafted which when passed into law, would become a comprehensive code on children.

\section{Law and Justice Sector}

The participant from the Attorney General's Office, Law and Justice Section, reported that the office was currently reviewing all of Samoa's criminal laws including the Crimes Ordinance of 1961. The participant considered that this was an old law. Following the proposed review, he was hopeful laws lacking could be added such as the CST problems. He stated one positive change occurred in 2008 when the Samoa government established a Law Commission. This was significant as the Law Commission was established to investigate care and protection legislation, especially for children. He commented: "If CST laws come under the care and protection legislation or part of our criminal code, that's something for us to consider, but it needs looking into."

A second positive change was that the formal government agencies such as the Ministry of Justice and Courts Administration, and the MWCSD had combined with NGOs and churches to form the Sector Steering Committee, tasked with investigating and reporting on law and justice issues. The Sector Steering Committee formulated a plan with goals aiming for inter-agency coordination. He said:

\section{Previously the Attorney General's Office did its own thing, and the police did} their own thing. Now we can come together on these issues because as a sector it is important that we do not just do it from a government perspective only. We should get the views and input of NGOs and community; this is a formal and more structured way of them having their say in the steering committee...if there's no system or mechanism in place where you can say let's all sit down and look into this, how can you get the information? One organisation, an NGO by itself saying we should do something, is somewhat hard.

The participant was of the firm opinion that Samoa should take a proactive role to try to prevent CST and people should not just sit back and wait until CST became a 
problem. He realised that with the numbers of tourists visiting Samoa, it was inevitable that some of them would be pedophiles, and some would be looking to exploit children. He was not willing to take the approach that it was acceptable to wait until CST became a serious problem, but rather wanted to prevent it now. He considered that having even one child affected by CST was a problem. Moreover, if there were any hearsay reports about CST, then that was a matter of concern. He noted that systems were needed for monitoring and reporting, and added, "Samoa can easily have its laws, but the system was only implemented if CST becomes a problem."

\section{The Transnational Crimes Unit}

Established in 2002, the Transnational Crimes Unit (TCU) operated within the Department of the Prime Minister. The TCU was made up of specialist officers from the Police Service, Ministry of Revenue (including Customs) and Immigration Department, the Attorney-General's Office and the Prime Minister's Office. My participant was a senior officer of the TCU. He explained that the TCU had worked closely with the coordination centre of the Pacific Transnational Crime Network that is based in Fiji. He said, if the TCU received any information from law enforcement agencies in the region (such as from Australia, New Zealand and other Pacific Island countries) about pedophiles coming to the area, it would act.

He recalled how a couple of years ago, the TCU had received an alert from the Australian government about a registered pedophile travelling to Samoa. As a result, when the pedophile arrived, the TCU was all set "to go." For security reasons, the participant could not elaborate on what "to go" meant. However, he went on to say "any registered pedophiles coming to Samoa in their yachts, would be a major problem to The Unit." He added:

We have to make sure we cover them all the time and that's how we achieve this pretty good...the other good thing about Samoa is its location. Most of the main routes, all the major flights are coming from New Zealand and Australia and also the United States plus 
Fiji. The Australia federal police were also working closely with the Transnational Crimes Unit of Fiji and they also have a branch at the airport in Nadi, Fiji...if any known suspects come our way, they will be notified before they arrive...we have had a number of cases in the past.

The participant said that at the time of the interview, the TCU had been working on three active investigations of pedophiles travelling to Samoa, one of whom was a frequent traveller to there. He said that the TCU had also been involved in child sex tourist profiling work with the Customs and Immigration Departments. In addition, the TCU had played a major part in changes to Samoan legislation about tourism issues. He said that following investigations, the TCU had presented a report to the Attorney General and the Cabinet "so we also played a role in that matter."

The TCU also collaborated with the STA on some cases after receiving a tip-off about a tourist who was filming pornography on one of the islands. The TCU did not have a contact on the island so the official explained how he was looking for someone who knew the family of the locals who were involved there. He contacted the Samoa Tourism Authority and they did some initial investigation. In his view, 'to get on top of the problem,' the TCU needed public assistance. Furthermore, a partnership with NGOs would bring in invaluable information. He considered the Mapusaga O'Aiga, the longstanding NGO group, to be the best one to work with and commented further:

We need that; we cannot just sit without them. We need to exploit that. We need to get more people involved, more organisations. That will be the only way to combat this issue. As law enforcement officers, we cannot do it alone unless the public will give us this information. That information will be vital for any successful prosecution.

In earlier discussions, participants wanted reporting mechanisms up and running on this issue as a repository to report CST. I asked why there were no reporting mechanisms in Samoa to report CST suspicions or incidents. He explained the Police Community Awareness Program was on-going and that it was traveling the country and 
giving presentations on issues of child protection, such as awareness and reporting and that the Police Community Awareness Program was the primary contact and they "will relate, transfer all the information to us to continue the primary investigation. They will be the people; they will contact us and give us the information...any information related to child pornography for example, would be referred to The TCU and then the investigation would start."

\section{Intergovernmental: UNICEF}

Since 2008, UNICEF has been based in Samoa. Samoa was a child protection priority country for both UNICEF and UNFPA. Other countries were Fiji, Vanuatu, Kiribati, and the Solomon Islands. A National Liaison Officer operated in Samoa, jointly funded by the two agencies, although administered by UNICEF. The Officer supported planning, management, reporting attending in inter-agency meetings/processes related to the overall UN Coordination and Programs, in regards to UNICEF and UNFPA under their Child Protection Program and Bureau of Statistics activities.

The UNICEF participant advised me that although UNICEF had not initiated or collaborated in any CST work, some important CSEC work had been done. Positive actions raised were:

1. Funded the aforementioned abandoned situational analysis on CSEC and CSA in Samoa. The money was returned to UNICEF;

2. Assisted to develop the National Plan of Action for Children (2008 -2012);

3. Funded the TALAVOU, a Youth Project: UNICEF, the UN Population Fund and other UN agencies had all pooled money for this group to become operational);

4. Funded a reproductive health initiative;

5. A gender-based anti-violence project;

6. A UNICEF-funded child protection baseline survey (to be undertaken in 2009) and;

7. Working towards child-sensitive facilities and effective recovery and reintegration measures for victims as included in the National Plan of Action for Children (20082012). 
According to the participant, UNICEF had funded a large child protection research project in 2009. The participant did not think CST was included in the project. The participant conveyed at that time of our interview, CST was not a UNICEF priority and would only become a priority if that were what the country wanted, and where the gaps were in the current literature. She said it was up to the researcher if they wished to include questions about CST. I enquired if there were any activities specifically aimed at preventing root causes for CST. The participant replied that both UNICEF and the UNFPA had a big gender-based violence project in Samoa. I asked her how that fit in with CST. She replied, "Because data showed that a lot of children were affected by domestic violence."

My participant was not aware of any capacity building between the relevant authorities and community watchdogs to protect children against child sex tourists. She also believed that no work had taken place on child-sensitive facilities and/or effective recovery and reintegration measures for CST victims. .

\section{Ministry of Women, Community, and Social Development}

The MWCSD participant held a senior role and, although only recently appointed as a senior, had worked at the Ministry long enough to be able to provide valuable historically based views.

My first question was what had happened to the Situational Analysis on CSEC and CSA that Samoa had agreed to in 2004. At the 2007 Regional Stakeholders' Consultation and Planning Workshop on the CSEC and CSA in the Pacific: a Pacific Regional Report, the Samoan delegation reported its study was finalised and awaiting publication. In 2009, the time of fieldwork the report had not come out. My participant said the research was abandoned. Then explained why: 
our consultant. We were not able to see to the findings of the survey. CSEC is an area we began to look into after the process in Bangkok. Then a regional meeting in Suva, Nadi, where we had participated. So, when the delegates came back to Samoa the first thing we did was hold a huge meeting on the issue. This was trying to gauge what people knew about CSEC, mainly for advocacy and awareness. So, that was a huge public turnout, because the target was community leaders. We had the village mayors and the government representatives at the time. That was as far as we have gone...It was a bit unfortunate that we were not able to see the findings of the 2006 survey that was lost.

Despite the data being 'lost', the participant explained that the Ministry had tried to put other measures in place to obtain such material. Each measure was reliant on four causes: 1) Budgetary support, 2) Human resource expertise, 3) Rapid government response to policy documents, and 4) Commitment by partner organisations.

The participant outlined a number of challenges that the Ministry had experienced as they worked to address child protection issues. The first was actions MWCSD had 'put in place' that were not fully implemented. One was the development of the National Policy for Children (2010-2015). This had begun in 2005, with extensive nationwide consultations, with an accompanying report. Yet, at the time of our interview, the Ministry was still waiting for Cabinet endorsement of the documents.

The second was the development of the National Plan of Action for Children (2008-2012). The National Plan of Action (2008-2012), had been a collaborative effort by stakeholders - both government and NGO - with an interest in this issue. The fiveyear plan set annual targets to line up with the national budgeting process. It also listed stakeholders who would collaborate in delivering against the planned outputs and what they would do such as take responsibility to deliver. In the participants view, the Ministry knew that it could not achieve everything listed in the Plan due to resource constraints and commitment. The participant said, "The Ministry was not able to do everything it wanted to do with its budget"; and "it was hard for the Ministry to get commitment when it came to work on children's issues." 
The participant acknowledged that programming and knowing the linkages and synergies, which could be achieved across programming, were weaknesses in the Ministry's work and thought the Ministry was the only one trying to coordinate the vital linking between organisations that other organisations should be doing:

They are not putting in the necessary effort, especially when it came to the commitment of resources - and you know, people can continue to have meetings, many national committees, but we can talk all day long, but when it comes to the doing and commitment in terms of resources, it falls apart.

A third activity by the Ministry was the Child Protection Information System through the Pacific Children's Program. The Ministry had travelled around Samoa trying to obtain information to update their data.

This participant considered a major breakthrough was a Policy for Women and Policy for `Children included in the Samoa Development Strategy (2008-2012):

If you look at the new Samoa Development Strategy (2008-2012), for the first time they have referred to the Policy on women and the Policy on Children, as the over-arching framework for the work on the advancement of women and children protection and for us that is a huge achievement.

The Ministry had been working to ensure that its top-level documents were reflected in sector and ministerial planning through their corporate plans, and hoped that the Policy on Children ( ) would be the driver that facilitated how children's issues are reflected at sector and ministerial level. My participant said, "But you know, it is very hard to get people to realise the Ministry of Women is not the only ministry responsible for children's issues."

My participant turned the discussion to 2005, when the Ministry had prepared its first National report to the CRC Committee. The Ministry had assessed legislative compliance on the CRC and shared it with the Attorney General's office with the 
understanding National child protection legislation would be introduced. The participant said:

One of the things is people have different perspectives on legislation for children. Now there's definitely a position that says, we don't need new legislation, we have sufficient legislation, we just need to amend them." Others say, "Yes, we need new legislation, the existing legislation is not sufficient".

A fourth Ministry initiative was the Community Facilitation Package, through which the MWCSD had trained community facilitators to facilitate dialogue to determine what strengths existed in their communities, how they could work to build on those strengths, what weaknesses were there and how they could be overcome.

This participant had a realistic view, based on personal experience, about the causes that affected the Ministry's ability to further its work. First was the need for data and statistics, to facilitate and strengthen national commitment to support the arguments that the ministry was making. This participant said that after the Situational Study on CSEC and CSA research was lost, the Ministry had facilitated assistance to do a smaller study from an international NGO; however, the NGO had presented minimal funding that the Ministry felt could not cover the cost of a study, therefore, the research had been put on hold. At the time of my research, UNICEF had planned a second baseline survey (2009). The participant considered that this would incorporate many of the earlier CSA/CSEC data that had been 'lost' or 'abandoned' and would provide solid data on CSEC.

In her view, policies for children, especially legislation, had to be evidence-based. In addition, despite a lot of available evidence, it was a matter of convincing the people responsible for policy development and law reform to do something. The participant was also of the view that a lot of work was happening on the ground in terms of program implementation yet not reflected in policy. Nor were the efforts the Ministry was making toward legislature and law reform: "We have to work extra hard to keep the link closed to 
ensure what we are on about on the ground is reflected in policy development, not just in the Ministry but across the board and planning."

Second and related was the need for collaboration. For example, during the participant's time at the MWCSD, there had been no discussions or collaboration between the MWCSD and the Ministry of Tourism on CST:

However, it's the kind of thing we would like to see happening down the line in terms of getting commitment from the relevant organisations - the different relevant organisations that have a stake in the area of child protection to do something. It is also the rationale behind these documents that they are not just for the Ministry but other organisations as well.

Workload pressure was another constraint and frustration. For example, when the UN asked about CST type issues, it was stated that "the finger is pointed at the Ministry to produce results, and yet we are talking about Samoans' children, not just children that belong to this Ministry; it's everybody's issue." The participant had agreed with the fact that CST was not a 'women's issue' and that women could do it on their own. CST was a family issue, a male/female issue and an 'age issue' as well - power relations.

The participant said that more males and young boys needed to be sensitized and involved in combating CST, and considered that, over the years, the Ministry had not listened to the voices of boys and men on how to address the issue, or for the place males had in CST generally. UN programs were pushing for engaging more men in eliminating violence and addressing gender equally. The participant said this was an area the Ministry wanted to push. Positive work with men was already underway, for example, the Ministry's Men against Violence initiative that had came out of village advocacy work. My participant said:

There is now this push towards engaging men and boys. It's something we initiated two years ago. In 2007, we said let's just look at engaging men, men taking action to eliminate violence against women. From that program, we were able to facilitate Men 
against Violence advocacy group. Last year we were able to facilitate a meeting of this group.

To champion this group, the MWCSD had employed a male national advocate under the PCP. The National advocate had targeted village councils. The participant explained:

You see, I was not going to go to meet with the village council because it's all older men and chiefs. We said we would employ a national advocate who was a matai, a former parliamentarian, and therefore had much better influence and was able to engage with matai and chiefs better than we could. Therefore, it came out of that. From child protection, we said we would engage the same group, focusing on men taking action on eliminating violence against women. Therefore, it was really something that came out of the community strength-based approach to addressing child protection.

The MWCSD vision was to support this group so that in two to three years, it would evolve into an organisation of its own. "We would like to see this group mobilize the men and the boys in addressing violence against women and all other associated issues to do with boys and girls, men and women." The discussion then turned to whether a men's group could unite to work against CSEC/CST issues in Samoa. My participant said:

Well you know, like I said, while it was a group that was formed to eliminate violence against women, we would like them to look at all forms of violence in general, and all forms of violence in the family and that also could include CST. I would like to think support could be given to that group so that they can grow and have the capacity to deal with these other issues and gradually expand rather than creating small groups now. That way, you have the power to reach many people and reach your own network of church ministers, for example, who will then reach their own, because that is the rationale behind the men's violence advocacy group. 
I turned our discussion to earlier interviews about adult $f a$ 'afafine facilitating sex tourism and fa' afafine children involved in it. I asked the participant "What had been done with fa'afafine children to prevent their sexual exploitation?" The reply was that there had been some attempt to bring mothers together over this issue. Moreover, the Ministry also looked at forming a support group for mothers of fa' afafine, so they were aware of the issues affecting fa'afafine boys and was able to do something about it or report on it. Neither issue was followed up.

My participant believed the best model to carry out CSEC/CST work would be the 'Child Protection Strengths-Based Model' that the Ministry was using to follow earlier work on children's issues. In this model, the Ministry targeted village councils because they had outreach into the villages. The Ministry also worked with church ministers through church advocacy. The idea was that churches would conduct outreach in their congregations as they had the power and were in the position to do so. As noted:

The success of the model was because it was for everyone. The Ministry wanted to have church leaders bring in a spiritual and Christian perspective, including traditional leaders who could bring in a cultural perspective and other people who were able to understand the issues and who were aware of national policy and plans as well as international obligations of the government, so that all these different perspectives were considered.

\section{The Samoa Tourism Authority}

The Samoa Tourism Authority (STA) is included in this section because it is a crown entity and because The Committee of the CRC recommendation was concerned about rising tourism and SEC. The participant saw their primary role was to market Samoa for the benefit of the national economy; therefore, her job was to promote tourism for the economy of the country. As we talked, it became increasing clear that because the focus of the STA was on economic returns, the participant had not contemplated other 
consequences that tourism might have. The participant was not aware if CST was a problem in Samoa because no one had said otherwise,

The participant considered CST was a police responsibility to prevent, and that before the STA could act, there had to be hard data to prove a CST problem existed. I asked the participant how statistics could be gleaned if there were no awareness rising material in public spaces that tourists could report their suspicions. The participant referred to the publication 'Jason's Handbook' that the participant said should have that type of information in it to advise tourists what to do if they suspect or encounter CST.

The participant said that at times hotels had contacted them, wanting more information on tourists they considered were acting suspiciously. In addition, the STA had done initial investigations on tourists when requested to by the police and reported this information back to them. The participant did not know of the CRC, the Stockholm Agenda for Action, or the World Tourism Code of Conduct or Global Code of Ethics. I stopped the interview because I believed the participant had become distressed not being able to answer my questions and because more specialised questions were coming up.

\section{Civil Society}

NGOs were particularly vocal asserting that the MWCSD as CRC focal point were responsible, yet interestingly, NGOs were not including their own roles as equally responsible. While many other participants considered an education, campaign by NGOs was necessary.

\section{SUNGO}

SUNGO is the National umbrella NGO in Samoa, representing a region-wide initiative to develop a network of NGOs to assist in implementing regional assistance and projects. I met with SUNGO to get their views on how CST was positioned within the national set of NGO programs. Our discussion showed that SUNGO had a more general 
function of training NGOs in donor compliance measures, for example, including governance and financial management issues. SUNGO did not operate programs itself, but recommended NGOs that I should contact on the issue.

\section{Mapusaga O’ Aiga}

Established in 1993 Mapusaga O' Aiga (MOA) is the NGO Focal Point for the CRC. The role of MOA is to eliminating violence and abuse of women and children. My participant from MOA was adamant that the core work of the organisation was on domestic violence issues, including sexual abuse and incest, and CST was not their 'core businesses'. However, my participant shared with me that she had talked to community groups about CST when an opportunity arose, based on what she knew. According to my participant, there had been no other work on CST. She commented:

How can NGOs do that when government says you don't have to? I looked through the periodical report about children that was submitted to Geneva and there was nothing mentioned in it about this issue. No one is thinking of doing research. NGOs should just do research on CST on our own.

I relayed to my participant that the TCU was interested in a partnership with the MOA. She said MOA was interested in collaborating with the TCU, and had been trying to do so for some time. She thought that once referrals came in, MOA could start investigating and build statistics. The participant continued:

They should contact us and do referrals. They should refer the victims and that's what we have been trying to do with them for a long time. To work with them - so refer them. I've already said that Police need someone specifically to interview those children - not a man - not a police - because kids will be scared to talk because they are police. But, look for a woman-someone who will come off their high horse and let the kids feel the warmth of a mother so they can be free to talk with. They cannot talk to a man. It doesn't matter how much you know - unless you talk to a woman. Because the woman is looking at it maybe from a mothers perspective, rather than talking to the guy. That's what I have been trying 
to push to them. We would be more than happy and then we can start building up stats when they do they do referrals to use. Because I can also report the statements from the children. We would be more than happy - so we can share the work - do the referrals and do follow ups .That is the major problem here, the networking is not effective.

My participant said that MOA had achieved positive outcomes because it had worked hard to get statistics to prove that incest and sexual abuse and indecent assault of children existed. She added:

This is what I have said that they should have research on this to prove the point. If it is reported to the police, it should be followed up and made sure it goes to court. We do follow ups and something is actually done. We are actively doing it - have to have some stats.

Generally, this participant was of the opinion that people contacted MOA because it was a highly recognised organisation. The organisation had already collected information with children, and "got results."

\section{ECPAT (Samoa)}

ECPAT Samoa was a local Samoan NGO not associated with the ECPAT International group. The participant pointed out that the organisation had conducted outreach programs on CSEC issues over the 2007, 2008, 2009 period. Their main strategy was awareness-raising programs, carried out in coastal districts. The organisation targeted youth at Sunday schools, educating the children to be aware of CST:

Now we have covered all the coastal areas around Savaii. There aren't any inland; all the villages are outside. We contact village mayors in rural villages to organise workshops for one or two days. Some workshops we do on Sundays when all the people are there. If we do workshops on a weekday, we pick the people to come into our office to be trained. They take this knowledge back to their communities. 
He pointed out that while children were the direct responsibility of the Ministry of Women, "ECPAT Samoa looked after them too." He considered CST happened in Samoa because of the misunderstanding of the Samoan people. The organisation's main constraint was:

We don't have information in places where there should be information like the airport, tourism authority sector - in other places - like in our office. We should have pamphlets explaining how to protect against tourism sex-in our job. We are educating the people to be aware and that there is some sort of protection from global influences.

He talked about the case of an international church organisation that had offered an adoption service for American couples wishing to adopt Samoan children. He said that after seven to 10 years operating in Samoa, the country had been "spied out," alluding to reports that the children were used for sex. A British couple had reported the issue, and following investigations, Samoa's Adoption laws were amended in 2006. ECPAT collaborated with The Disabled and Mapusaga O 'Aiga. There had been no collaborative work with the Ministry of Tourism, and despite media asking him to talk about CST, he refused, mainly because he believed that the topic was too sensitive.

\section{The Samoa Victim Support Group}

Established in July 2005, the Samoa Victim Support Group (Victim Support) was a relatively new organisation. The organisation was an initiative of four ex-police officers, all highly regarded women in the Samoan community, in response to a recognised need in the legal system to assist victims of abuse and other crimes. Its role was to support victims of sexual abuse and other crimes. As the participant explained, the priority in victim support was on the 'after abuse' stage. When a child victim had been referred to Victim Support, the process of recovery usually followed a set pattern. First, the general background of the abuse was determined, although not in detail so as not to revictimise the individual. Second, was to identify the perpetrator and the location of the abuse and lastly, to refer the case to the Police. The Police then dealt with the perpetrator 
based on the authority in the law. Follow-up occurred three days later so the victim did not lose confidence with Victim Support. If the victim knew the perpetrator, the victim was relocated. This procedure was followed whether the victim and perpetrator were local or an overseas tourist was involved.

At the time of our discussion, no child had been referred to Victim Support because of tourist abuse. However, he note that if there was tourist abuse of a child, Victim Support would follow the same procedure as described above, relying on the Police to take next steps. He would not contact the STA to report tourist abuse because he considered it was not the right channel to go through. If he had to contact anyone, it would be Border Security or the TCU. He explained in the case of victim abuse that there were many causes to be considered:

In every community in the world people, hide things. They do not want embarrassment or disgrace to family and village as we have a village system here. So, we have to protect our identity and our good reputation of village and family, so sometimes we have to hide those things.

The participant voiced as a community watchdog, the organisation was at times criticised by Police who viewed the victim's issues differently. The organisation had volunteers and was donor supported; nevertheless, resource constraints remained an ongoing problem.

\section{News Media}

The Samoa Observer was founded in 1979. It is the largest newspaper group in Samoa, published in English and Samoan, with all editions available online. Coverage includes local and international news, editorial opinion, sports, and investigative journalism. The independent paper has received awards for investigative journalism and press freedom. In the interview, the media representative, a newspaper employee, pointed out that it was part of the everyday job of reporters to venture out into the 
community to ask questions about serious issues. In regards to people voicing their opinions about specific issues, this was done in the paper's editorial column. He saw the editorial column as a way for Samoans to voice their opinions to the newspaper, and at the same time, for the paper to educate people on issues. In addition to the cultural adviser, and focus group facilitator, other support for this study came from the local newspaper, and church. Following an interview I had with a news reporter of a local newspaper, he asked me if I would consider a feature article in the newspaper about my study in Samoa, to which I agreed. I utilised the media's offer because I wanted to reach out to the Apia community for support and information.

According to the participant, the last CST case that the newspaper received was by way of an NGO, where a member of the community had reported the issue. He explained: "Once something goes public they try to catch the people before it even gets into the newspaper. We would probably be the last source of information because word of mouth spreads so quickly in Samoa." I asked the participant what types of abuse the paper usually reported on:

...we are talking about sexual abuse. For example, one case was out of the boat where some men came and gave two boys marijuana and I think money. When the family started looking for them, they found them at the boats in town. This was before the marina was done; they were having sex with these boys on the boat. They were young boys, maybe not even 14, or younger. So, that's the kind of abuse I'm talking about. It ranges from that kind of thing to taking suspicious pictures.

The participant held an opinion that most people did not know what child pornography really was because; there had been no public education on this. He believed that many people were aware of child pornography, but apart from the "educated" people, most people did not really know. Many times, he said, people viewed nude children as an innocent picture, which it had been in past times. 
I asked the participant if reporters followed up with stories such as the incident of the boys above. He recalled that at the time the story appeared, he had spoken to the Ministry of Women in terms of what they were doing about the issue because they dealt with it. The paper had also printed a couple of stories expressing concerns and highlighting what people should do. He could not recall the newspaper collaborating with the MOT. He said, "No, the Ministry of Tourism doesn't contact us. In fact, the last time we tried talking to them they didn't want to talk, I think."

Lastly, I asked the participant if he believed that the newspaper possessed detailed knowledge of CST to create awareness about CST. Like all other answers in this section, his answer confirmed the need for research. He replied, "That is one constraint. I would say we do not. We have some knowledge but we do not have detailed knowledge. What we know is what people tell us."

\section{The Church}

An investigation of the extent of the church's influence in people's lives and imaginations was beyond the parameters of this study; but religion was clearly a major aspect of the lives of Samoan people, with most participants describing themselves as religious, and the majority being active in their faith. Participants, particularly the taxi drivers considered the church was a powerful influence to power off CST. Comments included, "No. Churches teach to become good by learning from the bible"; and "Samoa is a Christian country we believe in the word of God."

A government participant confirmed the taxi drivers' belief that the church was an important ally to work with on these types of issues through the church. As the government participant explained, "we have worked with church ministers through the church advocacy, and the idea was for them to reach their own churches ....We wanted to have church leaders that bring in spiritual and Christian perspectives. That way, you have the power to reach many people and reach your own network of church ministers, for example, who will then reach their own." 
The participant from the news media agreed "at the same time church has got to perform its part as well - because people do listen to what the church ministers say, so you got to target those people as well - get them to preach on the message on the pulpit."

A participant from the civil society group described his involvement in a Christian youth programme:

The $[. .$.$] youth centre was what we set up for the young kids; it's just like a Christian$ nightclub. Instead of this young kids going down to this adult night clubs where a lot of bad influence is, they just go inside the youth centre and have their own stories and no alcohol inside and sometimes they have programs. The young kids they love to come and occupy their time there instead of going down to nightclub [...] it was a good impact for the children.

I was fortunate enough to engage in an informal discussion with the pastor of a local church. The discussion revolved around modern Samoa society, pressures for family, and youth and, how the church assisted families in need. There told me about an incident involving the sexual abuse of a boy at the local port, and recent media reports about the drug situation, involving Samoan youth. The Pastor invited me to church that following Sunday where I witnessed him preaching to the congregation in a roundabout way on CST, addressing the need to watch out for each other and to report criminal activity that people knew was wrong. He used the analogy of "the watchman" to impart moral guidance. As follows:

Become aware of your responsibility and accountability before God. In addition, ask God to help you live for him and become a watchman for those around you. What else is the Watchman's duty? In Ezekiel's day, cities were surrounded by great walls, which protected thousands of citizens of that city from attack. One of the most important people in the defence system of the city was the watchman who patrolled the walls. He would be the first to see an advancing army. The watchman was to be constantly alert because the lives of so many people depended on him. If he saw the enemy approaching, he sounded 
the alarm with the ram's horn trumpet, so the people could prepare to defend their city. (Appendix M: The Sermon)

Following the sermon, some congregation members had approached the pastor with information about criminal activity; they clearly felt obliged to be reported.

In addition to the above, another participant with a close association to the church in his role as trainee pastor explained to me the role his church took on to support the rehabilitation process of victims of abuse (sexual or physical). As follows:

You asked about the role of the church and what involvement of our church in the community. We could begin by talking about the relationship between the Constitution of Samoa and Christian Values. If we apply Christian values then we honor our Constitution. That is the difference. Some people break the Constitution because they are not founded in the word of God. That's why we need to build ourselves with the word of God. Like the constitution is a guideline to the government for how the people are going to live in our country. Also, there is one of the ministries of the church involved in the community because the mission of the church is building up strong families / relationships in the word of God and in the spirit of God.

We work closely with Victim Support that is a close relationship for us for this reason that we are willing to help those people who are in need. The involvement of our church with the Victim Support is we have bible studies groups located next door to Victim Support where all these kids are housed. The government had already allocated a house for them to stay in, and that is how we get a connection with all these kids. Sometimes there were about 20/30 kids there. That was when the church began to look at these young kids and we started to do something to help.

We really believe these children are in need of help because they had been abused psychologically and mentally and we try to build them up - give them hope. So, every month we support them with food and other needs. So, that is our relationship with Victim Support. We really support them in every way with their requests. Working with the children is building them up spiritually. 
Because they are victims, in their minds they always have that unforgiveness in their hearts for what has happened. What we give to them is all based on the word of God from the bible. Some of them still have their mindset focused on what had happened- so what we try to do was like rehabilitation, this is what we normally try to do to build the forgiveness. This is what we try to do to release the unforgiveness in them, and to give them a hope.

Whoever victimised them, that thing is still going to be in their mind forever. but we trying to take it out of their mind - let the focus and the mindset get out of there because they don't want to have a barrier for their life - they need to move on - those barriers that's going to stop them and not motivate them - we just want to give them hope and a good future so that they are always in charge. We can help them in education things like that - that's how we rebuild them, because looking at these young kids, some of them six years old, seven or eight up to 15 or16 year old it's all a mixture .

But this is something - emotionally with the kids life because they keep their emotions right up until their court case and all that time staying there at Victim Support - we rebuild - work with them and by the time they go back home there is always a change in their mind - they release that unforgiveness in their heart. Now they go back and have healthy relationship with their family. The funding is done by the church.

Like all the involvement of our church like to the Victim Support and the Marriage Course, it is church funded. We never ask NGOs and donors, we don't know where to get funding. So that's why. We are more concerned about people, so we do it ourselves.

\section{Village Councils and Chiefs}

The village system was attributed less responsibility. One taxi driver thought CST "should be discussed at village council, "so everyone should be aware." The urban focus group identified responsibility was that of the "village council - village laws and protocols," as did the rural focus group; "The village fono (meeting of chiefs) should carefully look at these problems and have a ruling that is possible to avoid this [CST]". 
Other comments were in the focus groups were, "The village fono (meeting of chiefs) should carefully look at these problems and have a ruling that is possible to avoid this [CST]" and "matai could be aware of the CST issues and could be effective in protecting against it." One participant from the media was sure that the village system did provide the best medium for addressing the problem; that "your culture and your church were the two most important things in Samoa."

\section{Family}

Most participants said parents and families held responsibility to protect children against CST, although the majority also thought parents were not doing this. Comments were "No proper relationships of parents and kids and parents role to bring them up in the right way". Including "No proper monitoring." In addition to "Parents are not doing their job at home." Often the discussions turned to "Broken families" and parents "Not looking after children because their "upbringing are in different areas." Other comments were "parents are not doing their roles like they used to," and a "lack of family values." Other comments were "Parents should be responsible for bringing up their own children in a proper way according to our culture and should have proper education."

\subsection{Defining Child Sex Tourism}

Was there a clear understanding as about what CST was? Are Samoans, particularly families, given the information they need to counter this issue - to be aware about CST and related issues? To find out, I put four questions to the seven taxi drivers, six of whom were married men with families. There were four questions. 1) The age of a child in Samoa? 2) The countries CST happen in most. 3) What is CST? 4) Who is the child sex tourist?

Table 15 and Table 16, presents findings that confirmed a lack of consensus of age of a 'child', in addition to a lack of understanding what CST is and entailed. 
Table 15: Age of a child in Samoa / Countries child sex tourism happens in most

\begin{tabular}{ccc}
\hline & Question 1 & Question 2 \\
& $\begin{array}{c}\text { Age of a child Considered an Adult in } \\
\text { Samoa. }\end{array}$ & $\begin{array}{c}\text { In Which Country or Countries Do You } \\
\text { think Child Sex Tourism Happens the } \\
\text { Most }\end{array}$ \\
\hline TD 1 & 16 & Not sure \\
TD 2 & 21 & Thailand, and Asia \\
TD 3 & 18 & Fiji, Vanuatu, started in Samoa \\
TD 4 & 18 & Never heard before \\
TD 5 & 18 & Asia Africa and India \\
TD 6 & Over 21 & No knowledge \\
TD 7 & 18 & \\
\hline Note. TD - Taxi Driver. & & \\
\hline
\end{tabular}

Table 16: What is child sex tourism / Who is the child sex tourist

\begin{tabular}{|c|c|c|}
\hline Taxi Driver & What is Child Sex Tourism? & $\begin{array}{l}\text { What Types of Tourists Deliberately } \\
\text { Target Children for Sex? }\end{array}$ \\
\hline 1 & Sex with an under-aged child & Don't know \\
\hline 2 & Unanswered & $\begin{array}{l}\text { Single male 50s: US: Australia: New } \\
\text { Zealand: United Kingdom. }\end{array}$ \\
\hline 3 & Tourism sex with young girls & $\begin{array}{l}\text { Single/married: Papua New Guinea 42: } \\
\text { India 29: New Zealand Australia }\end{array}$ \\
\hline 4 & No idea & Never came across such a case. \\
\hline 5 & Not really know & Old tourists maybe 45 years upwards. \\
\hline 6 & Need children for enjoyed living & Older ones. Single male/female. \\
\hline 7 & No knowledge about it & No Knowledge. \\
\hline
\end{tabular}

\section{A 'Child'}

One driver stated, 16 years - old because in Samoa, national law states consensual sex begins at age 16. Four of the drivers proposed 18 years, which aligned with the CRC, and two thought " 21 " and "over 21 " respectively. Lack of consensus was evident in other groups too, for example, in the urban focus group interview; a government ministry participant appeared to go against the CRC recommendation of childhood ending at 18 . He pointed out that a 'child' is always a child in the eyes of Samoan parents and that a 'child' could even be 60 or more for the fact that a person's child will always be their child no matter what age. One NGO participant referred to young ladies as 12-18 years. He offered the following explanation for my question, "But why?" 
According to him:

Here it's 18 for the CRC, but we still have 16 for the ladies. I hate that when someone from the CRC came here, and some people asked her, "Why 18 for the CRC?" She said, "Because of the ladies' development." I said “No, no. I think they develop faster. So, I do not accept 18, especially if the lady grew up without education and the man is more advanced than she is.

[Researcher] So young ladies are? [Participant] 12-18.

\section{What is Child Sex Tourism? The Countries? The Child Sex Tourist?}

Four of the seven drivers did not know how to define CST. The remaining three drivers answered, "CST is having sex with an under-aged child." This driver had earlier defined a 'child' as 16 meant that therefore for him, 16 was an underage child. Another driver defined CST as "a tourist that wants to have sex with young girls." He had earlier defined 'child' as 18. In addition, in his view, girls were most vulnerable to CST and not boys. A third driver answered that CST is "tourists need for sex with children for their enjoyed living." Earlier he had defined children as over 21. Clearly, the term was outside highlighted a lack of understanding and awareness to this issue. Collectively, drivers believed CST happened mainly in third world countries most commonly associated with CST such as Asia and Africa. Child sex tourists were perceived as either single males or females or married couples. Drivers presented perpetrators aged from 20 and older. Interestingly, one driver provided extra information alluding to the fact he may have had personal experience with child sex tourists. 


\section{Chapter 7: Findings}

\subsection{Introduction}

In this chapter, I will discuss my research findings aimed to meet the first two objectives of this study, as follows: 1) To report the scope of CST in Samoa, and 2) To identify and report the root causes that contributed to the risk of CST in Samoa. To meet Objective, 1, I provide some estimate of the scope of CST in Samoa, (in terms of numbers, perpetrator type, victim, and facilitator). Second, Objective 2, I present root causes. Objective 3 of this study that was to; present a set of recommendations as a baseline foundation for policy, advocacy, and research, is presented chapter 8 next, under 'Recommendations'.

Three sets of data enabled this findings discussion. The first set of data was the eyewitness testimony that was the two accounts of children sexually abused by foreign tourists. The second set was my direct observation of a prostitution operation in the Apia city centre involving children. The third set was participant's answers to the questions based on inside knowledge.

\subsection{The Scope}

The literature asserts it is virtually impossible to determine the scope of CST in any one country. Nonetheless, for the reason that the majority of participants in all groups believed CST operated in Samoa, including eyewitness testimony and my direct observation, I suggest Samoa has a serious CST problem.

\section{Numbers}

Anecdotal evidence, such as eyewitness testimony reported 19 Samoan children involved in sexual activity with two tourists. In addition, I observed a child prostitution operation in central Apia facilitated by two adults involving three girls and an overseas 
worker. The third set, the people's perspectives of the issue, had the potential to increase the scope of the phenomenon far higher. For example, I refer to the discussion of an informal marriage for the upkeep of a family home, and a mother as a pimp for her daughter's prostitution. In addition, CST reportedly took place in the hospitality industry, such as bars and nightclubs. Other discussions centered on expatriates facilitating the practice. Reportedly, UN workers had given young girls money in hotels and bars alluding to involvement in prostitution. Foreign employers had sexually exploited young housemaids.

Furthermore, participants reported CST happened in back villages, and that the scale of the problem remained unknown for the reason that no report had yet come out. The Transnational Crimes Unit had three tourists under 'watch', and cruise ship passengers sought out taxi drivers to take them to have sex with local children both boys, and girls. There was an observation from a health professional that secondary school boys, displayed transgendered traits towards the end of the school year (and not at the beginning of the year), suggesting this unexpected gender change was more than a 'developmental' issue, other than perhaps corresponded with the height of the tourist season, catering to sex tourists demand.

\section{Victims}

According to the eyewitness testimony, the victims in the two accounts were boys, girls, and fa' afafine (transgendered) boys. In Account 1, the girls and the fa' afafine boys appeared willing parties in the sexual acts with the tourist because the motive was money. In Account 2, victims were reportedly all girls, although they appeared less willing to participate in sexual acts with the tourist. Since the girl had said, "he always does this to us," her comment suggested their powerless position to stop it.

These findings above, correspond to those of The Pacific Interagency Report (2006), having reported boys and girls had been sexually exploited across all five Pacific 
countries involved in the report. Particularly, the interagency report noted that the sexual abuse of boys by foreign tourists in the Solomon Islands was a serious problem (UNICEF, UNESCAP, and ECPAT, 2006). Incidentally, some years earlier, the Solomon Islands Family Support Centre had organised the first Solomon Islands child protection conference in 1999. That was because it was recognised that child abuse was occurring in the Solomon Islands, and action were needed to prevent it.

Recommendations for action emerged from the conference such as review existing laws, the establishment of a child protection unit within the Police, and adoption of the Stockholm Agenda for Action as a framework for the prevention of CSEC of Solomon Island children. My findings reporting boys involvement in sexual activity with tourists, also correspond to the earlier report from Susman (2003) (chapter 1) having noted; “...when most people talk about exploitation of underage children for sex in the Pacific, the focus is on young girls; But there is also exploitation of boys, although that is less acknowledged and less frequently addressed" (p. 3).

Of note, the Pacific Interagency Report (2006) had not raised the phenomenon of transgendered boy's sexual exploitation in its report. In my fieldwork, fa 'afafine boys' involvement in CST was an unexpected result. However, this finding was comparable with a Pakistan Report having noted that the prostitution of adolescent boys in Lahore and Peshawar was rife, and that "boys with alternative sexual identities (boys with transvestite and feminine characteristics) made up the majority of boy victims of prostitution in Lahore" (ECPAT International and Pakistan Pediatrics Association, 2006, $\mathrm{p}$ ix).

\section{Perpetrators}

The eyewitness testimony presented a perpetrator type aligned to the actions of the 'preferential' child sex tourist. Similarities between the perpetrators in the two accounts were the two tourists were frequent travellers to Samoa and both older males. Victims appeared to be pre-pubescent youth. Differences between the two men were one 
perpetrator was from a less developed country (Peru) and the other perpetrator was from a developed country (Germany). Two, one perpetrator had reportedly financed his victim's education - the other perpetrator appeared to have not.

In addition to the above, was the testimony of the Transnational Crimes Unit participant that there were three overseas tourists under watch and, that the three were all males from separate developing countries. In addition, my own observation presented a New Zealand worker on contract in Samoa. In this case, 'opportunistic' CST operated in Samoa as well, and indicated that the problem of CST extended beyond the tourist industry, hotels, and services. Generally, these findings aligned to the global pattern of child sex tourists from developing countries travelling to the least developed countries (Lévesque 1999; David, 2000; Jhappan, 2005). Moreover, despite the majority of participants referring to the child sex tourist as the 'pedophile', findings were that the preferential and opportunistic child sex tourists were the greater perpetrators in Samoa.

\section{Facilitators}

In Samoa, facilitators of CST involved large parts of Samoan society, men, women, and transgendered adults, family, and children. Because participants had reported CST was happening in the back villages (yet to be reported), and CST operated in the hospitality industry, the question was; who were facilitating these practices in those two environments?

As noted in the Fiji Special Rapporteur report 1999 (chapter 1), sex tourists had coaxed island taxi drivers to facilitate child prostitution. In the Pacific Interagency Report (2006), facilitators were "taxi drivers, nightclub owners and workers, security guards, and hotel owners and employees" (UNICEF, UNESCAP and ECPAT, 2006, p. 48). Moreover, the report noted in Papua New Guinea "in some areas, children and youth acted as go-betweens, establishing contact with local girls and their families for adult male perpetrators" (p. 48). 
Moreover, a report from the Christian Care Centre, Church of Melanesia, titled Christian Care Centre, Church of Melanesia, (2007), presented findings that:

...children, particularly boys, were given money to approach or find girls. As such, these children were also victims of abuse by being coerced into engaging in illegal activity. In addition, there are concerns around what gender issues could arise from young boys encouraging girls they know well to engage in sex for money and being rewarded for this behaviour, as well as the role modeling of children being viewed as the preferred sex partners for older men. (p, 115)

The earlier Kenya (2003) report (chapter 2) had noted a similar finding: "The influence of friends and peers was found to be the primary motivating force for entry. Friends also play a primary role in the process of induction and initiation" (Government of Kenya and UNICEF, 2003, p. 61). Further, Lau's (2008), study in Thailand, had reported child sex tourists often utilised relatives, acquaintances, and other children, especially those desperate to obtain consumer materials in order to help them exploit and target children, child sex tourists often utilised relatives, acquaintances, and other children, especially those desperate to obtain consumer materials in order to help them exploit and target children.

The Samoa Tourism Authority Development Plan (2009-2013) SWOT Analysis), understood that prostitution and pedophilia were two aspects of tourism that contributed to negative tourism. Generally, the Samoa Tourism Authority had situated the problem likely facilitated by hotel workers. The Samoa Tourism Authority had ignored the wider spectrum of facilitators and owners of rental flats and houses that knowingly or unknowingly provided for tourists, rental accommodation as a cover for CST activity. According to the eyewitness, at least one of the two child sex tourists had rented a flat in a village. The abuses of the 19 children had reportedly taken place in hired vehicles. 


\subsection{Root Causes}

From Chapter 5, participants had presented 10 sub-root causes; in addition, my analysis of data teased out 10 more sub-root causes. As Table 17 (Root causes), the first of the two columns presents participant's perceptions of root causes from personal experience or other sources of knowledge. The second column presented 10 root causes gleaned from data analysis. As presented commonalities arose as well as some differences.

\section{Table 17. Root causes: According to Participants and Researcher}

\begin{tabular}{|l|l|l|}
\hline & Participant Perceptions & Data Analysis \\
\hline 1 & Financial pressures & Poverty \\
\hline 2 & Hospitality and 'the tourist as trader' & Hospitality \\
\hline 3 & Sex tourism & $\begin{array}{l}\text { Philanthropic exploitation - 'tourist as } \\
\text { trader' }\end{array}$ \\
\hline 4 & Family breakdown & Marginalisation of boys \\
\hline 5 & Lack of legal process and law enforcement & $\begin{array}{l}\text { Family under pressure and family } \\
\text { dysfunction }\end{array}$ \\
\hline 6 & Lack of data (planning and understanding) & Unsafe schools \\
\hline 7 & Lack of programs for men and boys & Ifoga(An apology) \\
\hline 8 & The child as individual and right to privacy & Sex tourism \\
\hline 9 & Tunnel vision & Tourism excused of action \\
\hline 10 & Ifoga / Shame & Lack of awareness about CST \\
\hline
\end{tabular}

\section{Poverty}

Samoan participants presented class divisions between the urban rich and the rural poor, with the latter perceived as most likely pushed into either facilitating CST or becoming a victim to it; "people could not even afford a mutton flap." Traditional social structures and safety nets had stretched as external influences affected attitudes and aspiration for a better life that created pressures for families looking for cash incomes.

An earlier report from Shuaib (2007) (chapter 3) reported traditional, subsistence production and extended kinship networks, meant that Samoa's social safety and living standards were high, but inequality between the urban rich and the rural poor were 
increasing. The report remarked traditional social structures, safety nets stretched as external influences affected attitudes, aspirations, creating mounting pressure to earn money, approximately 20 percent of Samoan households were below the national poverty line, and eight percent were in a state of food deficiency.

As the Pacific Interagency Report (2006) noted, poverty was a major cause underlying CSEC in all five Pacific countries. Poverty drove in-migration also identified a root cause for CST in Samoa. A UNICEF Pacific, and UNIFEM Pacific (2007), report noted that concurrently, internal male migration, and complete dependence on money for livelihoods, was contributing to a fragmentation of families, yet also a result of tourism development driving people off land for hotels and resorts.

Generally, children living in poverty were vulnerable to neglect, sexual or physical abuse (O’Connell Davidson, 2004; Jullien, 2003; Lévesque, 1999). Poverty was deemed a root cause of CST in the Kenya study (Government of Kenya and UNICEF, 2003); the India study (Kerala and Goa) (EQUATIONS and ECPAT International., 2003), and in the Gambia (Child Protection Alliance and Terre des Hommes, 2003).

\section{Hospitality}

Child sex tourists capitalised on Samoan hospitality to get close to Samoan children. This finding reflected a global pattern associated with hospitality. Samoans are hospitable in nature. The fa'asamoa prioritises relationships between people typically displayed through hospitality. In discussions, participants both male and female, younger and older, had discussed changes in the way Samoan "hospitality" was delivered and 'reinvented' but the Government of Samoa to pull tourists in. For example, as seen in the Samoa Tourism Development Plan (2009-2013). As follows:

The 'Samoan Experience' is underpinned by strong themes of pristine nature, soft adventure, cultural appreciation, personal rejuvenation, indulgence and self discovery, safety and security whilst also enjoying truly warm and genuine community welcome and 
exceptional and world renowned Samoan hospitality. (Government of Samoa and Samoa Tourism Authority, 2009)

Participants talked on how, this type of tourism promotion had been driven into the Samoan psyche to apply when interacting with tourists such as seen in the comment, "Here he is a foreigner so we have "to love him" (Chapter 5: NGO).

The earlier Special Rapporteur report undertaken in Fiji (1999) reported tourists had taken advantage of Fijian hospitality. As quoted in the report, "Fijians were generally very friendly and trusting people, and there have been instances where foreigners have taken the time to befriend whole families, gaining the trust of the parents and the child" (United Nations Commission on Human Rights, 1999, p.19).

Trinidad's (2005) research in the Philippines reported the welcoming nature of Asia and Pacific peoples to their countries was a cultural norm that often supported CST. Trinidad's study also reported that tourism dependency was an issue, that coupled with a rise in poverty explained why Filipinos were hospitable to foreigners and at times accepting of CST and the sex industry. Moreover, according to Trinidad, hospitality made it difficult to gather information on CST (Trinidad, 2005).

\section{Philanthropic Exploitation (the Tourist as Trader')}

Philanthropic exploitation operated in Samoa such as seen in the words of one participant:

They say to the family "When I come back I will build this for you." So when a tourist comes in and offers money, they accept it. That is the way the tourist gets in to find a way to have sex with the young people. Once a tourist creates a relationship with a family, they then leave the country but then come back, go home. Because Samoa is a very enclosed culture, people cannot walk in unless there is a close relationship or built up relationship and then things start to go both ways (Chapter 5: NGO) 
As a Pacific problem, the earlier1999 case of Mark Mutch (chapter 1) provided evidence of philanthropic exploitation. For example, to gain access to children for sex, Mutch had approached his victim's families, assisted to pay their children's school fees, and supported their families financially; thus gaining their trust and confidence.

In addition, philanthropic exploitation had been a significant problem for families in Samoa. For example, the case of the New Zealand couple adopting the eight Samoan children under the pretext of giving them an enhanced life (chapter 1). The adoptions of Samoan children had resulted in the complete revision of Samoan adoption laws.

In Samoa, philanthropic exploitation had extended past child adoptions for sexual activity, to perpetrators paying children's secondary education to gain access to children for sexual activity. The high cost of secondary education had been a luxury few families could afford. The expenses of books, lunches, school uniforms, and school-related costs were a financial burden families met. A taxi driver had to work two jobs to pay his bills, his children's education, and their school lunches. There was a tourist glut in Samoa. The possibility that this man might consider it easier to facilitate CST for effortless wok and money, adds another dimension to this issue. Private hotels offered tourists the opportunity to sponsor children's education, although, the sponsors of these scholarships schemes, did not appear to have been police vetted.

In addition, the earlier referred to study in The Gambia (2003) noted a similar trend: "Young Gambians benefit from the generosity of travellers, who wanted to contribute to the development of the country they are visiting" (p.4). Furthermore, friendliness with tourists had led to many children offered a year's school sponsorship by their newfound friends. Many young Gambians benefitted from the generosity of tourists who genuinely wanted to contribute to the development of the country. The report noted, "Some tourists had more sinister agendas which featured manipulation of this system to their own ends" (Child Protection Alliance and Terre des Hommes, 2003, p.7). 
Montgomery (2008) reported exploiters normally presented themselves as helpers, and gradually built trust with vulnerable families, by physically staying with them for a long period. For example, some tourists had stayed in hotels and wanted to thank their hosts for their hospitality by supporting the education of their secondary school students.

Trinidad (2005) identified 'philanthropic activity' happening during her research in the Philippines. Tourists bought families school supplies and provided tuition for their children's education. This occurred because poor parents did not have the resources to send their children to school, let alone buy these supplies for their children. She said, "Other times, these foreigners lend or give the families large sums of money to start a small business or to have their houses repaired" (p. 68). In discussions, a third form of philanthropic exploitation operating was the upkeep of family home in trade for the informal marriage between the tourist and family's daughter. Generally, the wider community had accepted this type of 'arrangement' as advantageous for the family who were poor.

\section{Marginalisation of Boys}

Globally, the sexual abuse and exploitation of children were due to root causes such as poverty, although other causes included gender inequality and the low status of children, particularly girls who were often seen as less 'important' than boys (Sanchez Taylor, 2010). A UNICEF Pacific and UNIFEM Pacific report (2007) noted that in the Pacific, children were often placed as the lowest status in society. In Samoa, I found that the low status of girls did not appear as problematic for children's entry into CST as did the low regard for boys.

Evidence of this was in Account 1, the eyewitness testimony having commented, "thank god it [the actual sexual acts] was only with the boys and not girls." This remark suggested that the sexual abuse and exploitation of boys and fa'afafine boys was 
considered less important than had it have been the girls. Moreover, as my data found, while the work for girls and women had advanced with the advent of CEDAW and the abundance of programmes for women and girls, a key concern from some of the older women in this study, was "where were the programmes for men and boys?"

Furthermore, the women who raised this issue were genuinely worried about boys' sexual abuse and exploitation for future aspirations. The Samoa data notes, boys were less inclined to remain in education than were girls. As one participant noted, families educate the girls while the boys dropped out of school and do manual work.

Incidentally, a 2009 Samoa Government Questionnaire on the Implementation of the Beijing Declaration and Action (1995), and the Outcome of the Twenty-Third Special Session of the General Assembly (2000), (Government of Samoa, 2009), reported that while the work for the advancement of girl's was ongoing, males fared less well. The report considered that the social and economic costs to society of not recognising the marginalisation of boys and their lack of opportunity could be inestimable in the next five to 10 years (United Nations, 2009).

\section{Family under Pressure and Family Dysfunction}

Although poverty was a major underpinning issue in the sexual exploitation of children, many other causes forced children into situations where they become most vulnerable. One cause was family dysfunction/family breakdown. A significant finding in this study was that 'family/aiga' - the major protective system for children, were uncertain about how to raise their children in these modern times; increasingly challenged to protect children in a 21 st century context. Challenges included; increased aspirations, cash poverty, and rapid urbanisation with the added problem of the development of hotels and, for the first time, large numbers of families and children living beyond the tight village community control and were moving into the city for better opportunities. Men were working long hours to provide the basics of everyday life for their families. Some men appeared under pressure. For example, in the taxi driver survey, one driver talked 
about working two jobs and long hours to pay his bills and lunches for his children. The possibility that these men might be tempted to facilitate CST for easy money was high, adding another worrying aspect to this issue.

Participants referred to traditional social structures and safety nets that were stretched as external influences affected attitudes and aspiration for a better life that created pressures for families looking for cash incomes. The report from UNICEF Pacific and UNIFEM Pacific, (2007), noted that the need for cash had contributed to internal male migration and complete dependence on money for livelihoods contributing to the disjointedness of families. Cash incomes and aspirations for a better life drove inmigration. In-migration was a root cause for CST in the India, and Goa and Kerala study. The UNICEF Pacific and UNIFEM Pacific (2007), report noted that concurrently, internal male migration and complete dependence on money for livelihoods, were contributing to a fragmentation of families. In Samoa, families were moved off land targeted for tourism development, settling in Apia without work and family protection. Families and children were already at risk of sexual abuse and exploitation by way of naivety to city situations. As the literature shows, children living in poverty are vulnerable to neglect and sexual or physical abuse (O'Connell Davidson, 2004; Jullien, 2003; Lévesque, 1999)

Family dysfunction surfaced in conjunction with discussions about traditional roles reversed, domestic violence, incest, inequality between genders, the physical, sexual, and emotional abuse and neglect of children. Children were malnourished because mothers were busy 'doing other things' and not looking after their children. Moreover, children were left to their own devices, and not been 'watched' as they once were. One participant believed that the sexual abuse of boys at an early age, contributed to their growing femininity and becoming a fa' 'afafine, and their involvement in CST.

Globally, family dissolution can be a result of domestic violence, and a contributory cause towards child abuse (Guinn and Steglich and Leal and Leal, 2003; 
Jones and Trotman Jemmott's, 2009; Canon, 2001; ECPAT, 2006; and Jeffrey, 1999; Hughes, 2001; Estes, 2001).

As presented in The National Policy for Children (2010-2015), from January to June 2010, there were 296 cases of domestic violence involving children. The most common forms of sexual abuse cases against children in the last 12 months were indecent assault, rape, and carnal knowledge (Samoa Government and the MWCSD, 2010, p. 9). Child sexual abuse was a Pacific problem, widespread and under-researched (Secretariat of the Pacific Community, 2005, p. 125).

Stockholm (1996) listed inter-and intra-familial problems as culpable root causes for children's entry into CSEC. Mainly having to do with the family breakdown, were root causes, such as poor family relationships, abuse, and neglect in the home, parental mental illness, and substance abuse including children leaving home and living on the streets. Griffin's (2006) research in the Pacific identified that children most at risk were the ones who were not cared for by their biological parents, and were supporting their family or themselves through sex work to pay for school fees or cover transportation costs. Samoa's initial report to the CRC (Government of Samoa, 2005), had presented a case for complacency to children's abuse as follows: “The delegation's responses revealed that very few pro-active measures had been taken to prevent the abuse of children....there was very little done to protect them from abuse from within their own family" (UNCRC, 2006, p.4).

\section{Unsafe Schools}

Account 1 of the eyewitness testimony reported a proportion of victims were secondary school students. Reportedly, the primary victim had access to a cell phone to accept a facilitator's call (taxi driver), to meet with a tourist or sponsor. The primary victim had left the school to engage in sex with a tourist. I assume he had become truant. 
According to the eyewitness, the student had returned to school before the end of the same school day.

The earlier Kenya study (Government of Kenya and UNICEF, 2003), had a similar finding, noting that students had become truant or dropped out of school to engage with tourists (not exclusively for sex other than other business). The key reasons for having done so were hardship and necessity (orphaning by one or both parents) and those whose parents had "some employment, but wanted disposable income and more material possessions and aspired to be Western-style teenagers. This desire to be more Westernised, more fashionable and stylish appears to have a bearing on entry into sex work" (pp. 57-58).

In addition, other discussions had revolved around an overseas New Zealand teacher had sexually abused children in an outer village primary school. Reportedly, this teacher faced trial back in New Zealand following deportation. Although no participant that discussed this incident with me knew what the outcome of this man's abuses was. Related to incidents such as this, was my interview with an educationist who told me an overseas teacher had walked in off the street looking for work. He had been employed to teach children in Samoa without police vetting or a background check of his teaching credentials.

\section{Ifoga/ Shame}

Another finding preventing a realistic scope of the CST problem in Samoa concerned the traditional ifoga or apology that had been utilised as a 21 st century problem solver. Research from the Protection Project (2007) highlighted that data collection was even more difficult, not less, when families are involved, because the families experience the revelation more as shame than as outrage. 


\section{Sex Tourism}

Samoa has an adult prostitution industry fuelling a sex tourism industry that participants talked about openly and often, that appeared to operate on a wide scale. Participants either believed, or knew of prostitution happening, even though they actively disapproved of the practice. An hotelier in the upper level revealed sex tourism was had been discussed and actions put in place to deal with it. Participants noted that prostitutes operated independently, either working from home or in isolated spots on the outskirts of town. I was shown where prostitutes operated in nighttime hours and younger ones operated in and around Apia bars and cafes and markets.

Globally, as Montgomery (1998) remarked, because of poverty, sex work pulled in children. Seabrook (2000) reported poverty had forced women, including young girls, to participate in sex tourism. Karen Jullien's (2003) study, presented poverty as a key cause in fostering child prostitution, as had Sealy-Burke's (2006) study in the Caribbean. Samoan results aligned to the Kenya (2003) report, and the Central America, Panama and the Dominican Republic report undertaken (Sorensen and Claramunt, 2003).

A notable finding of this study was that although people knew that prostitution was happening, they were unsure about how to stop it. An example was a mother had prostituted her daughter at the local market in full view of the Samoan public, the official had asked, "What can we do, nothing!" Interestingly, the people observing the problem had been child protection workers.

Of note, during my earlier one week pilot study in Apia (in 2008) to attend the Measina conference, I had taken the time and spent a number of nights observing child vendors selling wares and food items outside bars and nightclubs late at night, in addition to their interactions with tourists. Since then, the Compulsory Education Act (2009) had been introduced that specified any parent whose child was found selling wares in streets during school hours from 9am to $2 \mathrm{pm}$ would be penalised with a fine of Samoa Tala Dollars $\$ 1,000.00$. When I returned to Samoa to begin fieldwork some four months later, 
I revisited the same sites and observed no child vendors operating outside bars and nightclubs. What I did see instead, after the bars and nightclubs had closed, were fa'afafine instigating the prostitution of young girls in the main street of Apia.

I discovered a less often cited form of prostitution operating in the Pacific, (at least not raised in The Pacific Interagency Report, 2006), being sex tourism involving the transgendered community / fa'afafine, as both perpetrators and facilitators of sex tourism and CST, and young boys involvement. Only one participant discussed 'homosexual sex tourism', operating in Samoa, the participant linked to adult fa 'afafine, homosexual sex tourism increasingly involving transgendered boys. The worry for that participant was the 'homosexual' sex tourism industry could create a demand for fa' afafine boys. As per the eyewitness accounts, the concerns of the participant appeared spot on.

\section{Tourism Excused of Action}

Participants' responses to the question, "How do you regard tourism in Samoa positively or negatively", revealed a mix of emotions about tourism. The main line of positive discussion centered on tourism driving economic growth and tourists putting more money in people's pockets, contributing to village income and the benevolence of tourists' contributing directly to children's education. The taxi driver group held an opinion that tourism and tourists provided much-needed cash either to support their family, or to supplement other sources of incomes such as shop-keeping, security work, fishing and farming. That all participants rated tourism highly for the economy of the country, suggested Samoa had a tourism dependency problem.

In Samoa, there was an unregulated tourism industry, no taxi authority body, and a noticeable "taxi glut." Tourist's trends had changed, and tourists were now taking fewer rides around the two islands as had been done before. Participants talked about inappropriate tourist behaviour eroding the social and moral integrity of the Samoan lifestyle and cultural values, for example, tourists kissing publicly in front of children and women wearing bikinis and skimpy clothing in and around village areas. Often 
participants were unsure about how to respond to transgressions of traditional cultural mores generating new problems for families to cope with. The STA did not support a Code of Conduct to educate tourists on how they should conduct themselves in and around villages. Thus, villages felt compelled to devise their own Code of Conduct to manage tourism transgression. In their eyes, they were doing the job that the Samoa Tourism Authority should have been doing.

In addition, there was a lack of preparatory planning against the negative effects of tourism for Samoan families and children, such as CST. Generally, participants believed the Samoa Tourism Authority should be doing more to manage bad tourist behaviour, and to prevent CST. Participants in the urban focus group discussion drew emphasis to the lack of preparation for CST as seen in their questions:

1. What would be the effects of CST for Samoa's image?"

2. What impact does sex tourism have on the tourism industry in Samoa?

3. Would a CST problem in Samoa have any impact on the tourism industry?

4. Would CST impact on the way outsiders perceive the people of Samoa? (Rural Focus Group).

Yet, unsurprisingly, as my discussion with the STA participant, the STA did not consider that it had a role to play in the prevention of CST (a similar finding of the Special Rapporteur Calcetos-Santos in the Fiji Case, 1999, chapter 1) with a role of responsibility to promote the economy of the country.

\section{Awareness about Child Sex Tourism}

Amongst participants there was inconsistency about what CST was, about the age of a 'child' and who the child sex tourist was. The Convention of the Rights of the Child (1989) had defined 'child' as an individual who is under 18 years of age, and Samoan law presented a child who is 16 years of age. Yet, a number of participants provided a variation on the age of a 'child'. In discussion, ages ranged from 16 years to 65 years. 
The indecisive age of child was emphasised in a Samoa report entitled: A Situation Analysis of Children, Women, and Youth (Government of Samoa and UNICEF, 2006). in a recommendation that, "the appropriate Ministries needed to take action to resolve the matter of the different age definitions of a child used in the different sectors that work with children and within the legislation used in Samoa for particular situations" (p. 24).

Generally, there was a resistance to the CRC definition of 'child', child right's, and the child's right to privacy, resisted. Participants in the civil society group discussed the $\mathrm{CRC}$ push for the rights of a child to his or her privacy, took away a communal right to 'watch' the child that was a traditional social form of protection (doors open). Toganivalau (1999) explained, "The notion of child's rights was somewhat alien to the Pacific cultural context where strong extended families and communities are founded on group solidarity rather than individual rights" (p. 227).

In Apia, there was a noticeable lack of awareness about what CST was and entailed. Participants termed CST either "sex tourism" or "tourism sex with children" or just "tourist sex." In discussions, participants simply referred to the child sex tourist as a “pedophile'. This 'pidgin holing' CST as 'pedophile' problem also seen in The Samoa Tourism Authority Development Plan (2009-2013) SWOT Analysis having presented pedophilia as its focus for prevention (Government of Samoa and Samoa Tourism Authority, 2009, p.109). In addition, The Revised Pacific Platform of Action for Women (2005-2015), had emphasised the prevention of "pedophile tourism" as a regional priority (p.53).

The literature on CST usually referred to more than one type of perpetrator. The 'opportunistic / situational' (discovered operating in Samoa) was a perpetrator who did not intentionally travel for the purpose of engaging in sexual acts with minors, but saw it as something worth experiencing. Situational users were the most common types of users (ECPAT, 2008). As defined by ECPAT, (2008) the 'preferential' child sex perpetrator (the main type of perpetrator discussed as operating in Samoa) represented the minority 
of CST offenders. This perpetrator intentionally sought children out for sexual purposes. The pedophile was probably the most well known type of child sex offender, although representing a minority of CST abuse. As the term presents, pedophilia in general was a clinical term used to refer to adults with a sexual preference for pre-pubertal children.

The term, 'tourist as trader', was how Samoans were identifying CSEC / CST in Samoa. The "tourist as trader was defined by one participant as: "Samoan families provide hospitality, and offered trust, which the tourist took as an opportunity to 'pay his way in' and abuse Samoan hospitality." The term "Tourist as Trader" appeared to have aligned to the definition of CSEC as follows:

\footnotetext{
The "sexual abuse by the adult and remuneration in cash or kind to the child or a third person or persons," in the Declaration and Agenda for Action against Commercial Sexual Exploitation of Children. It is a process through which "the child is treated as a sexual object and as a commercial object" and "which constitutes a form of coercion and violence against children, and amounts to forced labour and a contemporary form of slavery. (ECPAT, 2008, p. 3)
}

\subsection{Key Root Causes}

Objective 2 of this study aimed to identify and report root causes that contributed to CST in Samoa. On a global scale, CST was a complex interplay between the forces of Push and Pull, and Supply and Demand. This was well understood and discussed earlier (in chapter 2). Participants had listed what they perceived were the root causes for CST, my analysis of data had raised another 10 . From the 20, I had identified a list of four root causes for CST in Samoa as follows: 1) Complacency; 2) Attitudes to data collection; 3) proving a problem exists, and 4) Under-reporting. 


\section{Complacency}

As Goodwin (2011) stated, “when something is everyone's responsibility, it can end up being nobody's" (p.31). Special Rapporteur Visit Muntarbhorn (2001) argued that the 1996 Stockholm implementation process was not clear-cut as its implementation was challenged by what he termed the five 'Cs', of which Complacency was one. As raised in Chapter 1, the Mutch case in Fiji, revealed widespread complacency that was a reason for the on-going sexual abuse of child victims spanning years. For this Samoan study, complacency was the major underlying cause driving this problem in Samoa, and best explained why child sex tourists were able to sexually abuse Samoan children over time.

Participants generally held an opinion that the Government of Samoan had a responsibility to enact the various $\mathrm{UN}$ treaties it had signed, such as the CRC. Generally the feeling from NGOs, were the government was not yet fulfilling even its statutory obligations. Participants considered the government held a responsibility to prevent CST particularly through government agencies such as the MWCSD. The MWCSD was tasked as responsible to work on CST. However, in some discussions it was apparent that this decision to make children the responsibility of the MWCSD had been a mistake such as seen in the comment of one participant: "We used to have Ministry of Youth; they should never have got rid of the Ministry of Youth." There had been a national marginalization of children in policy development. Within the Samoan government, the children's portfolio appeared unimportant, and given budgetary constraints, government departments in this area were under-resourced and policy development has been slow. The Child protection budget was inadequate and there was a lack of human resource.

Although the MWCSD had considered the Strategy for the Development of Samoa (2008-2012), implementation of the Policy on Women and the Policy on Children a major achievement, at all ministerial and sector levels, the feeling from the MWCSD was to devolve child protection responsibilities back to all the various government bodies 
by allocating two percent or three percent of their budgets, in their own context and in line with their own mandates, to do child protection work; so to raise awareness in their own areas on child's rights.

Three causes arose in discussions. First, agencies had their own set of priorities and ability ranging from education and raising awareness of CST, to legislation and strategies to protect victims of abuse. Second, while CST was a central concern for some agencies such as the TCU and ECPAT Samoa, the MWCSD regarded it as one aspect of a larger basket of programs. However, the Samoa Tourism Authority did not have counter measures in place, nor did it consider its role was to prevent CST.

Concerning, NGOs (considered child rights advocates and activists) - were not investing their time or effort on this issue. Reasons were that unless the government said they had to do so, there was no reason to do so. Other reasons included lack of funding, resource constraints (human and financial), or CST was not their issue. Taken together, this could explain why no reports had come out in the back villages where CST was able to continue unabated.

Media were not utilised for public awareness. Participants were not recognising the impact of CST for children. No participant recommended improvement in areas of recovery and reintegration for child victims of CST. In addition, there was no clear consensus on age of child. Neither was there a clear understanding of what CST was. Generally, all said and done, no participant raised the NCCRC or the CRC Partnership or CEDAW Partnership should be working on this issue. Most concerning, was the comment no organisation wanted to be in charge of children.

A second point of evidence for complacency was the earlier discussed news media report from Lesa (2000), reported approximately nine years earlier to this studytaking place in Samoa (2009), that clearly showed the issues happening back then, remained, and clearly not dealt with now. 


\section{As the discussion related to this study's findings, the report's main points were as}

follows:

- "That such a crime was slowly creeping into the country through the Tourism industry

- "Prostitution is indeed visible in the night life scene in Apia"

- "Because of Samoa's heavy reliance on the Tourism industry to boost the economy, It would be hard to distinguish the difference between 'clean tourists' and 'sex tourists.'

- 'Samoa's low-income per capita rate makes people easily vulnerable to dirty money, especially young children who are easily lured and seduced by the sight of a dollar or two."

- $\quad$ These highly competence criminals are very hard to detect because some of them are top business people, top business executives who enter the country as business people who want to carry out their businesses in Samoa,"

- $\quad$ "These people go out to the villages, stay with families and they (sex tourists) help out families with food and shelter. Samoans are polite people and they very much respect foreigners."

- Unfortunately, most Samoans do not know what some of these tourists are up to."

- The biggest problem was the fact that some families were poor. These families however are primary targets for sex tourists because of the money cause." The bottom line is money,"

- No matter how strong the fa' asamoa and Christianity principles are poor families are bound to give in because they don't have any money. The parents would eventually agree."

- $\quad$ There is a real need to reinforce the law which deals with child prostitution and pornography. Perhaps tighten it so we would be able to clamp down on this kind of crime."

- "The use of Internet promotes the illegal industry." Child sex has been widely facilitated by the use of the internet,"

- "Most parents don't know what their children are up to when they're surfing the web. The parents think their children are doing their school work but most of the time they're not." (Samoa Observer 1.11.2000 


\section{Attitudes to Data Collection (Funding Needs to be Large)}

A second underlying cause was attitudinal, that before research was done, and funding had to be large. Stockholm (1996) provided startling evidence that the CSEC was a major issue and had emphasised the urgency for delegates to conduct further research on the issue. The MWCSD had reported the Situational Study on CSEC and CSA in Samoa had not been followed up. That was despite in 2007, a Samoa delegation having had attended the Regional Stakeholders' Consultation and Planning Workshop on the Commercial Sexual Exploitation of Children and Child Sexual Abuse in the Pacific, reporting to the workshop that it had completed its CSA and CSEC situational study and awaiting publication.

The MWCSD had reported a number of challenges the Ministry had faced in getting the CSA and CSEC data for the situational study. Issues were a lack of commitment to CSEC from partners and stakeholders, including limited understanding of CSEC and getting CSEC on the Government's list of priorities. In addition was a lack of information for evidence-based advocacy, as well as the territorialism of organisations, which limits the sharing of information with others (ESCAP, 2007). Nevertheless, after the 'situational analysis' was abandoned, the MWCSD as CRC focal point also showed a lack of commitment to data collection and child protection. For example, the Ministry could not conduct a smaller research because the funding was reportedly minimal; a decision I suggest disingenuous to its role as co-protector of Samoan children.

\section{Proving a Problem Exists}

The third underlying cause was the opinion of people in the position of power to advance CST work further, that before any work could be done there had to be statistics to 'prove' the problem existed. That CST had to be 'proven' by statistics was incredulous because such an opinion premised on a child becoming a victim and then a 'statistic'. 


\section{Under Reporting: Child Sex Tourists Beaten and Deported}

The fourth finding was under reporting. Although participants considered that to combat CST, new laws were needed, the question remained, "what benefit were new laws if perpetrators were beaten and deported without prosecution?" Moreover, that equally applied to overseas workers deported under Memorandum of Understandings.

\section{Summary}

Child sex tourism (CST), is a serious problem in Samoa. The transcribed data once analysed, revealed 10 subsequent root causes, and four substantial root causes. Victims of tourists' sexual abuses were reportedly boys (including straight and transgendered ones) and girls. Perpetrators were preferential, and opportunistic. Facilitators consisted of many parts of the Samoan community. Few organisations were responding to CST. Chapter 8 presents, methodology, limitations , implications, recommendations, and this study's siginificance to the wider Pacific and global audience. 


\section{Chapter 8: Conclusions and Recommendations}

\subsection{Introduction}

This study began by reviewing the historical context of colonial stereotypes and the post-modern sexual exploitation of women and girls in the South Pacific tourism marketing and then went on to consider the current situation of CST in Samoa. My study grew out of a 2006, Committee of the CRC recommendation to Samoa. The Committee was concerned that the growing tourism industry in Samoa may facilitate sexual exploitation of children. The CRC Committee recommended that Samoa do the following:

[56]. The Committee recommends that the State party

a) Conduct a study to determine the root causes and the scope of sexual exploitation

b) Use the outcome of this study to develop and implement an effective and comprehensive policy addressing the sexual exploitation of children, in accordance with the Declaration and Agenda for Action and the Global Commitment adopted at the 1996 and 2001 World Congress against Commercial Sexual Exploitation of Children

c) Seek international cooperation, in particular from UNICEF. (UNCRC, 2006a, p. 12) '

This study concerned itself with recommendations [\#56] of The Committee's recommendation. I had set three objectives aimed to form the basis of my investigation and analysis, and a framework for final discussion, conclusions, and recommendations. I aimed to report the scope of CST in Samoa, to identify and report the root causes that contributed to the risk of CST in Samoa, and to present a set of recommendations as a baseline foundation for policy, advocacy, and research. From fieldwork and findings, I aimed to make baseline data for future research and recommendations to support child 
protection work already well underway in Samoa. Therefore, this final chapter of the thesis presents an overview of methodology, limitations, and implications of the results; followed by recommendations and the significance of this study to the wider audience.

\subsection{Methodology}

Due to the highly sensitive and criminal nature of this study's topic, undertaking research on CST was always going to be challenging. I knew that the questions I would be asking and asked were sensitive and in some cases unpalatable in a country where children are loved and valued and where family systems were so strongly drawn. Although, once raised it was almost impossible to stop the flow of concerned views on this topic. Based on my discussions with participants, clearly, Samoans do care for their children; they do not want CST operating there.

Overall, I believe that this study's qualitative research approach combined with the single embedded case study design, worked very well. The evidence for this was in the rich findings, and high level of participation from government, intergovernmental, civil society, and community and taxi drivers who spoke freely with me on this issue. I was able to engage freely with participants because the methods associated with a qualitative research were flexible, and because participants responded positively to a 'human face', and a researcher 'speaking from the 'heart'. Overall, I was able to collect a rich spectrum of data that enabled me to make a reliable description, and analysis of the data.

The cultural advisor's assistance proved valuable on so many levels. Because he was so well respected, he became a primary access point to participants whom ordinarily I would have had difficulty accessing. Other benefits were his help with cultural protocols and translation. The cultural advisor was also a taxi owner / operator. Numerous CSEC reports such as the Pacific Interagency Report (2006) had referred to taxi drivers facilitating CST, placing them in bad light. This study's findings also reported on taxi drivers facilitating CST. However, the taxi drivers participating in the 
survey were also men with families, who cared enough about the safety of Samoan children that they provided invaluable insight into how they perceived this issue; where they thought problems lay and actions needed to prevent the problem advancing.

\subsection{Limitations}

This case study was been carried out in Apia, a single tourist setting in Samoa, therefore, the study findings were not representative of Samoa as a whole. I had not included research participants under the age of 18. I was uneasy about the idea of interviewing CST victims, as to do so ethically, would require specialised training. In addition, I did not seek out from child sex tourists, their motivations to abuse children sexually.

To prevent interviewer bias, I included both male and female participants in this study. In interviews with men, my gender may have affected the type of information I received due to the sexual nature of the topic. This applied to female participants, who may have been less inclined to share sensitive information with me when the cultural advisor, a male, accompanied me into two interviews. However, since the saturated data generated consistent responses from both male and female participants, I believe gender bias was minimised.

A further limitation to this study could be the significant amount of time that had elapsed since my fieldwork in 2009. A number of important changes had taken place. Some of these changes are as follows:

1. A Strategy for the Development of Samoa (2012-2016) "Boosting Productivity for Sustainable Development"

2. A Samoa General Election 2011

3. A Samoa Tourism Sector Plan (2014 - 2019)

4. A Samoa Law and Justice Sector Plan (2012 - 2016) 
One positive improvement for children had occurred in 2010, when New Zealand and Australia jointly funded a major new initiative providing school fee grants to state, mission, and special education schools that removed the need for families to pay school fees. The scheme evolved as a response to the economic pressure on families from the Global Economic Crisis, and adopted as a long-term policy by the Samoan Government. Nonetheless, since fieldwork (in 2009), there had been no specific policy changes against CST. Neither had there been any study, small or large, academic or non academic, on CST.

\subsection{Implications}

In Samoa, there was an aggressive tourism industry and promotion, yet from the Ministry of Tourism, Samoa Tourism Authority, and tourism industry there was a conspicuous lack of adequate child protection effort against CST. Samoan tourism had not decreased poverty. To the contrary, it has produced pockets of profit for some, and for others, little or no profit, and a prostitution industry that facilitated CST.As detailed by the eyewitness testimony, boys, girls, and fa' afafine had engaged in sexual activity with two preferential child sex tourists and an overseas contract worker. The children returned to school, the perpetrators were beaten, and then deported. I harbor a number of concerns about this outcome.

It was highly unlikely that the children had sought medical assistance or counseling. To do so would have exposed their transgressions, and shame. The customary reconciliation system (ifoga) had been utilised as a means for resolving the sexual abuse of children by tourists; the question left standing "what purpose did 'apology' serve? How does this system serve the 'best interests' of the child in this situation? Additionally, we do not know if any of the perpetrators had a STD or HIV/AIDs. We do not know if any of the female victims had become pregnant, or if any victims had developed psychological damage then, and over time. As the data asserts, Samoa had a high STD rate, and teen pregnancy was rising, although the data did not 
reveal if STDs and teen pregnancies were because of sexual activity with tourists. HIV/AIDS was a worrying issue throughout the Pacific, and a lot of donor money invested for its prevention.

Following Samoa's initial report to The Committee (Government of Samoa, 2005), The Committee replied back requesting additional information on "statistical data by sex, age and by islands for 2003, 2004 and 2005, on the numbers of children sexually exploited, including prostitution, pornography and /or trafficking" (UNCRC, August, 2006, pp. 24-25). Samoa did not reply to this request. In part, this study's findings provided answers to The Committee's request. In Samoa, CST does not act in isolation; all forms of the SEC operated alongside it. Samoan children had engaged in prostitution; were involved in the production of child pornography, and trafficked within Samoa borders for the purpose of sexual activity. Although The Committee did not request information on CST or child bride/early marriage), informal marriage operated alongside CST.

Derived from my results, participants had not considered the detrimental effects of CST for children's health, both short term and long term. Evidence of this followed my question to participants about the positive and negative effects of tourism for them. Although participants conceded that increased tourism would bring in more sex tourism, including STDs and HIV/AIDs, no participant linked sex tourism to CST, and children pulled in to CST, or children contracting a STD or HIV/AIDs. Additionally, was the worrying revelation that moral judgments were applied in the distribution of condoms. A judgment made without consideration of the wider implications for the health of Samoan's, the remaining countries of the Pacific and beyond. Furthermore, the question asked of participants, "what actions needed to be done?" not one participant raised the need for provisions for the physical and psychological recovery and social reintegration of child victims or children's participation in preventions. Generally, CST was considered an adult problem to fix. Participants conceded that CST should be combated now before it became costly to fix. 
Incidentally, what stood out was a possible generational pattern of facilitator to sexual abuse and CST. For example, a participant revelation of a tourist targeting a child to bring in other children:

There was a van going round stopping at children along the road. He was giving them cakes and lollies so when a child came in, that one child will be the main target, and that child will go and ask another child, will they come back another day. He will pick them up - unseen, but it's happening.

The question was, this child victim, having tasted the benefits associated with this role of facilitator (luxury items), could be the next generation of CST facilitator?

The ramifications of CST for Samoa are significant. The Stockholm Declaration and Agenda for Action (1996) had recognised the serious implications of CST for children, families, and the national quality of life such as lifelong, life-threatening consequences for children's physical, psychological, spiritual, moral, and social development, including early pregnancy, maternal mortality, injury, retarded development, physical disabilities, and STDs including HIV/AIDS and the loss of childhood (Stockholm Declaration and Agenda for Action, 1996).

\subsection{Recommendations}

As Objective 3 of this study, I aimed to present recommendations as a baseline foundation for policy, advocacy, and research. To do so, I present two sets of recommendations. The first set was participants viewpoints about actions needed to prevent CST in Samoa. As follows:

\subsection{1 (According to Participants)}

\section{Raising Awareness}

- There needs to be more programmes on this issue in the town areas because nothing is coming out to address people there who need help. (Civil Society) 
- Education programmes out in the country about this issue. (Taxi Driver)

- Educate the people and let it be the people's responsibility to look into this problem. Increase CST awareness in tourism-related venues and outlets. (Taxi Driver)

- An education program aimed at parents explaining what CST is and how child sex tourists gain access to children using technology. More awareness about how pedophile networks operate on the internet and pornography sent to pedophile groups (Civil Society).

- Increased programmes to advance men and boys' opportunities in life. (Civil Society)

- Education programmes in the secondary school curriculum to deliver the right message to children on this issue so that they know how to overcome. (Taxi Driver)

- Programmes to teach locals about the types of diseases tourists bring in. (Government Official)

- For what they have seen or what they have heard from the briefing, they just realise the great needs for an awareness of what is going on, especially influence of outside - as the tourists come in and do that sort of things to our children and our customs. (Rural Focus Group)

- In our office, we should have pamphlets explaining how to protect children against tourism sex. In our job, we are educating the people to be aware and to be aware there is some sort of protection from global influences. (NGO, Civil Society)

- Awareness material, should distributed to villages, airports, wharves and the port authority. These should be in the Samoan language as well as English. (Taxi Drivers)

\section{Allocating Budgets for Child Protection}

- All government bodies should allocate two to three percent of their budgets to do child protection work, so to raise awareness in their areas on child's rights in their own context and in line with their own mandates. (Government Official)

- Provide funding for awareness programmes on TV, the radio and posters, etc. Parents and families should be made aware about the CST problem." (Urban Focus Group) 


\section{Legislation and Reporting Systems}

- There must be specific legislation to prevent CST in Samoa (Urban Focus Group). There must be a system of reporting. Every Samoan must receive information of this system with clear and easy to do contacts. Set up a hotline to report to the police. (Government Official)

\section{Data Collection}

- Research to show the extent and nature of CST. How tourism influences Samoan culture. Sex tourism involving children and fa'afafine boys. (Civil Society)

- More study looking at sex tourism; and homosexual tourism involving children and fa' afafine boys, so to get some qualitative information on this issue. (Civil Society)

- People are hospitable and accept tourists in the family without knowing that they are doing something else with the kids and the kids are taking money. So looking at this issue is a wake-up call. It is good to look at tourism influencing our culture and what tourism is doing to our young kids. (Civil Society)

\section{Village Based Strategies}

- I think the first thing that should be done is work through the villages as I think that's where it [CST] is happening. For example, the two most important things in Samoa is your culture and your church and you go through the church and the villages in terms of the village mayor and the government and the Ministry of Internal Affairs who is responsible for all of the pulenu' $u$ of all the villages. So that would be a big starting point. Call a meeting of the mayors and raise the issue there. Thereon the mayors go back to the villages, have meetings in the villages, get the matai's in, and discuss the issue within the village setting. Then matai's go back to their family.

At the same time, church has to perform its part as well because people do listen to what the church ministers have to say so you have to target those people as well. Those are the two most effective tools of getting this message across. TV yes, but not everyone has a TV. Paper, yes, but not everyone can afford a paper. I think if you want to get the 
message across you have to go through those two forums. This is where village power comes in, where matai rule can help.

\section{Community Consultation}

- The 'system' (the government) needs to listen to Samoans about these types of issues who are not within the 'system. It is very hard to break into the 'system' here. (Taxi Driver)

\section{Family Based Strategies}

- Re-affirm family and cultural wisdom. (Taxi Driver)

- Heighten vigilance and arrange a town curfew. (Taxi Driver)

- Always have someone older to take kids to school and pick them up and to teach the kids not to approach strangers. (Rural Focus Group)

- Strengthen relationships between children parents and schools (Taxi Driver)

- Strengthen family values and good communication between parents and children

- The key is family. Every Samoan family had lost family values and it was about time that parents spent time reinstating family values with their children. There must be good communication between parents and children. This country is very shy when we talk about sex but is time to let our family know this thing. Need to talk about it with our children. (Taxi Driver)

\subsection{2 (From Data Analysis)}

In addition, this second set of recommendations was gleaned from data analysis. As follows:

\section{Convene a National Discussion on CST}

As the MWCSD participant pointed out, the last national discussion on CSEC took part after the delegation had arrived back from Bangkok. After that, nothing else had happened. A national meeting should be convened to discuss the CST issue in 
Samoa. Participating groups should include the Law and Justice sector, MWCSD, CRC / CEDAW Partnerships, the Minister of Tourism, Health and Education, and civil society particularly, donors, SUNGO, NGOs the church, the Samoa Fa'afafine Association, HIV/AIDs Foundation, youth groups, and grassroots community organisations working with youth, including private hotel workers, taxi drivers, rental accommodation owners and any other party wanting to give voice on this issue.

In this study there were many issues that needed further discussion and action. Some of which were identified as follows:

- To adopt the Optional Protocol to the Convention on the Rights of the Child on the Sale of Children, Child Prostitution, and Child Pornography (2000)

- To determine, the extent of the adult sex tourism industry in Samoa, and its effects on children

- Children willing to engage in sex with tourists for money

- Non-reporting CST because of the culture of shame

- Families actively looking for the 'tourist as trader'

- Letting perpetrators go without a data trail? Including overseas workers and MOU

- The extent of philanthropic exploitation

- Fa'afafine facilitating prostitution of minors

- The role of the Ministry of Tourism / Samoa Tourism Authority and tourism industry in prevention of CST in Samoa.

\section{The Urban Focus Group Questions}

Particularly, the relevant authorities must answer the earlier raised urban focus group questions they asked of me. As follows: 
- What assistance is available to community organisations to carry out preventive work?

- Is there any assistance available for families needing help in this area, or if identified or if sexual tourism? What type of help is available?

- Would there be assistance available to a particular group of women who work within this area?

- What impact does sex tourism have in Samoa, in relation to the tourism industry? Does it have any impact? How would people outside Samoa perceive the people of Samoa?

- If there is a crisis, which area should families turn to for help?

- Are there any territorial laws to control tourism legislation or tourism behaviours?

- How important is this forum to setting recommendations for legislation?

- Will there be back-up from people from international tourism countries?

\section{The Ministry of Education}

The Ministry of Education needs to ask the question "why are students able to leave school during the school day to engage in sex with tourists?" Other issues for discussion are student use of cell phones in school. Clearly, students are contacted by cell phone to meet tourists for sex. Moreover, other discussions should centre on the high cost of secondary education, facilitating children's entry into CST. Finally, secondary school scholarship sponsorship by tourists and their misuse by tourists should be a priority discussion.

\section{The Ministry of Tourism}

Borrowing this recommendation from the Pacific Interagency Report (2006)

...promote the development of industry codes of conduct aimed at combating the commercial sexual exploitation of children and CST, as well as training and awareness raising for service providers (such as hotel and bar staff, night club owners and staff, tour 
operators, resort staff, taxi drivers, boat operators etc) in the recognition of s0trategies to prevent child sexual abuse and exploitation, and reporting obligations. (p.125)

In addition, the Ministry of Tourism should consider the ASEAN model:

- Mobilise responsible travellers and local citizens to report suspected CST on dedicated hotline numbers

- To deter potential child-sex offenders

- To create a culture of intolerance toward the sexual exploitation of children (Child Wise, 2007, p. 31)

\section{Civil Society}

Particularly, call upon grassroots organisations, and members of the community, to conduct smaller studies on all five forms of CSEC - as smaller building blocks toward the larger picture. In addition, NGOs should create public programmes / workshops / presentations, aimed towards providing awareness of all forms of CSEC, and what each form entails. Media should assist to provide awareness of CST through its editorial option.

\section{Data Collection}

In the first instance, the MWCSD should revisit the abandoned situational analysis on CSA and CSEC and complete it. As the original intention of the study, disseminate findings for advocacy, lobbying and designing child protection programming. Particularly, findings should be included into the next National Policy for Children, due to end 2015.

In addition, it is important that the Samoa research community contribute to work on this issue and CSEC in general. Already, the comments were graduates rehash information because there is no 'new' information. In this study, there are many issues needing further research from the academic community. 


\subsection{Significance of Findings}

On paper, the Government of Samoa had taken the eradication of CSEC in Samoa seriously and regarded it as an urgent matter. Evidence of this is the Government of Samoa having signed and ratified the Convention on the Rights of the Child (1994). By ratifying the Convention, the Government of Samoa had formally agreed to the following:

The family as the fundamental group of society and the natural environment, for the growth and well-being of all its members and particularly children, should be afforded the necessary protection and assistance so that it can fully assume its responsibilities within the community (Preamble to the CRC, 1989)

Specifically, the Government of Samoa, had recognised the child above all should be afforded precise protection against sexual exploitation as provided for in Articles, 32, 34, 35, and 36, of the Convention. Article 34, in particular recognised the cross-border aspects of the sexual exploitation of children (and was therefore of specific relevance to CST) by requiring governments to take action through national, bilateral and multilateral measures. In addition, as a Pacific forum country, the Government of Samoan had pledged its commitment to the Revised Pacific Plan for Action: A Regional Charter (2005-2015), of which one strategy aimed to combat pedophilia in the Pacific region. Moreover, the Government of Samoa had demonstrated a commitment to Stockholm (1996) and Yokohama (2001) agreements drawn up specifically for drawing attention to CSEC issues. More to the point, a number of high-powered Samoan organisations and agencies had attended a number of pivotal regional conferences, and workshops to work against CSEC, often in collaboration with East Asia partner countries, often donor funded and often convened for stronger collaboration and cooperation between countries to combat CSEC. 


\subsection{Final Words}

After many decades of tourism, Samoa is beginning to see, and feel the social impacts of tourism. It is likely that social impacts will become more pronounced, and more obvious as larger numbers of tourists and workers travel to Samoa, and the country retains a silence to CST and CSEC overall. This study's results extend upon the work on CST, to take it to the next level. As a starting point, regarding the National Policy for Children of Samoa (2010-2015): Reduction of Abuse, Violence, and Exploitation, this study's findings asserts that the children of Samoa are not well served by an informed and coordinated child protection service to ensure their greater protection against violence, abuse, and exploitation.

Given the serious implications of CST on child, family, and national quality of life, and given the undertakings to protect the rights of children mandated by the signatures on the CRC , and by the imperatives of social justice; I saw this research as not only important but vital, that bought with it a responsibility for action. I hoped that this study's findings would provide a working knowledge to assist policy makers to develop relevant policy, and programmes and civil society group's information about CST in a small island country, for increased advocacy. For the Pacific academic community, I hope this study offered a baseline for future qualitative, and quantitative research. Thus, attitudes and mindsets, and complacency are major obstacles. There is a need for strong will and participatory action to change social and ideological conditions. In particular, there is a need to provide psychological counselling and medical assistance to children who have been through the trauma of CST forced, or otherwise. Above all, it is the responsibility of family, and state together, that the full development of children to a happy and carefree childhood is provided. At stake is nothing less than the future of Samoan children, and their right to grow up in a safe environment that is free from the perils of CST. 


\section{References}

Agrawal, A., \& Gibson, C. (1999). Enchantment and disenchantment: The role of community in natural resource conservation. World Development, 629-649.

Arnold, C., \& Bertone, A. (2002). Addressing the sex trade in Thailand: Some lessons learned from NGOs. Retrieved from http://www.springerlink.com/content/klx38ax3mckfamae/

AusAid. (2012). Samoa country case study. AusAID Pacific social protection series. Retrieved from www.AusAID.gov.au/publications

Auseugaefa, M. (2004, June 23). Samoa: Government statement concerning Father Francis (Frank) Klep. Retrieved from http://www.samoa.co.uk/20040623-pmklep.html

Baker, C. (1995). Kiddy sex--luring the tourist for love beneath the palms. Currents in Modern Thought.

Barnitz, L. (1998). Commercial sexual exploitation of children: Youth involved in prostitution, pornography \& sex trafficking. Youth Advocate Program Intl.

Baxter, P., \& Jack, S. (2008). Qualitative case study methodology: Study design and implementation for novice researchers. In The Qualitative Report (pp. 544-559).

Bertram, G. (1999). The MIRAB Model Twelve Years On. The Contemporary Pacific, 11(1), pp. 105-38.

Betterton, R. (1996). An intimate disctance: Women artists and the body. London: Routledge.

Bhabha, H. (2004). Locations of culture. London: Routledge.

Bloomfield, P. (2002). Kingdom of Tonga: On the occasion of the United Nations General Assembly Special Session on Children. United Nations General Assembly Special Session on Children. New York: Kingdom of Tonga . Retrieved from http://www.un.org/gachildren/tongaE.htm 
Boyden, J., \& Mann, G. (2000, 9). Children's risk, resilience and coping in extreme situations: Challenges to children's wellbeing. 3-24. Retrieved from http://www.corwin.com/upm-data/5336_Ungar_I_Proof_Chapter_1.pdf

Brungs, M. (2002). Abolishing child sex tourism: Australia's contribution. Australian Journal of Human Rights.

Buenger, B. (1989). Representing the expressionist's simple life: Ernst Ludwig Kirchner's modern Bohemiain. In R. Grimm, \& J. Hermand (Eds.), From the Greeks to the Greens: Images of the simple life (pp. 78-110). Madison: Monatshefte.

Canon, M. (2001). Invited commentaries on: Cycle of child sexual abuse: links between being a victim and becoming a perpetrator. $B J P, 495-496$.

CEDAW. (2003). Report on the status of women in Samoa 2001: Consideration of reports submitted by States Parties under Article 18 of the Convention on the Elimination of All Forms of Discrimination against Women: Combined initial, second and third periodic report. Geneva: United Nations CEDAW/C/WSM/1-3.

Charmaz, K. (2000). Grounded theory: Objectivist and constructivist methods. In N. K. Denzin, \& Y. S. Lincoln, Handbook of Qualitative Research (pp. 509-535). Thousand Oaks, CA: Sage.

Chetty, K. (2007). Child sex tourism in South African law. Masters Thesis. South Africa: Faculty of Law Nelson Mandela Metropolitan University. Retrieved from http://dspace.nmmu.ac.za:8080/jspui/bitstream/10948/485/1/KChetty.pdf.

Child Protection Alliance and Terre des Hommes. (2003). Gambia... The Smiling Coast!. A study of child sex tourism in the Gambia and the involvement of Dutch tourists. Netherlands: Terre des Hommes.

ChildWise . (2004). Global action to combat child sex tourism. Australian Institute of Criminology International Conference (pp. 1-6). Melbourne: ChildWise Australia.

ChildWise. (2007). ASEAN child sex tourism review: An outcome of the annual meeting of the ASEAN regional taskforce to combat the sexual exploitation of children in tourism destinations. Melbourne: ECPAT Australia. Retrieved from http://www.childwise.net/images/stories/documents/online_publication 
Chow, R. (1996). Where have all the natives gone? In P. Mongia, Contemporay Postcolonial Theory: A reader. New York: Arnold Publishing.

Christian Care Centre of the Church of Melanesia and the Regional Rights Resource Team (RRRT). (2004). Commercial sexual exploitation of children and sexual abuse in the Solomon Islands: A situation analysis. Suva: UNICEF Pacific.

Christiansen, L. (2008a, April 16-18). What value the Pacific child? Building Pacific research capacity and scholarship in Aotearoa. Auckland, Fale Pasifika, University of Auckland, New Zealand.

Christiansen, L. (2008b, December 15-17). What value the Pacific child? The 4th Measina a Samoa Conference. E le o le fusiga po 'o le fisiga a o le niusina o le fa'asamoa: In search for the core elements of the fa'asamoa. Apia, Samoa: Centre for Samoan Studies. The National University of Samoa, Le Papaigalagala, Samoa.

CLARANET. (n.d.). Globalisation - tourism the new imperialism. Retrieved from http:/home.clara.net/heureka/gaia/global03.htm.

Collins, J \& Lutz

Crabtree, B., \& Miller, W. (1992). Doing qualitative research: Research methods for primary care (Vol. 3). Newbury Park, CA: Sage.

CREST: Centre for Responsible Travel. (2015, 03 Friday). Responsible travel: Global tends \& statistics. Retrieved from Responsible travel.org: http://www.responsibletravel.org/news/Fact_sheets/Fact_Sheet__Global_Ecotourism.pdf

David, F. (2000). Child sex tourism legislation is no 'paper tiger'. Australian Institute of Criminology.

Denzin, N., \& Lincoln, Y. (2005). Introduction: The discipline and practice of qualitative research. In N. Denzin, \& Y. Lincoln (Eds.), The Sage Handbook of Qualitative Research (3 ed., pp. 1-33). CA, Thousand Oaks: Sage.

Desai, N. (2001). See the evil: Tourism related paedophilia in Goa. Vikas Adhyayan Kendra. 
Durutalo, S. (1992). Anthropology and authoritarianism in the Pacific Islands. In L. Foerstel, \& A. Gilliam (Eds.), Confront the Margaret Mead Legacy: Scholarship, Empire and the South Pacific (pp. 206-232). Philadelphia: Temple University Press.

ECPAT. International (1998). Introduction. First Pacific regional conference on preventing the commercial sexual exploitation of Pacific children (p. 82). Suva: ECPAT Australia.

ECPAT International. (2003). Situational analysis studies on child sex tourism in tourist destinations of India, Nepal and Sri Lanka. Kathmandu: ECPAT Internattional. Retrieved from http://www.childtrafficking.com/Docs/ecpat_2003_situational_ana.pdf

ECPAT International and Pakistan Pediatrics Association. (2006). Situational Analysis Report on prostution on boys in Pakistan (Lahore \& Peshwar). Bangkok: ECPAT International.

ECPAT. International (2008). Combating child sex tourism: Questions and answers. Bangkok: Saladaeng Printing Co.Ltd.

Eisner, E. (1991). The enlightened eye: Qualitative inquiry and the enhancement of educational practice. New York, New York: Macmillan Publishing Company.

Ennew, J. (1986). The sexual exploitation of children. Cambridge: Polity.

EQUATIONS and ECPAT International. (2003). A situational analysis of child sex tourism in India (Kerala and Goa). EQUATIONS. Retrieved from http://lastradainternational.org/?main=documentation\&document=1412.

ESCAP, E. a. (2004). Post Yokohama mid-term review of the East Asia and Pacific regional commitment and action plan against CSEC .

Estes, R. (2001). The sexual exploitation of children: A working guide to the empirical literature. Philadelphia: University of Pennsylvania School of Social Work Center for Youth and Policy Studies. 
Fairbairn-Dunlop, P. (1991). E au le inailau a tamaitai: Women education and development Western Samoa. (PhD thesis, Macquarie University. Sydney, Australia).

Fanon, F. (1967). Black skin, white masks. London: Pluto Press.

Farran, E., \& Su'a, A. (n.d.). Discriminating on the grounds of status: Criminal law and fa'afafine and fakaleiti in the South Pacific. The University of the South Pacific, Emalus Campus. Fiji: The University of the South Pacific.

Farrelly, T., \& Nabobo - Baba, U. (2012). Talanoa as empathic research. International Development Conference (p. 12). Auckland: DEVNET.

Flanagan, K. (2004). Global action to combat child sex tourism. Australian Institute of Criminology International Conference (p. 6). Melbourne: ECPAT in Australia.

Flick, U. (2002). An introduction to qualitative research . Sage Publications.

Freeman, D. (1983). Margaret Mead and Samoa: The making and unmaking of an anthropological myth. Cambridge, MA: Harvard University Press.

Freeman, D. (1998). The fateful hoaxing of Margaret Mead: A historical analysis of her Samoan research. Boulder, Colorado: Westview Press.

Gauguin, P. (1947). Noa noa: Voyage a Tahiti. Stockholm: Jan Forlag.

Geographix, M. (-). Map of Samoa. Retrieved from www.maps.com

Goodwin, H. (2011). Taking responsibility for tourism. New York: Goodfellow.

Government of Kenya and UNICEF. (2003). The Extent and effect of sex tourism and sexual exploitation of children on the Kenyan Coast. UNICEF. Retrieved from $\mathrm{http}: / /$ lastradainternational.org/?main=documentation\&document=1418.

Government of Samoa. (1961). Crimes Ordinance 1961 (1961, No. 13). Apia: Samoa Government. Retrieved from http://www.ilo.org/dyn/natlex/docs/ELECTRONIC/72585/73867/F1240454562/ WSM72585.pdf 
Government of Samoa. (2003). Crimes (Extra-territorial Jurisdiction) Amendment, 2003, No 16. Government of Samoa. Retrieved from http://samoa.parliament.gohttp://samoa.parliament.gov.ws/documents/acts/CRIM ES\%20_ETJ_\%20AMENDT\%20ACT\%202003\%20english.pdf

Government of Samoa. (2005). Committee on the Rights of the Child: Consideration of reports submittedby states parties. Apia: Government of Samoa / CRC/C/WSM/1.

Government of Samoa. (2009). Government of Samoa questionnaire implementation of the Beijing Declaration and Platform for Action (1995) and the outcome of the Twenty-third Special Session of the General Assembly 2000. Retrieved from http://www.unescap.org/ESID/GAD/Issues/Beijing+15/Responds_to_Questionnai re/SAMOA.pdf

Government of Samoa and MWCSD. (2010). National Policy for Children of Samoa (2010-2015). Apia: Samoa Government. Retrieved from http://www.mwcsd.gov.ws/images/stories/PUBLICATIONS\%20WEBSITE/Newupdate\%202013/Ministry\%20Policies/NATIONAL\%20POLICY\%20FOR\%20C HILDREN\%202010-2015.pdf

Government of Samoa and Samoa Tourism Authority. (2009). Samoa Tourism Development Plan 2009-2013 - A guide to sustainable tourism. Apia: Samoa Government. Retrieved from http://www.preventionweb.net/files/27077_samoatourismdevelopmentplan200920 13.pdf

Government of Samoa and the Bureau of Statistics. (2014). International arrival statistics. Retrieved from http://www.sbs.gov.ws/index.php?option=com_advlisting\&view=download\&fileI $\mathrm{d}=957$

Government of Samoa and the Ministry of Finance. (2008). Strategy for the Development of Samoa 2008-2012. Apia: Treasury Department.

Government of Samoa and UNICEF. (2006). Samoa. A Situation analysis of children, women \& youth. Suva: UNICEF Pacific Office Fiji. 
Griffen, V. (2006). Gender relations in Pacific cultures and their impact on the growth and development of children. Childrens rights and culture in the Pacific. UNICEF.

Groenewald, T. (2004). Phenomenological research design illustrated. International Journal Of Qualitative Methods, 1-26. Retrieved from http://www.ualberta.ca/ iiqm/backissues/3_1/pdf/groenewald.pdf

Guba, E. (1981). Criteria for assessing the trustworthiness of naturalistic inquiries. Educational Communication and Technology Journal, 75-91.

Halapua, S. (2003, July 7-8). Walking the knife-edge pathways to peace - commentary including exerpts from peace conflict and development.

Hall, R., \& Hall, R. C. (2007). A Profile of Pedophilia: Definition, Characteristics of Offenders, Recidivism, Treatment Outcomes, and Forensic Issues.

Harper, D. (1987). Working knowledge:Skill and community in a small workshop. Berkely: University of California Press.

HELP Resources, Inc. and UNICEF (PNG). (2005). A situation analysis of child sexual abuse and the commercial sexual exploitation of children in Papua New Guinea. Suva: UNICEF (Pacific), (Commissioned by UNESCAP).

Helu-Thaman, K. (1993). Beyond hula, hotels, and handicrafts: A Pacific Islander's perspective of tourism development. The Contemporary Pacific, 5(1), 103-131.

Hoepfl, M. (1997). Choosing qualitative research: A primer for technology education researchers. Journal of Technology Education.

Holloway, I., \& Wheeler, S. (2002). Qualitative research in nursing. Oxford: Blackwell.

Holmes, L. (1987). Quest for the real Samoa: The Mead/Freeman controversy and beyond. Massachusetts: Bergin and Garvey Publishers.

Hoose, J., Clift, S., \& Carter, S. (2000). Combating tourist sexual exploitation of children. In S. Clift, \& S. Carter, Tourism and Sex-Culture, Commerce and Coercion (pp. 74-90). Printer. London. 
Hughes, D. (1999). Pimps and predators on the internet: globalizing the sexual exploitation of women and children. New York: ECPAT US.

Hughes, D. (2001). Globalization, information technology, and sexual exploitation of women and children rain and thunder. A radical feminist journal of discussion and activism, 13.

Huijsmans, R. (2008). Children working beyond their localities: Lao children working in Thailand, Childhood. 15, 331-353.

Jas. (2008, August 10). Sex Guide Escort Reviews: Australia and Pacific / Fiji (Lautoka Nadi and Suva Escort Review). Retrieved from Worldsexguide: http://www.worldsexguide.com/guide/Australia_and_Pacific/Fiji/

Jeffreys, S. (1999). Globalizing sexual exploitation: Sex tourism and the traffic in women. Leisure Studies, 18(3), 179-196.

Jennings, G. (2001). Tourism research. Milton: Wiley.

Jhappan, R. (2005). Of tsunamis and child sexual exploitation: The political economy of supply and demand in the sex tourism and trafficking trades. Asian women/Research institute of Asian women, 20, pp. 137-174.

Jones, A., \& Trotman Jemmott, E. (2009). Child sexual abuse in the Eastern Carribean: Perceptions of, attitudes to, and opinions on child sexual abuse in the Eastern Caribbean. UNICEF.

Jullien, K. (2003). The recent international efforts to end commercial sexual exploitation of children. Denver Journal of International Law and Policy, 31(4), 582-83.

Kakou, S. (2009). Tahitian beauties: Lucien Gauthier. Adler.

Klain, E. J. (1999). Prostitution of children and child-sex tourism: An analysis of domestic and international responses. Arlington VA: National Center for Missing and Exploited Children.

Kolone-Collins, S. (2010). Fagogo: "Ua molimea manusina": A qualitative study of the pedagogical significance of Fagogo-Samoan stories at night-for the education of 
Samoan children.New Zealand. Auckland University of Technology: Master's Thesis, Author.

Lau, C. (2008). Child sex tourism in Thailand. Journal of Child Health Care, 144-155. doi:10.1177/1367493508090172

Lesa, K. (2000). Child sex industry in Samoa considered as worrying. Samoa Observer.

Leuchtag, A. (2003). Human rights, sex trafficking, and prostitution. The Humanist, 1015.

Leung, P. (2003). Sex tourism: The case of Cambodia. In G. Bauer, \& B. McKercher, Sex and tourism: Journeys of romance, love and lust (p. 296). New York: The Haworth Hospitality Press.

Levesque, R. (1999). Sexual abuse of children. A human rights perspective. Bloomington and Indianapolis: Indiana University Press.

Lim, L. (1998). The economic and social bases of prostitution in Southeast Asia and child prostitution in the sex sector, ILO: Geneva,. Geneva: ILO.

Macpherson, C., Spoonley, P., \& Anae, M. (Eds.). (2001). Tangata O te moana nui: The evolving identities of Pacific people in Aotearoa New Zealand. Palmerston North, New Zealand: Dunmore Press Ltd.

Maxwell, J. (2009). Designing a qualitative study. In L. Bickman, \& D. Rog, Applied Social Research Methods (pp. 214-253). Thousand Oaks, CA: Sage.

McLellan, E., MacQueen, K., \& Neidig, J. (2003). Beyond the qualitative Interview: Data preparation and transcription. Field Methods, 63-84.

Mead, M. (1928). Coming of age in Samoa: A study of adolescence and sex in primitive societies. London: Penguin Books.

Mehr Khan. (2003). Violation of children's and womens rights : The case of trafficking and commercial sexual exploitation. Impact of Global Issues on Women and Children (pp. 39-48). Bangkok, Thailand: MCMasterUniversity. Retrieved from http://fhs.mcmaster.ca/slru/ic2003/Khan.pdf 
Meleisea, M. (1987). Lagaga: A short history of Western Samoa. Suva, Fiji. University of the South Pacific: Institute of Pacific Studies and the Western Samoa Extention Centre of the University of the South Pacific.

Merriam, S. (1998). Qualitative research and case study applications in education. San Francisco: Jossey-Bass.

Miles, M., \& Huberman, A. (1994). Qualitative data analysis: an expanded sourcebook (2 ed.). London: Sage.

Montgomery, H. (1998). Children, prostitution and identity: A case study from a tourist resort in Thailand. In Kempadoo, \& Doezema, Global sex workers: Rights, Resistance and Redefinition. Routledge: New York.

Montgomery, H. (2001). The child sex tourism in Thailand. In D. Harrison (Ed.), Tourism and the less developed world: Issues and case studies. CAB International.

Montgomery, H. (2008). Buying innocence: Child sex tourism in Thailand. Third World Quarterly, 29(5), 903-917. doi:10.1080/01436590802106023

Morgan, D. L. (1997). Focus groups as qualitative research. Thousand Oaks, CA: Sage.

Muntarbhorn, V. (2001). Report of the Second World Congress against Commercial Sexual Exploitation of Children. Yokohama, Japan: UNICEF. Retrieved from http://www.mofa.go.jp/policy/human/child/congress01-r.html

MWCSD. (2005). Child vendor pilot survey. Apia: Samoa Government.

Neal, K. L. (2007). Preventing child sex tourism: Legal responses and private sector/community partnership. UNICEF: Innocenti Research Centre.

Nette, A. (1999). Oceania: Child sex abuse on the rise in Pacific. Asia times (Online). Retrieved from http://www.atimes.com/oceania/AC27Ah03.html

NGO Group (Convention on the Rights of the Child). (2005). Sub-group against the sexual exploitation of children: Semantics or substance?: Towards a shared understanding of terminology referring to the sexual abuse and exploitation of children. Geneva: United Nations. 
O’Briain, M., Grillo, M., \& Barbosa, H. (2009). A contribution of ECPAT International to the World Congress III against Sexual Exploitation of Children and Adolescents 2008. Sexual Exploitation of Children and Adolescence in Travel \& Tourism. Retrieved from http://www.ecpat.net/sites/default/files/Thematic_Paper_CST_ENG.pdf

O’Connell Davidson, J. (2004). 'Child sex tourism': An anomalous form of movement? Journal of Contemporary European Studies. doi:10.1080/1460846042000207123

O'Connell Davidson, J. (1996). The sex exploiter. Theme paper for the Second World Congress against Commercial Sexual Exploitation of Children. Yokohama.

O'Connell Davidson, J., \& Sanchez Taylor, J. (1996). Child prostitution and sex ourism in Goa. Bangkok: ECPAT International.

O'Grady, R. (1992). The Child and the tourist: The story behind the escalation of child prostitution in Asia. (Bangkok). End Child Prostitution in Asian Tourism (EPCAT).

OHCHR \& PIFS. (2009). Ratification of international human rights treaties Ratification of human rights treaties:Added value for the Pacific region.

Oka, T., \& Shaw, I. (2000, September 21). Retrieved from Qualitative Research in Social Work : http://pweb.sophia.ac.jp/oka/papers/2000/qrsw/

Pacific Regional Rights Resource Team (RRRT). (2004). Commercial sexual exploitation of children and child sexual abuse in the Republic of Kiribati: A situation analysis. Tarawa: UNICEF.

Panko, T., \& George, B. (2011, 6 6). Child sex tourism: Facilitating conditions, legal remedies, and other interventions. Vulnerable Children and Youth Studies, pp. 134-143. doi:10.1080/17450128.2010.521599

Panko, T., \& George, B. (2012, 3). Child sex tourism: Exploring the issues. Criminal Justice Studies, pp. 67-81. doi:10.1080/1478601X.2012.657904

Patton, M. (1990). Qualitative evaluation and research methods (2nd ed.). Newbury Park, CA: Sage. 
Poulin, R. (2004). Globalization and the sex trade: Trafficking and the commodification of women and children. Canadian Woman Studies: Les Cahiers de la Femme, 22(3-4), 38-43. Retrieved from http://pi.library.yorku.ca/ojs/index.php/cws/article/viewFile/6411/5599

Prasso, S. (2005). The Asian mystique: dragon ladies, geisha girls, \& our fantasies of the exotic orient. Public Affairs.

Prescott, S. (2009). Pacific business sustainability in New Zealand: A study of Tongan experiences. (PhD thesis, Auckland University of Technology, New Zealand).

Quanchi, M. (2007). Photographing Papua: Representation, colonial encounters and imaging in the public domain 1880-1930. Paper presented to the Social Change in the 21st Century Conference (p. 13). Newcastle Cambridge: Scholars Publishing.

Rabiee, F. (2004). Focus group interview and data analysis. Proceedings of the Nutrition Society. Cambridge Journals Online, 655-660. doi:10.1079/PNS2004399.

Rao, N. (1999). Sex tourism in South Asia. International Journal of Contemporary Hospitality Management, 96-99. doi:org/10.1108/09596119910250940

ResearchGate. (2015, April Sunday). http://www.researchgate.net/publication/233158045_Child_sex_tourism_Facilitat ing_conditions_legal_remedies_and_other_interventions. Retrieved from ResearchGate: http://www.researchgate.net/publication/233158045_

Ritchie, J., Lewis, J., \& Elam, G. (2003). Qualitative research practice: A guide for social science students and researchers. In J. Ritchie, \& J. Lewis, Researchers. London: Sage.

Robinson, D., \& Robinson, K. (2005). Pacific ways of talk - hui and talanoa. Council on Public Policy Education. Ohio.

Rozga, D. (2013). The 3rd Global Conference on Child Labor. Retrieved from https://www.youtube.com/watch?v=iUO3YXO3kKY

Ruxton, S. (2001). Child sexual exploitation: An action plan for Europe. Stockholm, Brussels: Save the Children Sweden. 
Ryan, C., \& Hall, M. (2001). Sex tourism-Marginal people and liminalities. London: Routledge Taylor and Francis Group.

Sanchez-Taylor, J. (2010). Sex tourism and inequalities. In S. Cole, \& N. Morgan, Tourism and Inequality- Problems and Prospects (pp. 49-66). Oxfordshire: CABI International.

Saradjian, J. (1996). Women who sexually abuse children: From research to clinical practice. London: Wiley.

Save the Children (Fiji). (2004). The commercial sexual exploitation and sexual abuse of children in Fiji: A situational analysis. Fiji: Save the Children. Retrieved from http://www.unescap.org/esid/gad/issues/csec/CSEC\%20Fiji\%20Report\%20_Edite d_\%201205.pdf.

Seabrook, J. (1996). Travels in the skin trade: Tourism and the sex industry. London: Pluto Press.

Seabrook, J. (2000). Child sex tourism and the role of extraterritorial legislation. Zed Books.

Secretariat of the Pacific Community. (2005). Revised Pacific Platform for Action on Advancement of Women and Gender Equality 2005 - 2015 (Vol. 1). Suva.

Retrieved from http://www.pacmas.org/wp-content/uploads/2013/08/RevisedPacific-Platform.pdf

Seghorn, T., Prentky, R., \& Boucher, R. (1987). Childhood sexual abuse in the lives of sexually aggressive offenders. Journal of the American Academy of Child and Adolescent Psychiatry, 262-267.

Shaw, L., \& Williams, K. (2004). Tourism and tourism spaces. London: SAGE.

Shenton, A. (2004). Strategies for ensuring trustworthiness in qualitative research projects. In Education for Information 22 (pp. 63-75). IOS Press.

Shuaib, F. (2007). Leveraging Remittances with Microfinance: A Cross-country study. Foundation for Development Cooperation (FDC). 
Sirakaya-Turk, E., Uysa, M., Hammitt, W., \& Vaske. (2011). Research methods for leisure, recreation and tourism. Cambridge: $\mathrm{CAB}$ International.

Snow, D., \& Anderson, L. (1991). Researching the homeless: The characteristic features and virtues of the case study. In J. R. Feagin, \& A. Orum, A case for the case study (pp. 143-173). Chapel Hill: University of North Carolina Press.

Sorensen, B., \& Claramunt, M. (2003). Commercial sexual exploitation of children and adolescents in Central America, Panama and Dominican Republic - synthesis report, ILO/IPEC subregional coordination for Central America, Panama, and the Dominican Republic. Geneva: International Labour Organisation.

Spivak, G. (1988). Can the subaltern speak? In C. Nelson, \& L. Grossberg, Marxism and the Interpretation of Culture (pp. 271-313). Illionois: Urbana.

Stake, R. (1995). The art of case study research. Thousand Oaks: CA: Sage.

State v Mutch, 116 (FJHC October 26, 1999). Retrieved from http://www.vanuatu.usp.ac.fj/pacific\%20law\%20materials/Fiji_cases/FLR_1999/ State_v_Mutch.html.

Stockholm. (1996). Declaration of the first world congress against commercial sexual exploitation of children. Sweden. Retrieved from http://www.csecworldcongress.org/PDF/en/Stockholm/Press_materials/Stockhol m Congress Background Document 1996_EN.pdf.

Susman, E. (2003). AIDS: Is 'paradise' next? UPI Science News United Press International.

Swarbrooke, J. (1999). Sustainable tourism management. Wallingford: CABI.

Sweetman, D. (1995). Paul Gauguin: A life. New York: Simon and Schuster.

Tamasese Masiofo Filifilia. (2006). Official Speech. Samoan Custom and the Rights of Children. NZ/Samoan National Women's Synod Waitakere. Auckland.

Tamasese, K., Peteru, C. and Waldegrave, C. (1997) Ole taeao afua. The new morning. A qualitative investigation into Samoan perspectives on mental health and culturally appropriate services. Lower Hutt: The Family Centre. 
Tamasese, K., Peteru, C., Waldegrave, C., \& Bush. (2005). Ole Taeao Afua, the new morning: A qualitative investigation into Samoan perspectives on mental health and culturally appropriate services. Australian and New Zealand Journal of Psychiatry, 300-309.

Tamasese, T. (Director). (2009). Va tapuia - Sacred spaces [Motion Picture].

Tellis, W. (1997). Introduction to case study . Retrieved from http://www.nova.edu/ssss/QR/QR3-2/tellis1.html.

Tepanon, Y. (2006). Exploring the Minds of Sex Tourists:The Psychological Motivation of Liminal People. (Doctoral Dissertation, Faculty of Virginia Polytechnic Institute and State University).

Tepelus, C. M. (2008). Social responsibility and innovation on trafficking and child sex tourism: Morphing of practice into sustainable tourism policies? Tourism and Hospitality Research, 8(2), $98-115$.

The Protection Project. (2005). Human Rights Reports of Asia and the Pacific: Samoa. Retrieved from http://www.childtrafficking.com/Docs/the_protection_project\%20_samoa_0109.d oc

The Samoan Working Group. (2012). O le tôfā mamao: A Sāmoan conceptual framework for addressing family violence. Ministry of Social Development New Zealand Government. Retrieved from http://www.familyservices.govt.nz/documents/working-with-us/programmesservices/pacific-framework-samoan-fa2.pdf

The World Bank. (2007). Consultations with Civil Society: A sourcebook working document February 2007.

The World Bank. (2010). Retrieved from http://go.worldbank.org/4CE7W046K0

Tofaeono, A. (2000). Eco-theology: aiga - The household of life. A Perspective from living myths and traditions of Sāmoa. Erlanger Verlag für Mission und Ökumene, Erlangen (World Mission Script:7). 
Treaty Body Monitor. (2006). Committee on the Rights of the Child: 43rd Session Samoa. Human Rights Monitor Series, International Service for Human RIghts. Geneva: United Nations.

Trinidad, A. (2005). Child pornography in the Phillipines. Philippines. Psychosocial Trauma and Human Rights Program, UP Center for Integrative and UNICEF Manila. University of the Philippines, and UNICEF Manilla. Retrieved from http://www.state.gov/documents/organization/123357.pdf

UNCRC. (2006 September 29). Samoa: Committee on the rights of the child: consideration of reports submittedby states parties under Article 44 of the convention. New York: United Nations Publishing.

UNESCAP. (2006). Toolkit for implementing and monitoring the East Asia and Pacific Regional Commitment and Action Plan against Commercial Sexual Exploitation of Children (CSEC). Bangkok: UNESCAP.

UNESCAP. (2007). Regional stakeholders' consultation and planning workshop on the commercial sexual exploitation of children and child sexual abuse in the Pacific.

UNESCAP. (2009). Pacific perspectives on the commercial sexual exploitation and sexual abuse of children and youth. New York: United Nations Publication.

UNESCAP, ECPAT, UNICEF and UNEAPRO. (2003). Report of the Pacific regional workshop on combating poverty and commercial sexual exploitation of children and Youth - Adoption of Pacific Statement of Commitment. Nadi, Fiji: UNESCAP, ECPAT, UNICEF, NZAID, AusAID.

UNICEF. (2001). Second world congress against commercial sexual exploitation of children. Yokohama: UNICEF. Retrieved from http://www.unicef.org/events/yokohama/

UNICEF. (2005). A situation analysis of children, youth and women: Cook Islands. UNICEF Pacific, Fiji: Government of the Cook Islands.

UNICEF. (2014, 05 Monday). Fact Sheet: A summary of the Rights of Children under the Convention on the Rights of the Child (1989). Retrieved from UNICEF: Convention on the Rights of the Child: http://www.unicef.org/crc/index_30228.html 
UNICEF Pacific and UNIFEM Pacific. (2007). The elimination of all forms of discrimination and violence against the girl child: Situation paper for the Pacific Islands region. East Asia and the Pacific Regional Office, [Bangkok]: Suva, Fiji.

UNICEF, UNESCAP and ECPAT. (2006). Commercial sexual exploitation of children (CSEC) and child sexual abuse (CSA) in the Pacific: A regional report. UNICEF Pacific. Retrieved from http://www.unicef.org/eapro/Pacific_CSEC_report.pdf

United Nations. (2009). Questionnaire to governments on implementation of the Beijing Declaration and Platform for Action (1995) and the outcome of the Twenty-third Special Session of the General Assembly (2000): For preparation of regional review and ap.

United Nations Commission on Human Rights. (1999). Report of the special rapporteur on the sale of children, child prostitution and child pornography Ms. Ofelia Calcetas-Santos. Fiji: United Nations Publishing. Retrieved from http://www.unhcr.org/refworld/docid/3b00f25f4.html [a

United Nations Convention on the Rights of the Child. (2006a, 16 October). Consideration of reports submitted by states parties: Consideration of reports submitted by states parties under article 44 of the convention / $C R C / C / W S M / C O / 1$. New York: United Nations Publishing.

United Nations General Assembly. (1979). Convention on the elimination of all forms of discrimination against women: Article 16 (2), Adopted and opened for signature, ratification and accession by General Assembly resolution 34/180 of 18 December 1979 entry into force 3 September 1981. New York. Retrieved from www.un.org/womenwatch/

United Nations General Assembly. (1989). Convention on the Rights of the Child. UN Doc. A/44/49. New York: United Nations Publishing. Retrieved from http://www.ohchr.org/EN/ProfessionalInterest/Pages/CRC.aspx.

United Nations General Assembly. (2000). Optional protocol to the convention on the rights of the child on the sale of children, child prostitution and child pornography. New York: United Nations Publishing. Retrieved from http://www.crin.org/Law/instrument.asp?InstID=1002 
United Nations Population Fund . (2006). A Review of literature and projects 1995-2005: Adolescent sexual \& reproductive health situation analysis for Samoa -- ]. Situation Analyses in Adolescent Reproductive Health in the Pacific. No 4, UNFPA: Office for the Pacific, Suva, Fiji.

UNWTO. (1995). A Statement on the prevention of organised sex tourism. Resolution A/RES/338 (XI), Adopted by the General Assembly of the World Tourism Organization at its eleventh session. Cairo, Egypt. Retrieved from http://ethics.unwto.org/en/content/staements-policy-documents-child-protection

UNWTO. (1999). Global Code of Ethics for Tourism. Retrieved from http://ethics.unwto.org/en/content/global-code-ethics-tourism

UNWTO. (2008). Understanding tourism: Basic glossary. Retrieved from World Tourism Organisation (WTO): http://media.unwto.org/en/content/understandingtourism- basic-glossary

UNWTO. (2011). World Tourism Network on Child Protection.

US Department of State. (2007). Trafficking in persons report. Retrieved from http://www.state.gov/documents/organization/82902.pdf

Va'a, U. (2006). The Fa'asamoa. In A. So'o, U. Va'a, T. Lafotanoa, \& J. Boon (Eds.), Samoa national human development report: Sustainable livelihoods in a changing Samoa (pp. 113-133). Apia, Samoa: National University of Samoa.

Vaioletti, T. (2006). Talanoa research methodology: A developing position on Pacific Research. Waikato Journal of Education, 21-34.

Vermeulen, G., \& De Hauw, H. (2004). Missing and sexually exploited children in the EU. Epidemiological data. Antwerp-Apeldoorn: Maklu Publishers.

Wabwile, M. (2010). Implementating the social and economic rights of children in developing countries: The place of international assistance and cooperation. The international Journal of Children's Rights, 355-385.

Wan Smol Bag and the Regional Rights Resource Team (RRRT). (2004). Commercial sexual exploitation of children and child sexual abuse in Vanuatu: A situation analysis. Port Vila: UNICEF. 
Warburton and Camacho de la Cruz. (1996). Prevention and psycho-social rehabilitation of child victims of commercial sexual exploitation' in world congress against commercial sexual exploitation of children (Stockholm, August 1996).

World Health Organization. (1999). Report of the consultation on child abuse prevention. Geneva: United Nations. Retrieved from http://www.who.int/mip2001/files/2017/childabuse.pdf

Yin, R. (1989). Case study research: Design and methods. Applied Social Research Series, 5.

Yin, R. (1994). Case study research: Design and methods. Thousand Oaks, CA: Sage.

Yin, R. (2003). Case study research: Design and methods (3 ed.). London: Sage.

Zafft, C., \& Tidball, S. (2010). A survey of child sex tourism in the Philippines. Second annual interdisciplinary conference on human trafficking. Retrieved from http://digitalcommons.unl.edu/humtrafconf2/22

Zitze, P. (2007). International child sex tourism: Scope of the problem and comparative case studies. 


\section{List of Appendices}

\section{Appendix A: The CRC (1989) - A Fact Sheet Summary}

Article 1 (Definition of the child): The Convention defines a 'child' as a person below the age of 18 , unless the laws of a particular country set the legal age for adulthood younger. The Committee on the Rights of the Child, the monitoring body for the Convention, has encouraged States to review the age of majority if it is set below 18 and to increase the level of protection for all children under 18.

Article 2 (Non-discrimination): The Convention applies to all children, whatever their race, religion, or abilities; whatever they think or say, whatever type of family they come from. It does not matter where children live, what language they speak, what their parents do, whether they are boys or girls, what their culture is, whether they have a disability or whether they are rich or poor. No child should be treated unfairly on any basis.

Article 3 (Best interests of the child): The best interests of children must be the primary concern in making decisions that may affect them. All adults should do what is best for children. When adults make decisions, they should think about how their decisions will affect children. This particularly applies to budget, policy, and lawmakers.

Article 4 (Protection of rights): Governments have a responsibility to take all available measures to make sure children's rights are respected, protected and fulfilled. When countries ratify the Convention, they agree to review their laws relating to children. This involves assessing their social services, legal, health and educational systems, as well as levels of funding for these services. Governments are then obliged to take all necessary steps to ensure that the minimum standards set by the Convention in these areas are being met. They must help families protect children's rights and create an environment where they can grow and reach their potential. In some instances, this may involve changing existing laws or creating new ones. Such legislative changes are not imposed, but come 
about through the same process by which any law is created or reformed within a country. Article 41 of the Convention points out the when a country already has higher legal standards than those seen in the Convention, the higher standards always prevail.

Article 5 (Parental guidance): Governments should respect the rights and responsibilities of families to direct and guide their children so that, as they grow, they learn to use their rights properly. Helping children to understand their rights does not mean pushing them to make choices with consequences that they are too young to handle. Article 5 encourages parents to deal with rights issues "in a manner consistent with the evolving capacities of the child." The Convention does not take responsibility for children away from their parents and give more authority to governments. It does place on governments the responsibility to protect and assist families in fulfilling their essential role as nurturers of children.

Article 6 (Survival and development): Children have the right to live. Governments should ensure that children survive and develop healthily.

Article 7 (Registration, name, nationality, care): All children have the right to a legally registered name, officially recognised by the government. Children have the right to a nationality (to belong to a country). Children also have the right to know and, as far as possible, to be cared for by their parents.

Article 8 (Preservation of identity): Children have the right to an identity - an official record of who they are. Governments should respect children's right to a name, a nationality, and family ties.

Article 9 (Separation from parents): Children have the right to live with their parent(s), unless it is bad for them. Children whose parents do not live together have the right to stay in contact with both parents, unless this might hurt the child. 
Article 10 (Family reunification): Families whose members live in different countries should be allowed to move between those countries so that parents and children can stay in contact, or get back together as a family.

Article 11 (Kidnapping): Governments should take steps to stop children being taken out of their own country illegally. This article is particularly concerned with parental abductions. The Convention's Optional Protocol on the sale of children, child prostitution, and child pornography has a provision that concerns abduction for financial gain.

Article 12 (Respect for the views of the child): When adults are making decisions that affect children, children have the right to say what they think should happen and have their opinions taken into account. This does not mean that children can now tell their parents what to do. This Convention encourages adults to listen to the opinions of children and involve them in decision-making -- not give children authority over adults. Article 12 does not interfere with parents' right and responsibility to express their views on matters affecting their children. Moreover, the Convention recognizes that the level of a child's participation in decisions must be appropriate to the child's level of maturity. Children's ability to form and express their opinions develops with age and most adults will naturally give the views of teenager's greater weight than those of a preschooler, whether in family, legal, or administrative decisions.

Article 12 (Respect for the views of the child): When adults are making decisions that affect children, children have the right to say what they think should happen and have their opinions taken into account.

Article 13 (Freedom of expression): Children have the right to get and share information, as long as the information is not damaging to them or others. In exercising the right to freedom of expression, children have the responsibility to also respect the rights, freedoms, and reputations of others. The freedom of expression includes the right to share information in any way they choose, including by talking, drawing, or writing. 
Article 14 (Freedom of thought, conscience, and religion): Children have the right to think and believe what they want and to practice their religion, as long as they are not stopping other people from enjoying their rights. Parents should help guide their children in these matters. The Convention respects the rights and duties of parents in providing religious and moral guidance to their children. Religious groups around the world have expressed support for the Convention, which indicates that it in no way prevents parents from bringing their children up within a religious tradition. At the same time, the Convention recognizes that as children mature and are able to form their own views, some may question certain religious practices or cultural traditions. The Convention supports children's right to examine their beliefs, but it also states that their right to express their beliefs implies respect for the rights and freedoms of others.

Article 15 (Freedom of association): Children have the right to meet together and to join groups and organisations, as long as it does not stop other people from enjoying their rights. In exercising their rights, children have the responsibility to respect the rights, freedoms, and reputations of others.

Article 16 (Right to privacy): Children have a right to privacy. The law should protect them from attacks against their way of life, their good name, their families, and their homes.

Article 17 (Access to information; mass media): Children have the right to get information that is important to their health and well-being. Governments should encourage mass media - radio, television, newspapers, and Internet content sources - to provide information that children can understand and to not promote materials that could harm children. Mass media should particularly be encouraged to supply information in languages that minority and indigenous children can understand. Children should also have access to children's books.

Article 18 (Parental responsibilities; state assistance): Both parents share responsibility for bringing up their children, and should always consider what is best for each child. 
Governments must respect the responsibility of parents for providing appropriate guidance to their children - the Convention does not take responsibility for children away from their parents and give more authority to governments. It places a responsibility on governments to provide support services to parents, especially if both parents work outside the home.

Article 19 (Protection from all forms of violence): Children have the right to be protected from being hurt and mistreated, physically or mentally. Governments should ensure that children are properly cared for and protect them from violence, abuse and neglect by their parents, or anyone else who looks after them. In terms of discipline, the Convention does not specify what forms of punishment parents should use. However, any form of discipline involving violence is unacceptable. There are ways to discipline children that are effective in helping children learn about family and social expectations for their behaviour - ones that are non-violent, are appropriate to the child's level of development and take the best interests of the child into consideration. In most countries, laws already define what sorts of punishments are considered excessive or abusive. It is up to each government to review these laws in light of the Convention.

Article 20 (Children deprived of family environment): Children who cannot be looked after by their own family have a right to special care and must be looked after properly, by people who respect their ethnic group, religion, culture and language.

Article 21 (Adoption): Children have the right to care and protection if they are adopted or in foster care. The first concern must be what is best for them. The same rules should apply whether they are adopted in the country where they were born, or if they are taken to live in another country.

Article 22 (Refugee children): Children have the right to special protection and help if they are refugees (if they have been forced to leave their home and live in another country), as well as all the rights in this Convention. 
Article 23 (Children with disabilities): Children who have any kind of disability have the right to special care and support, as well as all the rights in the Convention, so that they can live full and independent lives.

Article 24 (Health and health services): Children have the right to good quality health care - the best health care possible - to safe drinking water, nutritious food, a clean and safe environment, and information to help them stay healthy. Rich countries should help poorer countries achieve this.

Article 25 (Review of treatment in care): Children who are looked after by their local authorities, rather than their parents, have the right to have these living arrangements looked at regularly to see if they are the most appropriate. Their care and treatment should always be based on "the best interests of the child." (See Guiding Principles, Article 3)

Article 26 (Social security): Children - either through their guardians or directly - have the right to help from the government if they are poor or in need.

Article 27 (Adequate standard of living): Children have the right to a standard of living that is good enough to meet their physical and mental needs. Governments should help families and guardians who cannot afford to provide this, particularly with regard to food, clothing, and housing.

Article 28: (Right to education): All children have the right to a primary education, which should be free. Wealthy countries should help poorer countries achieve this right. Discipline in schools should respect children's dignity. For children to benefit from education, schools must be run in an orderly way - without the use of violence. Any form of school discipline should take into account the child's human dignity. Therefore, governments must ensure that school administrators review their discipline policies and eliminate any discipline practices involving physical or mental violence, abuse, or 
neglect. The Convention places a high Value on education. Young people should be encouraged to reach the highest level of education of which they are capable.

Article 29 (Goals of education): Children's education should develop each child's personality, talents, and abilities to the fullest. It should encourage children to respect others, human rights and their own and other cultures. It should also help them learn to live peacefully, protect the environment and respect other people. Children have a particular responsibility to respect the rights their parents, and education should aim to develop respect for the values and culture of their parents. The Convention does not address such issues as school uniforms, dress codes, the singing of the national anthem or prayer in schools. It is up to governments and school officials in each country to determine whether, in the context of their society and existing laws, such matters infringe upon other rights protected by the Convention. In terms of discipline, the Convention does not specify what forms of punishment parents should use. However, any form of discipline involving violence is unacceptable. There are ways to discipline children that are effective in helping children learn about family and social expectations for their behaviour - ones that are non-violent, are appropriate to the child's level of development and take the best interests of the child into consideration. In most countries, laws already define what sorts of punishments are considered excessive or abusive. It is up to each government to review these laws in light of the Convention.

Article 20 (Children deprived of family environment): Children who cannot be looked after by their own family have a right to special care and must be looked after properly, by people who respect their ethnic group, religion, culture and language.

Article 21 (Adoption): Children have the right to care and protection if they are adopted or in foster care. The first concern must be what is best for them. The same rules should apply whether they are adopted in the country where they were born, or if they are taken to live in another country. 
Article 22 (Refugee children): Children have the right to special protection and help if they are refugees (if they have been forced to leave their home and live in another country), as well as all the rights in this Convention.

Article 23 (Children with disabilities): Children who have any kind of disability have the right to special care and support, as well as all the rights in the Convention, so that they can live full and independent lives.

Article 24 (Health and health services): Children have the right to good quality health care - the best health care possible - to safe drinking water, nutritious food, a clean and safe environment, and information to help them stay healthy. Rich countries should help poorer countries achieve this.

Article 25 (Review of treatment in care): Children who are looked after by their local authorities, rather than their parents, have the right to have these living arrangements looked at regularly to see if they are the most appropriate. Their care and treatment should always be based on "the best interests of the child." (See Guiding Principles, Article 3)

Article 26 (Social security): Children - either through their guardians or directly - have the right to help from the government if they are poor or in need.

Article 27 (Adequate standard of living): Children have the right to a standard of living that is good enough to meet their physical and mental needs. Governments should help families and guardians who cannot afford to provide this, particularly with regard to food, clothing, and housing.

Article 28: (Right to education): All children have the right to a primary education, which should be free. Wealthy countries should help poorer countries achieve this right. Discipline in schools should respect children's dignity. For children to benefit from education, schools must be run in an orderly way - without the use of violence. Any 
form of school discipline should take into account the child's human dignity. Therefore, governments must ensure that school administrators review their discipline policies and eliminate any discipline practices involving physical or mental violence, abuse, or neglect. The Convention places a high Value on education. Young people should be encouraged to reach the highest level of education of which they are capable.

Article 29 (Goals of education): Children's education should develop each child's personality, talents, and abilities to the fullest. It should encourage children to respect others, human rights and their own and other cultures. It should also help them learn to live peacefully, protect the environment and respect other people. Children have a particular responsibility to respect the rights their parents, and education should aim to develop respect for the Values and culture of their parents. The Convention does not address such issues as school uniforms, dress codes, the singing of the national anthem or prayer in schools. It is up to governments and school officials in each country to determine whether, in the context of their society and existing laws, such matters infringe upon other rights protected by the Convention.

Article 30 (Children of minorities/indigenous groups): Minority or indigenous children have the right to learn about and practice their own culture, language, and religion. The right to practice one's own culture, language, and religion applies to everyone; the Convention here highlights this right in instances where the practices are not shared by the majority of people in the country.

Article 31 (Leisure, play and culture): Children have the right to relax and play, and to join in a wide range of cultural, artistic, and other recreational activities.

Article 32 (Child labor): The government should protect children from work that is dangerous or might harm their health or their education. While the Convention protects children from harmful and exploitative work, there is nothing in it that prohibits parents from expecting their children to help out at home in ways that are safe and appropriate to their age. If children help out in a family farm or business, the tasks they do be safe and 
suited to their level of development and comply with national labor laws. Children's work should not jeopardize any of their other rights, including the right to education, or the right to relaxation and play.

Article 33 (Drug abuse): Governments should use all means possible to protect children from the use of harmful drugs and from being used in the drug trade.

Article 34 (Sexual exploitation): Governments should protect children from all forms of sexual exploitation and abuse. This provision in the Convention is augmented by the Optional Protocol on the sale of children, child prostitution, and child pornography.

Article 35 (Abduction, sale and trafficking): The government should take all measures possible to make sure that children are not abducted, sold, or trafficked. This provision in the Convention is augmented by the Optional Protocol on the sale of children, child prostitution and child pornography.

Article 36 (Other forms of exploitation): Children should be protected from any activity that takes advantage of them or could harm their welfare and development.

Article 37 (Detention and punishment): No one is allowed to punish children in a cruel or harmful way. Children who break the law should not be treated cruelly. They should not be put in prison with adults, should be able to keep in contact with their families, and should not be sentenced to death or life imprisonment without possibility of release.

Article 38 (War and armed conflicts): Governments must do everything they can to protect and care for children affected by war. Children under 15 should not be forced or recruited to take part in a war or join the armed forces. The Convention's Optional Protocol on the involvement of children in armed conflict further develops this right, raising the age for direct participation in armed conflict to 18 and establishing a ban on compulsory recruitment for children under 18. 
Article 39 (Rehabilitation of child victims): Children who have been neglected, abused or exploited should receive special help to physically and psychologically recover and reintegrate into society. Particular attention should be paid to restoring the health, selfrespect and dignity of the child.

Article 40 (Juvenile justice): Children who are accused of breaking the law have the right to legal help and fair treatment in a justice system that respects their rights. Governments are required to set a minimum age below which children cannot be held criminally responsible and to provide minimum guarantees for the fairness and quick resolution of judicial or alternative proceedings.

Article 41 (Respect for superior national standards): If the laws of a country provide better protection of children's rights than the articles in this Convention, those laws should apply.

Article 42 (Knowledge of rights): Governments should make the Convention known to adults and children. Adults should help children learn about their rights, too. (See also article 4.)

Articles 43-54 (implementation measures): These articles discuss how governments and international organisations like UNICEF should work to ensure children are protected in their rights. 


\section{Appendix B: Pacific Island Table of Treaty Ratification}

The following chart of states shows which are a party (indicated by the date of adherence: ratification, accession or succession) or signatory (indicated by an "s" and the date of signature) to the United Nations human rights treaties listed below. Selfgoverning territories that have ratified any of the treaties are also included in the chart.

\begin{tabular}{|c|c|c|c|c|c|c|c|c|c|}
\hline & ICESCR & ICCPR & CERD & CEDAW & CAT & CRC & CRMW & CRPD & CPPED \\
\hline $\begin{array}{l}\text { COOK } \\
\text { ISLANDS }\end{array}$ & & & & $\begin{array}{c}11 \text { Auq } \\
06\end{array}$ & & 6 Jun 97 & & $\begin{array}{c}8 \text { May } \\
09\end{array}$ & \\
\hline FIJI & & & $\begin{array}{c}11 \text { Jan } \\
73\end{array}$ & $\begin{array}{l}28 \text { Aug } \\
95\end{array}$ & & $\begin{array}{c}13 \text { Aug } \\
93\end{array}$ & & $\begin{array}{c}\text { S2 Jun } \\
10\end{array}$ & \\
\hline KIRIBATI & & & & $\begin{array}{c}17 \mathrm{Mar} \\
04\end{array}$ & & $\begin{array}{c}11 \mathrm{Dec} \\
95\end{array}$ & & $\begin{array}{c}27 \text { Sept } \\
13\end{array}$ & \\
\hline $\begin{array}{l}\text { MARSHALL } \\
\text { ISLANDS }\end{array}$ & & & & 2 Mar 06 & & 4 Oct 93 & & & \\
\hline $\begin{array}{l}\text { FED. STATES } \\
\text { MICRONESIA }\end{array}$ & & & & 1 Sep 04 & & $\begin{array}{l}5 \text { May } \\
93\end{array}$ & & $\begin{array}{c}\text { S } 23 \\
\text { Sep } 11\end{array}$ & \\
\hline NAURU & & $\begin{array}{c}S 12 \\
\text { Nov } 01\end{array}$ & $\begin{array}{c}\text { S 12-Nov } \\
01\end{array}$ & 23 Jun 11 & $\begin{array}{c}26 \text { Sept } \\
12\end{array}$ & $\begin{array}{c}27 \text { Jul } \\
94\end{array}$ & & $\begin{array}{c}27 \text { June } \\
12\end{array}$ & \\
\hline NIUE & & & & & & $\begin{array}{c}20 \mathrm{Dec} \\
95\end{array}$ & & & \\
\hline PALAU & $\begin{array}{c}\text { S } 20 \text { Sep } \\
11\end{array}$ & $\begin{array}{c}\text { S } 20 \\
\text { Sep } 11\end{array}$ & $\begin{array}{c}\text { S } 20 \text { Sep } \\
11\end{array}$ & $\begin{array}{c}\text { S20 Sep } \\
11\end{array}$ & $\begin{array}{c}S 20 \\
\text { Sep } 11\end{array}$ & 4 Aug 95 & $\begin{array}{c}\text { S } 20 \\
\text { Sep } 11\end{array}$ & $\begin{array}{c}11 \text { Jun } \\
13\end{array}$ & $\begin{array}{l}\text { S } 20 \\
\text { Sep } 11\end{array}$ \\
\hline $\begin{array}{l}\text { PAPUA NEW } \\
\text { GUINEA }\end{array}$ & 21 Jul 08 & $\begin{array}{c}21 \text { July } \\
08\end{array}$ & $\begin{array}{c}27 \text { Jan } \\
82\end{array}$ & 12 Jan 95 & & 2 Mar 93 & & $\begin{array}{c}26 \text { Sept } \\
13\end{array}$ & \\
\hline SAMOA & & $\begin{array}{c}15 \mathrm{Feb} \\
08\end{array}$ & & $\begin{array}{c}25 \mathrm{Sep} \\
92\end{array}$ & & $\begin{array}{c}29 \text { Nov } \\
94\end{array}$ & & & $\begin{array}{c}27 \mathrm{Nov} \\
12\end{array}$ \\
\hline $\begin{array}{l}\text { SOLOMON } \\
\text { ISLANDS }\end{array}$ & $\begin{array}{c}17 \mathrm{Mar} \\
82\end{array}$ & & $\begin{array}{c}17 \text { Mar } \\
82\end{array}$ & 6 May 02 & & $\begin{array}{l}10 \text { Apr } \\
95\end{array}$ & & $\begin{array}{c}S 23 \\
\text { Sep } 08\end{array}$ & \\
\hline TONGA & & & $\begin{array}{c}16 \text { Feb } \\
72\end{array}$ & & & 6 Nov 95 & & $\begin{array}{c}\text { S } 15 \\
\text { Nov } 07\end{array}$ & \\
\hline TUVALU & & & & 6 Oct 99 & & $\begin{array}{l}22 \text { Sep } \\
95\end{array}$ & & $\begin{array}{c}18 \mathrm{Dec} \\
13\end{array}$ & \\
\hline VANUATU & & $\begin{array}{c}21 \text { Nov } \\
08\end{array}$ & & $8 \operatorname{Sep} 95$ & $\begin{array}{l}12 \text { Jul } \\
11\end{array}$ & 7 Jul 93 & & $\begin{array}{c}23 \text { Oct } \\
08\end{array}$ & $\begin{array}{c}\text { S6 Feb } \\
07\end{array}$ \\
\hline \multicolumn{10}{|l|}{ KEY: } \\
\hline & \multicolumn{9}{|c|}{ Indicates the date of adherence: ratification, accession or succession } \\
\hline $\mathrm{s}$ & \multicolumn{9}{|c|}{ Indicates the date of signature } \\
\hline ICESCR & \multicolumn{9}{|c|}{ International Covenant on Economic, Social and Cultural Rights } \\
\hline ICCPR & \multicolumn{9}{|c|}{ International Covenant on Civil and Political Rights } \\
\hline CERD & \multicolumn{9}{|c|}{ Convention on the Elimination of All Forms of Racial Discrimination } \\
\hline CEDAW & \multicolumn{9}{|c|}{ Convention on the Elimination of All Forms of Discrimination Against Women } \\
\hline CAT & \multicolumn{9}{|c|}{ Convention Against Torture and Other Cruel, In human or Degrading Treatment or Punishment } \\
\hline CRC & \multicolumn{9}{|c|}{ Convention on the Rights of the Child } \\
\hline CRMW & \multicolumn{9}{|c|}{ Convention on the Protection of the Rights of All Migrant Workers and Members of Their Families } \\
\hline CRPD & \multicolumn{9}{|c|}{ Convention on the Rights of Persons with Disabilities } \\
\hline CPPED & \multicolumn{9}{|c|}{ Convention for the Protection of all Persons from Enforced Disappearance } \\
\hline
\end{tabular}

Note. From Source: https://treaties.un.org/Pages/CNs.aspx 


\title{
Appendix C: The Revised Pacific Plan: Strategy (vi)
}

\begin{abstract}
OBJECTIVE 2.3.1: Policies and programs to prevent sexual and family violence
Strategy (vi): Prevention of trafficking of women and children and sex and pedophile tourism
\end{abstract}

Why? So that governments is aware and has policies to prevent human trafficking

How? International and regional agencies and CSOs specializing in the issues raise governments awareness of the issue as an emerging issue in the Pacific region affecting women and girls in particular, and to ensure that governments has institutionalized measure to prevent and punish occurrence

Indicator or progress Governments has a policy to prevention of trafficking of women and children, and sex and pedophile tourism

Who is responsible? Departments of Foreign Affairs, Justice, Police and Social Welfare, National and International CSOs and inter-governmental agencies for crime prevention

Source: Revised Pacific Platform for Action on Advancement of Women and Gender Equality 


\section{Appendix D: Pacific Consultations and Workshops (2001-2007)}

2001 Cook Islands, Fiji Marshal Islands, Papua New Guinea (PNG), Samoa, Vanuatu. East Asia and Pacific Regional Consultation for the Second World Congress Against CSEC Bangkok In preparation for the Second World Congress.

- Improve research and data gathering;

- Ensure the participation of children and young people in research on CSEC;

- Develop and support a research agenda on CSEC, and encourage the intercountry sharing of information; and

- Recognize universities and other educational institutions as key partners in the recovery and reintegration processes, including training and research.

2003 Cook Islands, Samoa and Fiji.

Pacific Regional Workshop on Combating Poverty and CSEC (Held in Suva, Fiji).

- Develop and strengthen technical expertise and knowledge on the issue;

- Develop and consolidate regional partnerships in the Pacific to fight all forms of CSEC;

- Build upon the networks established at this forum to effectively address the issue through concrete regional initiatives and provision of mutual support; and

- Conduct situational analysis in Pacific countries and to share the findings regionally.

2004 Cook Islands, Fiji, Kiribati, Papua New Guinea, Samoa, Solomon Islands and Vanuatu.

Mid-term review of the East Asia and Pacific Regional Commitment and Action Plan against the SEC:

- A training workshop on CSEC and CSA to enable countries to undertake Situational Analysis research.

2007 Cook Islands, Fiji, Kiribati, Papua New Guinea, Samoa, Solomon Islands and Vanuatu.

Regional Stakeholders' Consultation and Planning Workshop on the Commercial Sexual Exploitation of Children and Child Sexual Abuse in the Pacific

- Review key findings from the situation analyses of CSEC and CSA, to share experiences, and to consider key elements of national plans of action, and to inform other Pacific stakeholders and involve them in responses to CSEC and CSA. 


\section{Appendix E: Pacific Signatories to Optional Protocols}

\begin{tabular}{|c|c|c|c|c|c|c|c|c|c|}
\hline & $\begin{array}{l}\text { ICESCR- } \\
\text { OP }\end{array}$ & $\begin{array}{l}\text { ICCPR- } \\
\text { OP1 }\end{array}$ & $\begin{array}{l}\text { ICCPR- } \\
\text { OP2 }\end{array}$ & $\begin{array}{l}\text { OP- } \\
\text { CEDAW }\end{array}$ & $\begin{array}{c}\text { OP- } \\
\text { CRC- } \\
\text { AC }\end{array}$ & $\begin{array}{l}\text { OP-CRC- } \\
\text { SC }\end{array}$ & $\begin{array}{c}\text { OP- } \\
\text { CRC- } \\
\text { CP }\end{array}$ & $\begin{array}{l}\text { OP- } \\
\text { CAT }\end{array}$ & $\begin{array}{c}\text { OP- } \\
\text { CRPD }\end{array}$ \\
\hline $\begin{array}{l}\text { COOK } \\
\text { ISLANDS }\end{array}$ & & & & $\begin{array}{l}27 \text { Nov } \\
07\end{array}$ & & & & & $\begin{array}{c}8 \text { May } \\
09\end{array}$ \\
\hline FIJI & & & & & $\begin{array}{l}\text { S } 16 \\
\text { Sep } 05\end{array}$ & $\begin{array}{c}\text { S } 16 \text { Sep } \\
05\end{array}$ & & & $\begin{array}{l}\text { S 2 Jun } \\
10\end{array}$ \\
\hline \multicolumn{10}{|l|}{ KIRIBATI } \\
\hline \multicolumn{10}{|l|}{$\begin{array}{l}\text { MARSHALL } \\
\text { ISLANDS }\end{array}$} \\
\hline $\begin{array}{l}\text { FED. STATES } \\
\text { MICRONESIA }\end{array}$ & & & & & $\begin{array}{c}\text { S 8 May } \\
02\end{array}$ & $\begin{array}{c}\text { S } 8 \text { May } \\
02\end{array}$ & & & \\
\hline NAURU & & $\begin{array}{l}\text { S } 12 \\
\text { Nov } 01\end{array}$ & & & $\begin{array}{c}\text { S 8 Sep } \\
00\end{array}$ & $\begin{array}{c}\text { S } 8 \text { Sep } \\
00\end{array}$ & & $\begin{array}{c}24 \text { Jan } \\
13\end{array}$ & \\
\hline \multicolumn{10}{|l|}{ NIUE } \\
\hline PALAU & & & & & & & & & $\begin{array}{l}11 \text { Jun } \\
13\end{array}$ \\
\hline \multicolumn{10}{|l|}{$\begin{array}{l}\text { PAPUA NEW } \\
\text { GUINEA }\end{array}$} \\
\hline \multicolumn{10}{|l|}{ SAMOA } \\
\hline $\begin{array}{l}\text { SOLOMON } \\
\text { ISLANDS }\end{array}$ & $\begin{array}{c}\text { S } 24 \text { Sep } \\
09\end{array}$ & & & 6 May 02 & $\begin{array}{l}\text { S } 24 \\
\text { Sep } 09\end{array}$ & $\begin{array}{c}\text { S } 24 \text { Sep } \\
09\end{array}$ & & & $\begin{array}{l}\text { S } 24 \\
\text { Sep } 09\end{array}$ \\
\hline \multicolumn{10}{|l|}{ TONGA } \\
\hline \multicolumn{10}{|l|}{ TUVALU } \\
\hline VANUATU & & & & $\begin{array}{c}17 \text { May } \\
07\end{array}$ & $\begin{array}{l}26 \text { Sep } \\
07\end{array}$ & $\begin{array}{c}17 \text { May } \\
07\end{array}$ & & & \\
\hline \multicolumn{10}{|l|}{ KEY: } \\
\hline & \multicolumn{9}{|c|}{ Indicates the date of adherence: ratification, accession or succession } \\
\hline s & \multicolumn{9}{|c|}{ Indicates the date of signature } \\
\hline ICESCR OP & \multicolumn{9}{|c|}{ Optional Protocol to the International Covenant on Economic Social and Cultural Rights } \\
\hline ICCPR-OP1 & \multicolumn{9}{|c|}{ Optional Protocol to the International Covenant on Civil and Political Rights } \\
\hline ICCPR-OP2 & \multicolumn{9}{|c|}{$\begin{array}{l}\text { Second Optional Protocol to the International Covenant on Civil and Political Rights, aiming at the } \\
\text { abolition of the death penalty }\end{array}$} \\
\hline OP-CEDAW & \multicolumn{9}{|c|}{ Optional Protocol to the Convention on the Elimination of Discrimination against Women } \\
\hline OP-CRC-AC & \multicolumn{9}{|c|}{$\begin{array}{l}\text { Optional Protocol to the Convention on the Rights of the Child on the involvement of children in } \\
\text { armed conflict }\end{array}$} \\
\hline OP-CRC-SC & \multicolumn{9}{|c|}{$\begin{array}{l}\text { Optional Protocol to the Convention on the Rights of the Child on the sale of children, child } \\
\text { prostitution and child pornography }\end{array}$} \\
\hline OP-CRC-CP & \multicolumn{9}{|c|}{ Optional Protocol to the Convention on the Rights of the Child on a communications procedure } \\
\hline OP-CAT & \multicolumn{9}{|c|}{$\begin{array}{l}\text { Optional Protocol to the Convention against Torture and other Cruel, Inhuman or Degrading } \\
\text { Treatment or Punishment }\end{array}$} \\
\hline OP- CRPD & \multicolumn{9}{|c|}{ Optional Protocol to the Convention on the Rights of Persons with Disabilities } \\
\hline
\end{tabular}

Note. From: https://treaties.un.org/Pages/CNs.aspx 


\section{Appendix F: Appendix F: East Asia Pacific Regional Commitment and Action Plan against Commercial Sexual Exploitation of Children, 2001).}

\section{Our Progress and Concerns:}

1. We, the delegates of 25 governments, in cooperation with United Nations agencies and bodies, international organisations, non-governmental organisations (NGOs), representatives of young people, other entities and observers, met at the East Asia and Pacific Regional Consultation from 16 to 18 October 2001 in Bangkok, Thailand, in preparation for the Second World Congress against Commercial Sexual Exploitation of Children to be held in Yokohama, Japan, from 17 to 20 December 2001.

2. We took this opportunity to review the progression of our work five years after the First World Congress against Commercial Sexual Exploitation of Children convened in Stockholm in 1996 and to consolidate our partnership, together with members of civil society, including young people, against the commercial sexual exploitation of children (CSEC), including child prostitution, child pornography and child trafficking for sexual purposes.

3. We reaffirm the spirit of the Stockholm Declaration and Agenda for Action, adopted by the First World Congress. More specifically, we note the seriousness of the problem of the CSEC as a result of multiple causes, including greed and power abuse, on the one hand, and of the decline in values, on the other. Therefore, we emphasize that strong government commitment and support, in cooperation with civil society that are responsive to our cultural wisdom and ethical values, are imperative for viable and lasting solutions to the problem of CSEC.

4. We recognize the achievements, wisdom and efforts of children/young people in the fight against CSEC, and we will continue to support their meaningful participation.

5. We underscore the rights of the child and recognize the developments in the East Asia and Pacific countries since the First World Congress, bearing in mind the following positive aspects

The undertaking, on the part of all countries of the region, to recognize and guarantee the rights of the child embodied in the Convention on the Rights of the Child in a comprehensive and holistic manner;

The participation of countries of the region in a number of key regional/subregional commitments to protect the child from CSEC, notably in Resolution 53/4 of the Economic and Social Commission for Asia and the Pacific (ESCAP) on Elimination of 
Sexual Abuse and Sexual Exploitation of Children and Youth in Asia and the Pacific (1997); the Bangkok Accord and Plan of Action to Combat Trafficking in Women adopted by the Regional Conference on Trafficking in Women (1998); the Asian Regional Initiative against Trafficking (ARIAT) Regional Action Plan against Trafficking in Persons, especially Women and Children (2000); the Conclusions and Recommendations of the Asia-Pacific Seminar of Experts in Preparation for the World Conference against Racism: Migrants and Trafficking in Persons with Particular Reference to Women and Children (2000); Resolution 57/1 of ESCAP on a Regional Call for Action to Fight the Human Immunodeficiency Virus/Acquired Immunodeficiency Syndrome in Asia and the Pacific (2001); the Beijing Declaration on Commitments for Children in the East Asia and Pacific Region for 2001-2010 (2001) supported by the United Nations Children's Fund (UNICEF); and the Declaration on the Commitments for Children in the Association of South-east Asian Nations (ASEAN) (2001);

- The contributive role played by countries of the region in developing international norms and new instruments for child protection, including the International Labour Organization (ILO) Convention No.182 concerning the Prohibition and Immediate Action for the Elimination of the Worst Forms of Child Labour (1998); the Optional Protocol to the Convention on the Rights of the Child on the Sale of Children, Child Prostitution and Child Pornography (2000); and the Protocol to Prevent, Suppress and Punish Trafficking in Persons, especially Women and Children, Supplementing the United Nations Convention against Transnational Organized Crime (2000);

The adoption of a number of activities at the regional level to implement the Declaration and Agenda for Action of the First World Congress against Commercial Sexual Exploitation of Children ("The Stockholm Declaration and Agenda for Action"), in particular the ESCAP Human Resources Development Course for Medical and Psychosocial Services for Sexually Abused and Sexually Exploited Children and Youth, and region-wide support from many governments and intergovernmental organisations, in cooperation with civil society, for programmes against CSEC;

The broad participation of civil society, including international and national nongovernmental organisations (NGOs), in action against CSEC;

The higher priority-setting to address the issue of CSEC and its linkage with drug abuse and the spread of sexually transmitted diseases, in particular HIV/AIDS;

The evolution of national plans of action against CSEC and more transparency concerning such situations in some countries;

The greater involvement of the private sector in measures against CSEC; 
- More mobilization of young people to promote and protect their rights against CSEC, as highlighted especially by the International Young People's Participation Project against the Commercial Sexual Exploitation of Children;

- More emphasis on law reform, law enforcement, policy implementation, as well as bilateral and multilateral legal cooperation in combating CSEC;

- More activities aimed at the prevention of CSEC to address the root causes, such as poverty, family disintegration, as well as gender and other forms of discrimination, negative traditional practices, and criminality; and

More efforts to build the capacity of the relevant authorities and community watchdogs to protect children, in addition to child-sensitive facilities and effective recovery and reintegration measures.

6. We welcome the convening, in Yokohama, of the Second World Congress against Commercial Sexual Exploitation of Children, to be hosted by the Government of Japan, support the process to ensure more effective actions against CSEC, and invite the Second World Congress to take into account this Regional Commitment and Action Plan.

7. We acknowledge that much remains to be done to protect the rights of the child and to eliminate the demand that fosters CSEC, and we abhor the existence of CSEC and emphasize our concern regarding this situation in the region and beyond. In this respect, we note that many countries in East Asia and the Pacific, especially Pacific Island countries, do not yet have national plans of action against CSEC, as well as the related national focal points and data, even though these are called for in the Stockholm Declaration and Agenda for Action. There is also a lack of integrated data, information and related networks to provide inputs for policy formulation and programming against CSEC.

8. We recognize the need to identify new and more adequate measures for the prevention of CSEC, protection of children who are vulnerable to CSEC, recovery and reintegration of child victims, and young people's participation against CSEC.

\section{Our Regional Commitment}

1. We commit ourselves to taking action on the following:

A. Ensure effective implementation of the Convention on the Rights of the Child and the Stockholm Declaration and Agenda for Action and undertake to provide sufficient resources for this purpose;

B. Support the process leading to the Second World Congress; 
C. Encourage early ratification of the relevant international instruments for child protection, including ILO Convention No. 182 concerning the Prohibition and Immediate Action for the Elimination of the Worst Forms of Child Labour, the Optional Protocol to the Convention on the Rights of the Child on the Sale of Children, Child Prostitution and Child Pornography, and the Protocol to Prevent, Suppress and Punish Trafficking in Persons, especially Women and Children, Supplementing the United Nations Convention against Transnational Organized Crime;

D. Aim for integrated and comprehensive measures against CSEC;

E. Improve laws and related procedures, policies, programmes and mechanisms, and train personnel against CSEC, while treating sexually exploited children as victims and not as criminals;

F. Address the interrelationship between CSEC and child trafficking, and improve laws to combat the phenomenon, while ensuring that the child victims of trafficking are not classified or treated as illegal immigrants and that they are able to access support systems to protect their security and safe return home;

G. Enhance cooperation and coordination against CSEC among governments, NGOs and others members of civil society, the private sector, the media, intergovernmental organisations, including regional organisations, and young people;

H. Improve research and data gathering to inform policy and programmes to address CSEC;

I. Improve the monitoring process at all levels concerning CSEC and ensure its sustainability; and

J. Strengthen young people's meaningful participation against CSEC and support their activities and networks on child protection. 


\section{Appendix G: A Pacific Statement of Commitment on Combatting Poverty and Comercial Sexual Exploitation of Children and Youth, 2003}

We, the representatives of Governments and civil society organisations from the Cook Islands, Fiji, Kiribati, Marshall Islands, Micronesia, Papua New Guinea, Samoa, Solomon Islands, Timor-Leste, Tonga, Tuvalu an Vanuatu, gathered in Nadi, Fiji, between 15-19 September 2003, at the Pacific Regional Workshop on Combating Poverty and Commercial Sexual Exploitation of Children and Youth,

Reviewed and assessed the progress made in the Pacific region to prevent the commercial sexual exploitation and sexual abuse of children and its socio-economic context,

Developed and strengthened technical expertise and knowledge on the issue, enabling nation states to advance actions to protect children and youth against this grave crime in each of our countries and territories,

Declare our commitment to develop and consolidate regional partnerships in the Pacific to fight all forms of commercial sexual exploitation of children, including child prostitution, child pornography and the trafficking of children for sexual purposes; also, to build upon the networks established at this forum to effectively address the issue through concrete regional initiatives and provision of mutual support,

Confirm our commitment to the Convention on the Rights of the Child and to the Stockholm Declaration and Agenda for Action, adopted at the First World Congress against Commercial Sexual Exploitation of Children, Stockholm, August 1996, and reaffirmed at the Second World Congress, Yokohama, December 2001, and we acknowledge the importance of the development and implementation of national plans of action to combat this phenomenon based on traditional values which are consistent with this commitment, We, individually and collectively, making full use of our capacity and the positions that we hold within our respective Government agencies and civil society organisations, agree to undertake all action to achieve this end, and Hereby proclaim our commitment by adopting this statement.

Signed:

Representatives of all participating government agencies and civil society organisations. 


\section{Appendix H: East Asia Pacific Regional Commitment and Action Plan}

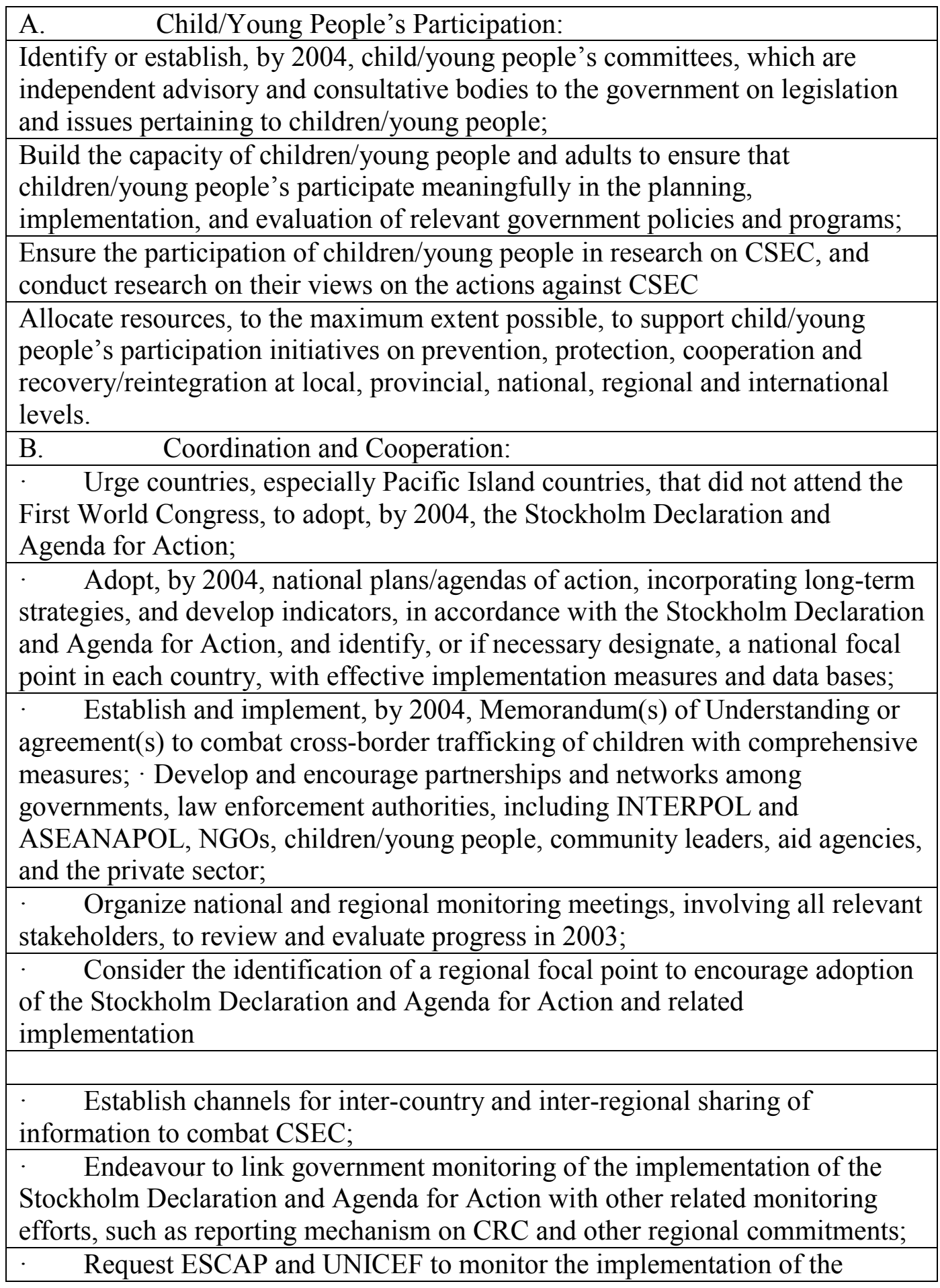


Agenda for Action, with assistance from ECPAT International's existing services of data collection and analysis;

- $\quad$ Assess the effectiveness of national action plans in order to share experiences on drafting and implementation and to facilitate follow-up actions; - $\quad$ Encourage sub-regional and regional agencies and organisations, such as ESCAP, ASEAN and the Pacific Islands Forum Secretariat, to concretize measures against CSEC, including effective implementation of Various existing resolutions and declarations on children/young people; and

- Call upon donors to support child participation, prevention of CSEC, and the recovery and reintegration of child victims through their long-term commitment.

C. Prevention:

Implement/strengthen programs that address poverty, family and community disintegration, gender discrimination, discrimination against indigenous and minority communities, and recover and reinforce positive cultural wisdom and practices which protect and promote the rights and dignity of women and children, as well as reduce practices and attitudes which negatively impact women and children;

- $\quad$ Promote better access to education for all children, more education on the rights of the child, and awareness-raising against CSEC and its linkage with drug abuse, STDs, including HIV/AIDS, reproductive health and sexuality, aiming at a process to promote the child's personal growth and self esteem, aimed at harm avoidance;

- $\quad$ Promote a humane socialization process and related actions to foster positive attitudes and behaviour to prevent CSEC and to counter demand for CSEC;

- Integrate the issue of CSEC into both formal and non-formal/informal education;

- $\quad$ Reaffirm the importance of the family and strengthen social protection for children/young people and families more concretely through sustained information campaigns and community-based surveillance/monitoring of CSEC, with particular attention to protection from exploitation;

- Undertake media and public awareness-raising campaigns to change attitudes that support CSEC and to eliminate the stigma against survivors of CSEC;

- $\quad$ Support media personnel in maintaining media ethics and practices consistent with the rights of the child, including respect for the child's/young person's privacy, and as partners for children's/young persons' protection; - $\quad$ Provide technical and financial support to community leaders and both formal and informal networks, including religious leaders, media, ethnic associations and community workers, to counter CSEC;

- $\quad$ Consolidate local, national, sub-regional and regional actions to prevent and counter CSEC, and monitor their impact on children/young people and their 
families, with effective follow-up;

- $\quad$ Recognize that child-sensitive laws are an essential part of action to prevent CSEC and support their development and implementation; and

- $\quad$ Develop and publicize relevant laws that prevent the exploitation of children/young people through information technologies and other channels of communication, including the use of videotapes and the Internet for child pornography.

D. Protection:

Encourage region-wide adoption/ratification of international treaties and other instruments concerning child protection and ensure their implementation and monitoring;

- $\quad$ Enact/improve laws, policies and programs promoting and protecting child rights and ensure effective implementation and enforcement of relevant laws, especially criminal and civil laws;

- $\quad$ Ensure that, under national immigration laws, child victims of trafficking are treated humanely, and ensure effective coordination among all relevant agencies;

- $\quad$ Encourage cross-border/transnational cooperation and sharing of information among law enforcement authorities against CSEC;

- $\quad$ Develop and implement child-sensitive judicial systems and programs to protect child victims and child witnesses;

- Adopt innovative responses to counter the negative aspects of technology, such as the transfer of child pornography via the Internet;

- $\quad$ Strengthen the capacity to combat CSEC of law enforcers, members of civil society, especially children/young people, NGOs, teachers, media, community groups and volunteers, and the private sector, through increasing awareness and training concerning child protection, international instruments, national laws and policies;

- $\quad$ Provide a supportive infrastructure for law enforcers and members of civil society to report and to counter commercial sexual exploitation of children;

- $\quad$ Reinforce existing structures and mechanisms for child protection and explore the possibility of using, for this purpose, Ombudspersons, local task forces and special police units, as well as child support systems;

- $\quad$ Encourage and support more child/young people's participation in combating CSEC, including their involvement in local task forces and/or the establishment of their own task force to pro-actively protect children; and

- Develop and support a research agenda on CSEC and encourage the intercountry sharing of information.

E. Recovery and Reintegration:

Ensure that all programs respect and respond to the diversity of children/young people's situations and backgrounds and the unique position of each child/young person, and include them as active partners in their own recovery and reintegration; 
· $\quad$ Provide/strengthen wide-ranging and effective services for the child victims of commercial sexual exploitation, which are gender-, child- and culture-sensitive, including peer counselling, hotlines/helplines in local languages, shelters, medical treatment, and psychosocial counselling; - Develop, in partnership with universities and service providers, monitoring and evaluation mechanisms, including impact indicators, as part of the design of recovery programs;

- $\quad$ Recognize that reintegration is a long-term process, requiring psychosocial support, job training and placement, destigmatisation, and program monitoring and follow-up;

- $\quad$ Ensure that reintegration involves a Variety of stakeholders, particularly the child/young person, family, community, NGOs, and religious organisations, and that the political will of governments is responsive to this issue;

- Train health and social service providers, religious and community workers, and indigenous healers in the provision of child-friendly services, including medical and psychosocial services, care for care-providers, HIV/AIDS and substance abuse programs, and life skills development;

- $\quad$ Provide community-level training programs concerning the rights and interests of the child on areas such as the Convention on the Rights of the Child and other international rights-related instruments, parenting, communication, peer counselling, and training of trainers, directed at teachers, parents, children/young people, and community leaders;

- $\quad$ Recognize social work as a key profession and strengthen professional and para-professional training programs, including skills in assessment, counselling, case management, and impact evaluation of programs;

- Call upon donors to recognize that recovery and reintegration are longterm processes, and to commit their support accordingly in partnership with key stakeholders;

- $\quad$ Recognize universities and other educational institutions as key partners in the recovery and reintegration processes, including training and research.

10 Selected Commitments for Monitoring

1. By 2004 - Identify or establish child/young people's committees, which are independent advisory and consultative bodies to the government on legislation and issues pertaining to children/young people 2. By 2004 - Urge countries, especially Pacific Island countries, that did not attend the First World Congress, to adopt the Stockholm Declaration and Agenda for Action 
3. By 2004 - Adopt national plans/agendas of action, incorporating long-term strategies, and develop indicators, in accordance with the Stockholm Declaration and Agenda for Action, and identify, or if necessary designate, a national focal point in each country, with effective implementation measures and data bases 4. By 2004 - Establish and implement Memorandum(s) of Understanding or agreement(s) to combat cross-border trafficking of children with comprehensive measures

5. Encourage region-wide adoption/ratification of international treaties and otherinstruments concerning child protection and ensure their implementation andmonitoring

6. Enact/improve laws, policies and programs promoting and protecting child rights and ensure effective implementation and enforcement of relevant laws, especially criminal and civil laws

7. Promote better access to education for all children, more education on the rights of the child, and awareness-raising against CSEC and its linkage with drug abuse, STDs,including HIV/AIDS, reproductive health and sexuality, aiming at a process to promote The child's personal growth and self esteem, aimed at harm avoidance

8. Reaffirm the importance of the family and strengthen social protection forchildren/young people and families more concretely through sustained information campaigns and community-based surveillance/monitoring of CSEC, with particular attention to protection from exploitation

9. Provide/strengthen wide-ranging and effective services for the child victims of commercial sexual exploitation, which are gender-, child- and culturesensitive, including peer counselling, hotlines/helplines in local languages, shelters, medical treatment, and psychosocial counselling

10. In 2003 - Organize national and regional monitoring meetings, involving all relevant stakeholders, to review and evaluate progress.

Note. From: UNICEF. Second World Congress against Commercial Sexual Exploitation of Children Retrieved from http://www.unicef.org/events/yokohama/easia-pac-regoutcome.html 


\section{Appendix I: Samoa: Proposed Plan of Action against CSEC}

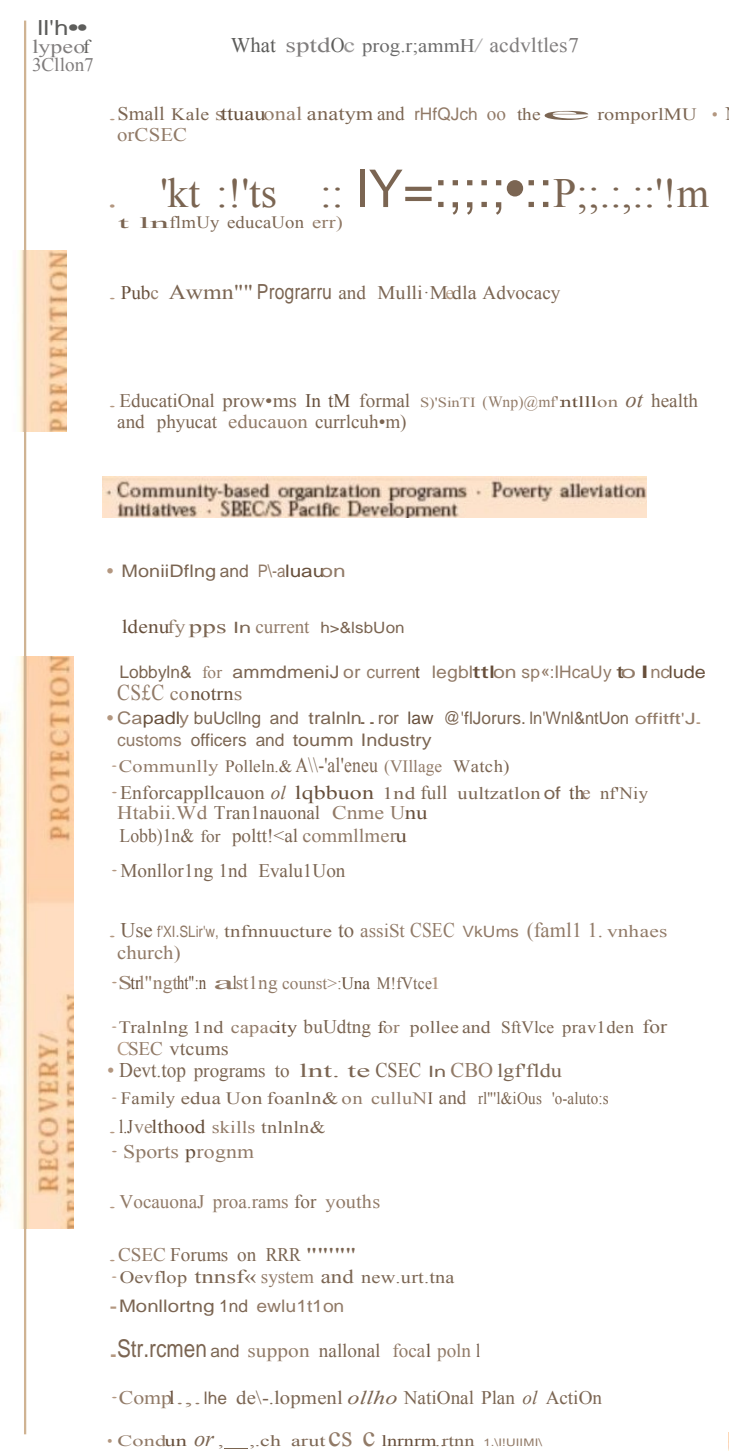

What aroups/ln.slltutlon.s/mlnbtrlu wUl do k7 $(\mathrm{C}<\mathrm{Mm}$...,.,NCO...)'C $>$ Jth.UN commur $<$ y._......)

NFP M $\backslash$ 'CSD In cotbbaauon wtth all CRC put

ニ.' $\quad$ rgs rypre;tv! !'t!'tn

nenl.

II:SD.ECPAT S.moa and Mapus'!P o Algillo lead In colbborsuon

wtoh CRC partne $<$ Shlp
YMCA men rocusod advocacy on CSEC

- MJntstl') or Educauon. SporiS and Culttn ID lead .., collaboratiOn 'olth CRC partnership

MV 'CSO.VUJa\&e CouncU, Women's CommltiH, Youth, Churdl In
collabontlon wtlh spoclaiUI NCO.

- All ImoiYed pannen

-Anomey Cmerattn coiLab;)rJtlon wtth Nauonal CouncU on CRC

Speclollsr NCCh and CRC partner>hlp

MWCSD. Mln!Siry ol Pol!a!. n11 uy ol jusua. Mlntsuy or Re.-.n"' and Samoa Tourbm Authoruy

MlniiU) or Polkt ond VII"'"' Councils

-M1n111ry or Polkt. Mlnlluy or jusu"' and CRC Partnership

NCCh and CRC Portne $<$ Shlp

-All tm'Ol...d partners

- CRC pannenhlp ror NCCRC to actiOn ( $\mathrm{nt}>$ uy or H"'lth)

$\cdot$ Sp«:taUs.t NCOs and govrrnrTlt":nl parUlft'S

. MWCSD. M . . suy ol Pollco. Mtnlslry or justice. Spedolt>r NCO.

MWCSD In collalxnuon $\cdot 11 \mathrm{~h}$ CRC partner>hlp

Speclollsl NCO. In collaborallon wtlh me Mlnl>rrte

-Sp«:11llst NCOs wllh aowmmern pannen

MJrUstry of [due Uon In colbboraHon $>$ A"1th ttl Sarno• Sports Fedtorlllon

MWCSD. Mln1>lry or EducatiOn. Sporu 11 Cultu,. ln colloborauon

With the church

CRC Pannenhlp

- CRC parrnenhtp

AU In't'Olpartners

Co'twnmt $>$ nt w1th reprds to ruourw $\bullet$ lloaitlon and Clpaclly bulldlfl\&

- MWCSD In collaboratiOn wllh CRC Pwtner>hlp

MWren Mindetry of Delise Minitetry of lueties in mollahoration with 


\begin{tabular}{|c|c|c|}
\hline $\begin{array}{l}\text { How will it be done? } \\
\text { (concrete steps to take) }\end{array}$ & $\begin{array}{l}\text { What resources } \\
\text { are needed? } \\
\text { (human, material, technical) }\end{array}$ & $\begin{array}{l}\text { When will it } \\
\text { be done? } \\
\text { (within the timeframe of } 1 \text { year) }\end{array}$ \\
\hline $\begin{array}{l}\text { CRC parties to contribute to the development of a proposal for UNICEF, UNESCAP or } \\
\text { ECPAT International financial assistance (Juvenile Justice Proposal with UNICEF as yet to } \\
\text { be achieved, approved in principle) }\end{array}$ & Technical assistance \& funds & . 1st quarter 2004 \\
\hline $\begin{array}{l}\text { Incorporate into currently planned CRC activities, making full use of CRC partnership } \\
\text { network }\end{array}$ & $\begin{array}{l}\text { Especially for internet safety training } \\
\text { we need technical assistance and } \\
\text { funds }\end{array}$ & $\begin{array}{l}\text { On-going with the } \\
\text { exception of internet } \\
\text { safety. Need to secure } \\
\text { funds. 2nd quarter } \\
2004\end{array}$ \\
\hline $\begin{array}{l}\text { Conduct National Forum on CSEC. Capitalize on the news producers, utilize public } \\
\text { programs on the media, make use of Ministries and NGOs media programs but long } \\
\text { term, we will seek funding. Also, we will request inclusion of CSEC issues in the currently } \\
\text { running Catholic church marijuana prevention campaign }\end{array}$ & $\begin{array}{l}\text { Share resources with other projects } \\
\text { Current team's commitment to } \\
\text { pursue the awareness drive and } \\
\text { assistance of regional and interna- } \\
\text { tional partners }\end{array}$ & $\begin{array}{l}\text { End of } 2003 \\
\text { On-going with } \\
\text { exception of long term } \\
\text { plan }\end{array}$ \\
\hline $\begin{array}{l}\text { Negotiate inclusion of CSEC in the Ministry of Justice and Ministry of Police School } \\
\text { Campaign on Prevention of Crime and Violence and assist with the implementation of } \\
\text { the health and physical education curriculum }\end{array}$ & Funding long term & $\begin{array}{l}\text { Currently running } \\
\text { except long-term plan } \\
\text { on the curriculum } \\
\text { implementation }\end{array}$ \\
\hline $\begin{array}{l}\text { Continue with the CBOs program using the Small Grant Scheme Community Develop- } \\
\text { ment Model (utilizing traditional methodologies of learning. Build on the Family and } \\
\text { Village Well-being Program as well as the Tourism Promotion Programs in the villages }\end{array}$ & $\begin{array}{l}\text { Small Grant Scheme. TA Funding } \\
\text { Availability of personnel to imple- } \\
\text { ment this aspect of the plan }\end{array}$ & On-going ASAP \\
\hline $\begin{array}{l}\text { - It will be done as an integral part of the partners' work. National Focal Point to follow up } \\
\text { and document for national report }\end{array}$ & $\begin{array}{l}\text { Technical assistance on information } \\
\text { systems and funding }\end{array}$ & . 1st quarter of 2004 \\
\hline $\begin{array}{l}\text { CRC partnership to identify gaps in legislation for Attorney General and NCCRC to action } \\
\text { in line with the jurisdiction of the Law Reform Commission }\end{array}$ & $\begin{array}{l}\text { Personnel and funds for consultative } \\
\text { processes }\end{array}$ & . On-going \\
\hline NGOs to lobby as an integral part of their core businesses & Funding & . On-going \\
\hline $\begin{array}{l}\text { Negotiate inclusion of CSEC issues in the current police training and on the job trainings } \\
\text { of all partners both government and NCOs }\end{array}$ & $\begin{array}{l}\text { Funding to support processes and } \\
\text { technical assistance }\end{array}$ & On-going \\
\hline Train communities selected representatives & Technical assistance \& funds & . 2nd quarter 2004 \\
\hline - Negotiate to incorporate CSEC in the police basic trainings and on the job trainings & CSEC specific resource people & On-going \\
\hline - Prepare cabinet submission on CSEC as the delegation's duty travel report & - & As soon as we return \\
\hline $\begin{array}{l}\text { It will be done as an integral part of the partners' work. National Focal Point to follow up } \\
\text { and document for the national report }\end{array}$ & $\begin{array}{l}\text { Technical assistance on Information } \\
\text { System and funding }\end{array}$ & $\begin{array}{l}\text { - On-going integral part } \\
\text { of the protection } \\
\text { component }\end{array}$ \\
\hline $\begin{array}{l}\text { Conduct training on CSEC issues and negotiate to incorporate these issues in their on- } \\
\text { going programs }\end{array}$ & Technical assistance \& funds & . 4th quarter 2004 \\
\hline Capacity building and training & $\begin{array}{l}\text { CSEC specific resource people and } \\
\text { technical assistance on counseling }\end{array}$ & $\begin{array}{l}\text { - Continue from } 4 \text { th } \\
\text { quarter } 2004\end{array}$ \\
\hline On the job training and basic training for police & CSEC specific resource people & - ASAP \\
\hline - National Focal Point to action in conjunction with existing initiatives for $\mathrm{CBOs}$ & CSEC specific resource people & On-going \\
\hline NGO partners to incorporate in their currently running programs & CSEC specific resource people & . On-going \\
\hline . Build on existing programs by other sectors (e.g. MWCSD, MOH, SFHA) & Funding & . 2nd quarter 2004 \\
\hline $\begin{array}{l}\text { Negotiate through the CRC partnership the inclusion of CSEC in the build up of the } 2007 \\
\text { South Pacific Games }\end{array}$ & Technical assistance \& funding & - ASAP \\
\hline $\begin{array}{l}\text { Integrate CSEC in the currently endorsed National Youth Project to implement the } \\
\text { National Youth Policy } 2001-2005\end{array}$ & - Technical assistance \& funding & . 4th quarter \\
\hline Negotiate integration of forum in Youth Week programs and Mother's Day Activities & Funding & . 4 th quarter 2004 \\
\hline Build on current success of partnership & - & On-going \\
\hline - It will be done as an integral part of the partners' work. National Focal Point to follow-up & $\begin{array}{l}\text { Technical assistance on Information } \\
\text { System and funding }\end{array}$ & $\begin{array}{l}\text { On-going integral part } \\
\text { of recovery program }\end{array}$ \\
\hline $\begin{array}{l}\text { Develop mechanism to monitor and evaluate the coordinating role of the national focal } \\
\text { point }\end{array}$ & Technical assistance \& funding & ASAP \\
\hline $\begin{array}{l}\text { Conduct consultative meetings with stakeholders to identify necessary activities and } \\
\text { resource allocation }\end{array}$ & Technical assistance \& funding & - ASAP (urgent) \\
\hline Write proposal for technical and financial assistance & Technical assistance \& funding & - ASAP \\
\hline Hope to facilitate ECPAT International assistance & Technical assistance \& funding & - ASAP \\
\hline We will depend on our partner member from the Police to negotiate & - & - ASAP \\
\hline $\begin{array}{l}\text { Conduct small scale situational analysis to identify the existing national, regional and } \\
\text { international networks }\end{array}$ & - & ASAP \\
\hline $\begin{array}{l}\text { Consultation with stakeholders, seek advice on content and have a collaborative forum to } \\
\text { finalize contents of MOU }\end{array}$ & Technical assistance \& funding & . 2nd quarter 2004 \\
\hline - It will be done as an integral part of the partners' work. National Focal Point to follow up & $\begin{array}{l}\text { Technical assistance on Information } \\
\text { System and funding }\end{array}$ & $\begin{array}{l}\text { On-going integral part } \\
\text { of recovery program }\end{array}$ \\
\hline Continue as we have done in the last three years with some modifications & Funding from international partners & - Annually \\
\hline $\begin{array}{l}\text { Consult the Youth Division of MWCSD and facilitate take over of CSEC issues in their } \\
\text { programs }\end{array}$ & CSEC specific resource and funding & - ASAP \\
\hline $\begin{array}{l}\text { Consultation and negotiation with all CRC partners to identify the roles and responsibili- } \\
\text { ties in capacity buildings at the different levels }\end{array}$ & CSEC specific resource people & - ASAP \\
\hline Support the initiatives of the churches and NGOs, monitor and evaluate achievements & $\begin{array}{l}\text { Need technical assistance in concepts } \\
\text { and principles }\end{array}$ & . 4 th quarter 2004 \\
\hline - It will be done as an integral part of the partners' work. National Focal Point to $f / u$ & $\begin{array}{l}\text { Technical assistance on information } \\
\text { systems and funding }\end{array}$ & $\begin{array}{l}\text { On-going integral } \\
\text { aspect of participation } \\
\text { component }\end{array}$ \\
\hline
\end{tabular}




\section{Appendix J: Consent to Participate in Research (Individual)}

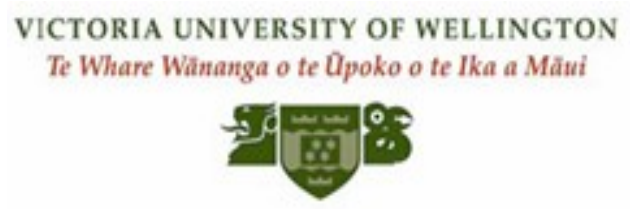

Title of Project:

Consent to Participate in Research (individual)

I have been given and have understood an explanation of this research project. I have had an opportunity to ask questions and have them answered to my satisfaction. I understand that I may withdraw myself (or any information I have provided for this project and before data collection and analysis is complete) without having to give reasons or without penalty of any sort.

I consent to information or opinions which I have given being attributed to me in any reports on this research

I understand that I will have the opportunity to check the transcripts of the interviews/ group meetings before publication

I understand that the data I provide will not be used for any other purposes or released to others without my written consent completed

I would like to receive a summary of the results of this research when it is

I agree to take part in this research

Signed:

Name of participant:

(Please print clearly)

Name of Organisation:

Name of the Responsible for the Project:

Function:

Email Address (if available):

Street or P.O Box:

City/Town:

Country:

Telephone 


\section{Appendix K: Consent to Participate in Research (Focus Groups) \\ VICTORIA UNIVERSITY OF WELLINGTON \\ Te Whare Wünanga o te Upoko o te Ika a Mătui

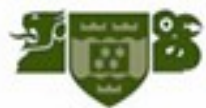

Consent to participate in research (Focus Group)

I have been given and have understood an explanation of this research project. I have had an opportunity to ask questions and have them answered to my satisfaction. I understand that I may withdraw myself (or any information I have provided for this project and before data collection and analysis is complete) without having to give reasons or without penalty of any sort.

The ground rules for focus group participation are to:

- Respect the views of others and, present their views in a dignified manner.

- Are at liberty to choose which questions they participate in and which they do not.

- Remain until the end of the session (not more than one hour) unless negotiated with the researcher.

- Each individual has the right to check his/her own information and withdraw information if appropriate.

- Understand that the views expressed in the focus group are confidential and not to be discussed with others.

I have read the ground rules for focus group participation and agree to abide by

these

I consent to information or opinions which I have given being attributed to me in any reports on this research

I understand that I will have the opportunity to check the transcripts of the interviews/ group meetings before publication

I understand that the data I provide will not be used for any other purposes or released to others without my written consent

I would like to receive a summary of the results of this research when it is completed

I agree to take part in this research

Signed:

Name of participant

(Please print clearly) 


\section{Appendix L: Questions to the Taxi Drivers (Survey)}

About you:

1. Age:

2. Gender: Male / Female (please circle one)

3. Marital status: Married / Single (please circle one)

4. How many children are in your family?

5. Is tourism better economically for you now than in the past?

Yes / No (please circle one)

5 b. Please provide reasons for your answer to Question 5.

6. Is tourism your only source of income?

Yes / No (please circle one)

$6 \mathrm{~b}$. If No, what are your other sources of income?

7. What was your job before your current one?

8. Have you migrated out of a rural area to an urban area to work in the tourism sector?

Yes / No (please circle one)

9. How many hours a day do you work?

10. Do you consider your earnings are appropriate for the job you do and the hours you work?

Yes / No (please circle one)

10b. If No, please provide reasons.

About the tourists you work with and tourism generally

11. Do you think tourists visiting Samoa respect local people / culture / laws, etc?

Yes / No (please circle one)

$11 \mathrm{~b}$. If No, why do you think this?

12. What do you think are the positive things for you from tourism?

13. What do you think are the negative things for you from tourism?

The following things have been described as the most significant threats to Samoa because of increased tourism:

Dependency on tourist dollars

Social values/traditions will decline

Environmental damage

Sexual exploitation of children

Please list them in the order of importance that you consider they should be in. 
14. Do you think local people have enough say in how tourism is managed?

Yes / No (please circle one)

14b. Please provide reasons for your answer to Question 14.

About child sex tourism

15 . What is child sex tourism?

16. At what age is a child considered an adult in Samoa?

17. In which country or countries do you think child sex tourism happens the most?

18. What types of tourists deliberately target children for sex? (age, gender, from which country, single or married, etc)

19. Some people think some tourists might be a danger to local children. What do you think? (Please tick one)

\begin{tabular}{|l|}
\hline I think they are a danger to local children \\
\hline I don't think they are a danger to local children \\
\hline I don't really know \\
\hline
\end{tabular}

20. What do you think are the main reasons for child sex tourism to happen generally?

21. What do you think are the main reasons for child sex tourism to happen in Samoa?

22. Do you think that child sex tourism may be happening in Samoa?

Yes / No (please circle one)

22 b. Why do you think that?

23. Do you think people will still travel to Samoa if such incidences are made known?

Yes / No (please circle one)

24. Do you think the Samoa Tourism Authority should be pro-active to combat this problem?

Yes / No (please circle one)

24b. If No, why not)?

25. Have you seen any material warning tourists that child sex tourism is not acceptable? (posters / pamphlets / hotline numbers for reporting it / magazine articles, etc?)

Yes / No (please circle one)

25b. If Yes, where did you see this? (please tick all that apply)

\begin{tabular}{|l|}
\hline Airport: \\
\hline Hotels: \\
\hline Other place(s): (please name the place(s)) \\
\hline
\end{tabular}


26. Who do you think is responsible for stopping child sex tourism happening in Samoa and why?

27. Have you observed suspicious behaviour between a tourist and a child (girl/boy or fa'afafine)?

Yes / No (please circle one)

27b. If Yes, what did you or others do about it? (Please tick one or more)

\begin{tabular}{|l|}
\hline Ignored it \\
\hline Mentioned it to a travel company \\
\hline Mentioned it to a tour operator \\
\hline Mentioned it to hotel management / staff \\
\hline Reported it to a local NGO \\
Name of the NGO: \\
\hline Told a respected member of the community / church, etc \\
\hline Talked to the person involved \\
\hline Other (please write what you or others did): \\
\hline
\end{tabular}

28. If you observed suspicious behaviour between a tourist and a child, which one of these would you most likely do? (Please tick one or more)

\begin{tabular}{|l|}
\hline Ignore it \\
\hline Mention it to a travel company \\
\hline Mention it to a tour operator \\
\hline Mention it to hotel management / staff \\
\hline Report it to a local NGO \\
Name of the NGO: \\
\hline Tell a respected member of the community / church, etc \\
\hline Talk to the person involved \\
\hline Other (please write what you would most likely do): \\
\hline
\end{tabular}

29b. If you ticked 'Ignore it', what would be your reasons doing this?

29. Have you had any training on laws surrounding the Convention on the Rights of the Child or commercial sexual exploitation of children?

Yes / No (please circle one)

$29 \mathrm{~b}$ If Yes, where did you receive this training?

30. Please tell us any suggestions you have for combating child sex tourism. 


\section{Appendix M: The Sermon}

"Each individual is accountable for his own sins and his response to Gods plan for salvation"

Accountability is a word that is not popular in modern society. People do not want to be held accountable for their actions. But God created people as free moral agents with the capacity to choose between right and wrong: and he holds them individually responsible for their decisions and choices. They cannot shift the blame to someone else.

God also holds believers accountable for sharing the gospel. In Ezekiel. God used the illustration of a watchman to challenge believers to warn sinners of impending judgement. "God's mercy is great. And he desires to forgive all who come to him through Christ." However, they cannot turn to him unless they are told by believers: "Brother and Sister, I want to challenge you to become an active soul winner this year". Become aware of your responsibility and accountability before God. And ask God to help you live for him and become a watchman for those around you.

What else is the Watchman's duty?

In Ezekiel's day, cities were surrounded by great walls which protected thousands of citizens of that city from attack. One of the most important people in the defence system of the city was the watchman who patrolled the walls. He would be the first to see an advancing army. The watchman was to be constantly alert because the lives of so many people depended on him. If he saw the enemy approaching, he sounded the alarm with the ram's horn trumpet, so the people could prepare to defend their city.

God used this military illustration to alert Ezekiel to his responsibilities as a spiritual leader. The watchman was responsible to warn the people of impending danger. If he was faithful and warned the people and they did not respond to his warning, the watchman was not held responsible for their actions for he has done his duty.

But if the watchman did not fulfil his responsibilities, he was held accountable for those who perished, because he'd not warned them.God provided this illustration to Ezekiel and to Israel because God wanted them to know that Ezekiel had been a faithful watchman for the Israelites. He had warned them of impending judgement, but they had not responded to his warning. It was their fault, not Ezekiel's that they were in captivity.

God has placed people around us to watch over our spiritual lives: our pastors, exhorters, deacons, Sunday school teachers and other believers have the responsibilities to help us in our Christian walk. Spiritual leaders to will give an account of how they care for us, but we need to be obedient to their Godly instructions. Ezekiel was both a prophet and a priest, and he was God's watchman for the entire nation. His commission was even greater than that of the watchman on the wall, for he was dealing with eternal matters. As God's spokesman, he was responsible for warning people of dangers that could cause 
more than just physical death. Their eternal souls were at stake.

Why did the Israelites need a watchman?

Although the Israelites were God's covenant people, their obedience brought its judgement: It was not God's desire to punish his people, and this is why it made Ezekiel a watchman - to warn of judgement and to proclaim of God's mercy. God again warned Ezekiel of his responsibility as a watchman. His message was not his own, his message came from God. "If God instructed Ezekiel to warn the wicked and he did not obey, the people would die". He would be accountable for their deaths because he did not warn them. But if he was faithful to proclaim God's warning, and the people did not respond, Ezekiel would not be held accountable for their deaths.

"My brother and sister, we have a responsibility in warning the unsaved of God's judgement." Sometimes the spiritual watchman has to warn professing Christians along with unbelievers. When we see believers involved in situations that could destroy them spiritually, we have the responsibility to warn them of the eternal consequences.Everyone has a circle of influence that includes both the saved and the unsaved. We are abandoned in our duty if we fail to warn sinners and believers of coming judgement. Proclaiming the truth of individual responsibility will not make you popular with the word, but we are accountable to God not others. Ezekiel did not win a popularity contest among his people. In fact most of them ignored his message, but he was true to his God-given calling. Truth is truth and does not change with the passing of centuries.

God's word is still only standing by which to measure our lives and conduct. Even if people today do not accept if God's message, we must still be faithful to proclaim its truth. The Jews were conscious that their captivity was God's punishment for their sins. The realization of their wrong doing had become a heavy burden they could hardly carry. They felt they were wasting away and cried. "How should we then live?" But God was ready to give them a message of hope. And that message of hope is repentance. And the first step to repentance is acknowledging sin. As long as we cling to our selfrighteousness and try to excuse our conduct, we can expect no relief from our burden. But when we acknowledge our sinful condition and our need of a saviour, God can send his saving grace to our lives. Sometimes it takes heavy pressure to make us face our true spiritual condition. This was true of the Israelites: The galling sense of being prisoners in heathen country finally accused them to see their lack of spirituality. They knew that if they were to find relief, they had to confess the sin that had brought this bondage on them. Praise the Lord - God responded to his people with an encouraging word through Ezekiel. God is the sovereign Lord, the almighty. Even though he judges sins, he does not enjoy seeing sinners die. If he will were realised, no one would perish.

But man is a free moral agent and Good will not force his will on anyone. Each individual has to make his own decision to repent and be saved. Sin must never be taken lightly."What might cause a righteous person to turn to sin?" Satan tailors his temptations to each individual. We need to always be conscious of the Holy Spirits warnings. He is 
faithful to warn us if we drift in the wrong direction. But God's mercy is great. God addressed those who are living wicked lives. If they turn to God, their past record will be erased. God will forget their sins and cleanse their conscience from guilt. They do not need to live any longer in sin. The promise of true forgiveness is promised by God. He will not even mention the sins of the sinner.

This is how God completely forgives those who come to him: When we accept Christ we can be assured that our sins are forgiven and we stand right before him. Brother and sister, God has called all believers to Godly living. Yet under the pressure of the world; we may be tempted to abandon the Godly standard of God's word. Remember, it is not how we run the race, but how we finish. If we run a good race, but stop just short of the goal, we forfeit the prize that was due us. Take time right now to make a renewed commitment to good living.

Turn from your wicked ways was God's cry to Israel: if they would only turn from sin and back to him, he would forgive them. Turning from one's sin and turning to God is the meaning of true repentance. Turning in the opposite direction and travelling a different road is a total change of thinking, attitudes and motives about sin. In God's message through Ezekiel, he addressed it not only to those who have always been outright sinners but those who are living righteously. God sent a warning that the righteous cannot turn back to sin and assume their past record of righteousness will have them. It is not what a person has done in the past that counts with God. It is what he is doing now.

Believers can lose out with if they turn back to a sinful lifestyle. A person can destroy in one moment what he spent a lifetime building. Ezekiel was to warn the righteous Jew's that they had to continue in the path of righteousness. They could not allow themselves to be influenced by their wicked friends, relatives or neighbors to give up the way of Godliness. If they did, they would die of their sins... and all of their past goodness would not be remembered; Christian's need to keep such warnings in mind. The pressure of the present is severe and the temptations to conform too it is always present.

Do not let anything or anyone keep you from finishing the Christian race. As believers, we have the responsibility to tell others about God's mercy. Tell them about God's willingness to forgive sins. Turn to him and ask him for his power in your life. Then you can be an effective watchman for him.

Amen. Amen. Amen. 
